\title{
Single-Shell Tank Integrity Project Analysis of Record - Preliminary Modeling Plan for Thermal and Operating Loads
}

\author{
R.S. Rast \\ Washington River Protection Solutions \\ Richland, WA 99352 \\ U.S. Department of Energy Contract DE-AC27-08RV 14800

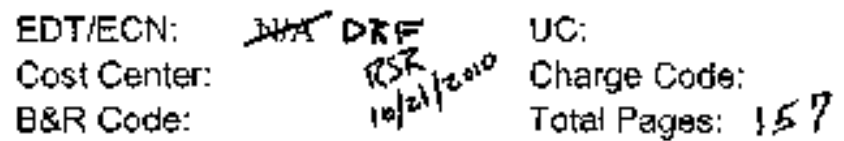

Key Words: Single-Shell Tank, SST, Analysis of Record, AOR, strtitural analysis, then'mal loard. operaimg Joad, temperature, pretiminaty modefiug, nateria] plopertics

Abstract: This document is a Phase I deliverable for the Single-ShellTank sulalysis of Recond cffort. This document is not the Analysis of Record. The intent of this docunsent is to guide the Phase IJ detajled modeling effort. Preljimitary finite element undels for each) of the tank types werc developed and differen case stuties were perfortut in 9ate or more of these tank typas. Cuse studies evaluated inclade thermal loading. waste level wariation, the sensitisity of boundary affects (scill radial extent, toxcavalion slope or nen to rise ratio, soil stratigraphic (proprenty and layer thickness) watialioth at different faum focatıons, and concrete material property vayation and their degradation under thermal loads.

TRADEMARK DSSCLAIAER, Reference herein to any specific commercial prodych, prosess, or service by trade name,

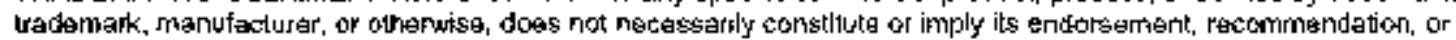
lavoring by the United States Gavemment or any agency thereaf or ita contractors or subcontraçoces.
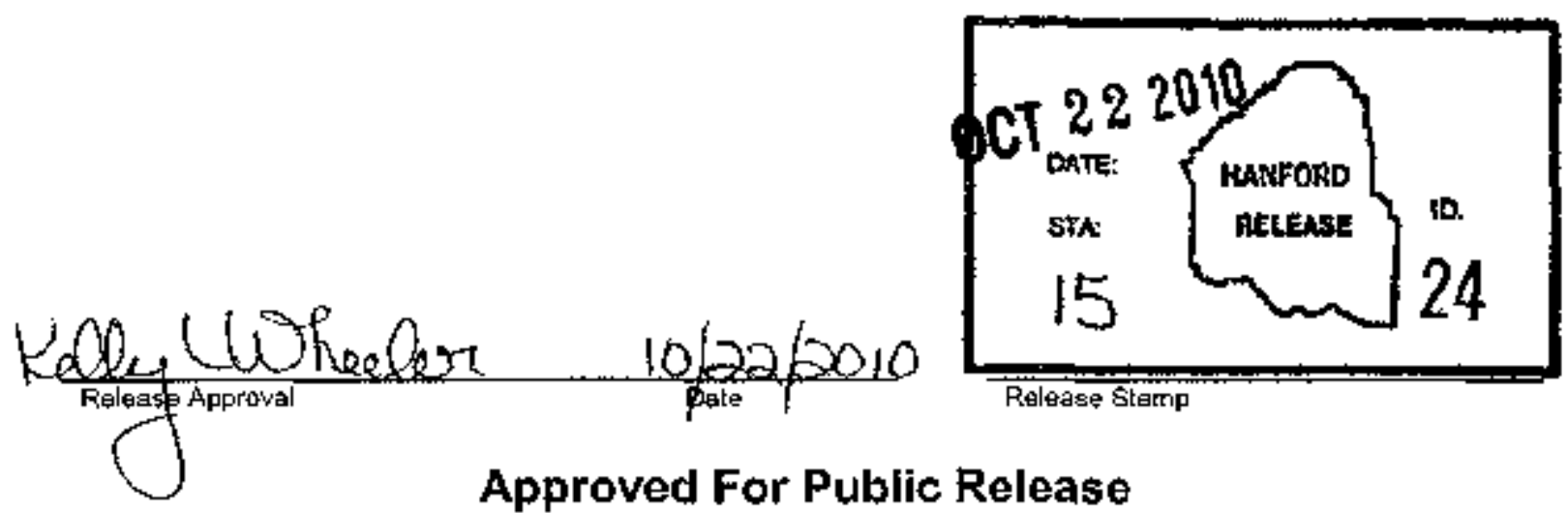

Approved For Public Release 
RPP-46644, Rev 0

Prepared for the U.S. Department of Energy under Contract DE-AC05-76RL 01830

\title{
Single-Shell Tank Integrity Project Analysis of Record
}

\section{Preliminary Modeling Plan for Thermal and Operating Loads}

\author{
MW Rinker \\ SK Bapanapalli \\ $\mathrm{KI}$ Johnson \\ JE Deibler \\ NK Karri \\ SP Pilli \\ CE Guzman-Leong \\ SE Sanborn
}

April 2010

Pacific Northwest

NATIONAL LABORATORY

Proudly Operated by Balletle Since 1965 


\title{
DISCLALMER
}

This report was prepared as an acevunt of work sponsered by an agency of the United States Government Nejther the United Stutes Govermment nor any agency thereat, nor Battelle Memorial Institute. nor any of their employees, nukes any warranty, cxprexs "r implitol, or asxumes any lequal liability or responsibjlity fir the accurycy, completeness, or usefulness of any information, upparatus, priduct, or pricess discksed, "1r represents that its ase would not infringe privately owned rights Reference herean to any sipectfie commereal product. proess, or service by trade neme, trademark, manufacturer, of otherwise does not necessanly consilule or umply sts enderwenent, secemmendaluen, or lavonng by the Unded Stales Government or uny agency these dof, or Battells Memonul Institute 'The views and opmions of aulhors expressed herein do not necessanly state or rellect those of the Unuled States (iovermment or any agency theroof

\author{
PACIFIC NORTHWEST NATTONAI. IABORATORY \\ aperoted by \\ BATIlLLL \\ for the \\ UNTTEDD STATTSS DEPARTMTINT OF ENTTRGYY \\ under (ontrater DE-ACO.5-75RI.OI83O)
}

\author{
I'rinted in the United Statea of America \\ Avalable to DOE and DOE contractors from the \\ OAfice of Scikntific waJ 'lexhnicul Informantion, \\ P.O. Bu1 62, Oak Fudge, I'N 37831-00162; \\ ph: (\$65) $576-8411$ \\ fax: (365) 570-5728 \\ emuil: reparts(o)edonis.1ksti.qow

\begin{abstract}
Avwilable to the public from the National Texhnisal lnformation Bervies, ILS. Depurtmenl of C.mmmeree, 5285 Pare Ruyul Rol, Springikdı, VA 22161 ph: (500) 553-6447 fax: $(703) 605-6900$ conal: ardersonotis.fedwordd.gov anline urdering: htep: $/$ twwerntix.gowfurdering,htm
\end{abstract}

Thus document was printed on recycled papen'

(अ2003) 


\title{
Single-Shell Tank Integrity Project Analysis of Record
}

\section{Preliminary Modeling Plan}

\author{
MW Rinker \\ KI Johnson \\ SK Bapanapalli \\ NK Karri \\ JE Deibler \\ SP Pilli \\ CE Guzman-Leong \\ SE Sanborn
}

April 2010

Prepared for

the U.S. Department of Energy

under Contract DE-AC05-76RL_01830

Pacific Northwest National Laboratory

Richland, Washington 99352 
RPP-46644, Rev.0

This page intentionally left blank. 


\section{Summary}

This report is the Phase I deliverable for the Single-Shell Tank Analysis of Record (SST AOR) Project. The preliminary analysis document reviews and preliminary modeling analysis results are reported herein. In addition, this report provides recommendations for the next phase of the SST AOR project, SST detailed modeling. Efforts and results discussed in this report do not include seismic modeling as seismic modeling is covered by a separate report. The combined results of both static and seismic models are required to complete this effort.

The SST AOR project supports the US Department of Energy's (DOE) Office of River Protection (ORP) mission for obtaining a better understanding of the structural integrity of Hanford's SSTs. The 149 SSTs, with six different geometries, have experienced a range of operating histories which would require a large number of unique analyses to fully characterize their individual structural integrity. Preliminary modeling evaluations were conducted to determine the number of analyses required for adequate bounding of each of the SST tank types in the Detailed Modeling Phase of the SST AOR Project. The preliminary modeling was conducted in conjunction with the Evaluation Criteria report, Johnson et al. (2010).

Reviews of existing documents were conducted at the initial stage of preliminary modeling. These reviews guided the topics that were explored in the SST preliminary modeling. The reviews determined the level of detail necessary to perform the analyses of the SSTs.

To guide the Phase II detailed modeling effort, preliminary finite element models for each of the tank types were developed and different case studies were performed on one or more of these tank types. Case studies evaluated include thermal loading, waste level variation, the sensitivity of boundary effects (soil radial extent, excavation slope or run to rise ratio, soil stratigraphic (property and layer thickness) variation at different farm locations, and concrete material property variation and their degradation under thermal loads. Conclusions were derived from case studies on one of the tank types when no additional runs of similar cases on other types of tanks were found necessary to derive those conclusions.

The document reviews provided relatively complete temperature histories for Type IV tanks. The temperature history data for Type I, II, and III tanks was almost nonexistent for years prior to 1975 . Document reviews indicate that there might be additional useful data in the US Department of Energy, Richland Operations Office (DOE-RL) records in Seattle, WA, and these records need to be reviewed to extract data that might have been disregarded during previous reviews.

Thermal stress analyses were conducted using different temperature distribution scenarios on Type IV tanks. Such studies could not be carried out for other tank types due to lack of temperature history data. The results from Type IV tank analyses indicate that factors such as temperature distribution in the tank waste and rate of rise in waste temperature have a significant impact on the thermal stresses in the tank structures.

Overall, the conclusion that can drawn from the thermal stress analyses is that these studies should be carried out for all tank types during the detailed analysis phase with temperature values that are reasonably close to the typical temperature histories of the respective tank types. If and/or when 
additional waste temperature data is acquired for tank Type I, II, and III tanks, additional cases need to be considered as tank structural integrity is sensitive to thermal loads.

A few case studies were also performed using Type IV-b models to comprehend the effects of excavation boundaries, change in soil stratigraphy (layer thickness and properties), and radial extent of soil in the finite element models. The result from the case studies indicates that the slight variation in soil stratigraphy has little effects on the tank sections force and moment demands under mechanical loads. The case study for excavation slope or backfill transition boundary indicated that inclusion of such boundary yields conservative demands in the wall region while demands at other locations remain unaffected. Hence this excavation slope will be modeled in the detailed analysis of SSTs. The radial extent studies showed that there is no significant effect of the soil far-field dimension; therefore, the radial extent can be reduced to minimize computational time in structural runs.

Material property variation load cases addressed concrete tensile strength and creep effects with a type IV-B model. The hoop and meridional demand showed a similar trend for both the zero concrete tensile strength and the mean concrete tensile strength. It is therefore recommended that a value of near zero is used for concrete tensile strength in detailed analysis. The creep load case was also performed. In general, creep relieves the stress in the concrete, thereby decreasing the section force. Therefore the recommendation is to conduct the ACI section evaluation in the detailed analyses without creep as this will result in higher demands (i.e., more conservative). However, any collapse load or other ultimate load analyses should be conducted with creep to obtain the best estimate of the actual material condition.

To investigate the structural effects on a single-shell-tank due to its waste level, three waste heights were evaluated. A Type II model was used to evaluate an empty, half-full, and full tank of waste having a conservative specific gravity value without any thermal loads. In summary, pressures due to waste heights do not have a significant effect on the stresses experienced by the tank. Since the thermal stresses due to waste temperature are more significant than the pressures due to the waste the waste height, the waste heights in the detailed modeling will correspond to the waste level/thermal histories. 


\section{Acknowledgments}

The authors would like to thank Theresa VanCorbach and Kelle Airhart for the administrative and overall project support, Meredith Willingham, Jennifer Blake, Kay Hass, and Theresa Vancorbach for the technical editing of the report, and Ron Schrotke, Evelyn Hirt, and Nancy Sargent, for their quality assurance assistance.

Project Management would especially like to thank the static modeling team for their unyielding dedication to the completion of task deliverables within the limited time available. 
RPP-46644, Rev.0

This page intentionally left blank. 


\section{Acronyms}

$\mathrm{ACI}$

AOR

$\mathrm{AP}$ ad

ASA

ASME

ASTM

AWS

AWWA

CTL

DOE

DOE-RL

DST

EED

EPA

FDN foundatio

FEM

HW Hanford

HWS

IDMS

LMFBR

NRA

ORP

PCA

PNNL

PQAP

QA Quality

QAPD

R\&D

RPP-WTP

SST Single-Shell

SACS

TWINS

UBC

UNSP Unspecified

WRPS
American Concrete Institute

analysis of record

ministrative procedure

Accelerated Safety Analysis

American Society of Mechanical Engineers

American Society for Testing and Materials

American Welding Society

American Water Works Association

Construction Technology Laboratory

US Department of Energy

US Department of Energy's Richland Operations Office

double-shell tank

Energy and Environment Directorate

US Environmental Protection Agency

$$
\text { n basemat }
$$

finite element models

Works

Hanford Works Specification

Integrated Data Management System

Liquid-Metal Fast Breeder Reactor

not readily available

DOE Office of River Protection

Portland Cement Associate

Pacific Northwest National Laboratory

Project Quality Assurance Plan

Assurance

Quality Assurance Program Description

research and development

River Protection Program Waste Treatment Plant

Tanks

Surveillance Analysis Computer System

Tank Waste Information Network System

Uniform Building Code

Washington River Protection Solutions 
RPP-46644, Rev.0

This page intentionally left blank. 


\section{Contents}

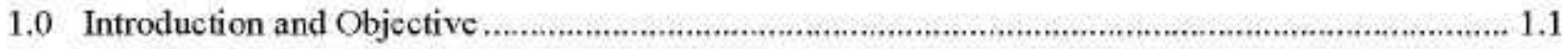

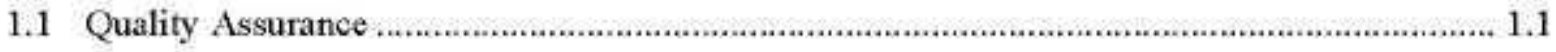

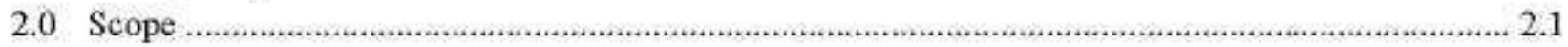

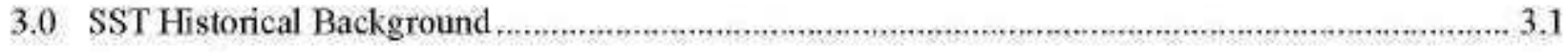

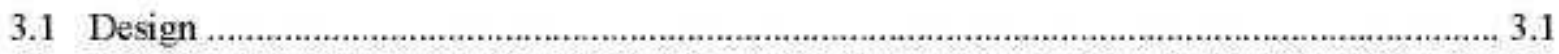

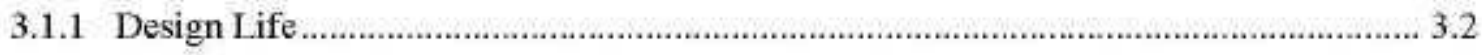

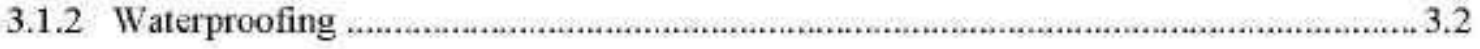

3.1.3 Design Waste Specific Gravity and Waste Height, Waste Storage Pressure, Max

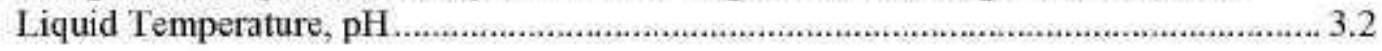

3.1.4 Design Overhead Equipment Loads ............................................................................ 3.7

3.1.5 Design Soil Backfilling and Cover, Density, Soil Bearing Value .................................. 3.7

3.2 Codes and Standards ....................................................................................................... 3.10

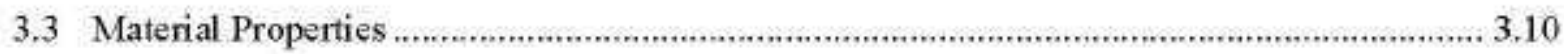

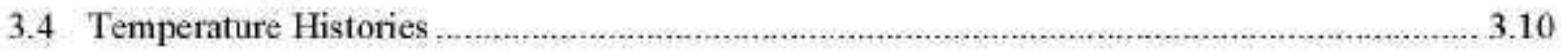

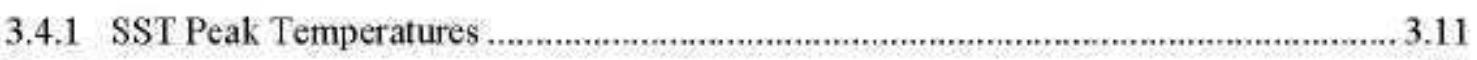

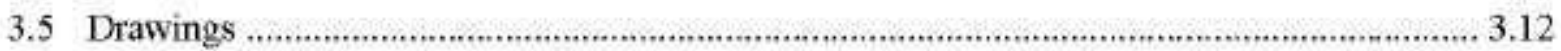

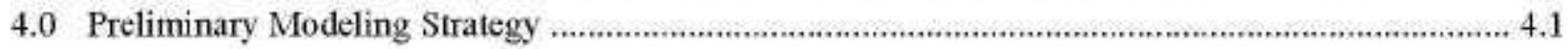

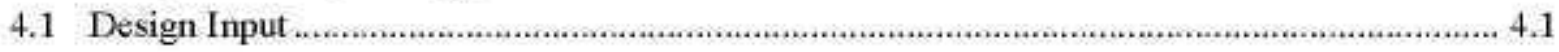

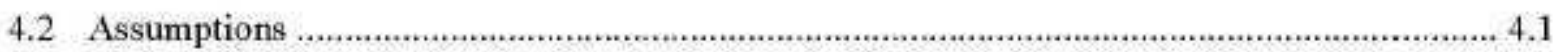

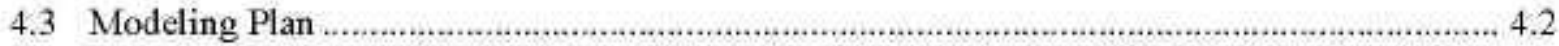

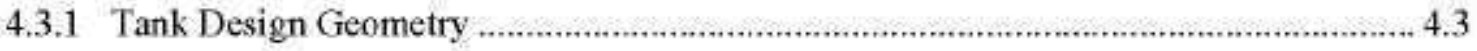

4.3.2 Temperature and Waste Profiles _........................................................................... 4.6

4.3.3 Thermal Modeling and Creep............................................................................... 4.13

4.3.4 Waste Level Modeling ...................................................................................... 4.16

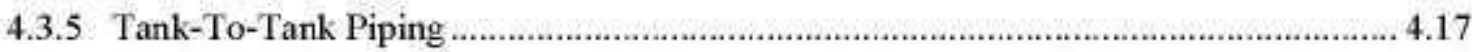

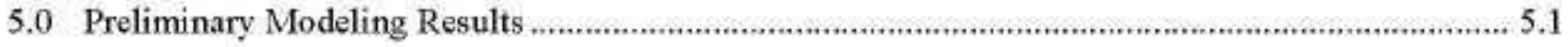

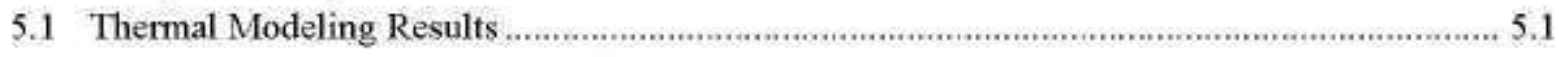

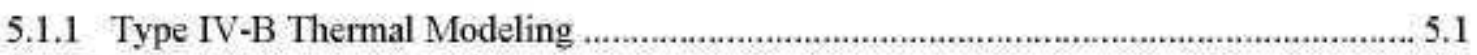

5.1 .2 Type III Thermal Modeling ................................................................................ 5.22

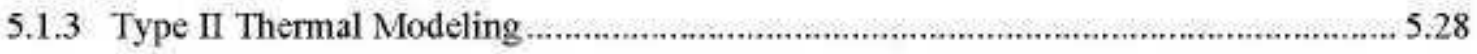

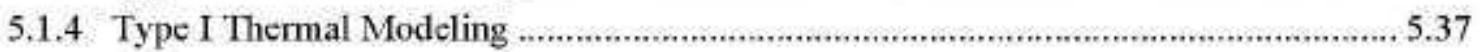

5.2 Waste Level Modeling Results ....................................................................................... 5.42

5.3 Material Property Variation and Creep Results .................................................................. 5.49

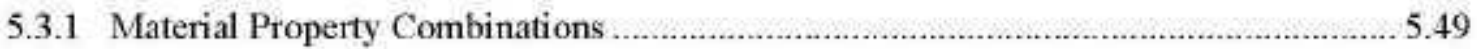

5.3.2 Concrete Tensile Strength-Sensitivity Analysis .....................................................5.50

5.3.3 Concrete Creep-Sensitivity Analysis................................................................... 5.59

5.4 Type IV Tanks Case Studies and Results...................................................................... 5.63 


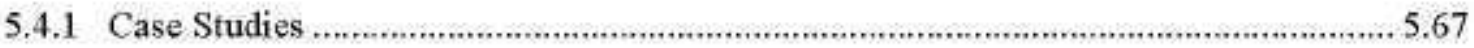

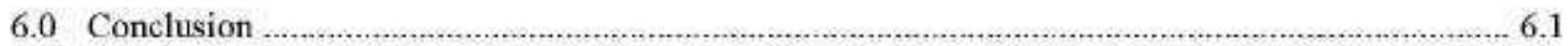

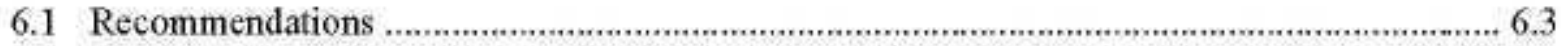

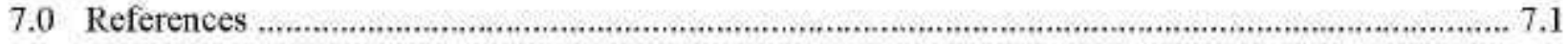

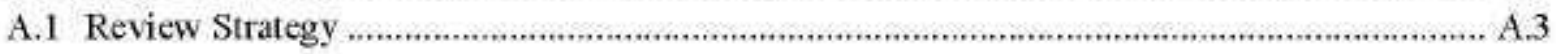

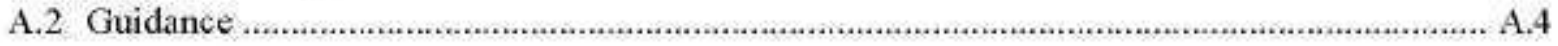

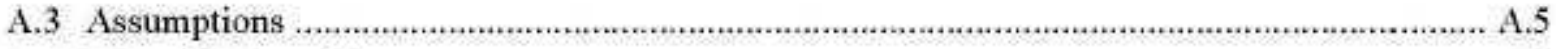

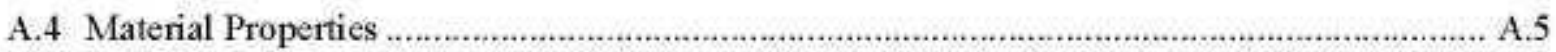




\section{Figures}

Figure 3.1 SST Peak Temperatures as Reported in Rifacy (2002, RPP-10435) ,.................................12

Figure 4.1 Temperature History of A Series Tanks Prior to 1972 (Data from Mercier 1981)............... 4.6

Figure 4.2 Proposed Temperature and Waste Height Profiles for Tank A-101 .................................... 4.7

Figure 4.3 Proposed Temperature and Waste Height Profiles for Tank A-106 ................................. 4.7

Figure 4.4 Temperature History for Farm AX Tanks ..................................................................... 4.8

Figure 4.5 Proposed Temperature and Waste Height Profile for Tank S-104 .................................. 4.9

Figure 4.6 Estimated Temperature History of Tank C-106 ........................................................ 4.10

Figure 4.7 Proposed Temperature and Waste Height Profile for Type-I tanks. The surface level profile for $\mathrm{C}-201$ was used in this plot.......................................................................... 4.11

Figure 4.8 Large Temperature Fluctuations in Tank A-106 during 1963-1964. This picture was extracted from Mercier (1981) report and the red ovals added for emphasis.......................... 4.12

Figure 4.9 Temperature Profiles Used in the Finite Element Thermal Modeling .............................. 4.12

Figure 4.10 The 2-D Thermal Model Showing the Element in the Tank Structure and the Element in the Waste Surface

Figure 4.11 Temperature Distribution in the Tank Structure at the End of Thermal Analysis Step

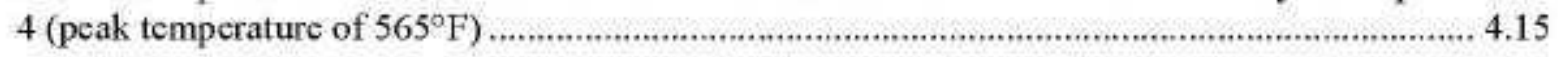

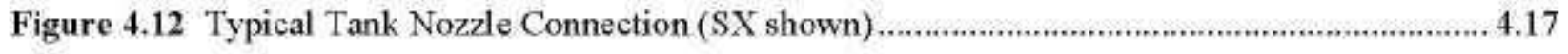

Figure 4.13 Typical Beam-Tank Connection ............................................................................... 48

Figure 4.14 SX Vapor Header Connection ........................................................................... 4.19

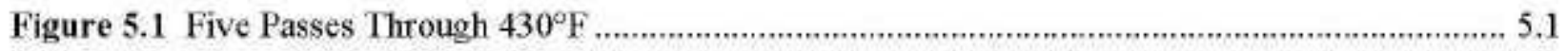

Figure 5.2 Comparison of section hoop forces for the themal cycling analysis................................ 5.2

Figure 5.3 Companison of section hoop moments for the thermal cycling analysis, ............................ 5.3

Figure 5.4 Comparison of section meridional forces for the thermal cycling analy sis......................... 5.3

Figure 5.5 Comparison of section meridional moments for the thermal cycling analysis.................... 5.4

Figure 5.6 Comparison of section shear forces for the thermal cycling analysis.............................. 5.4

Figures 5.7(a)-(c) Concrete Cracking in the Tank Footing at Different Passes through $430^{\circ} \mathrm{F}$ : (a)

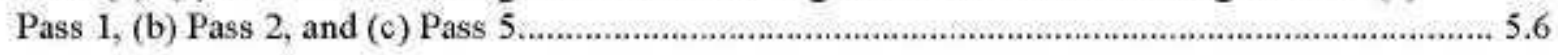

Figures 5.8(a)-(c) Concrete Cracking in the Tank Haunch at Different Passes through $430^{\circ} \mathrm{F}$ :

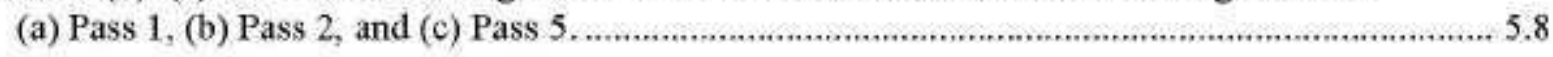

Figure 5.9 Comparison of section hoop forces for two different hot spot diameters at the Peak

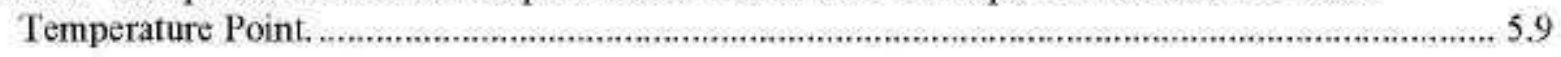

Figure 5.10 Comparison of section hoop moments for two different hot spot diameters at the

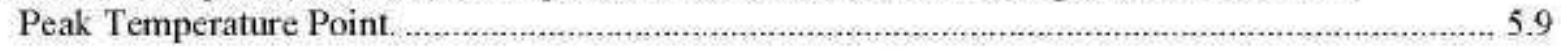

Figure 5.11 Comparison of section meridional forces at two different hot spot diameters at the

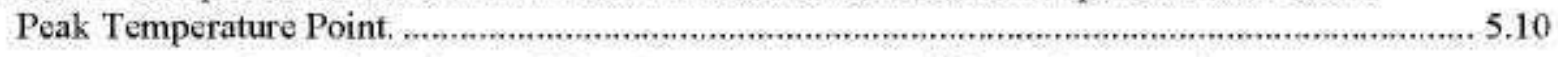

Figure 5.12 Comparison of section meridional moments at two different hot spot diameters at the Peak Temperature Point.......................................................................................... 5.10

Figure 5.13 Comparison of section shear forecs for two different hot spot diameters at the Peak Temperature Point. 
Figures 5.14(a) \& (b) Comparison of Concrete Cracking for the Two Analyses with Hot Spot Diameter (a) $30 \mathrm{ft}$ and (b) $50 \mathrm{ft}$

Figure 5.15 Comparison of section hoop forces at the peak temperature point for different rates of temperature rise...

Figure 5.16 Comparison of section hoop moments at the peak temperature point for different rates of temperature rise.

Figure 5.17 Comparison of section meridional forces at the peak temperature point for different rates of temperature rise.

Figure 5.18 Comparison of section meridional moments at the peak temperature point for different rates of temperature rise.

Figure 5.19 Comparison of section shear forces at the peak temperature point for different rates of temperature rise..

Figures 5.20(a) - (c) Concrete cracking in the footing region of the tank at the peak temperature point for: (a) 36 Fahrenheit-degrees/day, (b) 6 Fahrenheit-degrees/day, and (c) steady state conditions.

Figures 5.21(a) - (c) Concrete cracking in the haunch region of the tank the peak temperature point for: (a) 36 Fahrenheit-degrees/day, (b) 6 Fahrenheit-degrees/day, and (c) steady state conditions.

Figure 5.22 Comparison of section hoop forces for linear temperature variation and uniform waste temperature at the peak temperature point $\left(380^{\circ} \mathrm{F}\right)$

Figure 5.23 Comparison of section hoop moments for linear temperature variation and uniform waste temperature at the peak temperature point $\left(380^{\circ} \mathrm{F}\right)$.

Figure 5.24 Comparison of section meridional forces for linear temperature variation and uniform waste temperature at the peak temperature point $\left(380^{\circ} \mathrm{F}\right)$.

Figure 5.25 Comparison of section meridional moments for linear temperature variation and uniform waste temperature at the peak temperature point $\left(380^{\circ} \mathrm{F}\right)$.

Figure 5.26 Comparison of section shear forces for linear temperature variation and uniform waste temperature at the peak temperature point $\left(380^{\circ} \mathrm{F}\right)$

Figures 5.27(a)-(d) Comparison of Cracking: Linear Temperature Variation (a) footing and (b) haunch; uniform temperature variation (c) footing and (d) haunch.

Figure 5.28 Type III Model Element Plot.

Figure 5.29 Type III Temperature Distribution.

Figure 5,30 Type III ACI Section Location

Figure 5.31 Type III Meridional Force

Figure 5.32 Type III Meridional Moment.

Figure 5.33 Type III Hoop Force

Figure 5.34 Type III Hoop Moment.

Figure 5.35 Type III Shear Force.

Figure 5.36 Temperature Profile Assigned to Tank for January 1972 Case (left) and October 1978 Case (right). Peak temperatures for January 1972 and October 1978 are $290^{\circ} \mathrm{F}$ and $310^{\circ} \mathrm{F}$, respectively. 
Figure 5.37 Radial Stresses for January 1972 Mechanical Loads Only (top left), October 1978 Mechanical Loads Only (top right), January 1972 All Loads (bottom left), and October 1978 All Loads (bottom right).

Figure 5.38 Hoop Stresses for January 1972 Mechanical Loads Only (top left), October 1978 Mechanical Loads only (top right), January 1972 All Loads (bottom left), and October 1978 All Loads (bottom right).

Figure 5.39 Vertical Stresses for January 1972 Mechanical Loads Only (top left), October 1978 Mechanical Loads Only (top right), January 1972 All Loads (bottom left), and October 1978 All Loads (bottom right).

Figure 5.40 Concrete Cracking for January 1972 Mechanical Loads Only (top left), October 1978 Mechanical Loads Only (top right), January 1972 All Loads (bottom left), and October 1978 All Loads (bottom right).

Figure 5.41 Locations of Sections Used for Force and Moment Evaluations. Sections in dome center, haunch, and outer footing are magnified for legibility.

Figure 5.42 Meridional Force for Each Section Number for Cases of 1978 Thermal and Mechanical Loads, 1972 Thermal and Mechanical Loads, 1978 Mechanical Loads Only, and 1972 Mechanical Loads Only.

Figure 5.43 Meridional Moment for Each Section Number for Cases of 1978 Thermal and Mechanical Loads, 1972 Thermal and Mechanical Loads, 1978 Mechanical Loads Only, and 1972 Mechanical Loads Only

Figure 5.44 Shear Force for Each Section Number for Cases of 1978 Thermal and Mechanical Loads, 1972 Thermal and Mechanical Loads, 1978 Mechanical Loads Only, and 1972 Mechanical Loads Only

Figure 5.45 Hoop Force for Each Section Number for Cases of 1978 Thermal and Mechanical Loads, 1972 Thermal and Mechanical Loads, 1978 Mechanical Loads Only, and 1972 Mechanical Loads Only

Figure 5.46 Hoop Moment for Each Section Number for Cases of 1978 Thermal and Mechanical Loads, 1972 Thermal and Mechanical Loads, 1978 Mechanical Loads Only, and 1972 Mechanical Loads Only

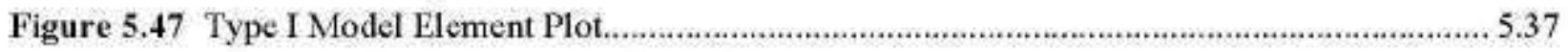

Figure 5.48 Type I Model Temperature Distribution...................................................................... 5.38

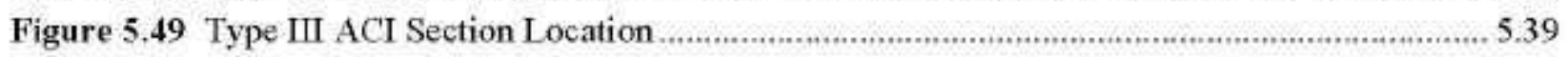

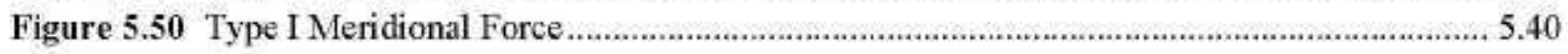

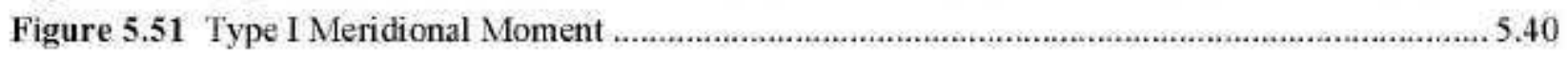

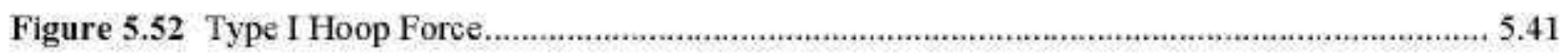

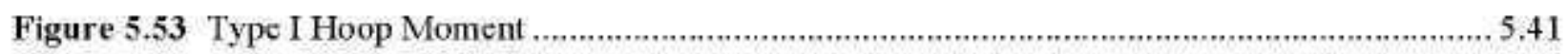

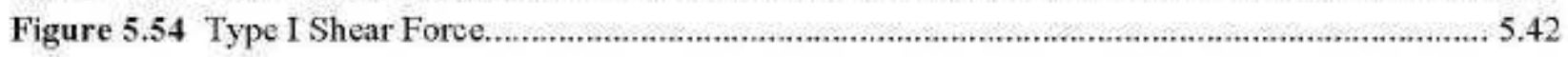

Figure 5.55 Radial Stress for Empty Tank (top left), Tank Half Full of Waste (top right), and Tank Full of Waste (bottom left).

Figure 5.56 Hoop Stress for Empty Tank (top left), Tank Half Full of Waste (top right), and Tank Full of Waste (bottom left).

Figure 5.57 Vertical Stress for Empty Tank (top left), Tank Half Full of Waste (top right), and Tank Full of Waste (bottom left). 
Figure 5.58 Cracking Observed in Concrete for Empty Tank (top left), Tank Half Full of Waste (top right), and Tank Full of Waste (bottom left)..

Figure 5.59 Shear Force for Each Section Number for Cases of Empty Tank, Tank Half Full of Waste, and Tank Full of Waste

Figure 5.60 Meridional Force for Each Section Number for Cases of Empty Tank, Tank Half Full of Waste, and Tank Full of Waste

Figure 5.61 Meridional Moment for Each Section Number for Cases of Empty Tank, Tank Half Full of Waste, and Tank Full of Waste

Figure 5.62 Hoop Force for Each Section Number for Cases of Empty Tank, Tank Half Full of Waste, and Tank Fuil of Waste

Figure 5.63 Hoop Moment for Each Section Number for Cases of Empty Tank, Tank Half Full of Waste, and Tank Full of Waste.

Figure 5.64 Concrete Tensile Strength vs. Temperature.

Figure 5.65 Thermal Profile Used for Concrete Tensile Strength Sensitivity Analysis

Figure 5.66 Plot of Concrete Cracking at the End of Load Step 3 (mechanical loads)

Figure 5.67 Plot of Concrete Cracking at the End of Load Step 4 (mechanical and thermal loads)..... 5.52

Figure 5.68 Plot of Concrete Cracking at the End of Load Step 8 (mechanical and thermal loads including creep).

Figure 5.69 Force and Moment Section Locations. 5.53

Figure 5.70 Meridional Force Comparison at the End of Load Step 3 5.54

Figure 5.71 Meridional Moment Comparison at the End of Load Step 3 5.54

Figure $\mathbf{5 . 7 2}$ Hoop Force Comparison at the End of Load Step 3 5.55

Figure 5.73 Hoop Moment Comparison at the End of Load Step 3. 5.55

Figure 5.74 Shear Force Comparison at the End of Load Step 3 5.56

Figure 5.75 Meridional Force Comparison at the End of Load Step 8 5.56

Figure 5.76 Meridional Moment Comparison at the End of Load Step 8 . 5.57

Figure 5.77 Hoop Force Comparison at the End of Load Step 8 . 5.57

Figure 5.78 Hoop Moment Comparison at the Fnd of Load Step 8 5.58

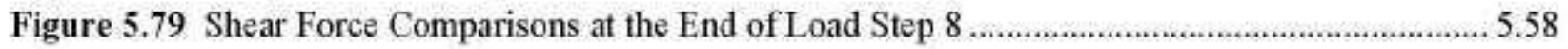

Figure 5.80 Thermal History for Creep Analysis .............................................................................5.60

Figure 5.81 Effect of Creep on Meridional Force........................................................................... 5.60

Figure 5.82 Effect of Creep on Meridional Moment ....................................................................61

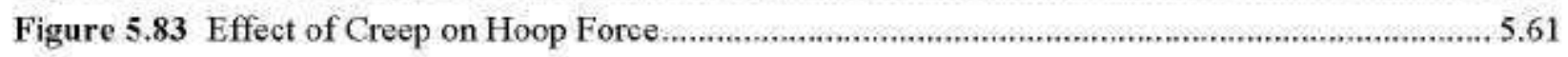

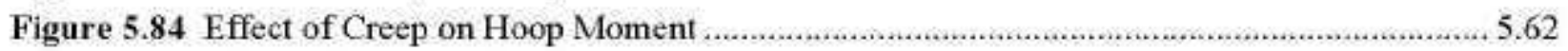

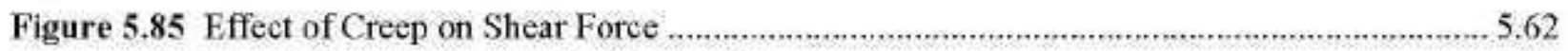

Figures 5.86(a)-(d) Type IV(b) FE Model Detail ............................................................................ 5.66

Figures 5.87(a)-(d) Type IV(a) FE Model Details ....................................................................... 5.67

Figure 5.88 Type IV(b) Excavation Slope Study Model ........................................................... 5.68

Figures 5.89(a) \& (b) Type IV(b) ACI Sections …................................................................... 5.69

Figure 5.90 Type IV(b) Excavation Slope Study Meridional Forces................................................ 5.70 
Figure 5.91 Type IV(b) Excavation Slope Study Hoop Forces ...................................................... 5.70

Figure 5.92 Type IV(b) Excavation Slope Study Meridional Moments ...................................... 5.71

Figure 5.93 Type IV(b) Excavation Slope Study Hoop Moments ...................................................... 5.71

Figure 5.94 Type IV(b) Excavation Slope Study Shear Forces .................................................. 5.72

Figures 5.95(a) \& (b) Type IV(b) Soil Radial Extent Study Models ................................................. 5.72

Figure 5.96 Type IV(b) Soil Radial Extent Study Meridional Forces ................................................ 5.73

Figure 5.97 Type IV(b) Soil Radial Extent Study Hoop Forces ........................................................ 5.74

Figure 5.98 Type IV(b) Soil Radial Extent Study Meridional Moments ........................................... 5.74

Figure 5.99 Type IV(b) Soil Radial Extent Study Hoop Moments .................................................. 5.75

Figure 5.100. Type IV(b) Soil Radial Extent Study Shear Forces.................................................. 5.75

Figures 5.101(a)-(c) Far-Field Soil Radial Stresses ................................................................... 5.76

Figure 5.102 Model for Soil Layer Study ................................................................................. 5.77

Figure 5.103 Type IV(b) Soil Layer Study Hoop Forces....................................................... 5.78

Figure 5.104 Type IV(b) Soil Layer Study Meridional Forces .................................................... 5.78

Figure 5.105 Type IV(b) Soil Layer Study Hoop Moments ................................................................ 5.79

Figure 5.106 Type IV(b) Soil Layer Study Meridional Moments .................................................... 5.79

Figure 5.107 Type IV(b) Soil Layer Study Shear Forces ….......................................................... 5.80 
RPP-46644, Rev.0

This page intentionally left blank. 


\section{Tables}

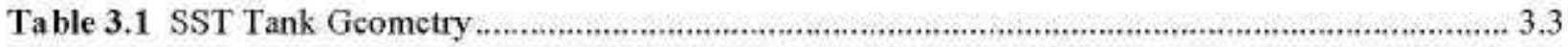

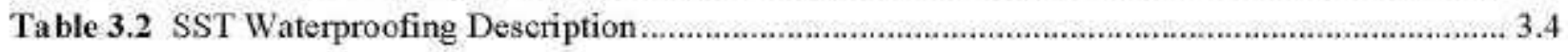

Table 3.3 SST Waste Design Parameters ...............................................................................

Table 3.4 SST Design Equipment Loads .......................................................................................... 3.7

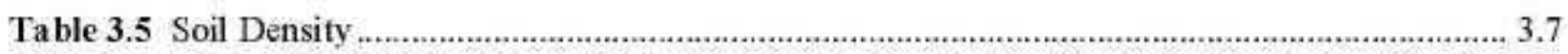

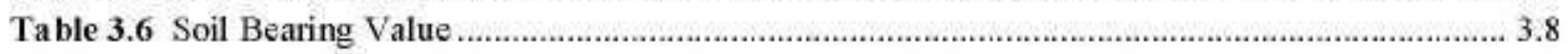

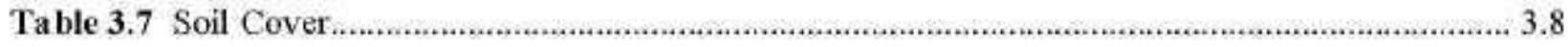

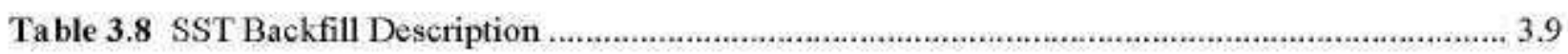

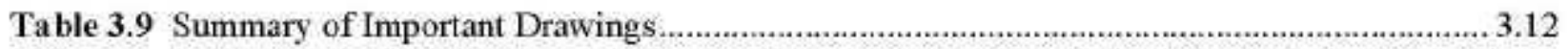

Table 4.1 Preliminary Modeling Scope ............................................................................................. 4.2

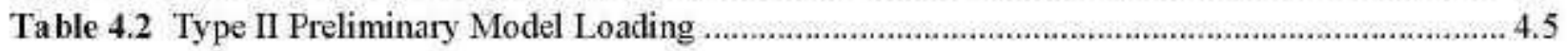

Table 4.3 Temperature and Waste Height Values at the End of Each Analysis Step for.................... 4.14

Table 5.1 Possible Material Property Variables .................................................................................. 5.49

Table 5.2 Reduced Material Property Variables ............................................................................. 5.49

Table 5.3 Possible Run Matrix Using Material Property Variables Listed in Table 5.2 ..................... 5.50

Table 5.4 Reduced Run Matrix Based on Concrete Tensile Strength and Creep Analysis.................. 5.59

Table 5.5 Time and Temperature as a Function of Load Steps ........................................................... 5.60

Table 5.6 Type IV Tank Drawings for Comparison..........................................................................5.63

Table 5.7 Type IV Tank Structural Features Comparison ............................................................. 5.64 
RPP-46644, Rev.0

This page intentionally left blank. 
RPP-46644, Rev.0

\subsection{Introduction and Objective}

The US Department of Energy (DOE) Office of River Protection (ORP) has determined the need to better understand the integrity of the Single-Shell Tanks (SSTs). To address this need, Pacific Northwest National Laboratory (PNNL) is performing an SST analysis-of record (AOR) for Washington River Protection Solutions (WRPS).

The primary objective of the SST AOR Project is to perform a comprehensive structural analysis of record for the SSTs in order to understand the existing SST structural integrity. The first phase of the SST AOR Project, preliminary analysis documentation, conducted an extensive review of SST reports, specifications, drawings, and supporting documents, followed by model analyses, calculations and benchmarking resulting in recommendations for subsequent phases. The next phase of the SST AOR project will be conducting detailed SST modeling and analysis.

This report summarizes the SST information acquired during the preliminary analysis documentation review effort. The preliminary analysis document reviews guided the topics that were investigated in the SST preliminary finite element modeling. Preliminary modeling results will serve as the basis for limiting selected load cases in the detailed SST modeling efforts. The preliminary modeling investigations intend to provide the technical basis for the load cases and tank geometries selected for the detailed modeling analyses in Phase II of the SST AOR Project. However, efforts and results discussed herein do not include seismic modeling; seismic modeling is covered by a separate report.

\subsection{Quality Assurance}

The PNNL Quality Assurance (QA) Program is based on the requirements of 10 CFR 830, "Energy/Nuclear Safety Management," Subpart A - "Quality Assurance Requirements" (i.e., the Quality Rule) and the US Department of Energy (DOE) Order 414.1C, "Quality Assurance." Compliance with these documents requires the development of a Quality Assurance Program consistent with a national or international consensus standard (Additionally, DOE Order $414.1 \mathrm{C}$ requires that software activities be performed consistent with ASME NQA-1-2000, Subpart 2.7 or an equivalent national or international consensus standard). PNNL has developed its Quality Assurance Program, in a graded approach, using ASME NQA-1-2000, Part IV, Subpart 4.2, "Guidance on Graded Application of Quality Assurance (QA) for Nuclear-Related Research and Development" for both research and development activities and management systems. A QA Program Description (QAPD) describes the PNNL's Quality Assurance Program.

Consistent with the structure of ASME NQA-1, other parts of this standard (i.e., NQA-1) are applied, where appropriate, to nuclear and radiological work. For example, by applying the following consensus standards, as appropriate:

ASME NQA-1: "Quality Assurance Requirements for Nuclear Facility Applications, Part 1, Requirements for Quality Assurance Programs for Nuclear Facilities"

ASME NQA-1, Part II, Subpart 2.7: "Quality Assurance Requirements for Computer Software for Nuclear Facility Applications." 
The implementing procedures and processes, described in the DOE-approved PNNL Quality Assurance Program Description (QAPD), are made available in a web-based system for the delivery of PNNL requirements and laboratory-level workflow and procedures.

Because the efforts of the project (i.e., Single Shell Tank Integrity Project Analysis of Record Project) are beyond those defined as research and development (R\&D), such as Subpart 4.2 of NQA-1, a Quality Assurance Program to Parts I and II of NQA-1 (using a graded approach) is necessary and is required per the project Statement of Work. PNNL-NQA-EQAM-1, Energy and Environment Directorate (EED) Quality Assurance Plan, provides that NQA-1 Quality Assurance Program (plan). PNNL-NQAEQAM-1, provides the general, or high-level, overview of the implementation of NQA-1-2008.

PNNL-NQA-EQAM-1, is supported by administrative procedures (APs) which provide the more specific requirements for implementation of NQA-1 requirements. The Project Quality Assurance Plan (PQAP), Single-Shell Tank Integrity Project Analysis of Record Project (57926-QAP, Revision 1), is subordinate to PNNL-NQA-EQAM-1 and utilizes the processes and procedures of PNNL-NQA-EQAM-1 to provide the applicable quality assurance requirements for the specific work activities for the Project (based on client requirements and PNNL requirements) and is compliant with the QAPD.

The requirements contained in the PQAP will satisfy the requirements of DOE Order $414.1 \mathrm{C}$, and 10 CFR 830 (when applicable).

The client did not direct (or specify) that the work conducted as part of the Project comply with EPA QAR-5. Additionally, the client identified that the results of the Project's efforts were not an "analysis of record" as defined by EPA QA/R-5 (EPA Requirements for Quality Assurance Project Plans). 


\subsection{Scope}

Phase I of the single-shell tank (SST) analysis of record (AOR) project is comprised of SST documentation reviews and preliminary modeling to guide and minimize efforts in Phase II — detailed modeling. Preliminary analysis document reviews investigated SST construction and design specifications, material properties and standards (soil, concrete, steel liner and rebar reinforcement), waste and temperature histories, soil backfill, tank watcrproofing, and tank ancillary equipment such as pump pits, hanging long length equipment, risers, and tank-to-tank piping. Concrete material properties also addressed creep and thermal degradation. Documents were acquired from various resources and databases including: Tank Waste Information Network System (TWINS), Office of Science and Technology Information Bridge, ACCESS document database (SST Database 04-27-2009) provided by WRPS, Integrated Data Management System (IDMS), and Hanford Technical Library and Document Control Services. The resulting documentation reviews under the preliminary analysis task must provide detailed information necessary to support the detailed SST modeling analyses. Appendix A summarizes the document review process.

Preliminary modeling analyses addressed the variation of tank designs, concrete properties, steel properties, degradation of mechanical properties due to various conditions, soil conditions within the SST tank farms, and other parameters as necessary. Preliminary modeling analysis recommendations include the number of models required for adequate bounding of each of the SST tank types, as well as the type of ANSYS $^{*}$ models necessary to produce credible results.

However, the review and comparison of SST technical reports, data tabulation from plots, SST waste source and characterization, the addition of tank risers and other ancillary components, and leak integrity are not in the scope of the preliminary analysis documentation review task. In addition, analyses discussed herein do not include seismic modeling, which is being covered by an independent report. SST modeling will focus on the original design of the tanks, as shown on the construction drawings. SST information not found within the documents obtained from the various document sources and databases was considered out of scope in the sense that a best effort was made to acquire and review pertinent SST documentation available. 
RPP-46644, Rev.0

This page intentionally left blank. 


\subsection{SST Historical Background}

Subsequent sections summarize the single-shell tank (SST) original design information on the SSTs collected during the preliminary analysis documentation efforts.

\subsection{Design}

In response to Hanford's plutonium production, a total of 149 underground tanks were constructed to contain the nuclear waste between 1943 and 1964 in twelve separate tank farms in the 200 East and West areas of the Hanford Site. Initially, four tank farms were constructed - each consisting of $4 \times 55,000$ gallon capacity Type 1 tanks with a 20-foot internal diameter. Additionally, there are five tank farms comprised of a total of $60 \times 530,000$ gallon capacity Type II tanks with a 75-foot internal diameter. The larger capacity tanks include 48 Type III tanks, each with a 758,000 gallon storage capacity, and 25 Type IV tanks, 1,000,000 gallons capacity, both of which also have a 75-foot intemal diameter. Each of these tanks is a concrete structure with a carbon steel liner along the base and cylindrical walls of the SSTs. The steel liner is not a structural member of the SSTs, but was intended to create a watertight, leak-proof membrane for storing the nuclear waste.

Construction specifications for each of the 12 SST tank farms are provided in the Evaluation Criteria report, Rinker et al. 2010, and therefore are not listed herein. Single-shell tank analysis of record (AOR) documents reviews confirm the specifications assigned to each of the tank farms. However, the following notes apply:

- BX Specifications H-7-5264 apply to TX except for the steel liner in which HW-3061 apply, per GE (1953b):

"The same general specifications used for the construction of the 241-BX Tank Farm (C-112) were used for the 241-TX Farm. These specifications, entitled, "Specifications for construction of composite storage tanks, "issued December 6, 1946, were supplemented by material specifications shown on the drawings and were further stupplemented by special specifications for steel tank liners."

- HWS-4799-S is listed as applicable for the AX Tank Farm, but this is only for the transportation of concrete;

- HWS-4798-S is listed as applicable for the AX Tank Farm, but this is only for the placing of reinforced concrete;

- HW-3937 supersedes HW-4038 for the S Tank Farm;

- HW-1961 applies for the Type IB, C, T, and U Tank Farms;

- There were other specifications that were found for the AX Tank Farm, but as stated previously, they were not listed as final specifications; these were HW-70529 and HW-72780;

- HWS-5814 is a specification for a temperature monitor system for monitoring a nuclear process and is not relevant to SST design specifications. 


\subsubsection{Design Life}

Design life was not listed in the construction specifications for the majority of the tank farms. The design life for Type IV-C, AX Tank Farm was listed as 25 years in Stivers (1961) and Doud (et. al 1962) specifications. However, these documents do not represent the final tank design. The earliest document found suggesting a design life for the SSTs was Stivers (1957). The Stivers (1957) report lists an approximate SST design life of 25 to 35 years. This however only applies to the SX and A Tank Farms, as the document states the suggested design life assumes a waste heat up period of six months, followed by a two to four-year boiling period - and the AX Tank Farm had not been constructed at this time. In Stivers (1957), a figure shows Tank Types II and III having integrity (design life) of 100 years. In addition, SX and A Tank Farm integrity is listed on the same figure as indeterminate based on "current knowledge of waste characteristios." As shown, the original design life of Hanford's SST is not determinate based on the documents reviewed. However, for this SST AOR effort, the original design life will be speculated as 25 to 35 years for all SSTs.

Table 3.1 summarizes the geometrical characteristics of each tank farm. Waterproofing information for each of the SST tank farms is provided in Section 3.1.2.

\subsubsection{Waterproofing}

Corrosion protection for the steel liners and concrete structures included asphaltic waterproofing and paint on their surfaces. The following asphaltic waterproofing descriptions are listed in Table 3.2. However, waterproofing layers were not included in the structural modeling efforts as discussed in Section 4.2 .

\subsubsection{Design Waste Specific Gravity and Waste Height, Waste Storage Pressure, Max Liquid Temperature, $\mathrm{pH}$}

Type IV SSTs were designed for boiling waste as indicated by the maximum liquid temperature in Table 3.3 (Harvey 1970). 
Table 3.1 SST Tank Geometry

\begin{tabular}{|c|c|c|c|c|c|c|c|}
\hline $\begin{array}{l}\text { Tank } \\
\text { Farm }\end{array}$ & $\begin{array}{l}\text { Tank } \\
\text { Type }\end{array}$ & $\begin{array}{l}\text { Cencrete Foundation } \\
\text { Centerline Thickness } \\
\text { (in) }\end{array}$ & $\begin{array}{l}\text { Reinforced } \\
\text { Concrete Wall } \\
\text { Thickness (in) }\end{array}$ & $\begin{array}{l}\text { Reinforced } \\
\text { Concrete Dome } \\
\text { Thickness (in) }\end{array}$ & $\begin{array}{l}\text { Steel Liner } \\
\text { Height (in) }\end{array}$ & Reference (Drawings) & $\begin{array}{l}\text { Steel Liner } \\
\text { Centerline } \\
\text { Thickness (in) }\end{array}$ \\
\hline AXIV & $-\mathrm{C}$ & $18^{(2)(b)} 24$ & to $15^{(\mathrm{c})} 1$ & 5 & 390 & $\mathrm{H}-2-44562^{(\mathrm{d})} 0$. & 375 \\
\hline SXIV & $-\mathrm{A}$ & $8^{(x)} 24$ & to $15^{(0)} 1$ & 5 & 373 & $\mathrm{H}-2-3951 \mathrm{I}^{\mathrm{N}} \mathrm{0}$ & 375 \\
\hline $\begin{array}{l}\mathrm{BY}, \mathrm{S}, \\
\mathrm{TX} \text {, and } \\
\mathrm{TY}\end{array}$ & III 6 & (it) & $\sim 15$ & 15 & $\sim 287$ to 288 & $\begin{array}{l}\mathrm{BY}: \mathrm{H}-2-1312^{(\mathrm{d})}, \mathrm{S}: \mathrm{H}-2- \\
1783^{(\mathrm{d})}, \mathrm{TX}: \mathrm{H}-2-808^{(\mathrm{d})} \\
\text { and TY: H-2-2244} \\
\text { For steel liner thickness } \\
\text { BY: H-2-1313 } \\
1784^{(\mathrm{d})}, \mathrm{S}: \mathrm{H}-2- \\
\mathrm{H}-2-2245^{(\mathrm{d})}\end{array}$ & 0,375 \\
\hline $\begin{array}{l}\mathrm{B}, \mathrm{C}, \mathrm{T} \text {, } \\
\mathrm{U} \text {, and } \\
\mathrm{BX}\end{array}$ & II 6 & (1) & 12 & 15 & -216 & $\begin{array}{l}\mathrm{B}, \mathrm{C}, \mathrm{T} \text {, and U: W-71387, } \\
\text { Rer. 19, BX: H-2-602 }\end{array}$ & 0.25 \\
\hline $\begin{array}{l}\mathrm{B}, \mathrm{C}, \mathrm{T} \text {, } \\
\text { and } \mathrm{U}\end{array}$ & I 6 & (I) 12 & & 12 & 300 & $\begin{array}{l}\text { Centerline concrete } \\
\text { thickness, steel liner } \\
\text { beight and thickness: } \\
\text { HW- } 72417 \text {; } \\
\text { Reinforced concrete wall } \\
\text { thickness D-21; and } \\
\text { Reinforced concrete } \\
\text { dome thickness D-20 }\end{array}$ & 0.25 \\
\hline $\begin{array}{l}\text { (a) } \\
\text { (b) } \\
\text { (c) } \\
\text { (d) } \\
\text { (e) } \\
\text { (f) }\end{array}$ & $\begin{array}{l}\text { Flat bottc } \\
\text { Has drain } \\
\text { Tapered, } \\
\text { Checked } \\
\text { Steel line } \\
\text { Dished b }\end{array}$ & $\begin{array}{l}\text { slots } \\
\text { hicker at bottom } \\
\text { or as-built } \\
\text { height } \\
\text { tom }\end{array}$ & & & & & \\
\hline
\end{tabular}


Table 3.2 SST Waterproofing Description

\begin{tabular}{|c|c|c|c|c|c|c|c|}
\hline $\begin{array}{l}\text { Tank } \\
\text { Tarm }\end{array}$ & $\begin{array}{l}\text { Tank } \\
\text { Type }\end{array}$ & $\begin{array}{l}\text { Steel Liner } \\
\text { Foundation }\end{array}$ & Reference & Steel Liner Walls & Reference & Concrete Exterior & Reference \\
\hline A & IV-B & $\begin{array}{l}3 \text { ply } 3 / 8 \text { " thick } \\
\text { asphaltic water- } \\
\text { proofing } \\
\text { membrane } \\
\text { covered with } 2^{n} \\
\text { grout }\end{array}$ & $\begin{array}{l}\text { Drawing H-2- } \\
55911^{(9)}\end{array}$ & None Dra & $\begin{array}{l}\text { wing } \mathrm{H}-2- \\
55911^{(2)}\end{array}$ & $\begin{array}{l}2 \text { ply asphaltic water- } \\
\text { proofing membrane, } \\
\text { covers top of dome } \\
\text { and } 4^{\prime}-101 / 16^{\prime} \text { down } \\
\text { side wall, fiberglass } \\
\text { fabric and steel strap } \\
\text { tised around risers }\end{array}$ & $\begin{array}{l}\text { Drawing H-2- } \\
55911^{(3)}\end{array}$ \\
\hline SX & IV-A & $\begin{array}{l}3 \text { ply } 3 / 8 \text { " thick } \\
\text { asphaltic water- } \\
\text { proofing } \\
\text { membrane } \\
\text { covered with } 2^{\prime \prime} \\
\text { grout }\end{array}$ & $\begin{array}{l}\text { Drawing H-2- } \\
39511^{(3)}\end{array}$ & None Dra & $\begin{array}{l}\text { wing } \mathrm{H}-2- \\
39511^{(\mathrm{a})}\end{array}$ & None Dra & $\begin{array}{l}\text { wing } \mathrm{H}-2- \\
39511^{\text {(a) }}\end{array}$ \\
\hline BY III & & $\begin{array}{l}3 \text { ply asphaltic } \\
\text { membrane } \\
\text { waterproofing } \\
3 / 8^{\prime \prime} \text { thick, } 2^{\prime \prime} \\
\text { grout reinforced } \\
\text { with wire mesh } \\
2^{\prime \prime} \text { openings }\end{array}$ & $\begin{array}{l}\text { Drawing H-2- } \\
1312^{(\hat{)})}\end{array}$ & $\begin{array}{l}3 \text { ply asphaltic } \\
\text { membrane } \\
\text { waterproofing } \\
\text { covered with } \\
\text { asphalt, } 3 / 8^{\prime \prime} \text { to } 1 / 2 \text { " } \\
\text { thick, and } 5 / 8^{\prime \prime} \\
\text { thick gunite }\end{array}$ & $\begin{array}{l}\text { Drawing H-2- } \\
1312^{(*)}\end{array}$ & $\begin{array}{l}3 / 4^{\prime \prime} \text { gunite reinforced } \\
\text { with wire mesh } 2^{\prime \prime} \\
\text { openings over } 3 \text { ply } \\
\text { asphaltic membrane } \\
\text { waterproofing, covers } \\
\text { top of dome and }-6 \\
\text { down side wall }\end{array}$ & Drawing $\mathrm{H}-2-1312^{(\theta)}$ \\
\hline
\end{tabular}




\begin{tabular}{|c|c|c|c|c|c|c|c|}
\hline $\begin{array}{l}\text { Tank } \\
\text { Farm }\end{array}$ & $\begin{array}{l}\text { Tank } \\
\text { Type }\end{array}$ & $\begin{array}{l}\text { Steel Liner } \\
\text { Foundation }\end{array}$ & Reference & Steel Liner Walls & Reference & Concrete Exterior & Reference \\
\hline $\begin{array}{l}\mathrm{B}, \mathrm{C}, \mathrm{T} \\
\text {, and } \\
\mathrm{U}\end{array}$ & II $2^{n}$ & \begin{tabular}{l}
\multicolumn{1}{c}{ grout } \\
reinforced with \\
wire mesh and \\
3 ply asphaltic \\
membrane \\
waterproofing
\end{tabular} & $\begin{array}{l}\text { 1943_NA_ } \\
\text { Specifications } \\
1946,1945 \text { NA } \\
\text { Specifications and } \\
\text { Drawings D-2, W- } \\
\text { 71387, Rev. D-24 }\end{array}$ & $\begin{array}{l}3 \text { ply asphaltic } \\
\text { membrane } \\
\text { waterproofing. } \\
3 / 16^{\prime \prime} \text { to } 1 / 4^{\prime \prime} \text { thick, } \\
\text { covered with } \\
\text { asphalt, } 3 / 8^{\prime \prime} \text { to } \\
1 / 2^{n} \text { thick, and } \\
\text { cement mortar or } \\
\text { gunite }\end{array}$ & Drawing D-2 & $\begin{array}{l}3 \text { ply membrane water- } \\
\text { proofing covered with } \\
3 / 4 \text { " protective cement } \\
\text { grout or gunite, rein- } \\
\text { forced with chicken } \\
\text { wire, covers top of } \\
\text { dome and 1' down side } \\
\text { wall }\end{array}$ & $\begin{array}{l}1943 \text { NA } \\
\text { Specifications 1946, } \\
1944 \text { NA } \\
\text { Specifications, } \\
1945 \text { NA } \\
\text { Specifications and } \\
\text { Drawing W-71387, } \\
\text { Rev. D-24 }\end{array}$ \\
\hline
\end{tabular}


Table 3.3 SST Waste Design Parameters

\begin{tabular}{|c|c|c|c|c|c|c|c|c|c|c|c|}
\hline $\begin{array}{l}\text { Tank } \\
\text { Farm }\end{array}$ & $\begin{array}{l}\text { Tank } \\
\text { Type }\end{array}$ & $\begin{array}{c}\text { Max } \\
\text { Specific } \\
\text { Gravity }\end{array}$ & Reference & $\begin{array}{l}\text { Height } \\
\text { (in) }\end{array}$ & Reference & $\begin{array}{c}\text { Storage } \\
\text { Pressure (psi) }\end{array}$ & Reference & $\begin{array}{c}\text { Max Liquid } \\
\text { Design } \\
\text { Tempera- } \\
\text { ture }\left({ }^{\circ} \mathrm{F}\right)\end{array}$ & Reference & pH & Reference \\
\hline AXIV & C & 2.0 & Mercier 1981 & $\begin{array}{l}\text { Not } \\
\text { Found }\end{array}$ & - & -1.0 to 3.0 & $\begin{array}{l}\text { Stivers } 1961 \text { and } \\
\text { Doud et al. } 1962\end{array}$ & 300 & Shefcik 1964 & 8 to 10 & $\begin{array}{l}\text { Harvey } 1970 \text { and } \\
\text { Rifaey } 2002\end{array}$ \\
\hline A & IV-B & 2.0 & $\begin{array}{l}\text { Sinith } 1955 \text { and } \\
\text { Stivers } 1957\end{array}$ & $\sim 363 \mathrm{D}$ & $\begin{array}{l}\text { awing } \\
55911^{(\mathrm{s})}\end{array}$ H-2. & $\sim(-0.55)$ to 2.2 & $\begin{array}{l}1996 \text { HanFC and } \\
\text { 1981_MercierPF }\end{array}$ & 250 Stivg & $\begin{array}{l}\text { Is } 1957 \\
\text { and Harvey } \\
1970\end{array}$ & 8 to 10 & $\begin{array}{l}\text { Stivers } 1957 \text { and } \\
\text { Harvey } 1970\end{array}$ \\
\hline SXIV & A & 1.5 & $\begin{array}{l}\text { Stwers } 1955 \\
\text { and Rifaey } \\
2002\end{array}$ & 360 & Smith 1955 & Atmosphenc & $\begin{array}{l}\text { Stivers } 1957 \text { and } \\
\text { Harvey } 1970\end{array}$ & 250 Stave & $\begin{array}{l}\text { is } 1957 \\
\text { and Harvey } \\
1970\end{array}$ & 8 to 10 & $\begin{array}{l}\text { Stivers } 1957 \text { and } \\
\text { Harvey } 1970\end{array}$ \\
\hline TXIII & & 1.5 & $\begin{array}{l}\text { Stivers } 1955 \\
\text { and Rifaey } \\
2002\end{array}$ & 282 & Smith 1955 & Atmospheric & $\begin{array}{l}\text { Stivers } 1957 \text { and } \\
\text { Harvey } 1970\end{array}$ & 220 Stive & $\begin{array}{l}\text { [s } 1957 \\
\text { and Harvey } \\
1970\end{array}$ & 8 to 10 & $\begin{array}{l}\text { Stivers } 1957 \text { and } \\
\text { Harvey } 1970\end{array}$ \\
\hline BY III & & 15 & $\begin{array}{l}\text { Stivers } 1955 \\
\text { and Rifaey } \\
2002\end{array}$ & 282 & Smith 1955 & Atmospheric & $\begin{array}{l}\text { Stivers } 1957 \text { and } \\
\text { Harvey } 1970\end{array}$ & 2201957 & \begin{tabular}{|l} 
Stivers \\
HW
\end{tabular} & 8 to 10 & $\begin{array}{l}\text { Stivers } 1957 \text { and } \\
\text { Harvey } 1970\end{array}$ \\
\hline BXII & & 1.25 & $\begin{array}{l}\text { Drawing H-2- } \\
602\end{array}$ & $192 \mathrm{Dr}$ & $\begin{array}{ll}\text { wing } & \mathrm{H}-2- \\
002 & \end{array}$ & Atmospheric & Drawing $\mathrm{H}-2-602$ & 220 & $\begin{array}{l}\text { Stivers } 1957 \\
\text { and Harvey } \\
1970\end{array}$ & $10 \mathrm{DT}$ & $\begin{array}{ll}\text { fing } \\
602\end{array}$ \\
\hline $\begin{array}{l}\mathrm{B}, \mathrm{C}, \mathrm{T} \text {, } \\
\text { and } \mathrm{U}\end{array}$ & II 1.25 & & $\begin{array}{l}1943 \text { NA_ } \\
\text { Specifications } \\
1946 \text {, and } \\
\text { Drawing } \\
\text { W-71387, } \\
\text { Rev.D-24 }\end{array}$ & 19219 & $\begin{array}{l}\text { 3_NA } \\
\text { Specifications } \\
1946 \text {, and } \\
\text { Drawing } \\
\text { W-71387, } \\
\text { Rer. D-24 }\end{array}$ & Atmospheric 19 & $\begin{array}{l}\text { 3_NA } \\
\text { Specifications } \\
1946 \text {, and } \\
\text { Drawing D-2 }\end{array}$ & 2201943 & $\begin{array}{l}\text { NA } \\
\text { Specifications } \\
1946 \text {, and } \\
\text { Drawing } \\
\text { W-71387, } \\
\text { Rev_D-24 }\end{array}$ & 10194 & $\begin{array}{l}\text { NA } \\
\text { Specifications } \\
1946 \text {, and } \\
\text { Drawing D-2 }\end{array}$ \\
\hline $\begin{array}{l}\mathrm{B}, \mathrm{C}, \mathrm{T}, \\
\text { and } \mathrm{U}\end{array}$ & 11.25 & & $\begin{array}{l}1943 \text { NA } \\
\text { Specifications } \\
1961 \text {, and } \\
\text { Drawing HW- } \\
72417\end{array}$ & 28819 & $\begin{array}{l}3 \mathrm{NA} \\
\text { Specifications } \\
1961 \text {, and } \\
\text { Drawing } \\
\text { HW-72417 }\end{array}$ & Atmosphenic 19 & $\begin{array}{l}3 \text { NA } \\
\text { Specifications } \\
1961\end{array}$ & 2201943 & $\begin{array}{l}\text { NA } \\
\text { Specifications } \\
1961 \text {, and } \\
\text { Drawing HW- } \\
72417\end{array}$ & 1019 & $\begin{array}{l}\text { NA } \\
\text { Specifications } \\
1961 \text {, and } \\
\text { Drawing HW- } \\
72417\end{array}$ \\
\hline
\end{tabular}




\subsubsection{Design Overhead Equipment Loads}

Design tank loads - listed as live loads per temporary equipment - in addition to soil and gravity loads, were found for most of the tank types, categorized under "live loads" in the Evaluation Criteria report (PNNL-18837). None were found for the 55 kilogallon Type I SST's. Tank loads in Table 3.4 summarize what was found, but loads used in the preliminary modeling and those to be used on the detailed modeling will be those defined in the Evaluation Criteria report, Johnson et al. (2010). These do not include waste loads, however; design information on the waste loading characteristics is presented in Section 3.1.3.

Table 3.4 SST Design Equipment Loads

\begin{tabular}{|c|c|c|c|}
\hline Tank Farm & Tank Type & Equipment Loading & Reference \\
\hline AX & IV-C & $\begin{array}{l}40 \text { psi plus a } 50 \text { ton concentrated load for tank dome live } \\
\text { load }\end{array}$ & $\begin{array}{l}\text { Stivers } 1961 \text { and } \\
\text { Doud et al. } 1962\end{array}$ \\
\hline \multirow[t]{2}{*}{$\mathrm{A}$} & \multirow[t]{2}{*}{ IV-B } & $2 \times \mathbf{3 5}, 000 \mathrm{lb}$ tractors, $1^{1}-3^{n}$ concrete slab at $150 \mathrm{psf}$ & Stivers 1955 \\
\hline & & a 28 ton concentrated load for tank dome live load & Shefcik 1964 \\
\hline SX & IV-A & $2 \times 35,000 \mathrm{lb}$ tractors, $1^{\prime}-3^{n}$ concrete slab at $150 \mathrm{psf}$ & Stivers 1955 \\
\hline $\begin{array}{l}\text { BY, S,TX, } \\
\text { and TY }\end{array}$ & III & $2 \times 35,000 \mathrm{lb}$ tractors, $1^{1}-3^{n}$ concrete slab at $150 \mathrm{psf}$ & Stivers 1955 \\
\hline BX & II & $\begin{array}{l}34,000 \text { lbs concentrated load applied at top of backfill in } \\
\text { any location during backfilling operations }\end{array}$ & Drawing H-2-602 \\
\hline $\mathrm{B}, \mathrm{C}, \mathrm{T}$, and $\mathrm{U}$ & II & $\begin{array}{l}34,000 \mathrm{lb} \text { concentrated load applied at top of backfill in } \\
\text { any location during backfilling operations }\end{array}$ & Drawing D-2(b) \\
\hline
\end{tabular}

\subsubsection{Design Soil Backfilling and Cover, Density, Soil Bearing Value}

This section tabulates soil property and backfilling information taken from the earliest design of origin documents obtained. However, soil property values listed in the Evaluation Criteria will be used in the finite element modeling of the SSTs. Refer to Table 3.5 for soil density values, Table 3.6 for design soil bearing values, Table 3.7 for soil cover, Table 3.8 for Backfill.

Table 3.5 Soil Density

\begin{tabular}{|c|c|c|l|}
\hline Tank Farm & Tank Type & Soil Density Specification $\left(\mathbf{l b}_{\gamma} / \mathbf{f t}^{3}\right)$ & \multicolumn{1}{|c|}{ Reference } \\
\hline SX, A, and AX & IVA, B and C & 110 & Harvey 1970 and Mercier 1981 \\
\hline S, and TY & II & 110 & Harvey 1970 and Mercier 1981 \\
\hline TX & III & 110 & Harvey 1970 and Mercier 1981 \\
\hline BY & III & 110 & Harvey 1970 and Mercier 1981 \\
\hline BXI & I & 100 & Drawing H-2-602 \\
\hline B,C,T, and U & II & 100 & GE 1943, GE 1946 and Drawing D-2 \\
\hline B,C,T, and U & I & 100 & 1943 NA_Specification HW-1961 \\
\hline
\end{tabular}


Table 3.6 Soil Bearing Value

\begin{tabular}{|l|c|c|l|}
\hline \multicolumn{1}{|c|}{ Tank Farm } & Tank Type & Soil Bearing Value $\left(\mathbf{I b}_{\mathbf{f}} \mathrm{ft}^{2}\right)$ & \multicolumn{1}{|c|}{ Reference } \\
\hline SX, A, and AX & IVA, B and C & 6000 & Harvey 1970 and Mercier 1981 \\
\hline BY,S,TX and TY & III & 6000 & Harvey 1970 and Mercier 1981 \\
\hline BX I & I & 8000 & Drawing H-2-602 \\
\hline B,C,T, and U & II & 8000 & $\begin{array}{l}1943 \text { NA_Specifications HW-1946 } \\
\text { and Drawing W-71387 }\end{array}$ \\
\hline B,C,T, and U & I & 8000 & $\begin{array}{l}1943 \text { NA_Specification HW-1961 } \\
\text { and Drawing HW-72417 }\end{array}$ \\
\hline
\end{tabular}

Table 3.7 Soil Cover

\begin{tabular}{|c|c|c|c|}
\hline Tank Farm & Tank Type & $\begin{array}{l}\text { Soil Cover Depth from } \\
\text { Top of Dome Apex to } \\
\text { Finished Backfill } \\
\text { Grade (in.) }\end{array}$ & Reference \\
\hline SXI & VA & 72 & Drawing $\mathrm{H}-2-39511^{\text {(क) }}$ \\
\hline AI & VB & 84 & Drawing $\mathrm{H}-2-55911^{(2)}$ \\
\hline $\mathrm{AX}(101$ and 103$)$ & IVC & $\sim 78$ & Drawings $\mathrm{H}-2-44552$ and $\mathrm{H}-2-44562^{(\mathrm{i})}$ \\
\hline $\mathrm{AX}(102$ and 104$)$ & IVC & -90 & Drawings $\mathrm{H}-2-44552$ and $\mathrm{H}-2-44562^{(2)}$ \\
\hline TYI & II & $\sim 74.6$ & Drawing $\mathrm{H}-2-2244^{(n)}$ \\
\hline TXII & I & 96 & $\begin{array}{l}\text { Drawing H-2-808 }{ }^{(\mathrm{da})} \text { and } \\
1953 \text { NA_Design HW-24800-35 }\end{array}$ \\
\hline BY I & II & 96 & $\begin{array}{l}\text { Drawing H-2-1312(2) and } \\
1953 \text { NA Specification HW-24800-30 }\end{array}$ \\
\hline SI & II & -74.6 & Drawing $\mathrm{H}-2-1783^{(a)}$ \\
\hline$\overline{\text { BXI }}$ & I & 96 & Drawing $\mathrm{H}-2-601$ \\
\hline $\mathrm{B}, \mathrm{C}, \mathrm{T}$, and $\mathrm{U}$ & II & $108(\max )$ & $\begin{array}{l}\text { 1943_NA_Specifications } 1946 \text { and } \\
\text { Drawing W-71387, Rev } 19\end{array}$ \\
\hline $\mathrm{B}, \mathrm{C}, \mathrm{T}$, and U & I & 132 & 1943 NA Specifications 1961 \\
\hline
\end{tabular}

(a) Checked for as-built

It should be noted that the detailed modeling phase will apply soil overburden values reported in the Rifaey (2002) report - as stated in the Evaluation Criteria report Johnson et al. (2010). These values differ from the design values listed in Table 3.7, but the 2002 Rifaey soil overburden values bound the design maximum specification values. In addition, a more recent effort, the Mackey (2004) report, WHCSD-WM-TI-665, Rev. OD) provides results on a detailed soil survey from field walkdowns and revises soil height data above DSTs and SSTs at the Hanford site. There are two instances when the soil overburden values provided in the Mackey (2004) report are greater than those in the Rifaey (2002) report, respectively:

- BX Tank Farm, 100 to 110 inches versus 98 to 108 inches; and

- S Tank Farm, 76 to 91 inches versus 79 to 89 inches.

However, soil cover values listed in the Rifaey (2002) report are generally bounding for the most part and should produce more conservative results. 
Table 3.8 SST Backfill Description

\begin{tabular}{|c|c|c|c|}
\hline Tank Farm & Tank Type & Backfill Description & Reference \\
\hline A & IVB & $\begin{array}{l}\text { Only selected material free from frozen particles, stones larger than } 8 \text {-in, vegetable matter } \\
\text { and trash will be used, backfill will take place after } 28 \text { days of the last dome concrete } \\
\text { placement and after } 10 \text { days of the last wall pour and will be done in layers not to exceed } \\
6 \text {-in for material for load bearing, wet down and thoroughly compacted, material for non- } \\
\text { load bearing backfill shall not be placed in layers to exceed } 24 \text {-in loose measurement and } \\
\text { thoroughly compacted, layers will be uniformly around and over structure so that all } \\
\text { weight and pressures are equally distributed. }\end{array}$ & Engler 1953 \\
\hline AX & IVC & $\begin{array}{l}\text { Non-load bearing backfill: No rocks larger than } 8 \text { " in diameter, placed in layers no deeper } \\
\text { than } 12^{\prime \prime} \text {, cach layer compacted by at least } 2 \text { passes of any acceptable type vibratory } \\
\text { machine, Top layer of backfill coarse gravel pass a } 3 / 4^{\prime \prime} \text { screen and retained on a \#4 } \\
\text { screen, } 3^{\prime \prime} \text { deep. }\end{array}$ & Alger 1963 \\
\hline$\overline{B Y}$ & III & Backfill will be placed in layers $6^{\prime \prime}$ to $24^{\prime \prime}$ deep. & $\begin{array}{l}1948 \text { NA_Specification HW } \\
3783\end{array}$ \\
\hline S & III & $\begin{array}{l}\text { The top layer of backfill coarse gravel } 4 \text { " deep. Backfill placed in layers no deeper than } \\
24 " \text { ". }\end{array}$ & Rutherford 1949 \\
\hline $\mathrm{BX}$ & II & $\begin{array}{l}\text { Backfill will be done in } 6 \text { to } 24 \text { in layers uniformly around and over structure so that all } \\
\text { weight and pressures are equally distributed. }\end{array}$ & $\begin{array}{l}\text { 1946_NA_Specifications HW- } \\
7-5264\end{array}$ \\
\hline $\mathrm{B}, \mathrm{C}, \mathrm{T}$, and U & II & $\begin{array}{l}\text { Backfill will take place after } 28 \text { days of the last concrete placement and will be done in } 6 \\
\text { to } 24 \text { in layers uniformly around and over structure so that all weight and pressures are } \\
\text { equally distributed. }\end{array}$ & $\begin{array}{l}\text { 1943_NA_Specifications } 1946 \\
\text { and } 1944 \text { NA Specifications }\end{array}$ \\
\hline $\mathrm{B}, \mathrm{C}, \mathrm{T}$, and $\mathrm{U}$ & I & Backfill will be placed in layers from 6" to $24 "$. & $\begin{array}{l}\text { 1943_NA_Specifications } 1961 \\
\text { and 1944_NA_Specifications }\end{array}$ \\
\hline
\end{tabular}


RPP-46644, Rev.0

\subsection{Codes and Standards}

Construction Codes and Standards found agree with those listed in the Evaluation Criteria report, Johnson et al. (2010).

\subsection{Material Properties}

Material property data for concrete, soil, and reinforcing steel is provided in the Evaluation Criteria report, Johnson et al. (2010). Best-estimate, lower-bound and upper-bound values for concrete strength and modulus due to the variation in properties that is reported for Hanford concrete, single recommended values for the reinforcing steel properties, and the static stiffness properties of Hanford soils used in this preliminary analysis are presented in the Evaluation Criteria report, Johnson et al. (2010).

\subsection{Temperature Histories}

The temperature history of the tanks in Tank Farm A, AX and SX (Type IV) were obtained from two sources - Mercier (1981) for temperature history from the $1950 \mathrm{~s}$ to $1970 \mathrm{~s}$ and Tank Waste Information Network System/Surveillance Analysis Computer System (TWINS/SACS) databases for temperature history from the late 1970 s to the present.

The temperature data in Mercier (1981) was obtained from various sources including DOE-RL records from the storage warehouse in Seattle, Washington and discussions with 14 Rockwell Hanford Operations employees. The temperatures recorded were of two types - bulb temperature and waste temperature. Further, the waste temperature was of two types - high or only thermocouple and average thermocouple. In the instances where both bulb temperature and waste temperature are available for the same tank and the same time period, the waste temperature was taken into account. If only one of the bulb temperature and waste temperature is available, then the available data is taken into consideration. In the instances where both high or only thermocouple and average thermocouple data were available for the same tank for the same time period, the high or only thermocouple reading was taken into account.

The location of the recorded temperatures in Mercier (1981) is not clear defined. The only definition in Mercier (1981) is given for bulb temperature in a footnote (on page B-1) as "Bulb Temp. = Temp. of annulus air." This is not sufficient to obtain definitive locations of the thermometers. Brevick (1994, WHC-SD-WM-ER-324-SX-Farm, Rev 0, p. D-1 to D-37) records the temperature of SX tanks in plots with the heading "Historical Vapor Space Temperature." When cross checked with the Mercier (1981) report, these values correspond to the bulb temperature values. On the contrary, Rifaey (2002, pages A-59 \& A-60) states that, "Both the bulb thermometers and the thermocouples measured waste temperature at the bottom of the tank" and "... the reports on the A and AX farm tanks give the average sludge temperature for the eight to 22 thermocouples on the tank bottoms as well as the peak temperature for the "hot-spot" in the sludge." Of the three reports, the Rifaey (2002) report appears credible since the location of the thermometers and thermocouples has been explicitly identified in this report. However, at present there is no clear conclusive evidence to determine the location of the thermocouples or thermometers and further investigation is necessary. 
The Julyk (1994) Report (SD-W320-Anal-001) is another source of temperature and waste level data for preliminary modeling. This report analyzes the Tank C-106 and thus serves as the basis for the temperature and waste level history of Type II tanks.

TWINS/SACS databases provide temperature readings from different thermocouples from the thermocouple trees. Thermocouple- 1 has the highest temperatures for most of the tanks and provides the temperature measurement closest to the bottom of the tank (about 4 inches from the tank bottom). Therefore, temperature data from this thermocouple will be used to be consistent with the data available from Mercier (1981). While the TWINS/SACS database provides recorded temperature data for a large number of SSTs starting from 1975 and later, there are huge gaps in the recorded temperatures for many of the tanks.

The waste level histories of all the SSTs can be obtained from Brevick (1994) reports, except for Tank Farms T, TX and TY. These reports provide the waste level for each tank in a tabulated format with quarterly waste level readings for the periods beginning the first year of tank operation up to 1993. The readings include waste level in inches, waste volume in kilogallons, solids level in inches, and solids volume in kilogallons. However, there a large number of gaps in the data at certain time periods.

\subsubsection{SST Peak Temperatures}

Rifaey (2002) provides SST peak temperatures in a tabulated form. These values have been plotted, shown in Figure 3.1. Unfortunately the reported temperatures do not provide an exact time nor duration of the experienced high temperature. As can be seen, some of the tanks in Tank Farm A experienced the highest waste temperatures of all SSTs. In general, the Type IV tanks containing self-boiling waste were subjected to the highest waste temperatures. 


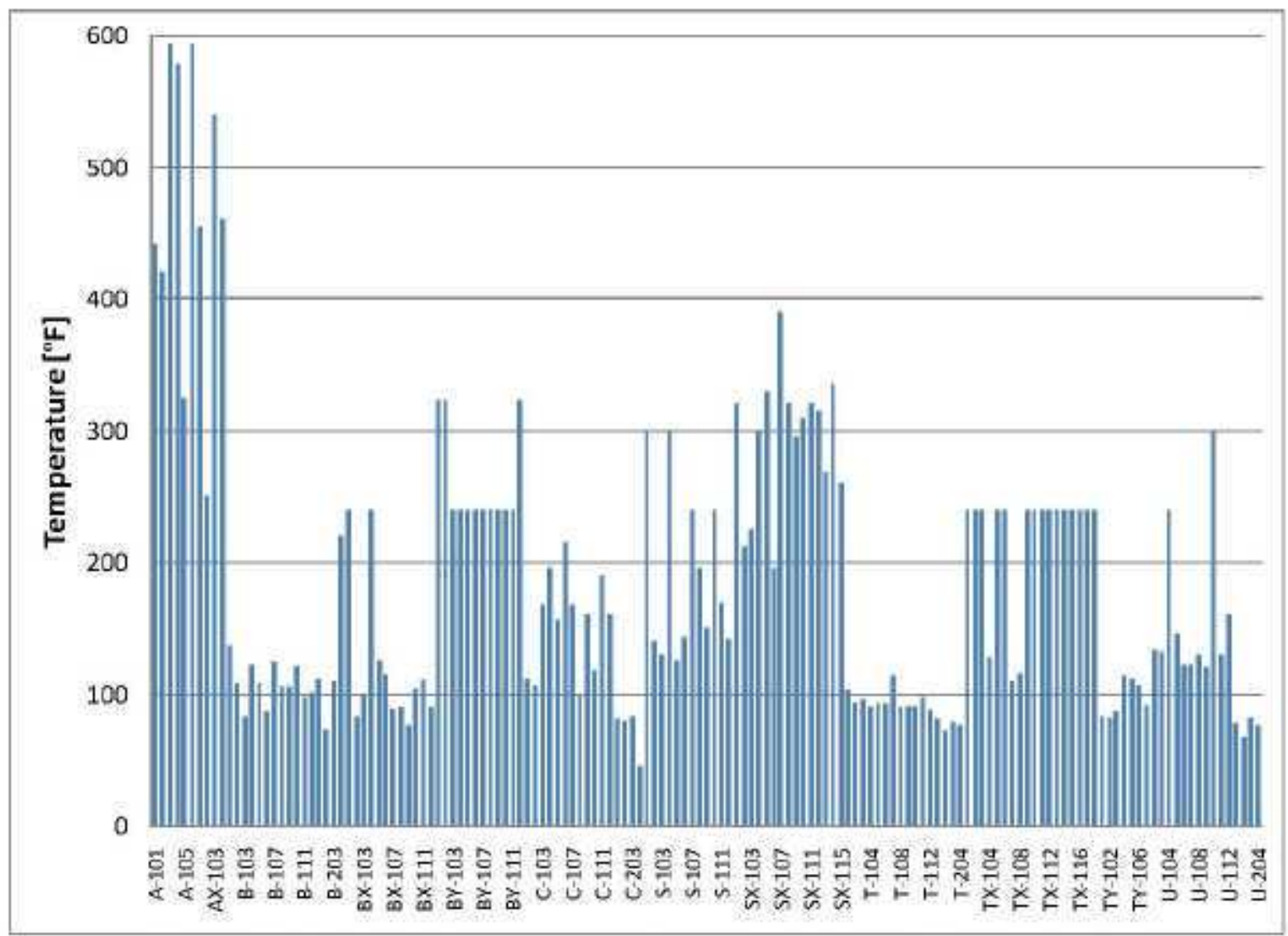

Figure 3.1 SST Peak Temperatures as Reported in Rifaey (2002, RPP-10435)

\subsection{Drawings}

Table 3.9 shows a summary of the important drawings necessary to build each finite element model. The overall geometry of the each tank is derived from the drawings found under the composite tank details column. Typically the details of the wall and floor reinforcement and the dome reinforcement were found in separate drawings. These drawings were used to assign the proper reinforcement volume fractions in concrete.

Table 3.9 Summary of Important Drawings

\begin{tabular}{|c|l|l|l|l|}
\hline $\begin{array}{c}\text { Tank } \\
\text { Type }\end{array}$ & \multicolumn{1}{|c|}{ Tank Farm } & \multicolumn{1}{|c|}{ Composite Tank Details } & \multicolumn{1}{|c|}{$\begin{array}{c}\text { Wall \& Floor } \\
\text { Reinforcement }\end{array}$} & $\begin{array}{c}\text { Dome } \\
\text { Reinforcement }\end{array}$ \\
\hline & & \multicolumn{1}{|c|}{ (Farm Specific) } & \multicolumn{1}{c|}{ (Farm Specific) } & (Farm Specific) \\
\hline I & C, B, T, and U & HW-72417, HW-72742, D-20 & D-21 & D-22 \\
\hline II & C, B, T, and U & H-W-72743,W-71387, D-1, D-2 & D-5 & D-6 \\
\hline II BX & H-2-602 & H-2-605 & H-2-606 \\
\hline III BY & H-2-1312 & $\mathrm{H}-2-1314$ & H-3-1315 \\
\hline III S & $\mathrm{H}-2-1783$ & $\mathrm{H}-2-1785$ & $\mathrm{H}-2-1786$ \\
\hline III TX & $\mathrm{H}-2-808$ & $\mathrm{H}-2-812$ & $\mathrm{H}-2-813$ \\
\hline III T & $\mathrm{H}-2-2244$ & $\mathrm{H}-2-2246$ & $\mathrm{H}-2-2247$ \\
\hline IV-A SX & $\mathrm{H}-2-39511$ & $\mathrm{H}-2-39512$ & $\mathrm{H}-2-39513$ \\
\hline IV-B A & $\mathrm{H}-2-55911$ & $\mathrm{H}-2-55912$ & $\mathrm{H}-2-55913$ \\
\hline IV-C A & $\mathrm{H}-2-44562$ & $\mathrm{H}-2-44562, \mathrm{H}-2-44563$ & $\mathrm{H}-2-44565$ \\
\hline
\end{tabular}




\subsection{Preliminary Modeling Strategy}

The primary goal of preliminary modeling is to provide recommendations as to the number of models/runs required for adequate bounding of each of the SST tank types in the detailed modeling phase of the single-shell tank (SST) analysis of record (AOR) project. In order to reduce the number of ANSYS $^{\circ}$ (version 12.0) runs in SST AOR detailed modeling efforts, a basis must be established for omitting selected load cases. Preliminary modeling results serve as the basis for limiting selected load cases in the detailed SST modeling efforts. The preliminary analysis needs to provide recommendations as to the number of models required for adequate bounding of each of the SST tank types. The preliminary analysis document reviews guide the topics that will be explored in the SST preliminary modeling.

Preliminary modeling topics and their impact to tank structural integrity include material properties, waste elevation, and thermal and waste histories tank geometry variations. Material properties preliminary modeling includes upper bound, best estimate, and lower bound properties of concrete. SST thermal histories will address thermal cycling, creep, and shock. Subsequent sections summarize the preliminary modeling strategy, design input, and assumptions.

As stated earlier, seismic modeling is not in the scope of this report. Consequently, preliminary seismic modeling is not addressed in the following strategy, but will be defined by the M\&D Professional Services team in a separate report.

\subsection{Design Input}

Per information exchanges with the client at biweekly Tuesday meetings, it was determined that finite element models should be constructed to allow future design modifications, such as adding large risers. In other words, models should be flexible, and "easily" manipulated to accommodate potential design/modeling changes in the future.

\subsection{Assumptions}

Initially, thermal modeling for the SX Tank Farm was planned for preliminary modeling. However, after comparing the structural model results for the SX and A tank models, and evaluating the bounding temperature profile for the Type IV(b) tanks, it was decided that thermal modeling for the SX Tank Farm was no longer necessary.

Even though the steel liner is not a structural component of the SST, it was necessary to investigate whether the steel liner and surrounding asphalt and grout layers should be included in the finite element tank models. The steel liner, asphalt, and grout layers were not included in the preliminary models for several reasons. First, the steel liner has the lowest thermal resistance and capacitance compared to the asphalt, grout, and concrete wall. Secondly, the total thermal effect of the steel, asphalt, and grout combined is negligible compared to the thermal effect of concrete within the range of SST concrete wall thicknesses. The concrete wall stiffness is also approximately seven times greater than the steel liner thickness - soil loads will not be transmitted to the steel liner, and the steel liner thermal strain indicates hydrostatic loading will be shifted to the concrete wall. Furthermore, exposing the SST concrete walls 
directly with the tank waste will produce greater temperature gradients, which is more conservative. In summary, excluding the steel liner, asphalt, and grout layers will produce conservative thermal and structural loads on the SST concrete walls.

\subsection{Modeling Plan}

As described in the scope of this report in Chapter Two, one of the purposes of preliminary modeling is to identify the extent of details necessary to be included in the detailed analyses of each of the tank types. For this purpose, the preliminary finite element models for each of the tank types were developed, and different case studies were performed on one or more of these tank types. The case studies were performed to study the sensitivity of boundary effects (soil radial extent), excavation slope, soil stratigraphic (property and layer thickness) variation at different farm locations, concrete material property variation and their degradation under thermal loads, etc. Conclusions were derived from case studies on one of the tank types when no additional runs of similar cases on other types of tanks are deemed necessary to derive those conclusions. The case studies include soil backfill transition (excavation) slope, depth and properties of soil layers with averaged values, soil radial extent, creep and thermal degradation studies, and material property studies which include lower bound, upper bound, and best estimate soils and their combinations with lower bound, upper bound, and best estimate concrete. In addition to the case studies listed above, tank-to-tank piping was investigated.

Table 4.1 summarizes the type of tank used for each of the case studies. The tank types were chosen such that any conclusions derived from their studies were based on the analyses that are bounding or conservative, or by the availability of data like thermal histories (profiles) at the time of this project. For instance, the Type IV(b) million gallon tanks of Tank Farm A were chosen for the studies of soil radial extent, soil layer depth, excavation slope effect, thermal degradation, and creep because it has the thinnest slab of all the Type IV tanks, which makes the analyses geometrically conservative. Its waste level and thermal histories (profiles) are available from previous reports and or other database (Tank Waste Information Network System, etc). The following sections present a brief description of the types of tanks used in the analyses and their modeling in ANSYS ${ }^{*}$.

Table 4.1 Preliminary Modeling Scope

\begin{tabular}{|l|c|}
\hline \multicolumn{1}{|c|}{ Case Study } & Tank Type \\
\hline Excavation slope transition effect study & \multirow{2}{*}{ IV(b) } \\
\hline Soil radial extent study & \\
\hline Soil layer effect study (stratigraphy) & II \\
\hline Thermal creep studics & IV(b), III, II, and I \\
\hline Waste level & Thermal studies
\end{tabular}

It should be noted that different- yet equivalent, terms are used to describe the direction or orientation of tank features, forces, moments, and stresses in the sections ahead. The following terms are used interchangeably: meridional and radial; and hoop, circumferential, and tangential. 
RPP-46644, Rev.0

\subsubsection{Tank Design Geometry}

\subsubsection{Type II}

It should be noted that models were created for each tank type during preliminary modeling efforts, with the exception of the model(s) used for Type II tanks. The following discusses the baseline model and changes made to accommodate structural analyses performed. Tank design geometry for the remaining tank types are covered in Sections 5 and 6, as appropriate.

All models using the Type II tank geometry were hased on the existing C-107 slice model originally developed to analyze the effect of adding a large riser to the center of the tank (Rinker et al. 2009). The C-107 slice model is a three dimensional, two degree axisymmetric slice of the C-107 tank. The tank geometry, liner, steel reinforcement, and other details were taken from drawings D-1 through D-6.

The main features of the existing C-107 model include: steel liner and liner stiffeners, soil, conerete, and reinforced concrete. The liner and liner stiffeners were not included in the Type II thermal models. However, they remained in the Type II waste level models but were not part of the structural evaluation of tank sections. As stated in Section 4.2, the steel liner and stiffners will not be included in any of the future detailed modeling. The concrete and the soil interact by using contact elements. ANSYS ${ }^{*}$ elements CONTA173 and TARGE170 are used for this interface. Depending on the run, either these contact normal stiffnesses or these contact penetration tolerances were adjusted to achieve convergence.

The soil in the Type II models was modeled as three layers with a distinction between backfill and undisturbed soil in the top layer. A soil overburden of seven feet was used. This value was chosen in Rinker et al. (2009), as it is conservative for C Tank Farm. However, for detailed modeling the overburden will be increased to a value conservative for all Type II tanks. The top layer of soil extends from the surface to the bottom of the tank footing; the backfill extends to a radius of twice the outer radius of the tank footing. The soil is modeled as undisturbed soil beyond this distance out to a distance of 240 feet. The second layer of soil is modeled as all undisturbed soil that extends from the bottom of the tank footing to 100 feet below the tank footing. The final layer of soil is modeled as undisturbed soil that extends from 100 feet below the tank footing to a depth of 167 feet 4 inches below bottom of the center of the tank. The material properties chosen for each layer of soil were the average of the applicable bestestimate soil properties found in the appendix of the SST Structural Evaluation Criteria Document, Johnson et al. (2010). The soil was modeled using the ANSYS ${ }^{2}$ element SOLID185 for structural analyses and SOLID70 for thermal analyses using the extended Drucker-Prager plasticity material model.

The concrete and reinforced concrete in the Type II models were modeled using the nominal material properties. The concrete was modeled using the ANSYS element SOLID65 for structural analyses and SOLID70 for thermal analyses. The concrete was set to crack if the principal tensile stresses exceeded the nominal tensile strength of the concrete. Upon element cracking, the concrete can no longer transfer any tensile stress normal to the cracking direction, while the amount of shear stress transferred depends on whether the crack is open or closed. The layers of reinforcement are explicitly meshed within the concrete slab, footing, wall, and dome. For each layer of reinforcement throughout the concrete, the volume fraction of steel in the hoop and meridional directions is calculated from drawings D-5 and D-6 and assigned to the SOLID65 elements in that layer; the SOLID65 element assumes the steel is smeared throughout the element. Within the haunch region, there is an additional small volume of reinforcement assigned between the exterior and interior reinforcement layers. 
For detailed modeling, the existing C-107 model needs to be updated in two areas. First, the existing C-107 model and any Type II models based on the existing C-107 model contain an extra thickness applied to the concrete to account for grout, mortar, and or waterproofing on the exterior top of the dome, the interior tank wall, and the interior top of the slab. During detailed Type II modeling this extra thickness will not be included. Second, the meshing within the concrete, particularly in the haunch, is not regular. This creates a problem when choosing sections to evaluate forces and moments in the tank. The sections chosen do not necessarily align with the nodes and elements in the model. This creates ambiguity when choosing which nodes and elements to include for each section, as well as accuracy issues when calculating section areas from the elements. During detailed Type II modeling, the meshing within the concrete will be aligned to conform to predetermined sections for force and moment evaluations.

Table 4.2 lists the loads applied to the Type II tank model for preliminary modeling load cases. The $200,000 \mathrm{lb}$. concentrated load was applied over a $15 \mathrm{ft}$. diameter area. This dimension reflects the equipment dimensions which were implemented in the C-107 large riser evaluation model (Rinker et al. 2009). The detailed analysis will use a $20 \mathrm{ft}$. diameter concentrated load on all tanks. 
Table 4.2 Type II Preliminary Model Loading

\begin{tabular}{|c|c|c|}
\hline $\begin{array}{l}\text { Thermal } \\
\text { Stresses }\end{array}$ & $\begin{array}{l}\text { Usung existing slice motel of C-107 (Type II), apply temperature } \\
\text { profiles from best estimate C-106 models for Jan } 1972 \text { and Oct } \\
\text { 1978 Run steady state themal + mechatucal cases } w \text { study the } \\
\text { effects of themal stress Compare forces and nioments of } \\
\text { therma] + mechanical cases versus mechanical only cases }\end{array}$ & 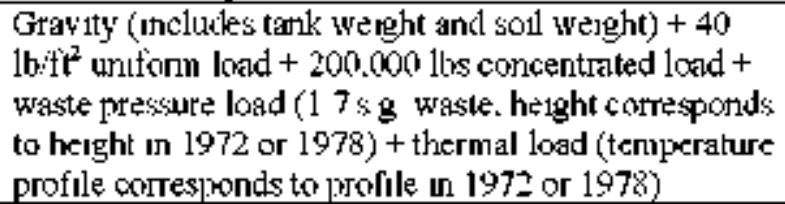 \\
\hline Wiaste Level & $\begin{array}{l}\text { Using the existing C-107 shice model, run cases with an enopty } \\
\text { tank to stuly the effects of wraste lived on the tanks Comprare } \\
\text { resulting force and mometit demands to other waste level results }\end{array}$ & Grav 1ty (mcludes tank wejght and soll wejght) \\
\hline Waste Level & $\begin{array}{l}\text { Using the existing C. } 107 \text { slice motlel, nun cases with a half full } \\
\text { tank to study the effects of waste load on the tanks Compare } \\
\text { resulting force and moment demands to other waste level results }\end{array}$ & $\begin{array}{l}\text { Gravity (utcludes tank we ght and soll wejght) + waste } \\
\text { pressure due to } 96 \text { mohes of } 17 \mathrm{sg} \text { waste }\end{array}$ \\
\hline Waste Level & $\begin{array}{l}\text { Using the existing C. } 107 \text { slice motlel, nun cases with a full tank } \\
\text { to study the effects of waste load on the tanks Conpare } \\
\text { resulting force and moment demands to other waste level results }\end{array}$ & $\begin{array}{l}\text { Gravity (uncludes tank wenght and soll wejght) + wasle } \\
\text { pressure due to } 192 \text { mehes of } 17 \mathrm{sg} \text { waste }\end{array}$ \\
\hline
\end{tabular}




\subsubsection{Temperature and Waste Profiles}

This section presents the background and reasoning behind the choice of the bounding temperature and waste height profiles for single-shell tanks (SSTs). These temperature and waste height profiles were used in the preliminary thermal and structural modeling of the tanks to estimate thermal creep and understand the effects of temperature gradients in the tank structural integrity. In order to be conservative, the single-shell tanks that have experienced consistently high temperatures were chosen for further analysis. The following temperature profiles may be revised as necessary for the detailed modeling phase as additional data is retrieved.

\subsubsection{Tank Farm A (Type IV-B)}

Figure 4.1 shows the available temperature history of Tanks A-101 to A-106, from 1956 to 1972 , obtained from Mercier (1981). Tank A-101 has a full record of temperature history, and on an average its temperatures are higher compared to A-102, A-103 and A-105. Tank A-104 appears to have temperature peaks comparable to A-101, but the data for this tank prior to 1963 is not available. Tank A-106 clearly shows the highest recorded temperature peaks, even though the temperature data for this tank is not available prior to 1963 . From these temperature histories, Tank $A-101$ was chosen as a typical case and A-106 as a special case for further modeling. Tank A-106 also has the highest recorded temperature (594 degrecs Fahrenheit) of all SST tanks. The peak temperature in Tank A-106 was a brief temperature excursion and thus is not shown in Figure 4.2. Further, A-101 temperature profile was chosen as a typical temperature profile for Type IV tanks and large temperature fluctuations were not considered in this profile. The proposed temperature and waste height profiles for A-101 and A-106 tanks are shown in Figures 4.2 and 4.3. These profiles cover the entire life of the tanks from 1956 to 2010.

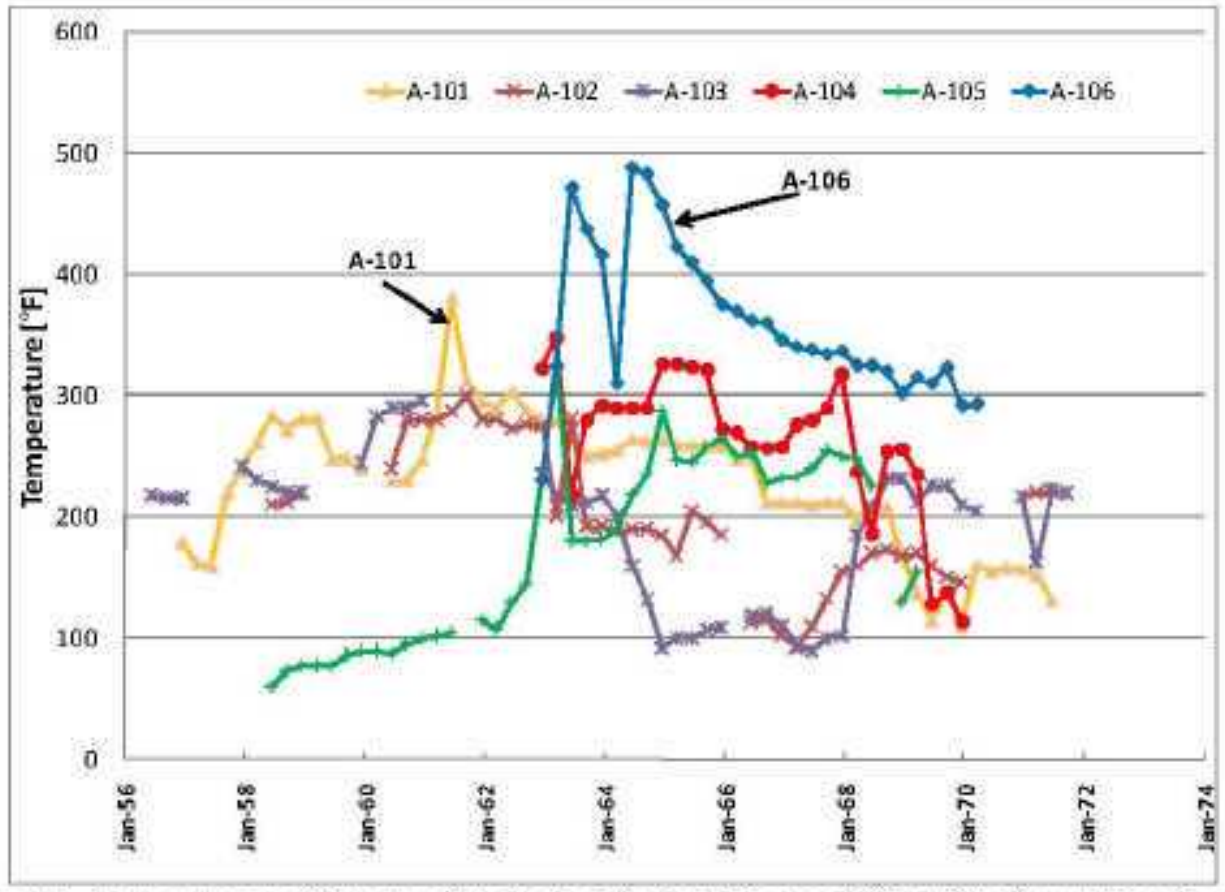

Figure 4.1 Temperature History of A Series Tanks Prior to 1972 (Data from Mercier 1981) 
RPP-46644, Rev.0

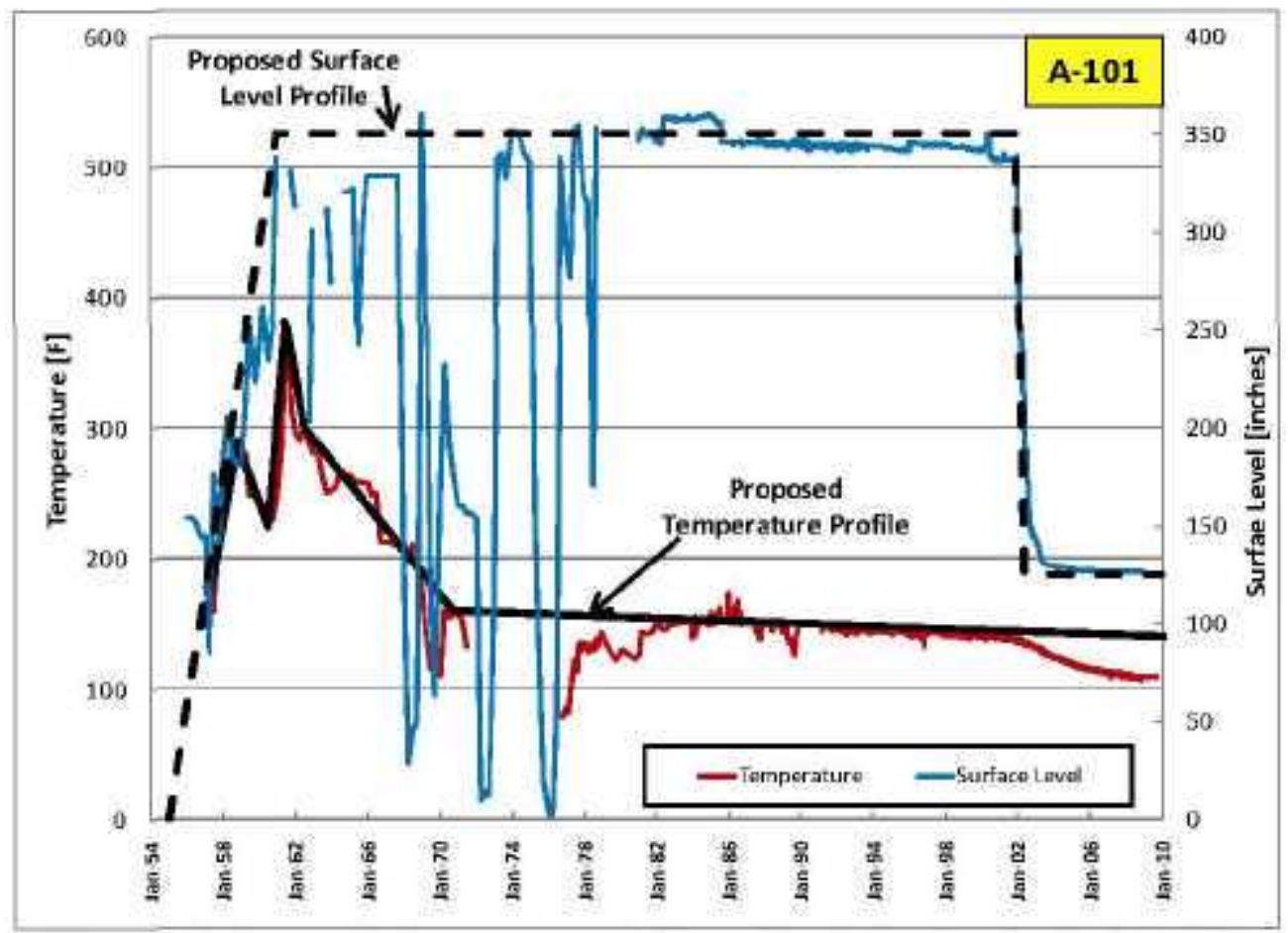

Figure 4.2 Proposed Temperature and Waste Height Profiles for Tank A-101

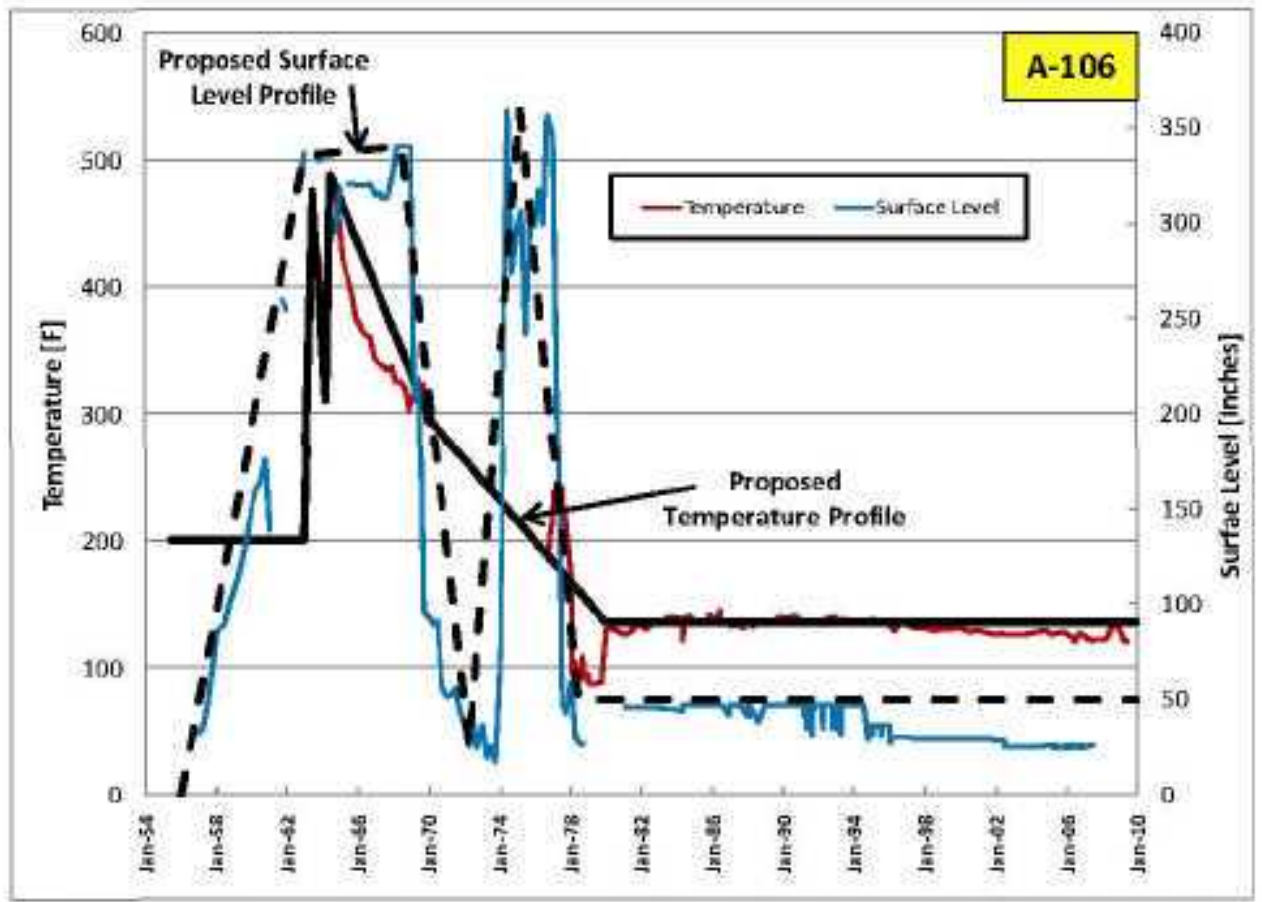

Figure 4.3 Proposed Temperature and Waste Height Profiles for Tank A-106

\subsubsection{Tank Farm AX (Type IV-C)}

Farm AX tanks began operation in 1965 and 1966, almost 10 years later than Farm A tanks. Figurc 4.4 shows the available temperature data for the AX tanks obtained from Mercier (1981). Based on the available temperature histories reviewed to date, Farm A tanks bound Farm AX tanks. In addition, 
geometric comparisons between the three Type IV tank designs show that modeling the SX and A Tank Farms designs is more conservative. While the creep and property degradation analysis can be done during detailed analysis for the AX tank design, the findings in the preliminary analysis may not vary significantly from the A Tank Farm analysis results. Therefore, the AX tanks will not be modeled in the preliminary modeling and analysis efforts.

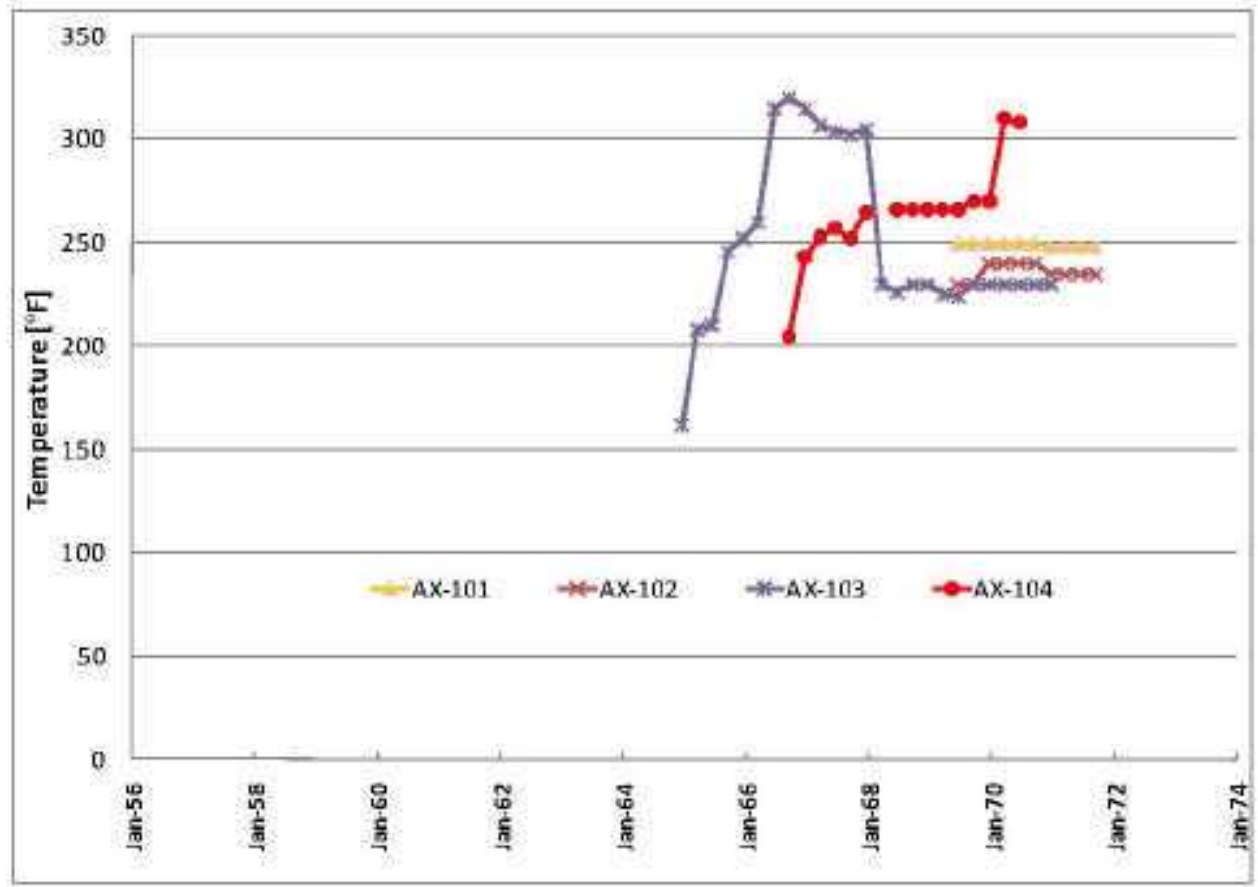

Figure 4.4 Temperature History for Farm AX Tanks

\subsubsection{Type III Tanks}

Limited temperature history data is available for Type III ( 758,000 gallon) tanks. Only S Tank Farms have temperature data available for a period from 1956 to 1959 . Two tanks, S-101 and S-104, from the $\mathrm{S}$ Tank Farm have seen peak temperatures of 300 degrees Fahrenheit (Rifacy 2002). Figure 4.5 shows the proposed temperature profile for Tank S-104 which was constructed based on the limited information available from Mercier (1981) report and Tank Waste Information Network System/Surveillance Analysis Computer System (TWINS/SACS) database.

Since document reviews to date do not provide complete temperature and/or waste level profiles for tank Type II, Washington River Protection Solutions (WRPS) is attempting to obtain further temperature and waste level information from DOE-RL stored in Seattle, Washington. In the event that additional Type III information is retrieved, the proposed Type III temperature and waste level profile will be revised accordingly. 


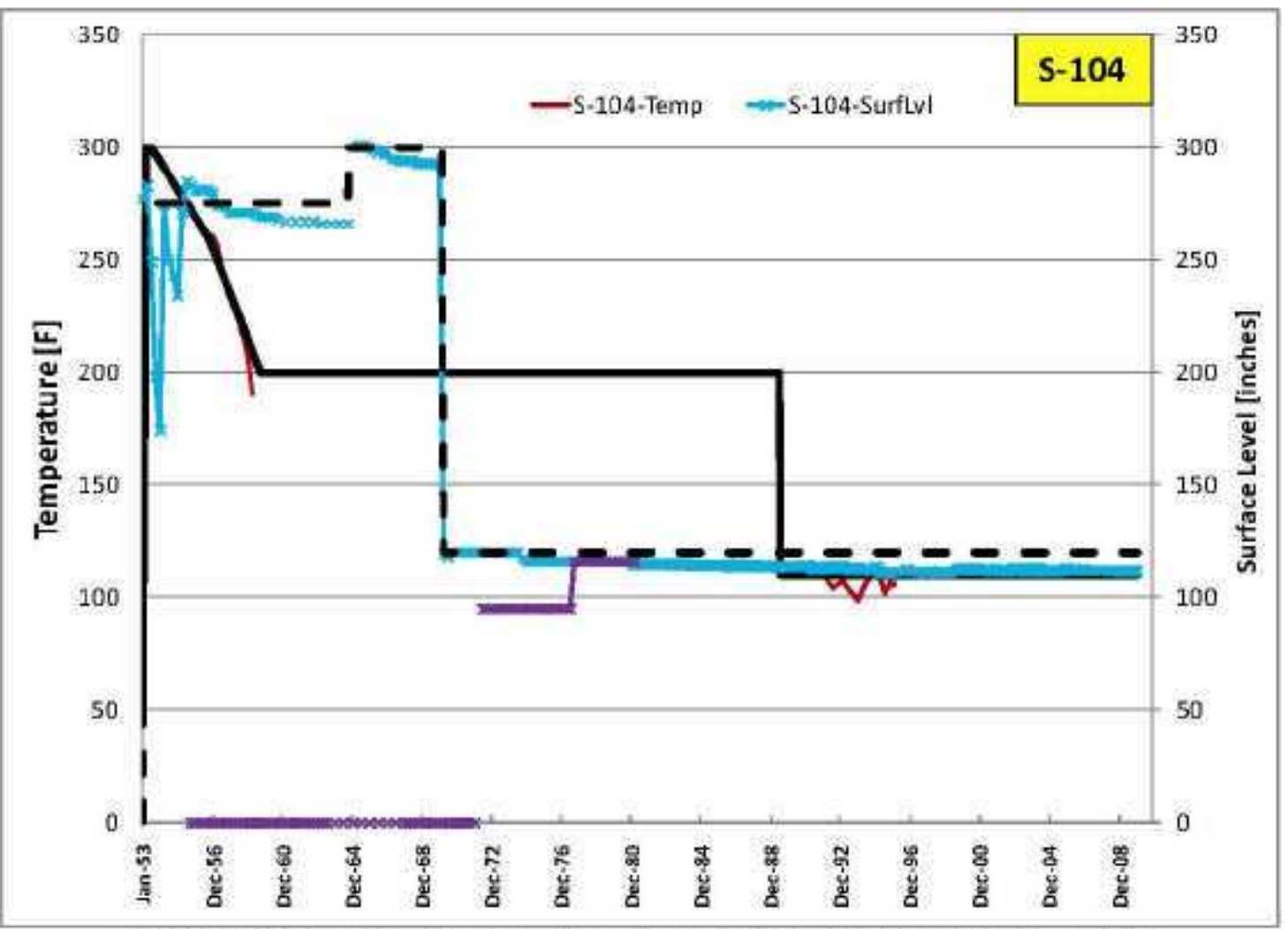

Figure 4.5 Proposed Temperature and Waste Height Profile for Tank S-104

\subsubsection{Type II Tanks}

Limited amount of temperature history is available for Type II tanks $(530,000$ gallon tanks). Tanks $\mathrm{C}-109, \mathrm{C}-111$ and $\mathrm{C}-112$ have temperatures available from 1961 to 1964 . Tanks U-110, U-111 and U-112 have temperatures available from 1956 to 1957. Given the period of operation of these tanks, this data is not sufficient to obtain a full picture of their temperature history.

Rifaey (2002) lists the "historic peak temperatures" for all the single-shell tanks. Tanks C-104 and $\mathrm{C}-106$ have experienced high temperatures of 195 degrees Fahrenheit and 216 degrees Fahrenheit, respectively, and have been reported for high temperature occurrences. Tanks U-104 and U-110 have experienced high temperatures of 240 degrees Fahrenheit and 260-300 degrees Fahrenheit, respectively. U-104 has been reported for leak and liner-bulge occurrences, and U-110 has been reported to reach selfboiling temperature conditions. Tanks BX-101 and BX-104 both reached temperatures of 240 degrees Fahrenheit and have been reported to experience self-boiling conditions. None of the tanks in Farms B and $\mathrm{T}$ have been reported for high-temperature occurrences.

The Julyk (1994) report analyzes Tank C-106 in great detail. Tank C-106 was not designed for selfboiling waste. However, high-heat materials (PUREX sludge wash waste) were added to this tank, which caused it to reach self-boiling temperatures in 1971. In order to solve this problem, a venting system was added to actively cool the tank by removing heat through the venting system. This tank was analyzed in the late 1990s primarily because of failure of the tank venting system in the early 1990s. Since the temperature history of this tank was not available, the authors devised methods to estimate the temperatures at various stages based on the waste characteristics. The estimated temperature data for C- 
106 was visually obtained from the plot in Julyk (1994) report. Figure 4,6 shows an approximate reproduction of the estimated temperature history.

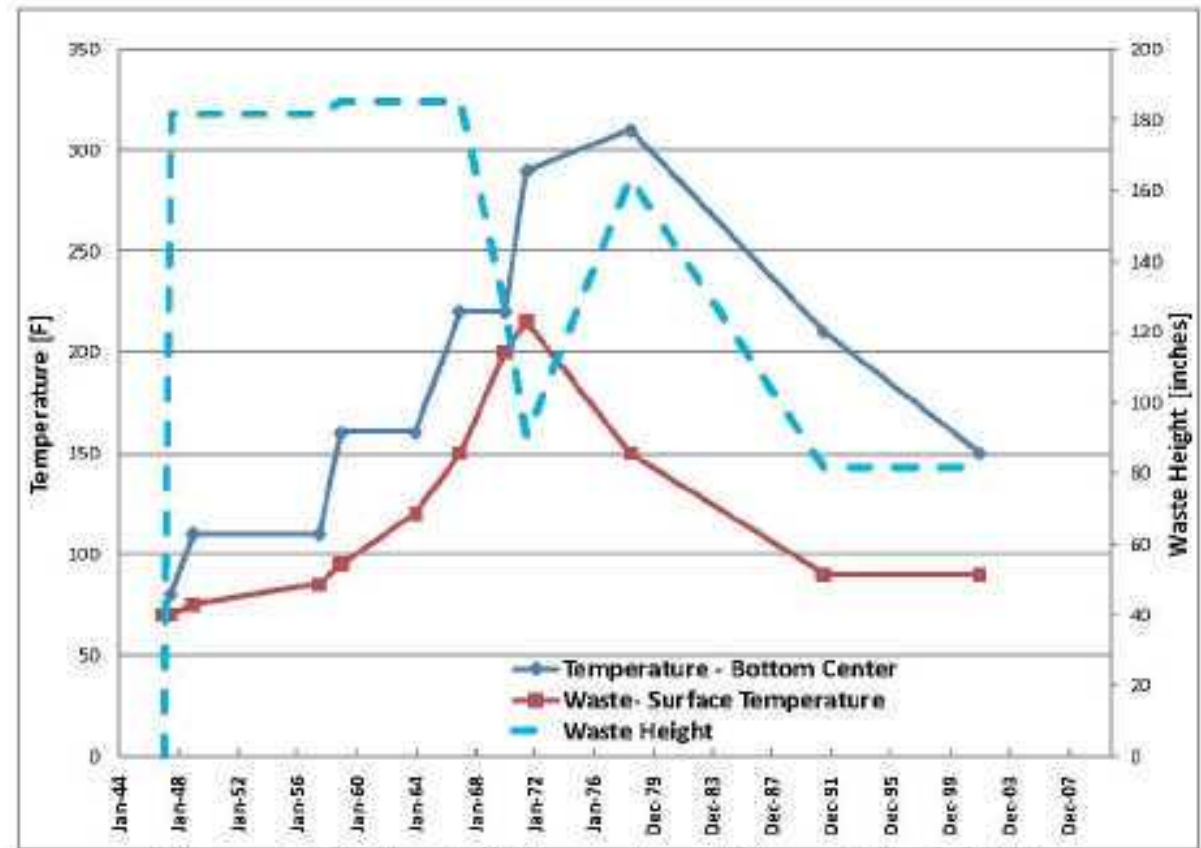

Figure 4.6 Estimated Temperature History of Tank C-106

\subsubsection{Type I Tanks}

Currently, there is no available temperature data for Type I tanks ( 55,000 gallons) for periods prior to 1975. Most of these tanks were out of service by 1977. Communications with WRPS indicate that C-200 series tanks were filled with potential high heat generating waste. The surface level profiles of $\mathrm{C}-201$ and C-202 were similar and appear bounding for the C-200 series tanks. Assuming that the C-201 tank reached maximum temperature of 250 degrees Fahrenheit, the proposed temperature and waste height profile are shown in Figure 4.7. Temperature data available for all Type I tanks from 1975 onwards indicate that the temperatures have been around 100 degrees Fahrenheit, except for the B-204 tank, which experienced a peak temperature of 220 degrees Fahrenheit in 1989 (Rifaey 2002). The B-204 peak temperature will be ignored at present, assuming it is an outlier, because this could not be confirmed from the data extracted from the TWINS/SACS database. The temperature and surface level profile presented for Type I tanks were selected for use in the preliminary analysis and may be changed for a detailed analysis phase as more temperature and waste level data become available. 


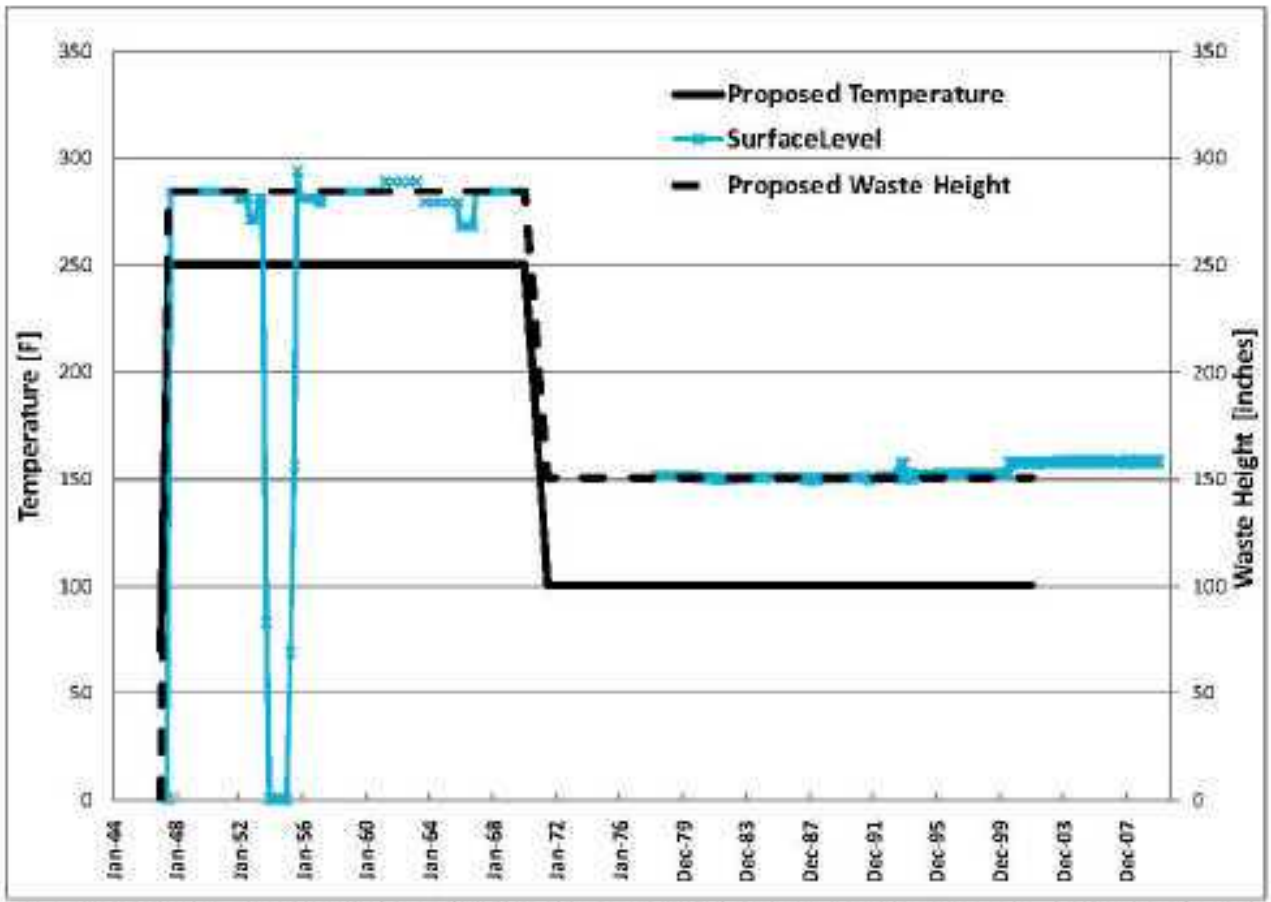

Figure 4.7 Proposed Temperature and Waste Height Profile for Type-I tanks. The surface level profile for C-201 was used in this plot.

\subsubsection{Large Temperature Changes}

Through discussions with WRPS, it was evident that unlike the double-shell tanks (DSTs), the SSTs were not subjected to regular thermal cycling (drain-fill-drain cycles). Therefore, there is no basis for carrying out a thermal cycling analysis. However, from available temperature histories, it is evident that some of the tanks were subjected to severe temperature changes over short periods of time, and these events are similar to thermal cycling. The Type IV tanks have been subjected to large temperature fluctuations over small periods of time. While some arguments (Julyk 1994) state that these spikes will not have significant effect on the tanks due to the large thermal mass of the tanks, this argument has not been substantiated through analysis. Figure 4.8 shows large temperature fluctuations over a small period of time in Tank A-106 during 1963-64. These special cases of temperature changes will be studied during preliminary analysis to determine whether or not such temperature changes lead to significant thermal gradients and stress-gradients in the tanks. WRPS pointed out that Tank SX-108 was subjected to some thermal cycling when the supernatant was drawn out and filled with river water in two steps. However, PNNL considers the special case of Tank A-106 to be bounding of any temperature fluctuations that might have taken place in Tank SX-108. In summary, thermal modeling of the A-106 temperature and waste level profile will include thermal shock and two thermal cycles, as shown in Figure 4.8.

The exact temperature profiles used for modeling are shown in Figure 4.9. Two types of temperature values were available for Tank A-106 - high or only thermocouple and average or only thermocouple. Based on the discussions with WRPS, it was concluded that the highest temperature was localized in a relatively small region called a "hot spot." The manner in which these temperatures were applied in the finite element model will be described in the following section. 


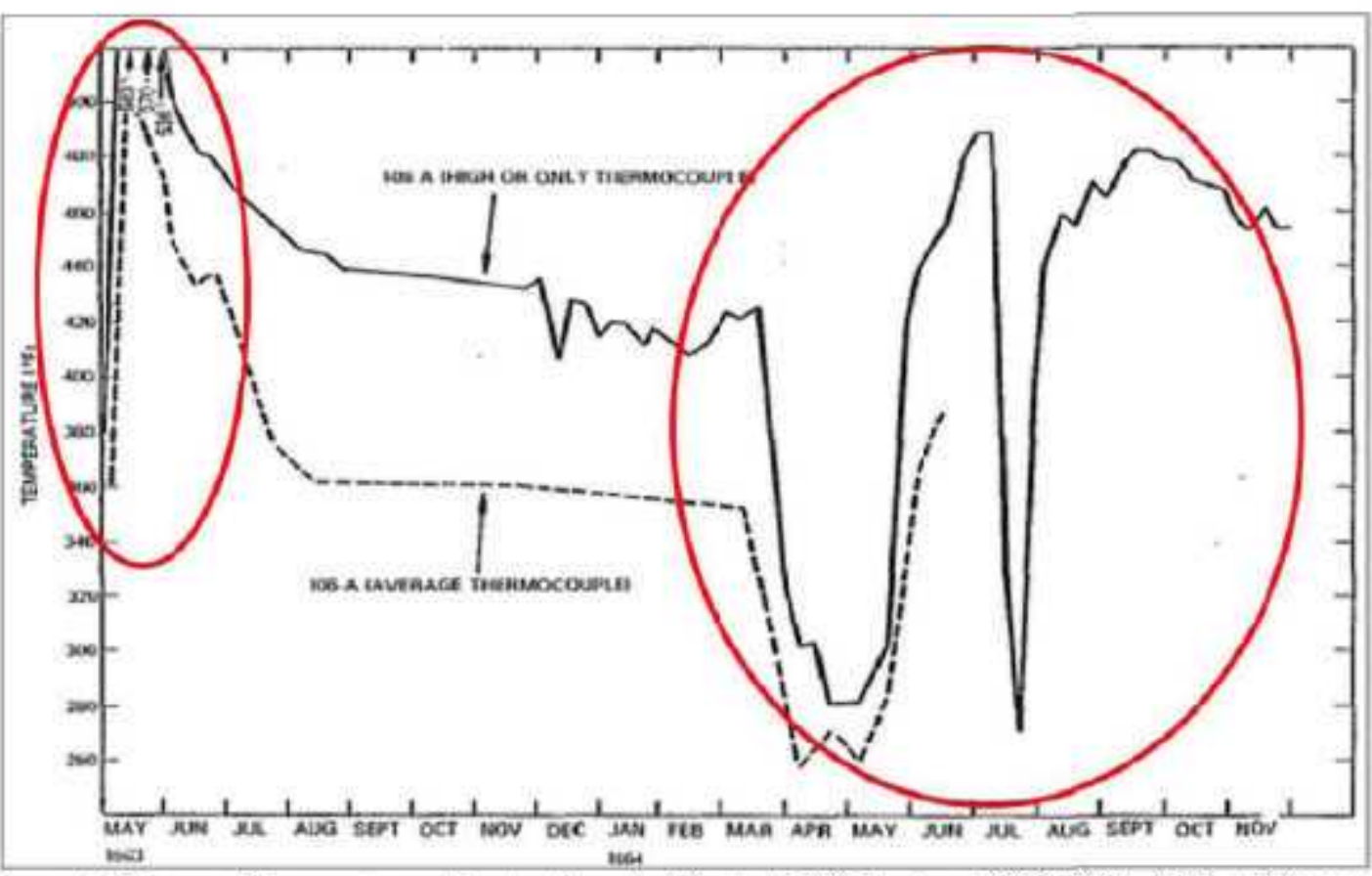

Figure 4.8 Large Temperature Fluctuations in Tank A-106 during 1963-1964. This picture was extracted from Mercier (1981) report and the red ovals added for emphasis.

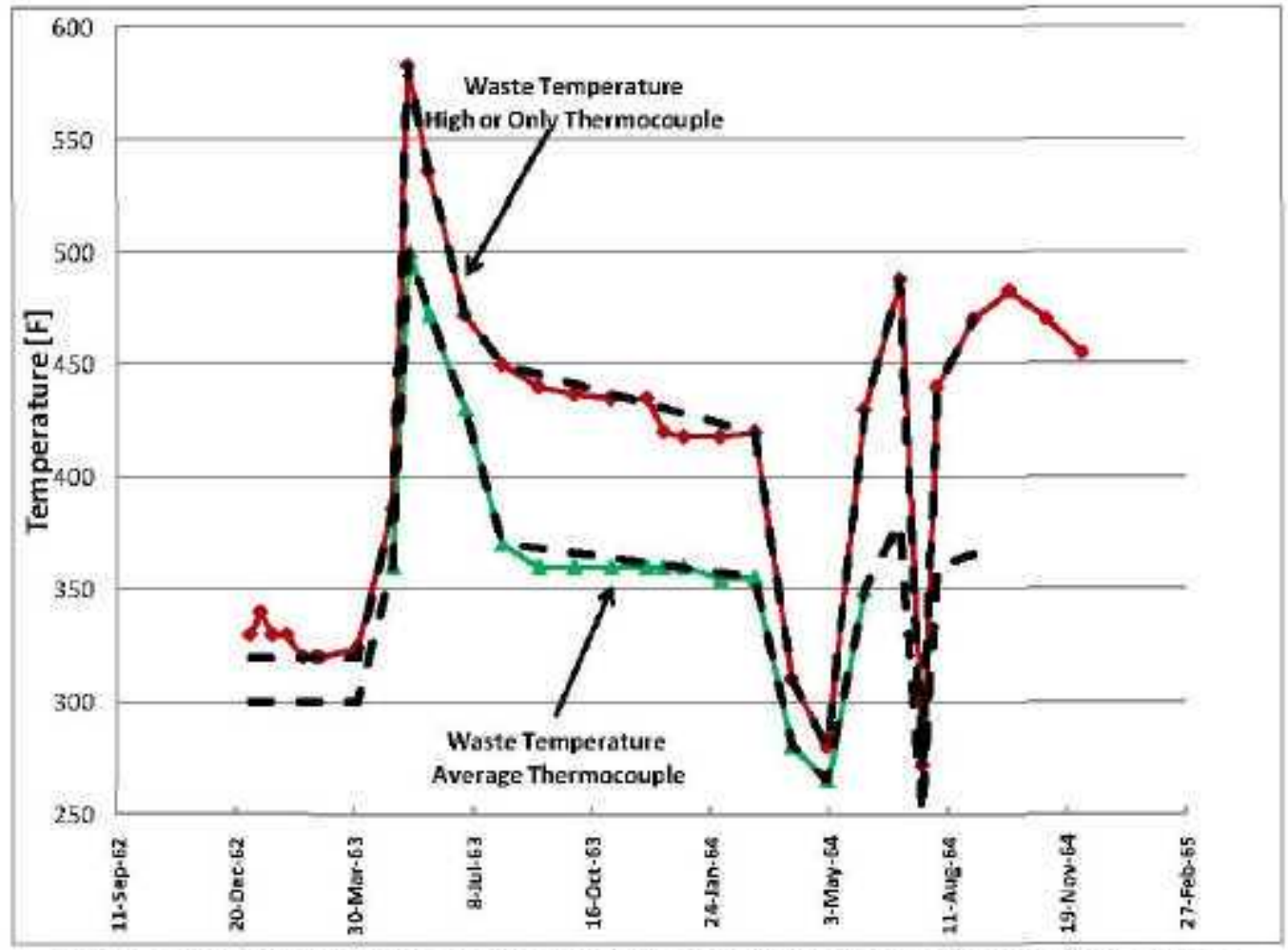

Figure 4.9 Temperature Profiles Used in the Finite Element Thermal Modeling 


\subsubsection{Thermal Modeling and Creep}

The thermal analysis of SSTs was carried out using a 2-D axisymmetric model. The nodal temperatures at the end of each analysis step were extracted and recorded in a text file. These nodal temperatures were then imposed as body forces in the 3-D (two-degree slice) structural model with the aid of interpolation (BFINT command in ANSYS ${ }^{\star}$ ). The thermal stress analysis was then carried out with these temperature loads.

The structural analysis was divided into two parts. The first part was carried out with purely mechanical loads as described in Section 4.3.1.1. The resulting ANSYS ${ }^{\circledR}$ database file was resumed in the second part of the analysis and augmented with further analysis steps including temperature loads, as described above. Thus, the tank structural analysis in the second part contained both the mechanical and thermal loads.

\subsubsection{2-D Thermal Analysis}

The 2-D finite element model and its mesh is a subset of the two-degree slice model. It was generated by suppressing the two-degree rotation in the slice model. The elements were changed from structural to thermal elements. The soil extent is the same as those in the two-degree slice model. One addition to the 2-D thermal model was the waste surface as shown in Figure 4.10. This waste surface was added to simulate radiation and lumped convection, heat transfer from the waste surface to the tank dome and walls. The waste surface is not physically linked to the rest of the tank elements. Therefore, there is no conduction between the waste surface elements and the tank elements. The radiation surfaces have been identified in Figure 4.10 with the aid of red and blue arrows. ANSYS ${ }^{*}$ calculates the radiation view factors for all element surfaces based on the axisymmetric model.

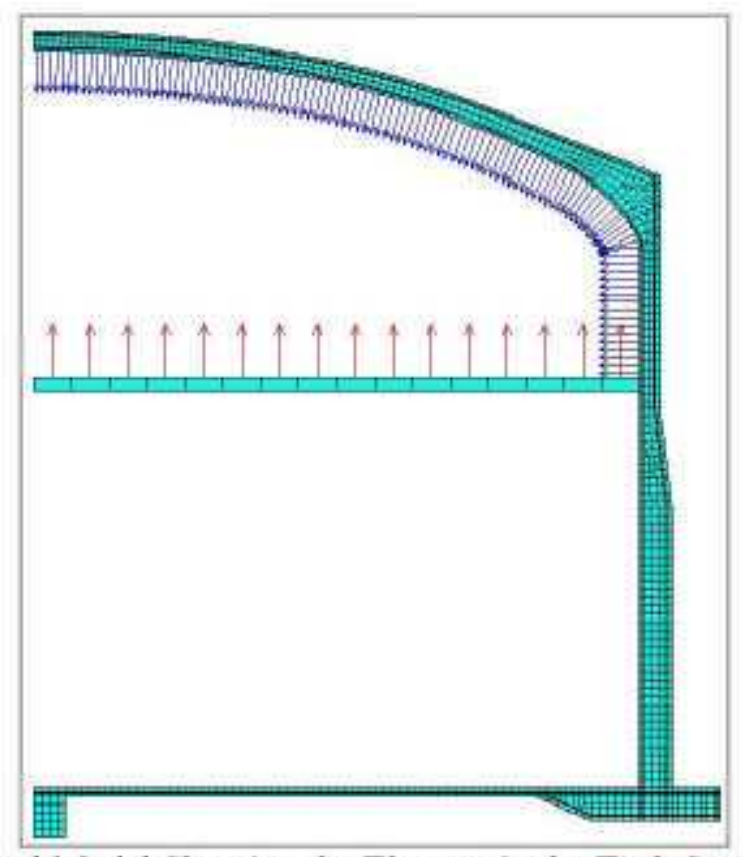

Figure 4.10 The 2-D Thermal Model Showing the Element in the Tank Structure and the Element in the Waste Surface 
The waste temperatures were imposed in the model by assigning the waste temperature values to the nodes on the inner surface of the tank that are located at or below the waste height. In cases where the whole waste was assumed to be at a uniform temperature, all these nodes were assigned the specific uniform temperature value. In cases where the temperature decreased linearly from a maximum value at the tank bottom to a minimum value at the waste height, the $y$-coordinate value of the nodes was used to calculate and specify the exact linearly-varying temperature value. Similarly, variation of temperature in the radial direction on the tank bottom was imposed by using the $\mathrm{x}$-coordinate value of the nodes. The waste surface that radiates to the tank dome was specified a uniform waste surface temperature. There is sufficient flexibility in the thermal model to simulate the different scenarios of temporal temperature variation and the spatial temperature distribution in the waste

The manner in which the temperature was assigned to the tank nodes will be illustrated here with the example of Tank A-106 analysis. Table 4.3 shows a tabulated version of the temperature and waste height profiles shown in Figure 4.9. The analyses for Tank A-106 contained two types of waste temperatures. The high or only thermocouple temperature was assumed to be a localized "hot spot." There is no information on the size or location of the hot spot. Therefore, it was assumed to be centered at the bottom of the tank, and analysis was carried out with a hot spot diameter value of 30 feet. The maximum temperature (high or only thermocouple) value was assigned to the node at the center of the tank bottom. The assigned temperature was decreased linearly with radial distance in such a way that the node at a distance of 15 feet (half the hot spot diameter) from the center of the tank bottom was assigned a value equal to the average thermocouple temperature. The temperature was further linearly decreased with radial distance up to the end of the tank bottom and then linearly decreased with waste height up to the waste surface. The rates of temperature decrease in the tank bottom and through the waste height were different, and these gradients were assumed values. Temperature distribution in the tank structure at the end of step 4 is shown in Figure 4.11.

Table 4.3 Temperature and Waste Height Values at the End of Each Analysis Step for Tank A-106 Thermal Modeling

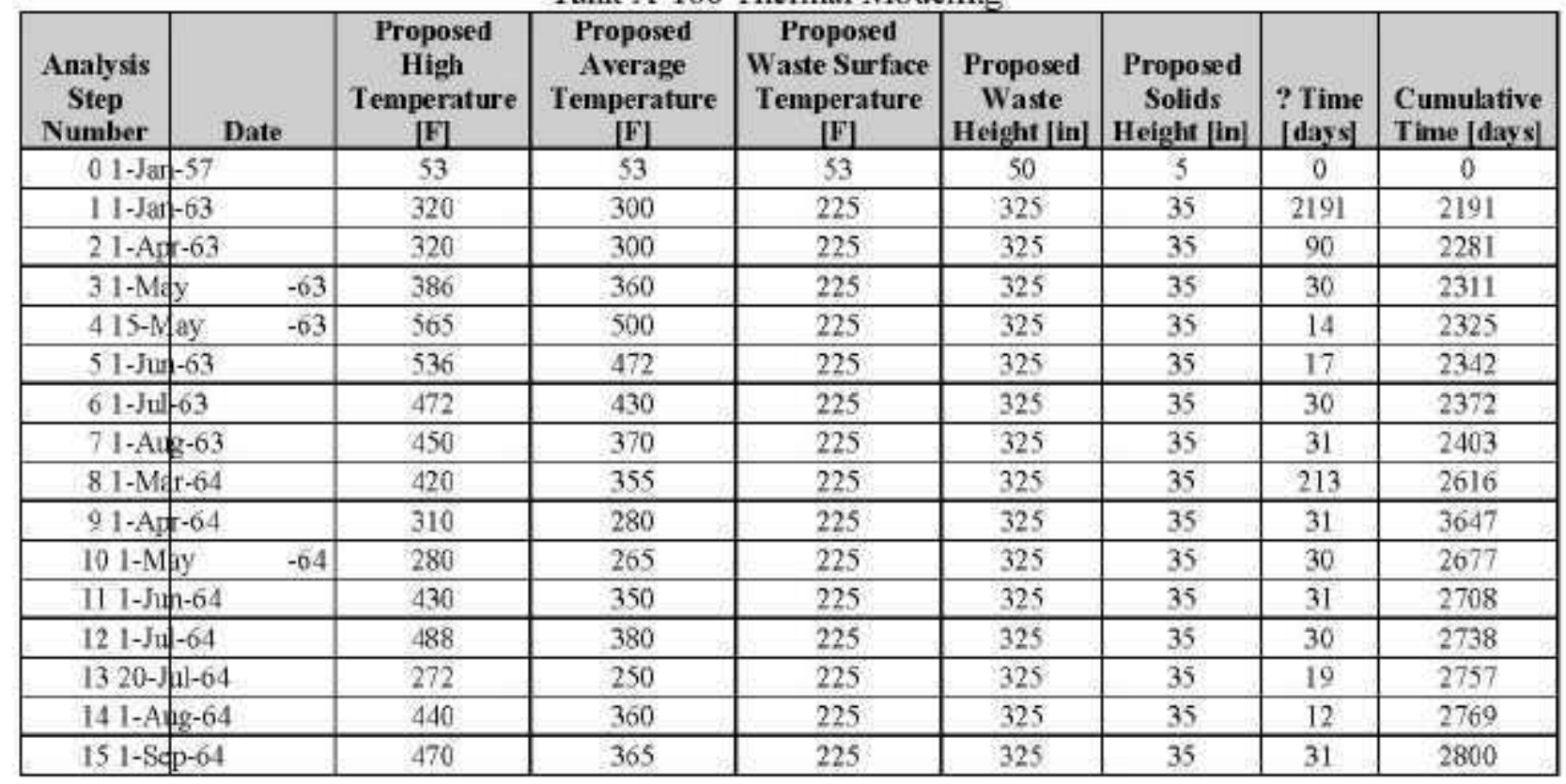




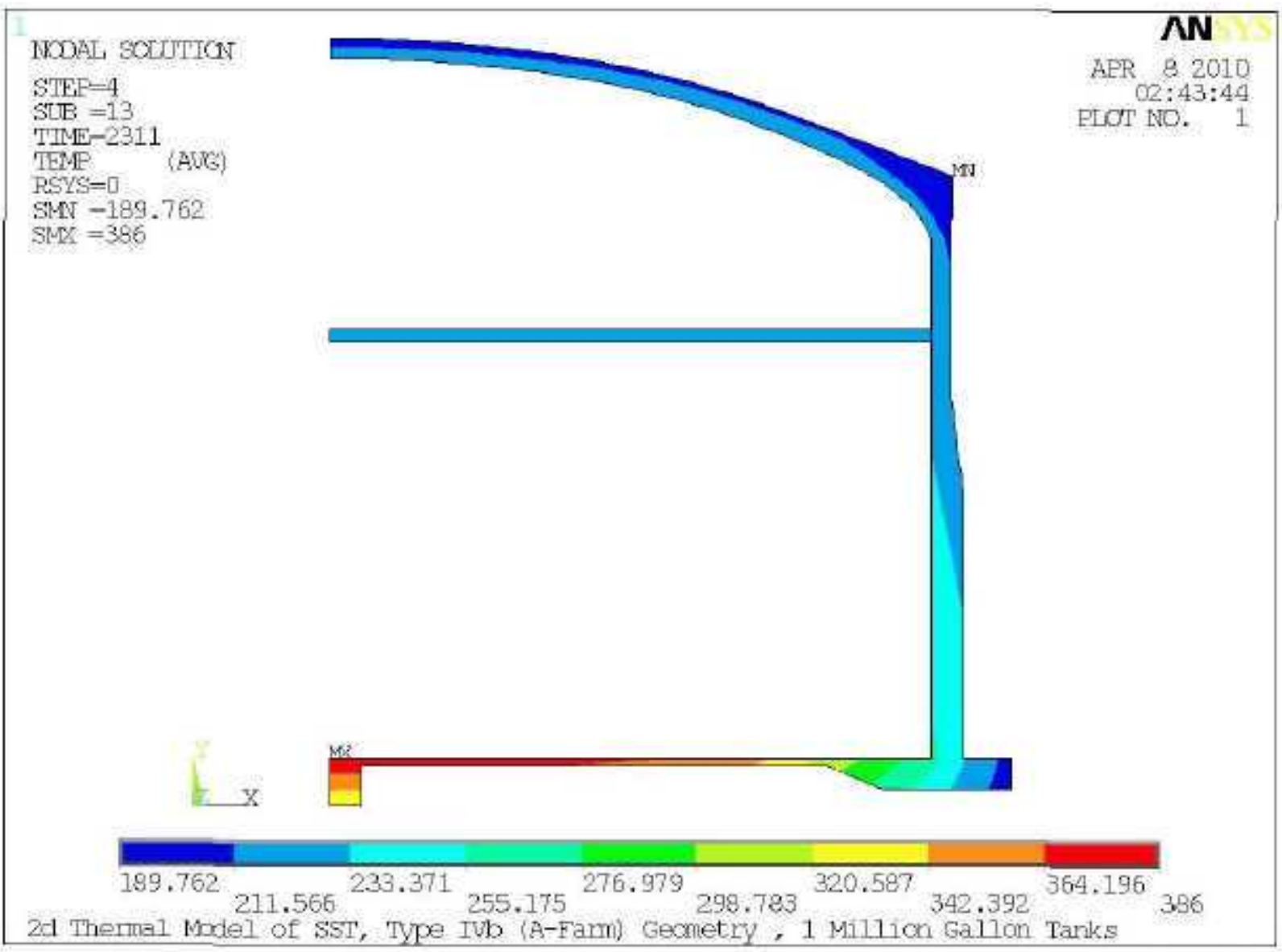

Figure 4.11 Temperature Distribution in the Tank Structure at the End of Themal Analysis Step 4 (peak temperature of $565^{\circ} \mathrm{F}$ )

\subsubsection{Thermal Stress Analysis}

As mentioned at the beginuing of this section, the nodal temperatures obtained from the thermal analysis were imposed as body forces on the nodes of the two-degree slice model in order to carry out the thermal stress analysis. The concrete properties, such as Young's modulus and tensile strength, decrease with increase in temperature. This degradation starts around 200 degrees Fahrenheit and becomes more pronounced as the temperature increases above 300 degrees Fahrenheit. The degraded material properties were obtained from the DST TOLA report (Rinker 2004) for temperatures up to 350 degrees Fahrenheit. These were approximately extrapolated to temperatures up to 600 degrees Fahrenheit.

Once a concrete element is subjected to a high temperature value, the element's properties should stay at the degraded level even when its assigned temperature decreases in the subsequent analysis steps. In order to simulate this effect, two different material property files were input during the (purely) structural analysis (first part). The first material property file (MP-1) contains the temperature-dependent material properties that ANSYS ${ }^{*}$ uses to assign the material properties to the elements, based on their temperatures at any particular time point in the analysis. This MP-1 file is used to assign material properties to the elements when the element temperatures increase monotonically through all the analysis steps. However, when the element temperatures increase to a large value and then decrease (as in the A106 temperature profile shown above), the properties in the second material property file (MP-File-2) are 
used. The MP-2 file contains 40 different linear elastic materials named Concrete-205, Concrete-215, Concrete-225 and so on, up to Concrete-595. The Young's modulus and tensile strength of the material Concrete-205, for example, is equal to the corresponding values of the concrete material in the MP-1 file at a temperature of 205 degrees Fahrenheit.

At the beginning of each analysis step, the element temperatures at the end of previous step are compared to the corresponding temperature at the end of the current step. If the element temperatures at the end of the current step are lower compared to those at the end of the previous step, then the elements are assigned the material properties (corresponding to their temperatures) from the MP-2 file. For example, in the analysis of Tank A-106, the temperature increases monotonically to 565 degrees Fahrenheit in four steps. Therefore, for the first four steps the temperature-dependent material propertics are used from the MP-1 file.

In load step 5 the temperature decreases to 472 degrees Fahrenheit. At the beginning of step 5 , the temperature of each concrete element is obtained and a corresponding material property is assigned from the MP-2 file. For example, if the temperature of an element is in the range 320 degrees Fahrenheit and 329 degrees Fahrenheit, then that element is assigned the linear elastic properties of Concrete- 315 material. The peak temperature of each concrete element is stored in an array. At the end of each analysis step, each element's current temperature is compared against its peak temperature, and the array is updated at every step. At the beginning of each step, a decision is made regarding the temperature changes in the next step based on the waste temperature profile. If it is determined that the temperatures of the elements will be higher than their respective previous peak temperature values, then those elements are assigned their original temperature-dependent material properties from the MP-1 file. However, if it is determined that the temperatures will not exceed their previous peak values, then the assigned material properties from the MP-2 file are retained, and the analysis for the next step as well.

The thermal stress analysis models have sufficient flexibility built into them to simulate different spatial and temporal temperature variation scenarios. The temperature history of SSTs can be simulated as accurately as necessary by increasing the number of analysis steps. A post-processing file has also been created to extract the section forces and moments at different cross-sections in the tanks structure. These section forces and moments have been used to understand the trends during the preliminary analysis phase. The section forces and moment will be used for ACI evaluations during the detailed analysis phase.

\subsubsection{Waste Level Modeling}

To study the effect of waste level on the tank, two different cases were run using the existing C-107 Type II tank model. Both runs initially began with the mechanical load of gravity and an empty tank. Then, within the first run, a load for a tank half full of waste (96 inches) with a 1.7 specific gravity was added. Within the second run a load for a tank full of waste (192 inches) with a 1.7 specific gravity was added. Forces and moments for sections throughout the tank of the half full and completely full tank were compared against the empty tank. 


\subsubsection{Tank-To-Tank Piping}

Previous SST structural analyses have not considered the effects of tank-to-tank piping on the structural integrity of the tank. Vapor headers, waste transfer lines and their supporting structures contreet the individual tanks in a farm with the potential to influence tank integrity. The Brookhaven report on Seismic Design and Evaluation Guidelines (Bandyopadhyay et al, 1995) describes the evaluation methodology for the tank underground piping systems. While the current analysis is concerned with the structural integrity of the tanks as opposed to piping integrity, the Brookhaven report provides a useful perspective on piping loads.

Review of the tank drawings discloses piping connecting to the tarks in both the dome and the wall. The vapor headers and nozzle assemblies penetrate the full concrete depth of the dome or wall of the tank, Precise details vary by tank farm, bot a common feature is a steel pipe embedded in the tank concrete.

The nozzle connections in the tank wall incorporate a pipe-in-pipe design as illustrated in Figure 4.12. The inner waste transfer pipe is welded to the primary tank steel wall but the annular space between it and the larger diameter pipe embedded in the concrete wall serves to isolate the concrete from any load transfer. The arnulus will accommodate any rotational displacement without applying load to the concrete and the weld will fracture before applying any significant axial load.

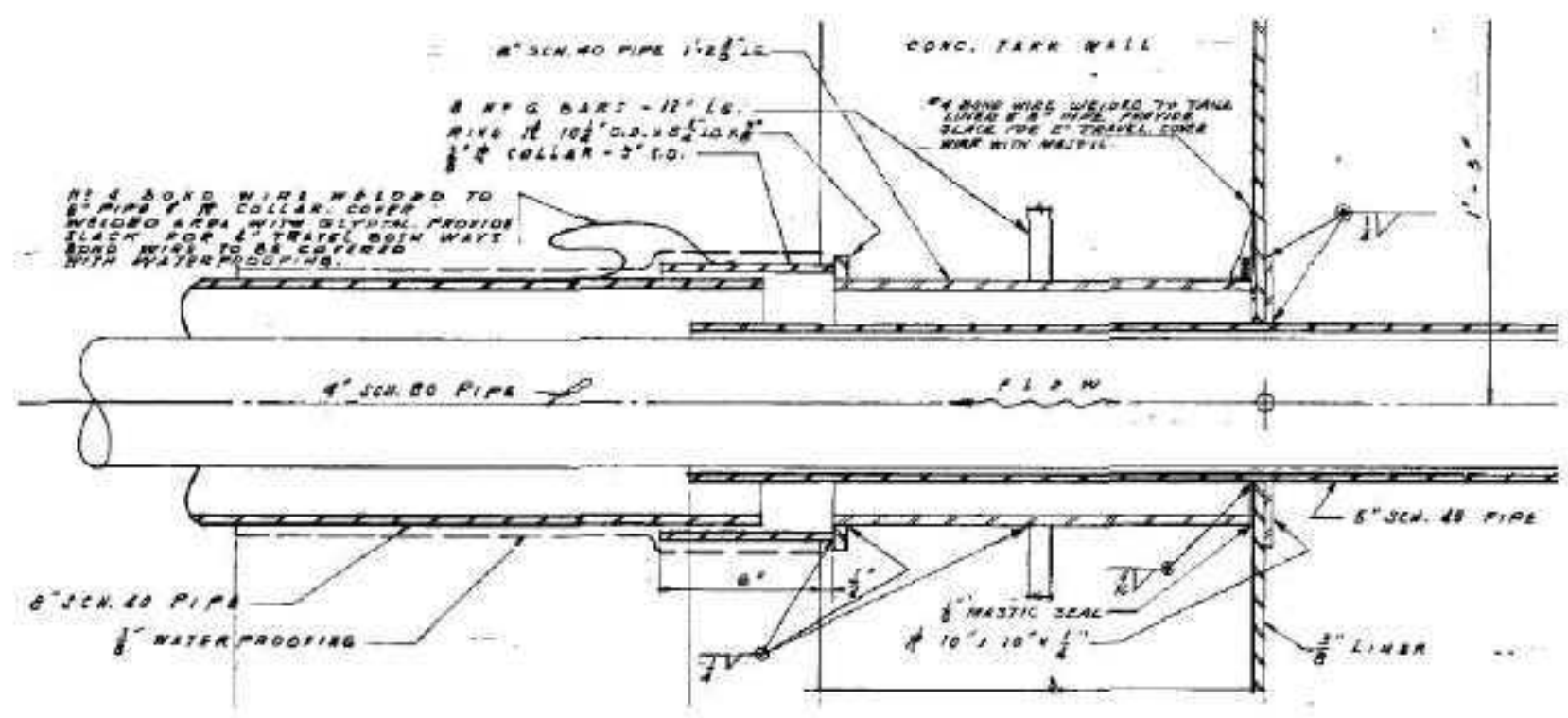

Figure 4.12 Typical Tank Nozzle Connection (SX shown)

This piping is typically supported on concrete beam and column frames. The entire structures are embedded in the backfill soil. Figure 5.13 (a. shows B, C, T, U tanks, b. shows AX tanks) illustrates the support of the beams at the tank wall. The beam rests on the pilaster such that there is no rigid connection between the beam and tank wall. The design accommodates any relative motion between the beam and tank wall that might arise from soil settlement, thermal or seismic effects. This precludes the piping support beam from applying any force or moments to the tank wall. 
Figure 5.14 shows the 24 " vapor header in the dome of the AX tanks. Similar 20" headers exist in the other Type-IV tanks ( $\mathrm{A}$ and $\mathrm{AX}$ ). These pipes are rigidly connected to the dome and are sufficiently stiff and strong that it cannot be readily concluded that they do not have an effect on the tank dome. It is recommended that an analysis be conducted during the detailed modeling of Type-IV tanks to definitively address effect of the large vapor headers. Smaller diameter piping will plastically deform prior to exerting significant loads on the dome so does not need to be considered in the detailed modeling.

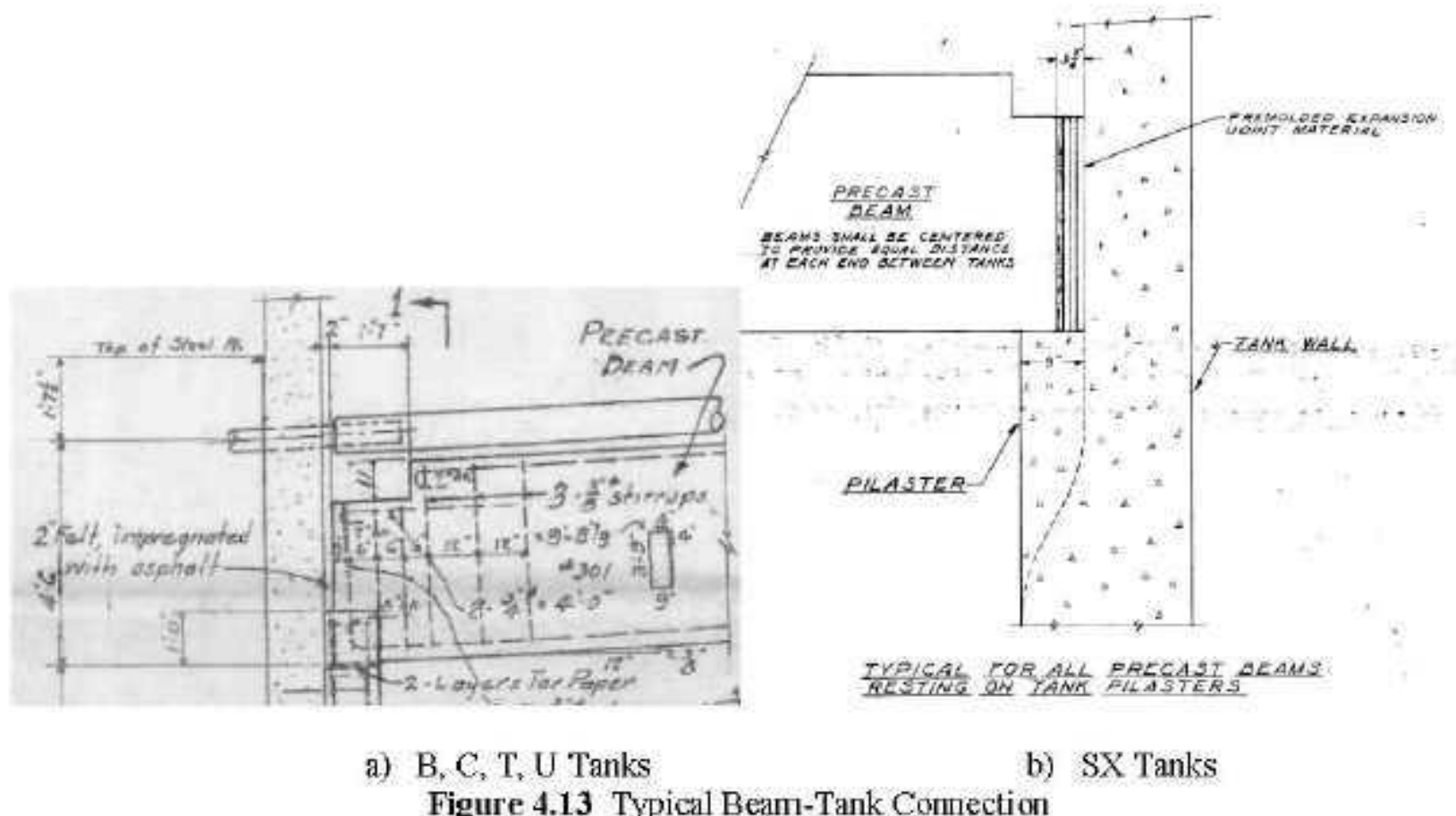

This detailed modeling analysis would consist of, first assessing the marginal capacity of the dome or walls after accounting for the normal operating and seismic loads. Next, assess the strength of the piping or piping connection to impart loads which exceed the remaining capacity. It is assumed that a seismic event is the only credible source of underground piping loads. Accordingly, a dynamic analysis will be conducted to determine whether loads of the required magnitude can be developed. 
RPP-46644, Rev.0

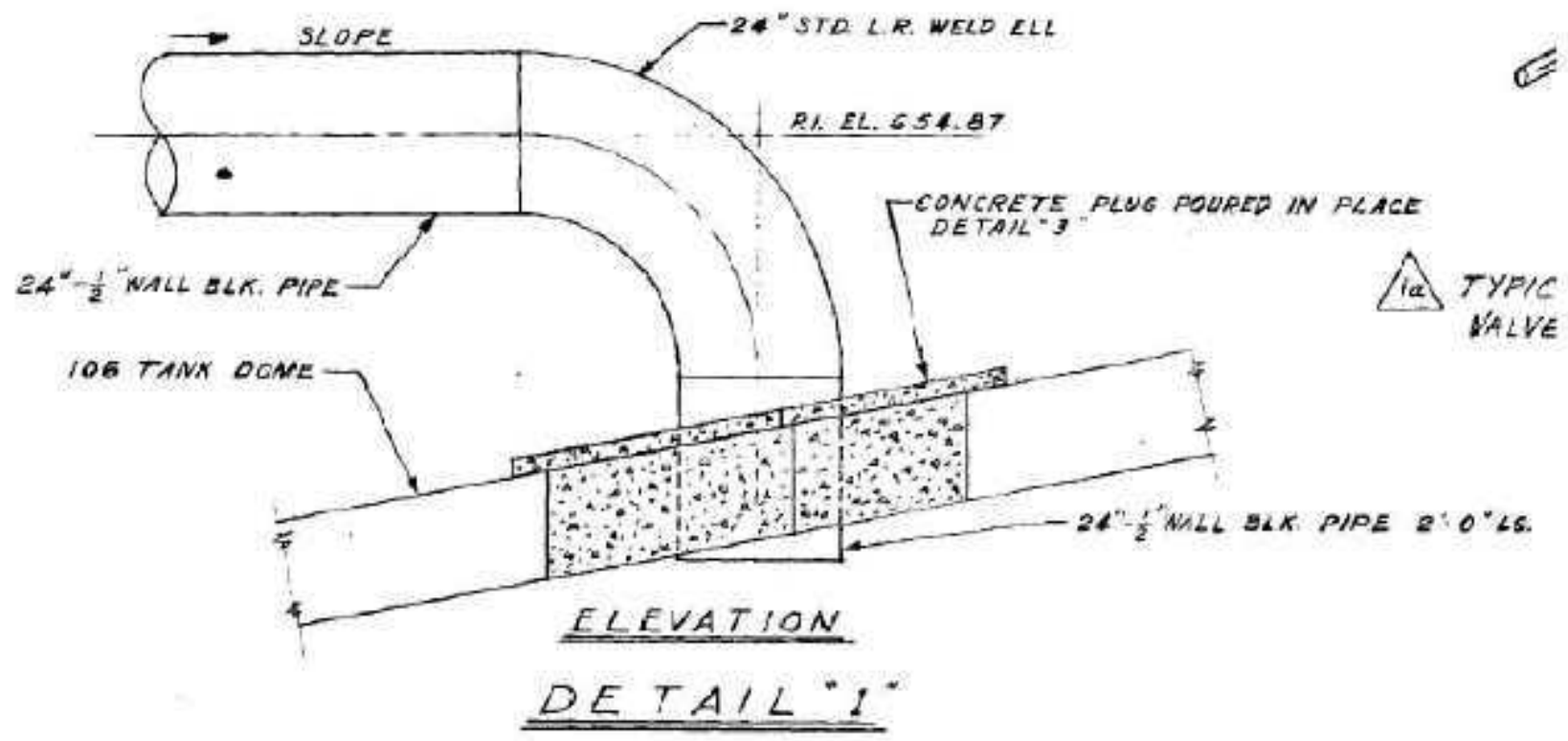

Figure 4.14 SX V apor Header Connection 
RPP-46644, Rev.0

This page intentionally left blank. 


\subsection{Preliminary Modeling Results}

The following section discusses the static modeling results for the case studies presented in Section 4.3 .

\subsection{Thermal Modeling Results}

\subsubsection{Type IV-B Thermal Modeling}

\subsubsection{Thermal Cycling}

Unlike the double-shelled tanks (DSTs), the SSTs were not subjected to regularly scheduled thermal cycling operations. However, Tank A-106 waste temperature history from 1963 to 1964 shows an interesting phase when there were large fluctuations in the waste temperature over a relatively short period of time. This temperature history provides a realistic scenario for thermal cycling analysis of Type IV SSTs. The effect of thermal cycling can be studied by obtaining the section forces and moments at similar temperature distribution states, but at different times. For the preliminary analysis study, the section forces and moments were evaluated at 430 degrees Fahrenheit. As shown by a horizontal line in the Figure 5.1, there are five different times at which the peak temperature in the tank was at 430 degrees Fahrenheit. Three of these states correspond to the states when the waste temperature was increasing, and two of them correspond to states when the waste temperature was decreasing. For this analysis, the temperature was assumed to be uniform throughout the sludge layer ( 35 inches in height from the bottom) and equal to the peak temperature. The temperature was assumed to decrease linearly from the solids surface to the waste surface.

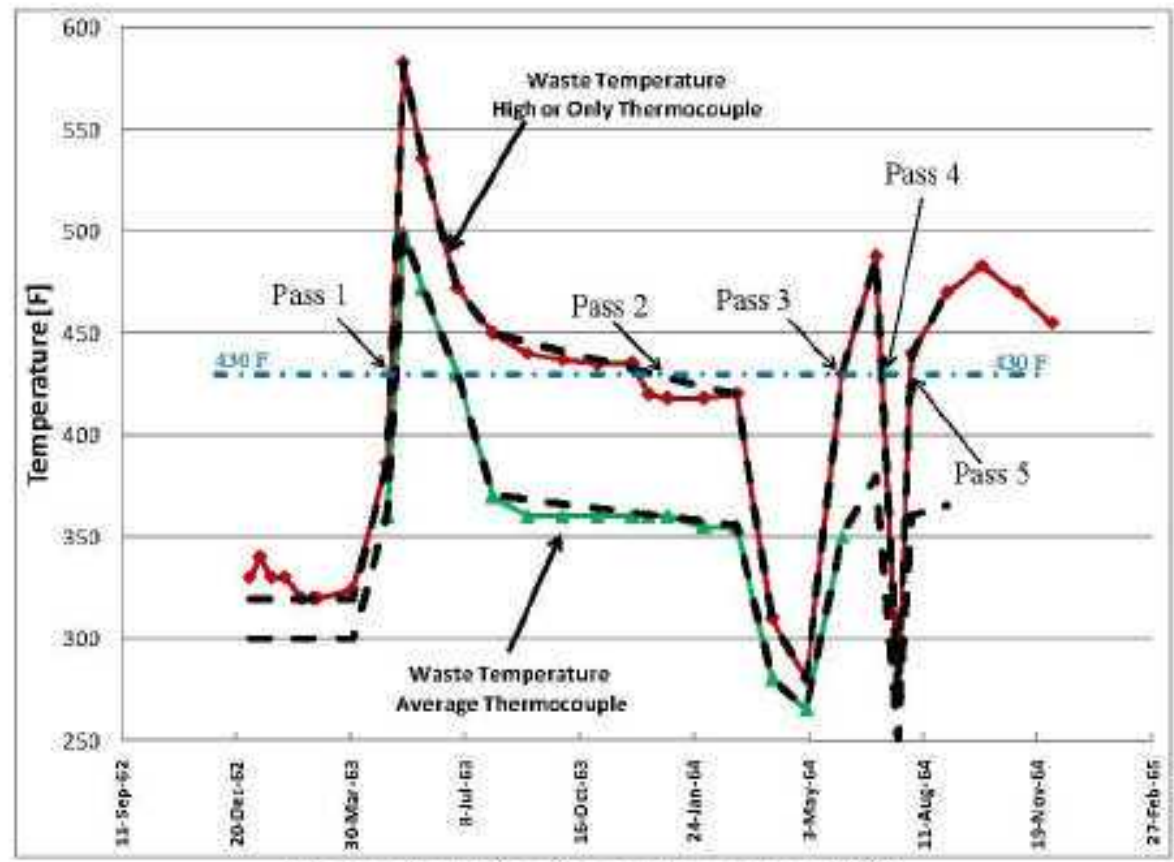

Figure 5.1 Five Passes Through $430^{\circ} \mathrm{F}$ 
Figures 5.2 to 5.6 show the section forces and moments at the five passes through 430 degrees Fahrenheit. The forces and moments for the last four passes through 430 degrees Fahrenheit are different from those at the first pass. This is because of the degradation of the concrete properties when the peak temperature in the concrete reaches a temperature of 565 degrees Fahrenheit after the first pass. The property degradation and concrete cracking causes a relaxation in the stresses and, consequently, a reduction in the magnitude of forces and moments during the later passes. The section forces and moments show some differences in cases where the temperature was increasing (Passes 3 and 5) and decreasing (Passes 2 and 4 ) because of the difference in the temperature distribution through the tank structure.

The results of this thermal cycling study indicate that it is important to capture any high-temperature incident, even if it were a brief one such as the one witnessed at the peak temperature of 565 degrees Fahrenheit in Tank A-106, because it significantly alters the load distribution in the tank sections as a result of the degradation of the concrete properties.

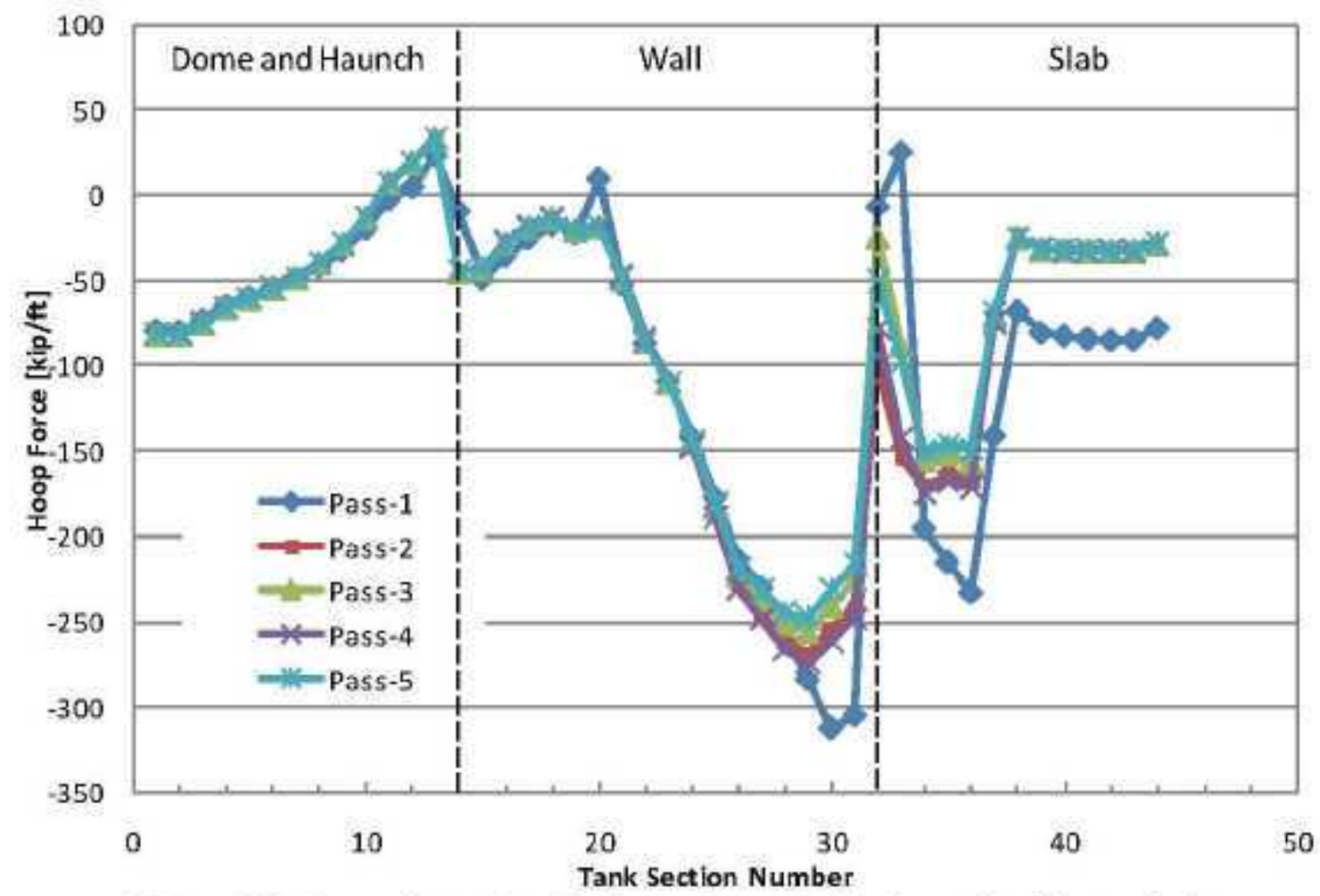

Figure 5.2 Comparison of section hoop forces for the thermal cycling analysis. 
RPP-46644, Rev.0

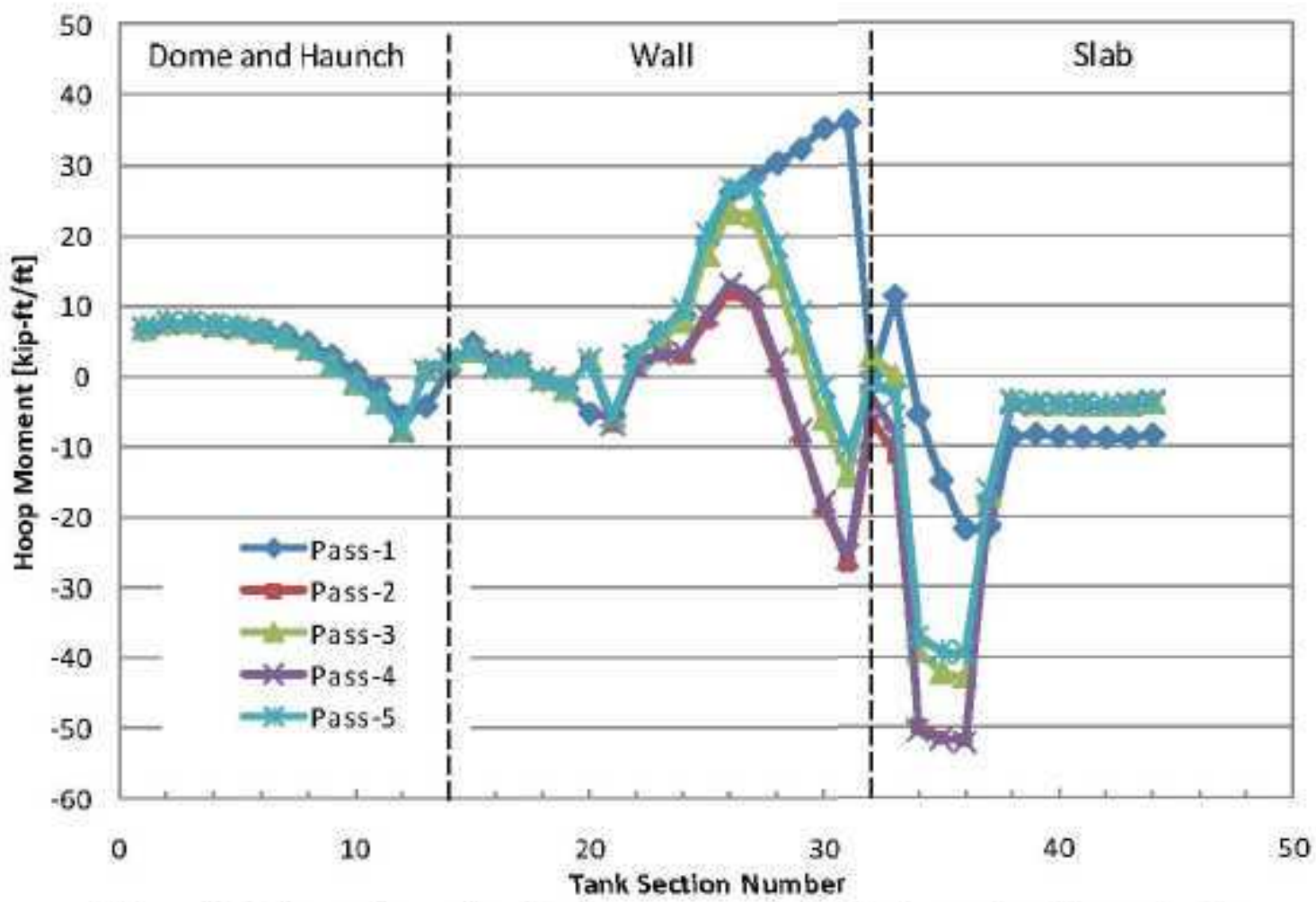

Figure 5.3 Comparison of section hoop moments for the thermal cycling analysis.

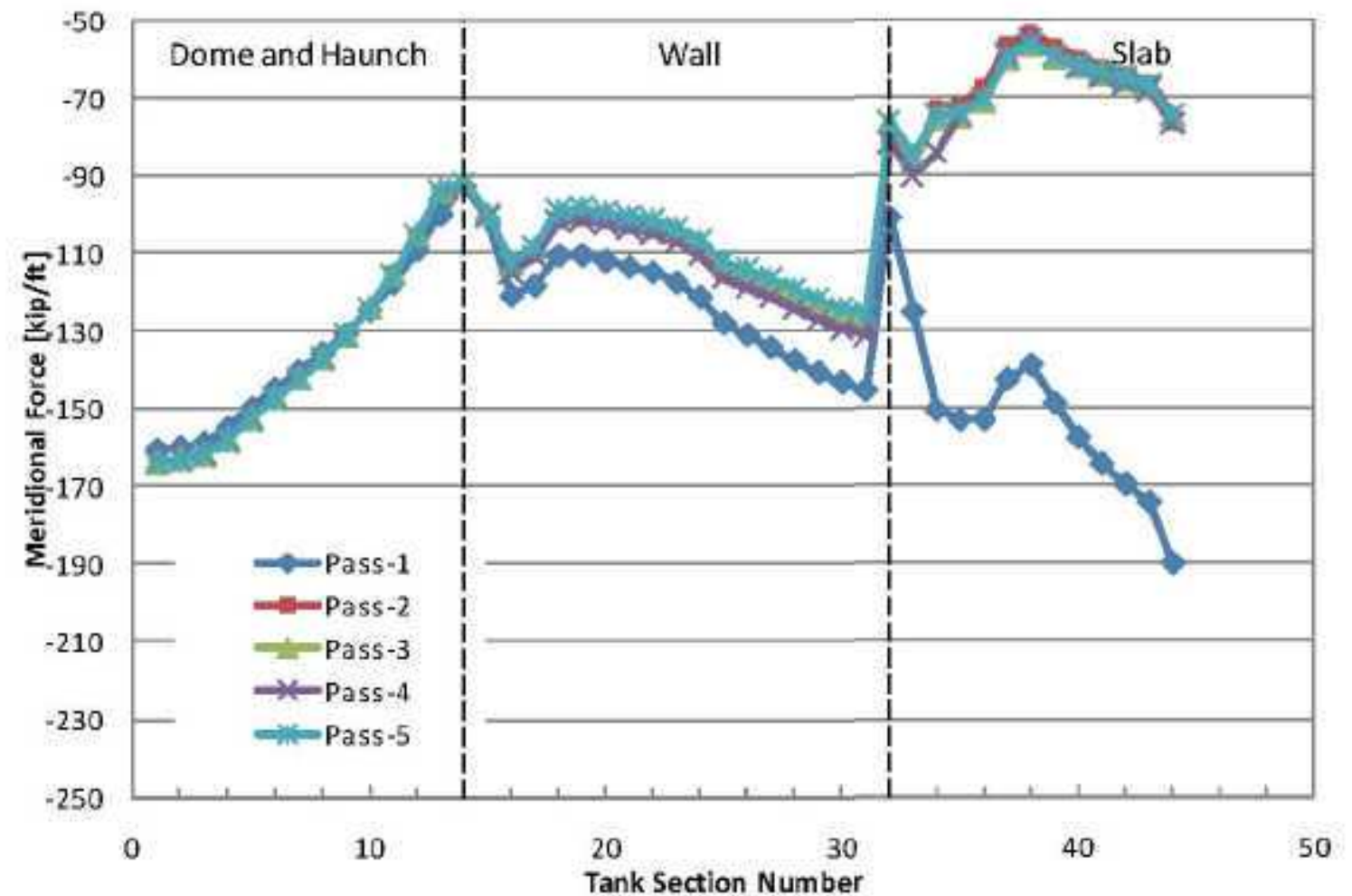

Figure 5.4 Comparison of section meridional forces for the thermal cycling analysis. 


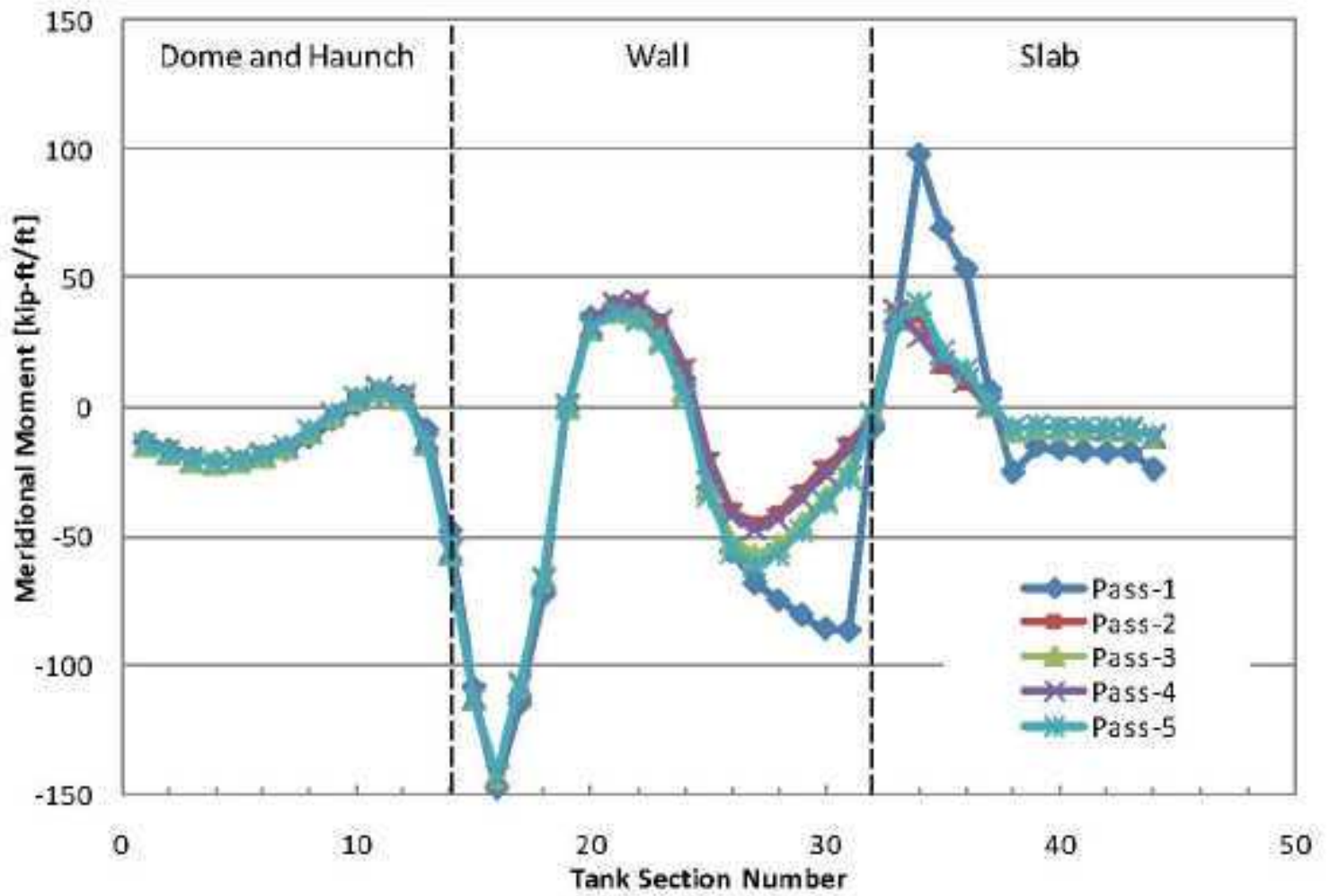

Figure 5.5 Comparison of section meridional moments for the thermal cycling analysis.

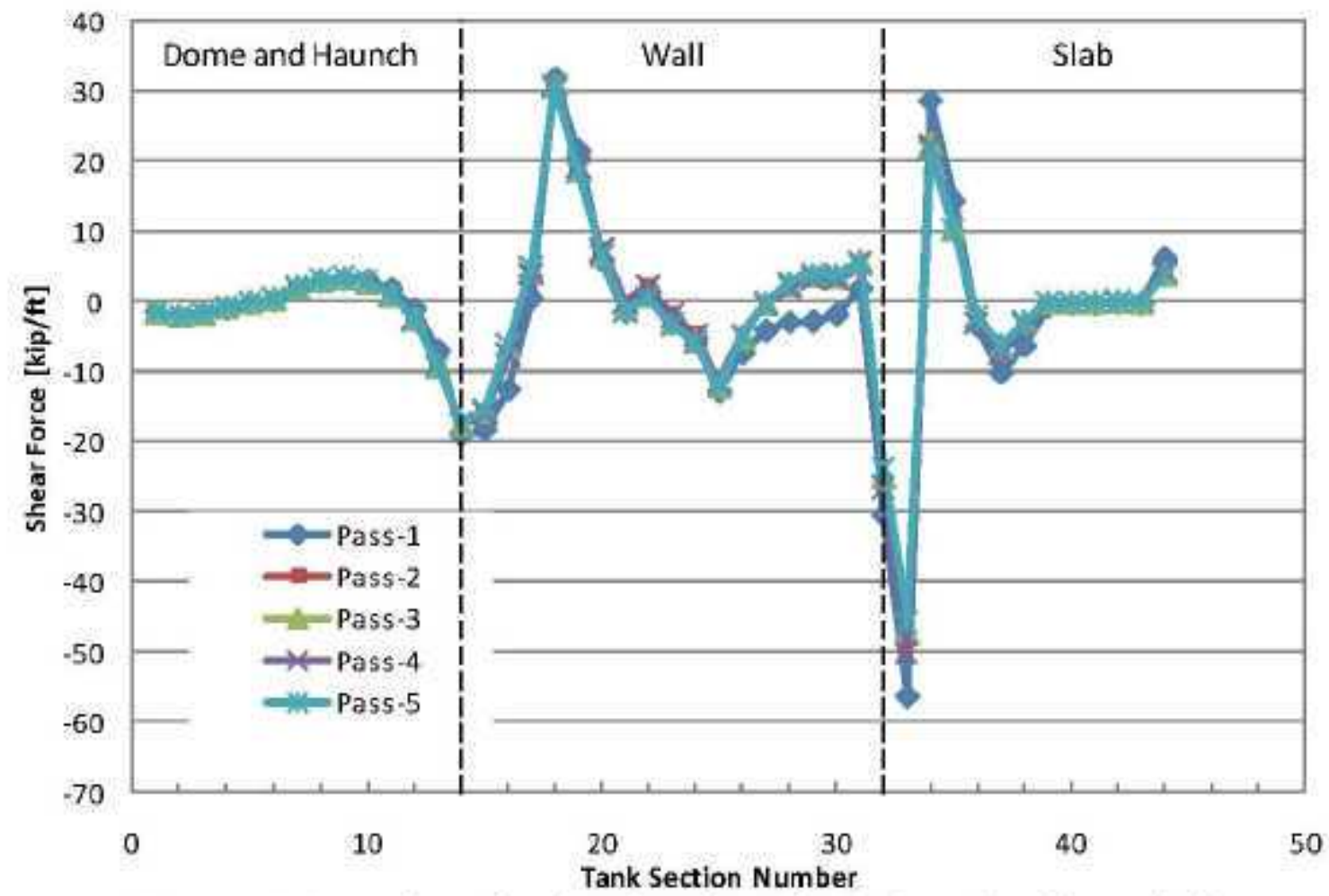

Figure 5.6 Comparison of section shear forces for the thermal cycling analysis. 
Figures 5.7 (a) to (c) show the concrete cracking in the tank footing at Passes 1,2 and 5. The increase in temperature to 565 degrees Fahrenheit gives rise to a large amount of cracking. There is no noticeable increase in cracking in later steps. Figures 5.8 (a) to (c) show the concrete cracking in the haunch. The cracking increases from the first pass to the second pass due to the intermediate high temperature ( 565 degrees Fahrenheit) excursion. But there is no increase in cracking through the next 3 passes. It can be concluded that a brief thermal cycling will not lead to any significant changes to the tank structure. However, it is important to model even a brief high temperature excursion in the waste in order to accurately capture the load distribution in the tanks in future time periods.

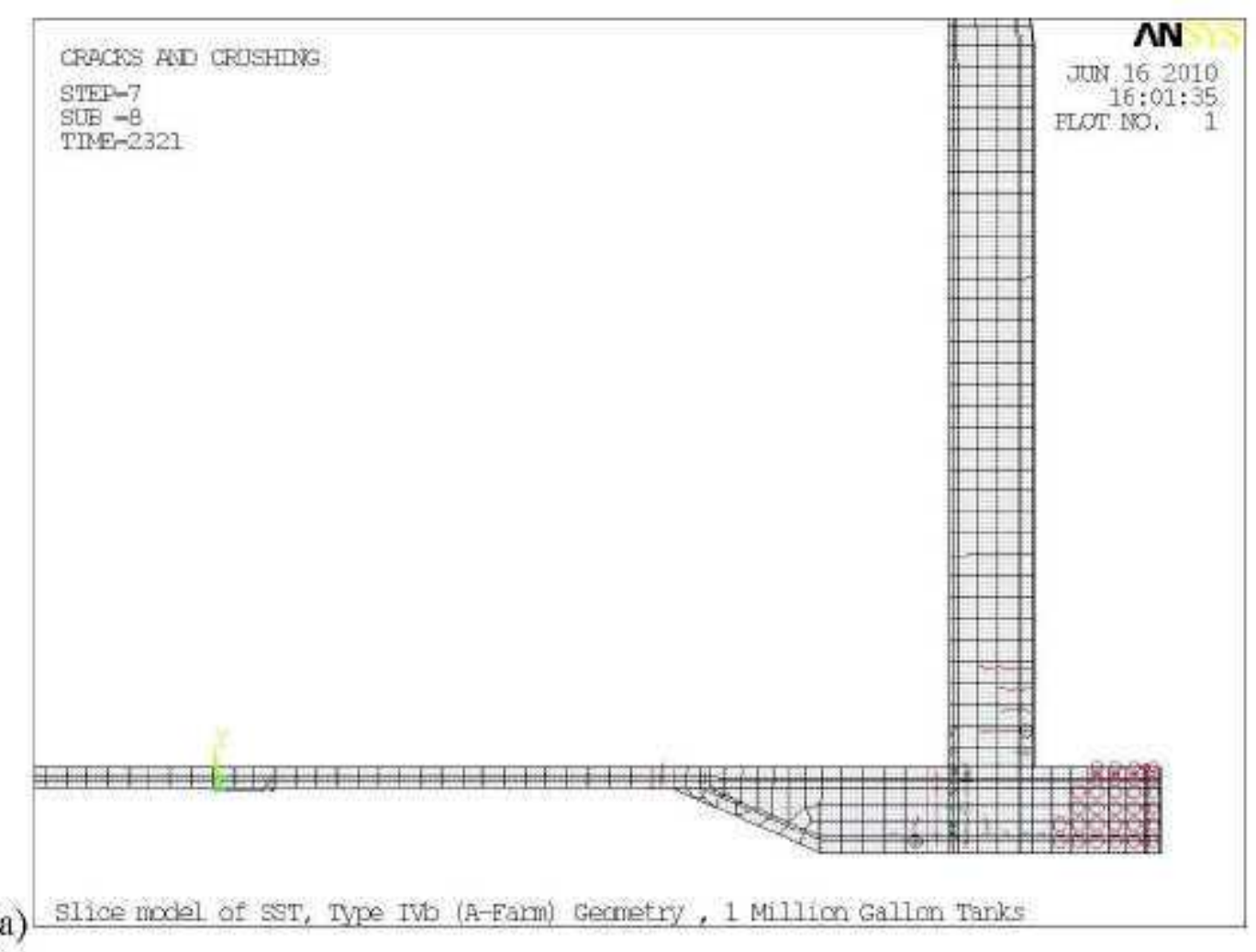


RPP-46644, Rev.0
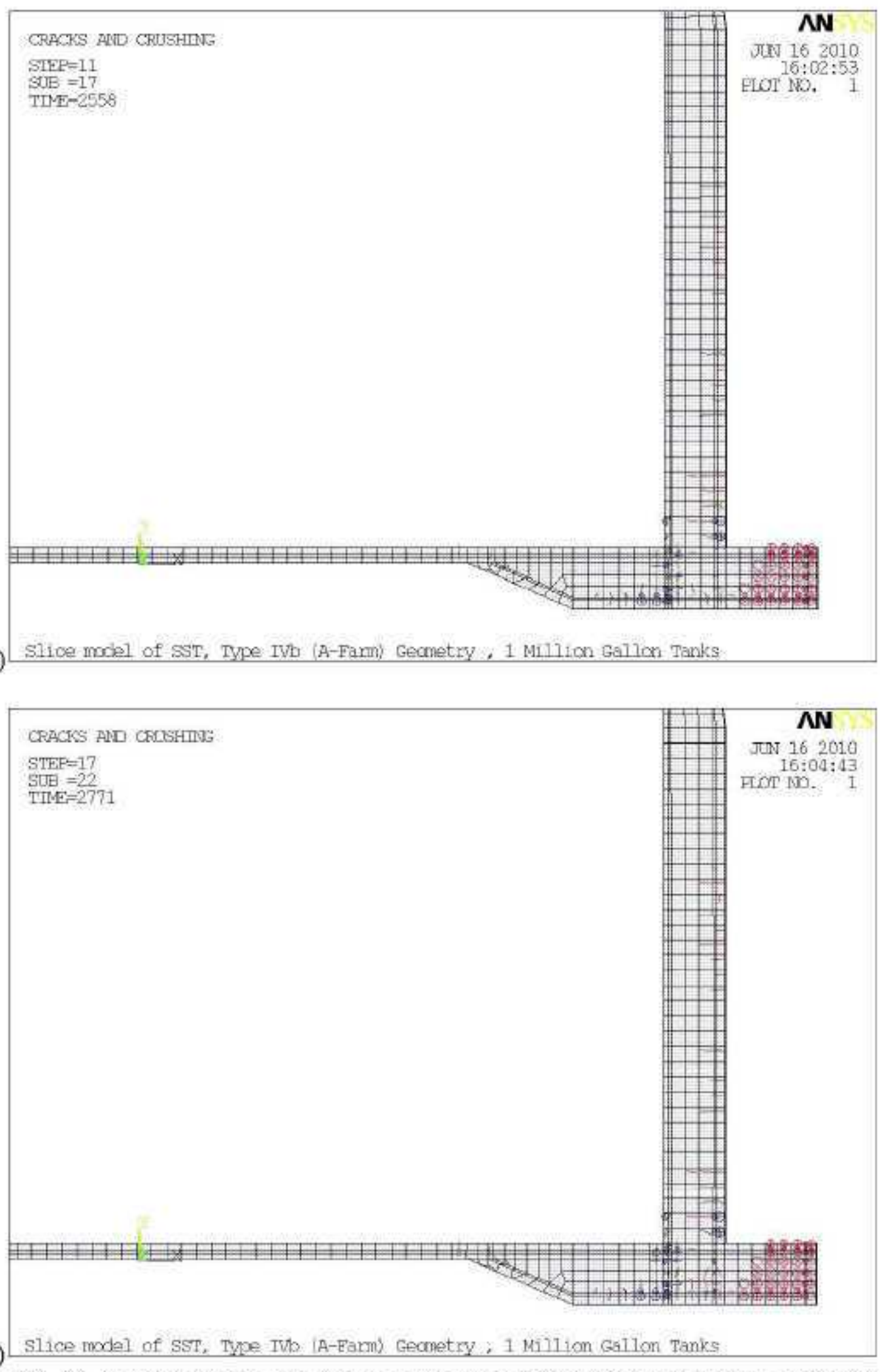

Figures 5.7(a)-(c) Concrete Cracking in the Tank Footing at Different Passes through $430^{\circ} \mathrm{F}$ : (a) Pass 1 , (b) Pass 2, and (c) Pass 5 
RPP-46644, Rev.0

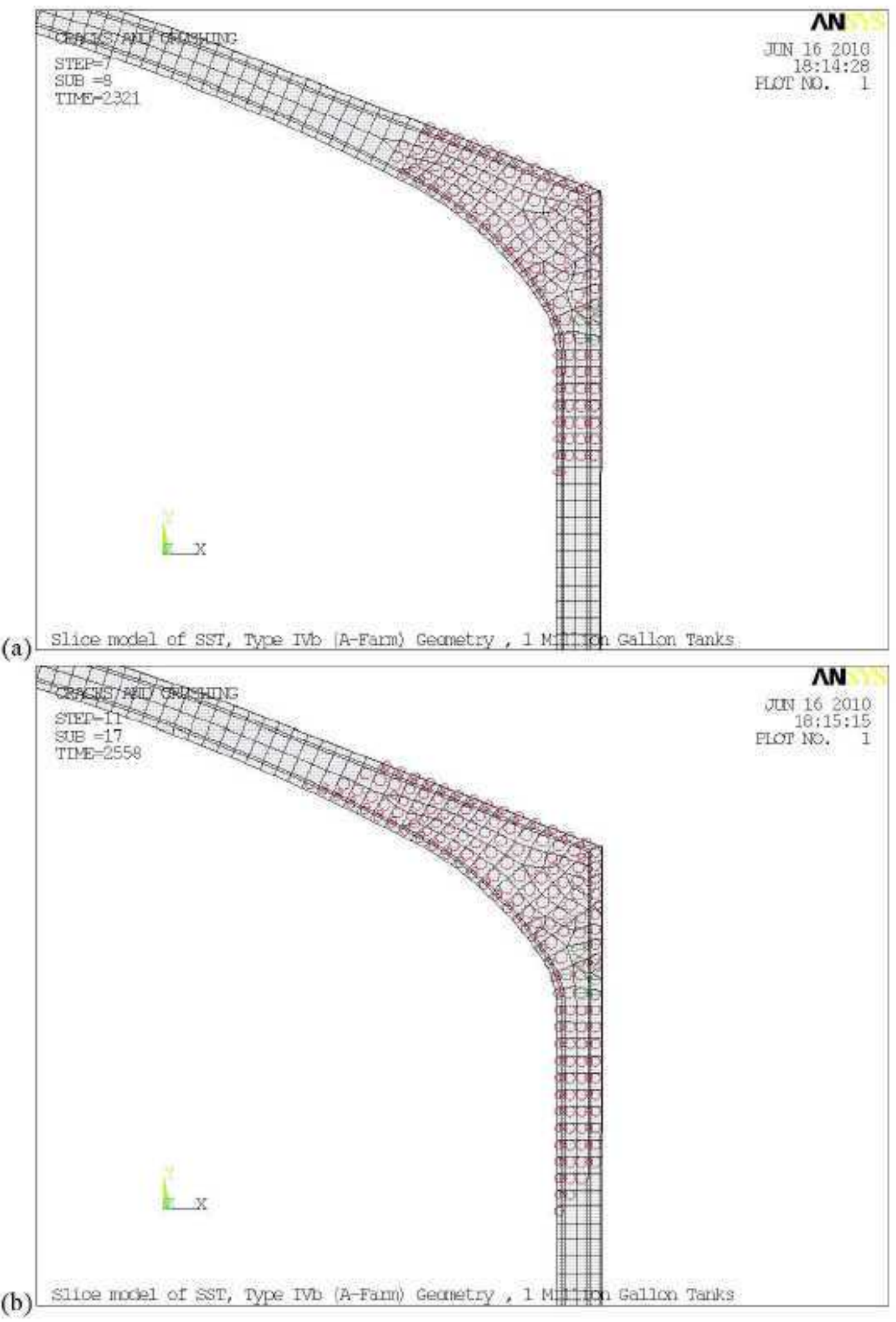




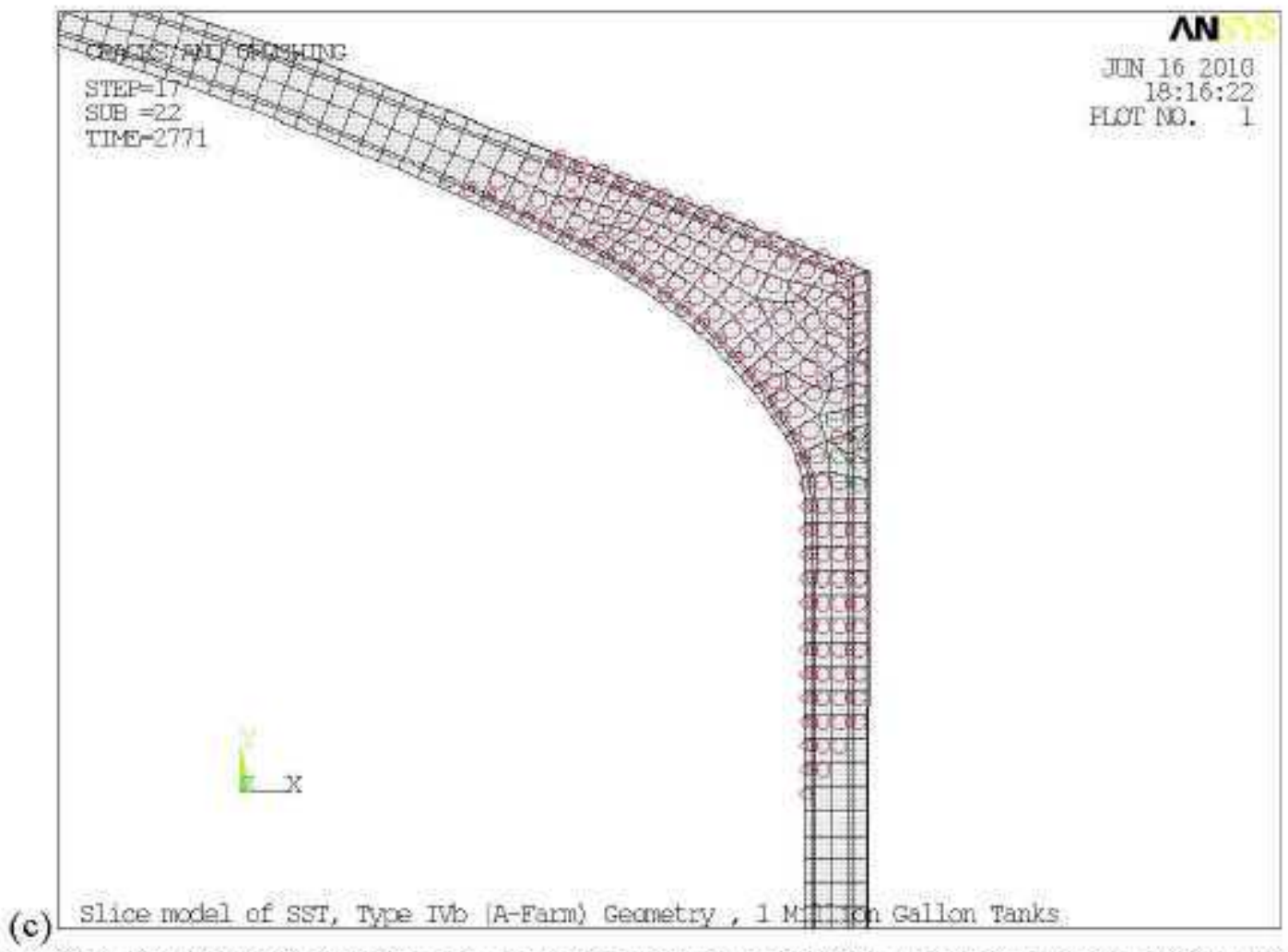

Figures 5.8(a)-(c) Concrete Cracking in the Tank Haunch at Different Passes through $430^{\circ} \mathrm{F}$ : (a) Pass 1 , (b) Pass 2, and (c) Pass 5.

\subsubsection{Diameter of the Hot Spot}

In order to understand the effect of the size of hot spot, thermal stress analysis were conducted using two different hot spot diameters: 30 feet and 50 feet. Figures 5.9 to 5.13 indicate that the change in hot spot diameter influences the section forces and moments in the slab region only and does not affect the wall, haunch and dome regions. Forces and moments plots at the end of the analysis (step 15), not shown, also do not show a significant difference between two analyses. However, the cracking in the footing increases with increase in the hot spot diameter, as shown in Figures 5,14 (a) and (b). The cracking in the footing region does not appear to have a significant impact on the load distribution in the rest of the tank structure. 


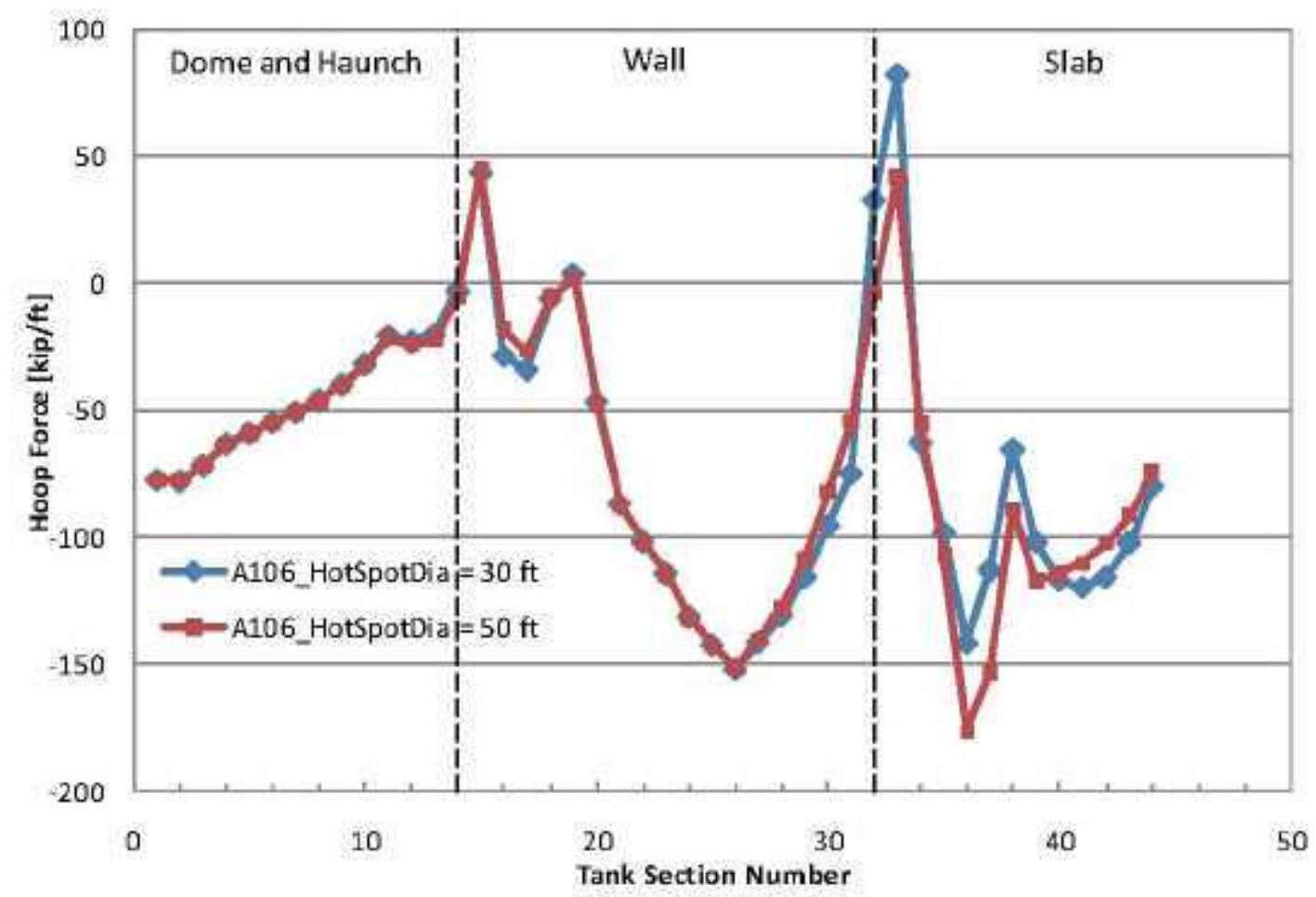

Figure 5.9 Comparison of section hoop forces for two different hot spot diameters at the Peak Temperature Point.

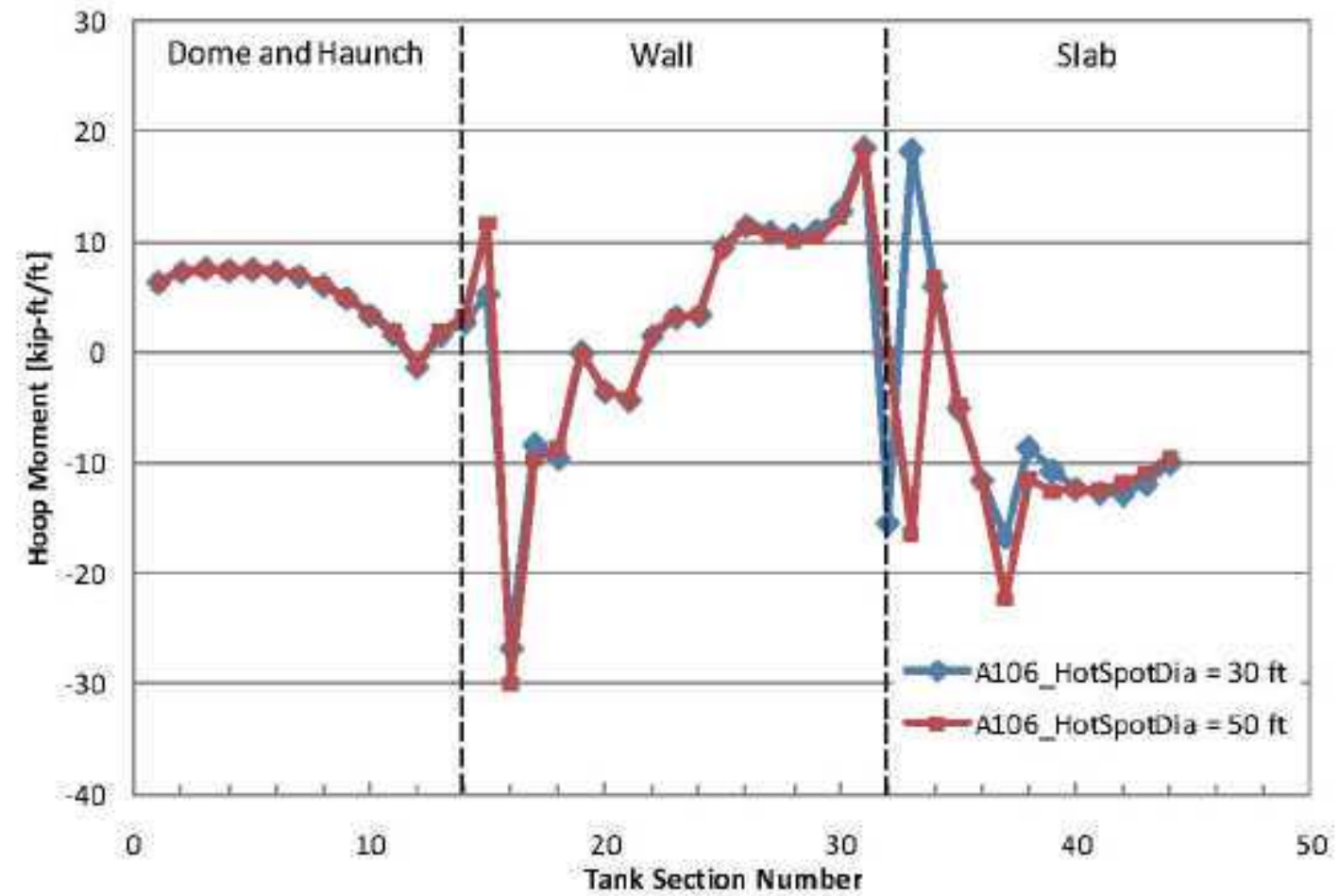

Figure 5.10 Comparison of section hoop moments for two different hot spot diameters at the Peak Temperature Point. 


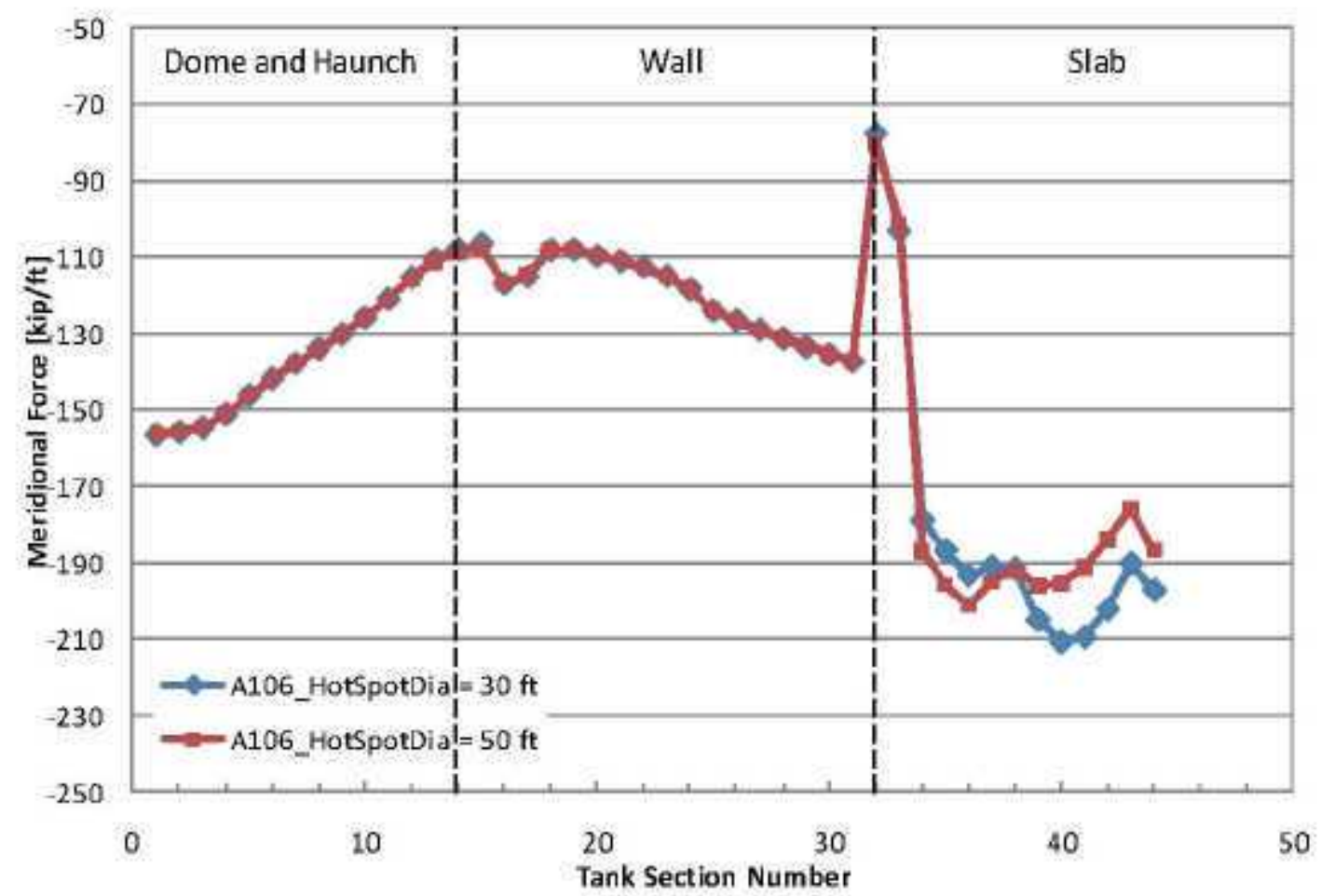

Figure 5.11 Comparison of section meridional fores at two different hot spot diameters at the Peak Temperature Point.

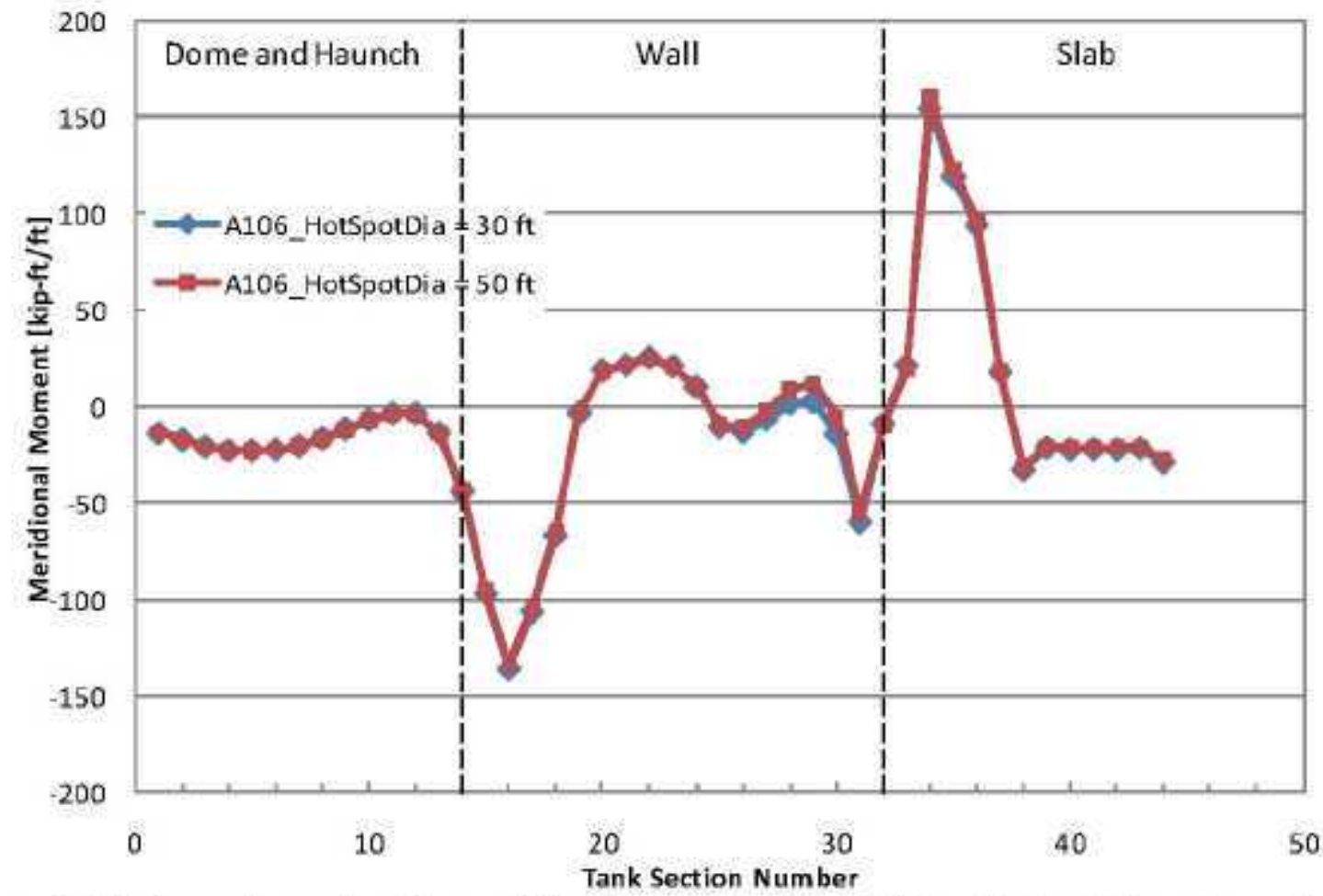

Figure 5.12 Comparison of section meridional moments at two different hot spot diameters at the Peak Temperature Point. 


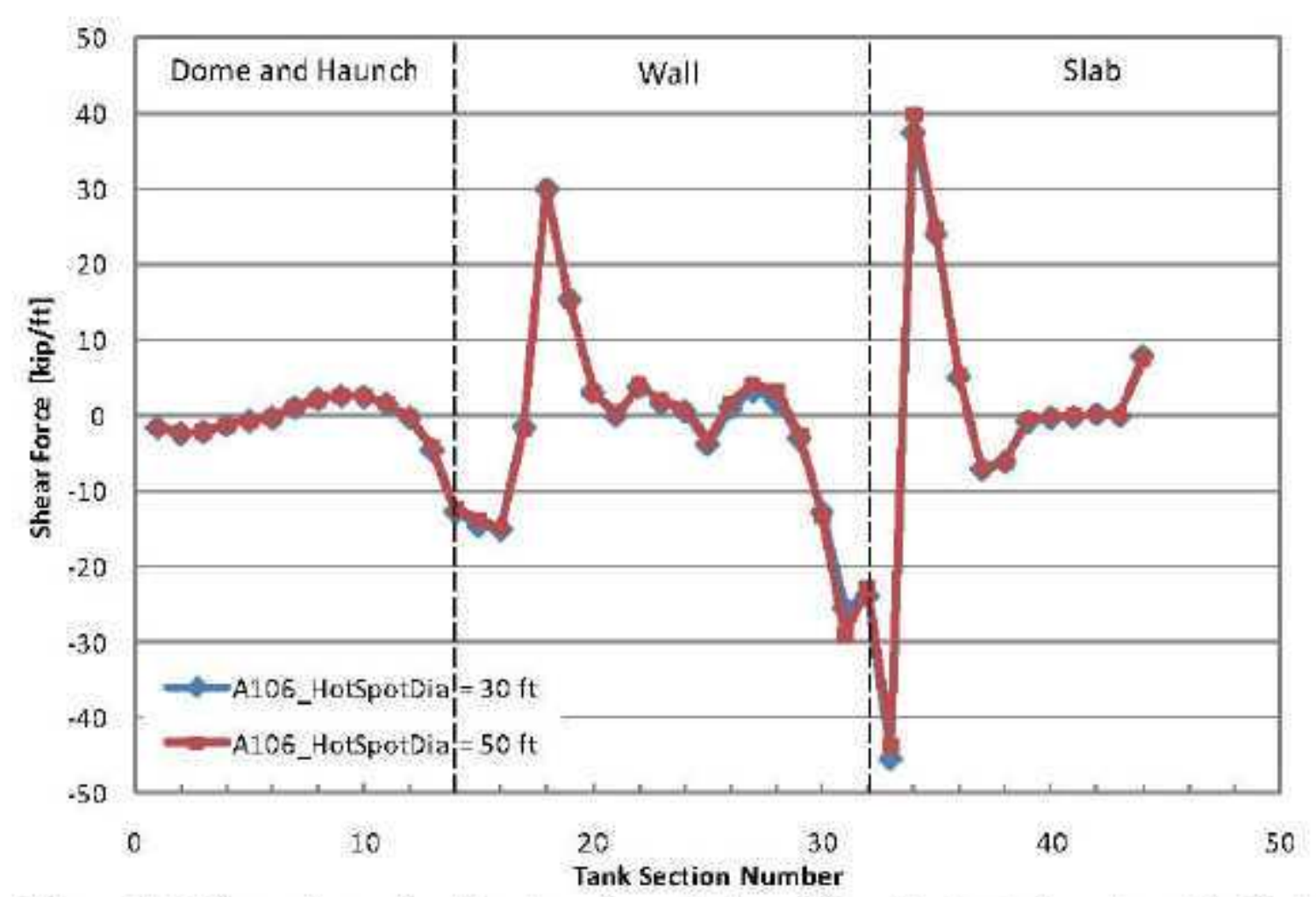

Figure 5.13 Comparison of section shear forces for two different hot spot diameters at the Peak Temperature Point.

(a)
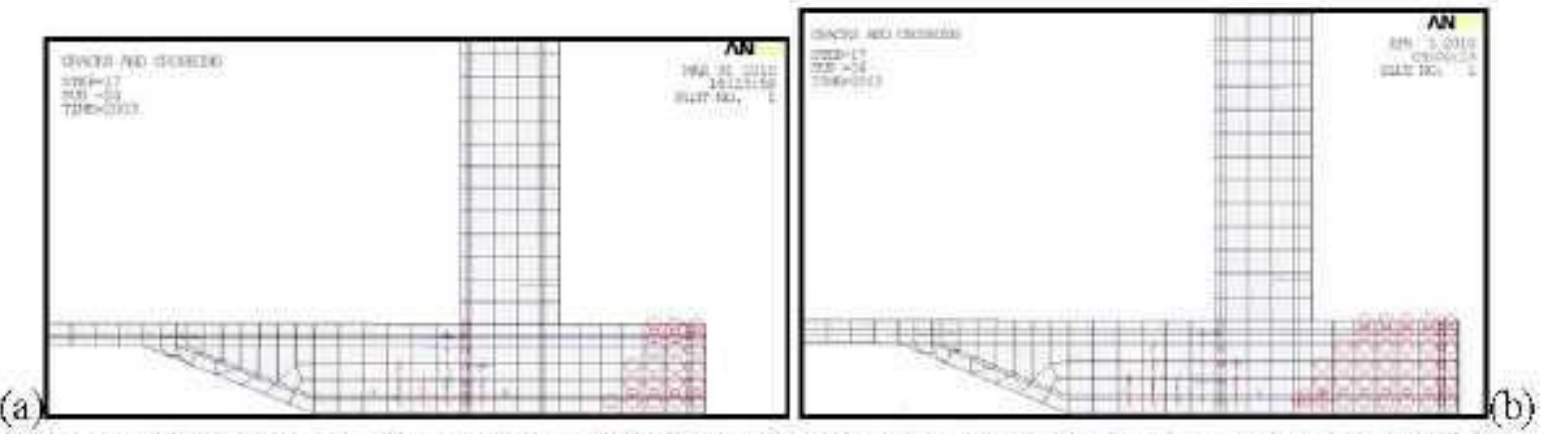

Figures 5.14(a) \& (b) Comparison of Concrete Cracking for the Two Analyses with Hot Spot Diameter (a) $30 \mathrm{ft}$ and (b) $50 \mathrm{ft}$

\subsubsection{Rate of Temperature Rise}

The waste temperatures were obtained by visually reading the plots from the Mereier (1981). The dates shown in Figure 5.1 were estimates and could be different from the actual values. Step 4 in Table 4.3 has a duration of 14 days, within which the waste temperature increases by a value of 179 degrees Fahrenheit (from 386 to 565 degrees Fahrenheit). Since it is probable that the visual estimate of the time period could be enroneous, it is necessary to study the difference in the analysis results if the time period were to be smaller than estimated, because a rapid rate of increase in temperature could lead to more severe thermal gradients through the thickness of the tank walls, leading to higher stresses and stress gradients. In order to understand this sensitivity, an analysis was carried out where the duration for increase in temperature from 386 to 565 degrees Fahrenheit was changed to different values $5,14,30$ and 
120 days. These correspond to approximate temperature increase rates of $36,13,6$ and 1.5 Fahrenheitdegrees/day. The cumulative time values for the latter steps (Step 5 onwards) were adjusted according to accommodate the increased number of days in Step 4.

Another analysis was carried out to simulate quasi-steady-state conditions by increasing the temperature to 565 degrees Fahrenheit in the first step and keeping it constant through steps 2,3 and 4 . The temperature remains at the peak value of 565 degrees Fahrenheit for about 134 days (more than four months), which is assumed to be sufficient time for the temperature distribution to reach near-steady-state conditions. For this analysis, the temperature of the sludge (or solids) is assumed to be uniform and equal to the maximum temperature value. It was assumed to decrease linearly with waste height from solids surface to the waste surface. The sectional forces and moments comparison for the different temperature increase rates and the steady-state analyses are shown in Figures 15 to 19 . When compared to the steadystate values, there is a significant difference in the tank response at different temperature increase rates especially in the hoop force, hoop moment and meridional forces plots. Figures 5.20 (a) to (c) show a significantly higher amount of concrete cracking at high temperature rise rates not only in the footing region but more importantly in the tank wall near the footing region. Figures 5.21 (a) to (c) show a slightly higher amount of cracking in the steady state case compared to the cases with high temperature rise rates.

Similar analysis with a hot spot diameter of 50 feet instead of the uniform solids temperature did not yield as significant difference in forces and moments for 36 and 13 Fahrenheit-degrees/day, except for the tank slab or hot spot region. It can be concluded that if the temperature rise was restricted to the hot spot region, then the rate of femperature rise does not have a significant impact on the tank load distribution. However, in general, the rate of temperature rise appears to have a significant effect. 


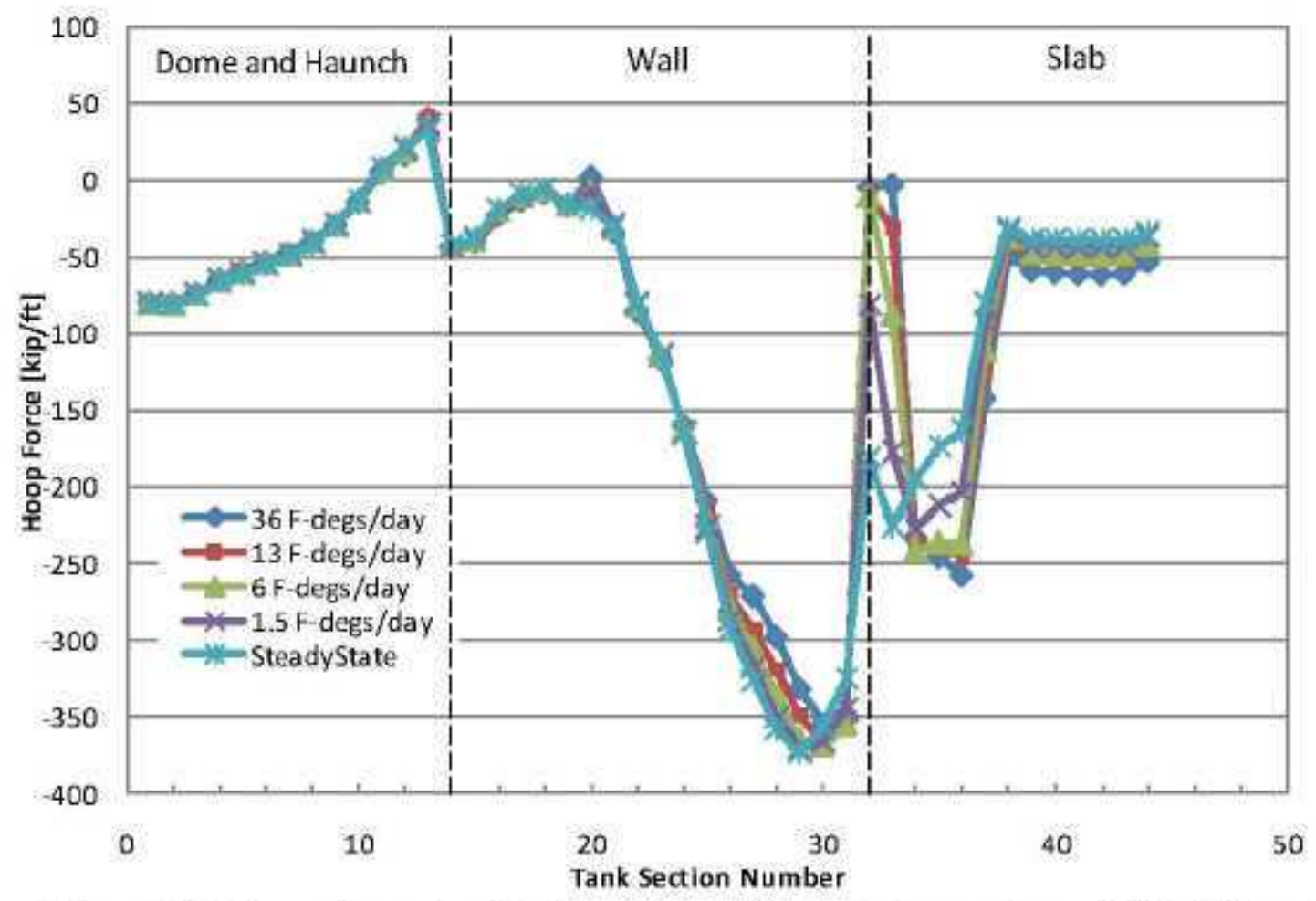

Figure 5.15 Comparison of section hoop forces at the peak temperature point for different rates of temperature rise.

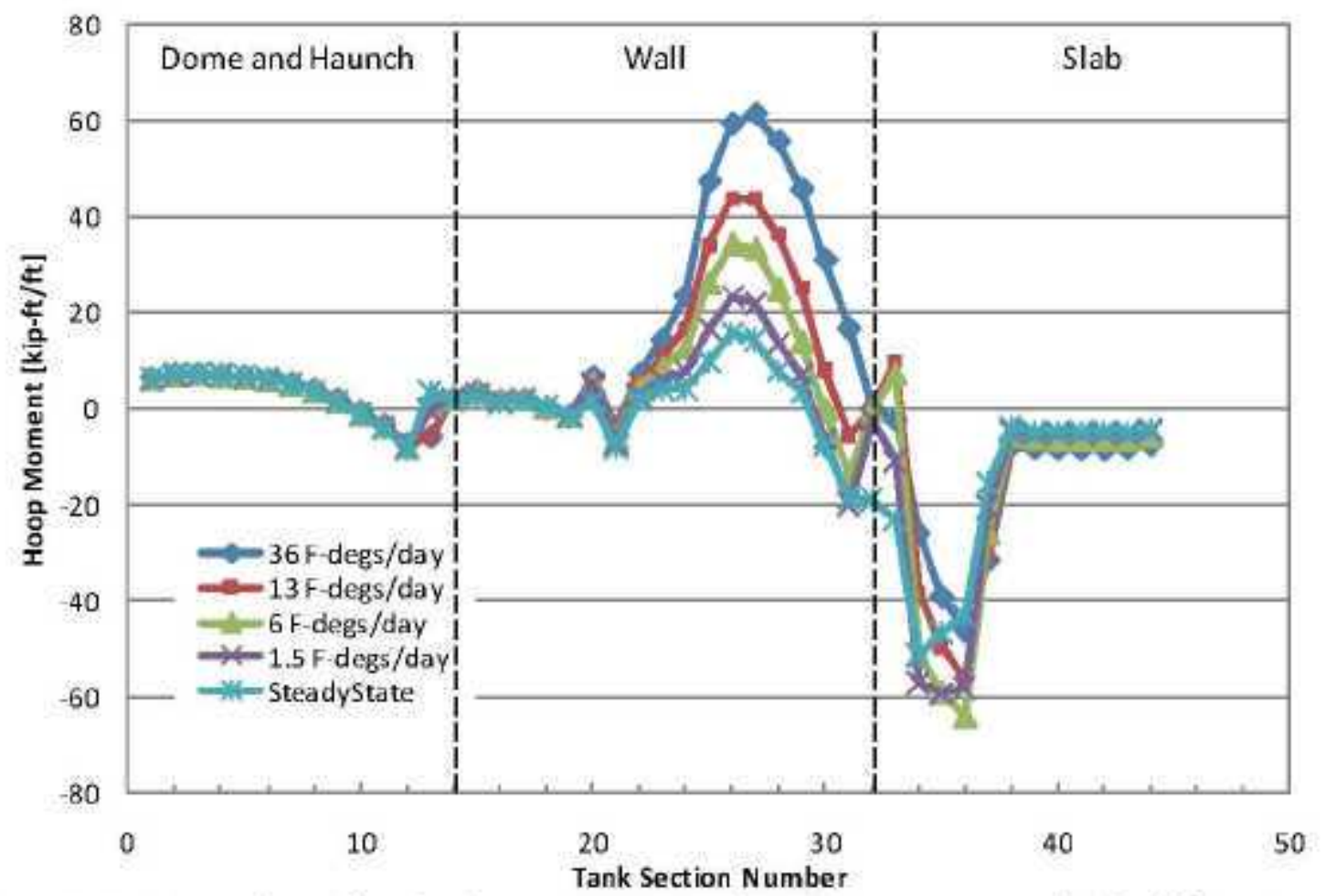

Figure 5.16 Comparison of section hoop moments at the peak temperature point for different rates of temperature rise. 


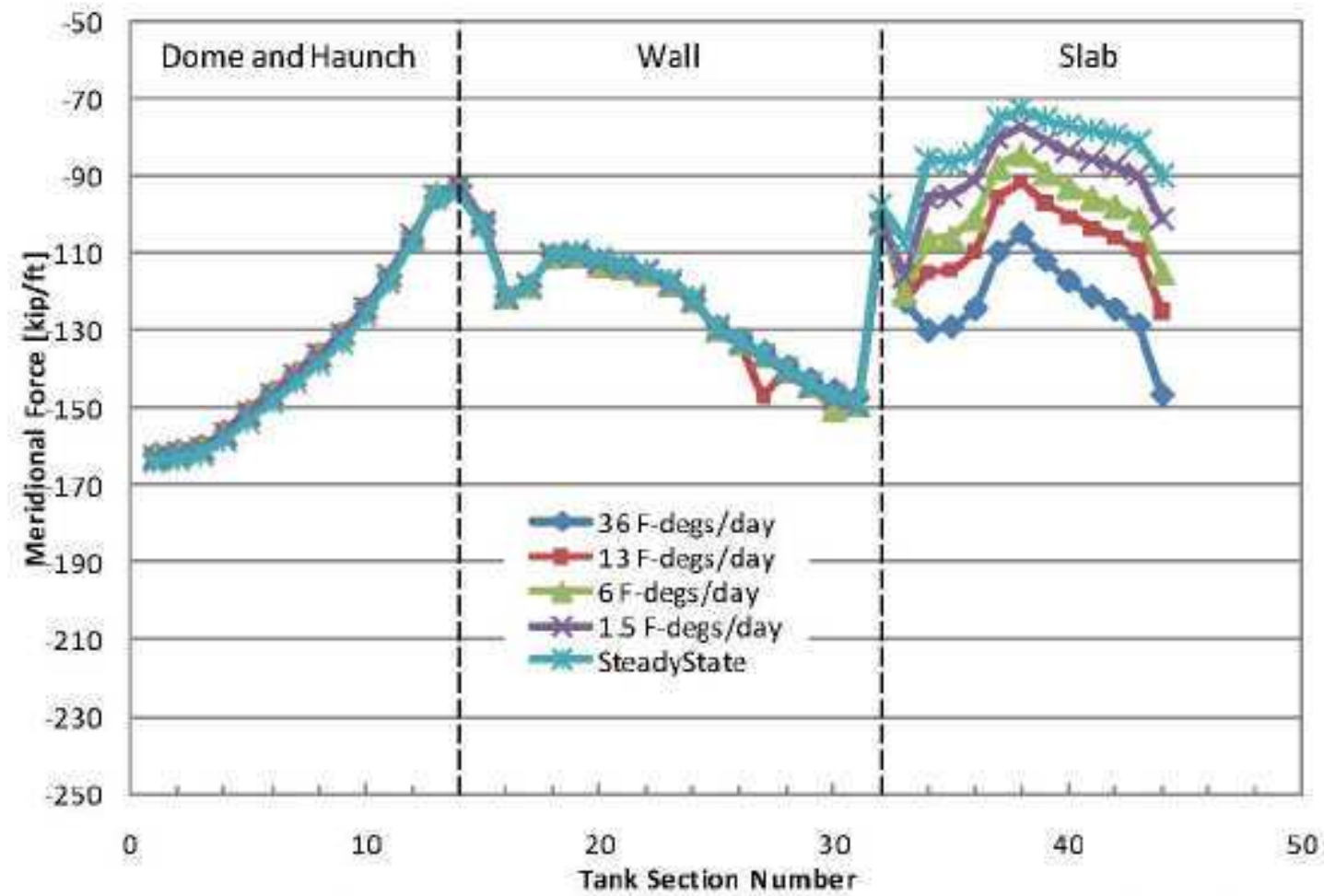

Figure 5.17 Comparison of section meridional forces at the peak temperature point for different rates of temperature rise.

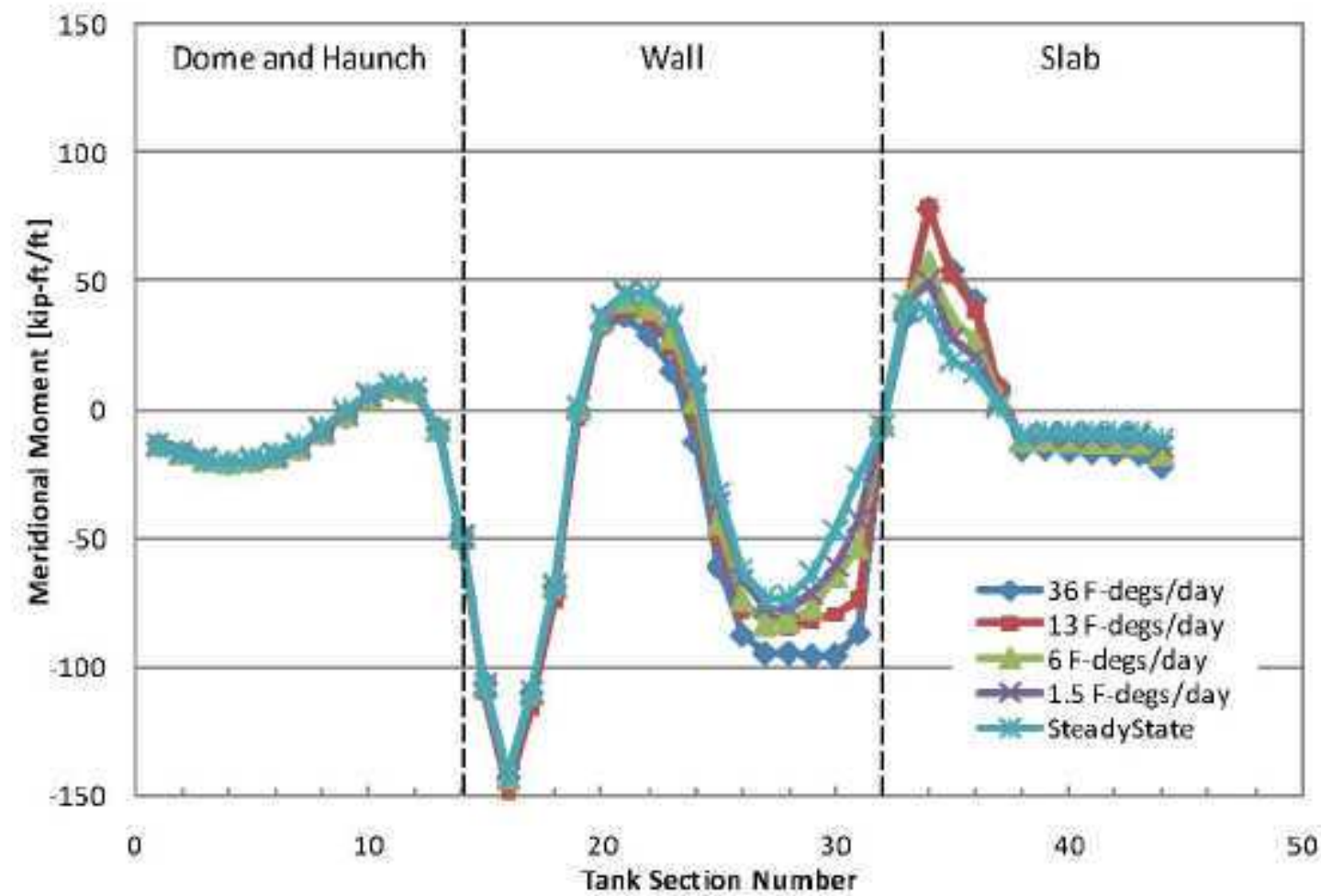

Figure 5.18 Comparison of section meridional moments at the peak temperature point for different rates of temperature rise. 
RPP-46644, Rev.0

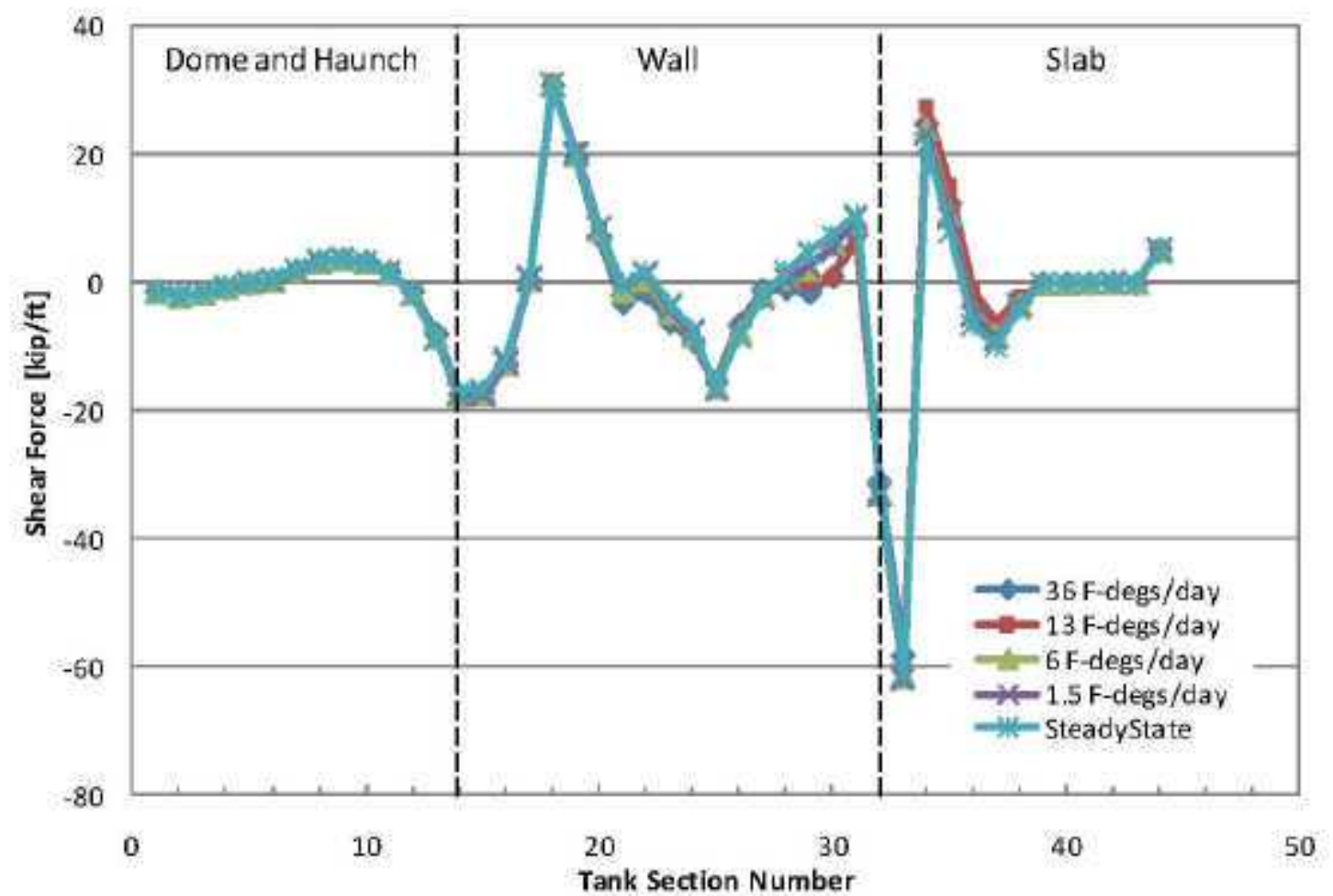

Figure 5.19 Comparison of section shear forces at the peak temperature point for different rates of temperature rise.

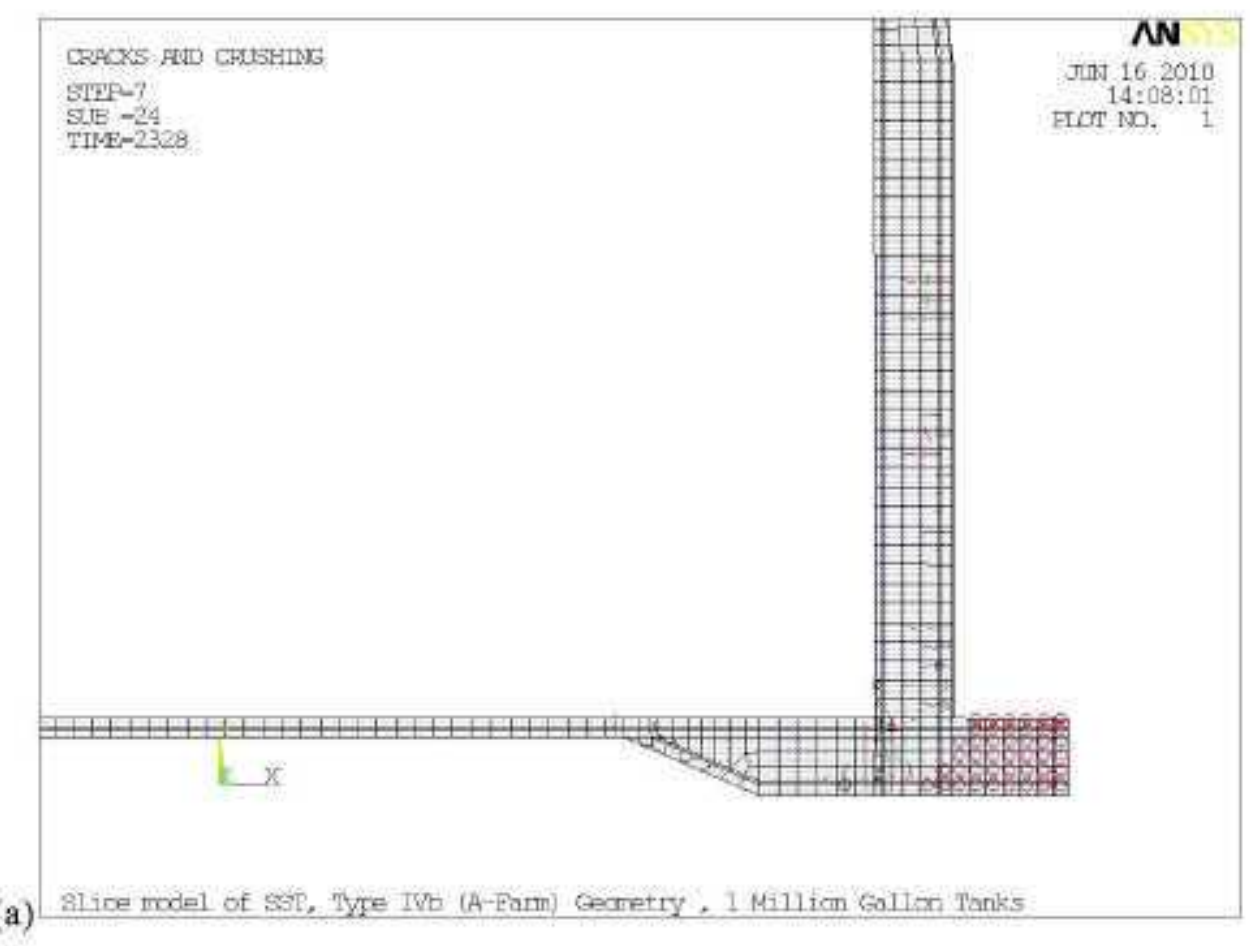


RPP-46644, Rev.0

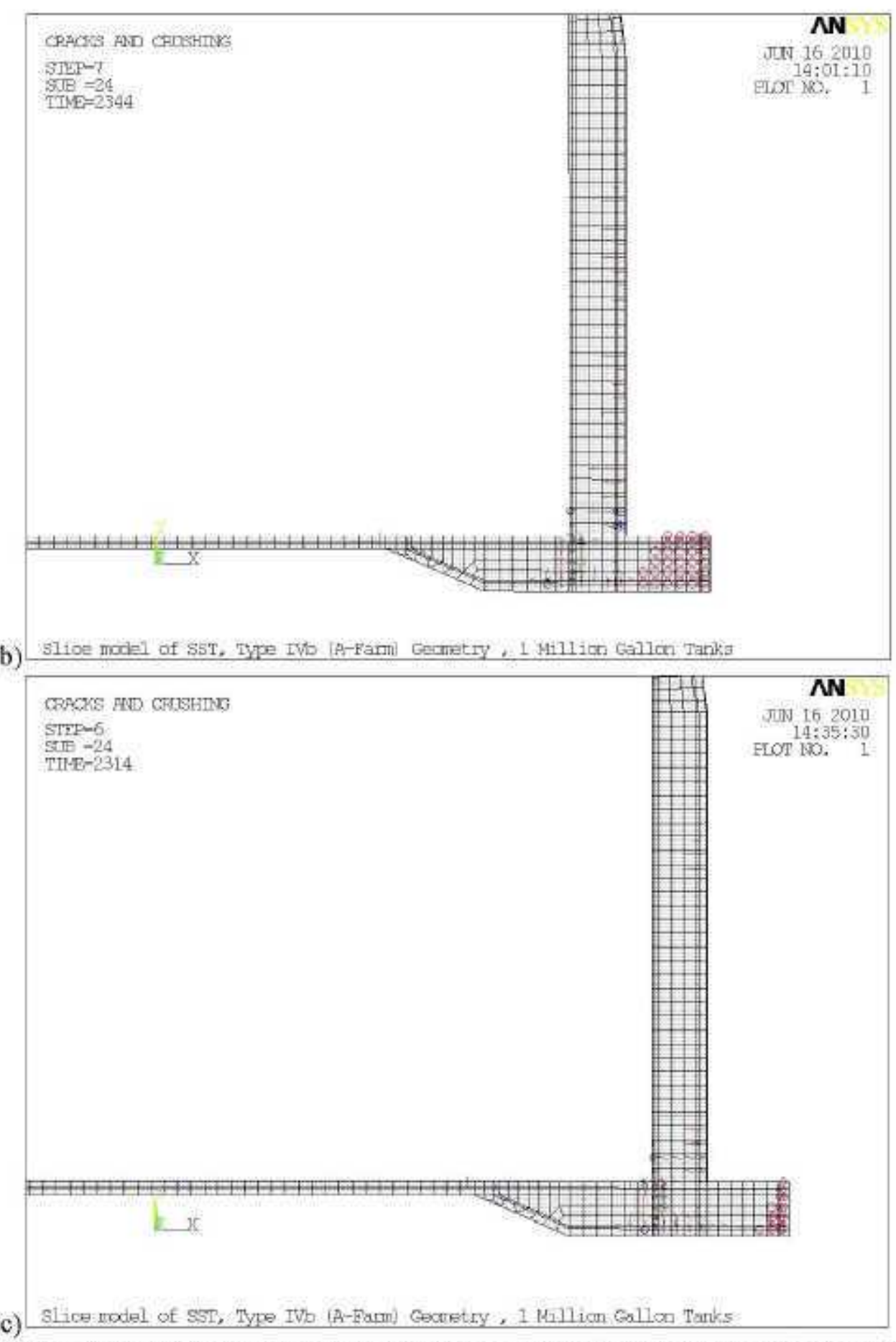

Figures 5.20(a) - (c) Concrete cracking in the footing region of the tank at the peak temperature point for: (a) 36 Fahrenheit-degrees/day, (b) 6 Fahrenheit-degrees/day, and (c) steady state conditions. 
RPP-46644, Rev.0

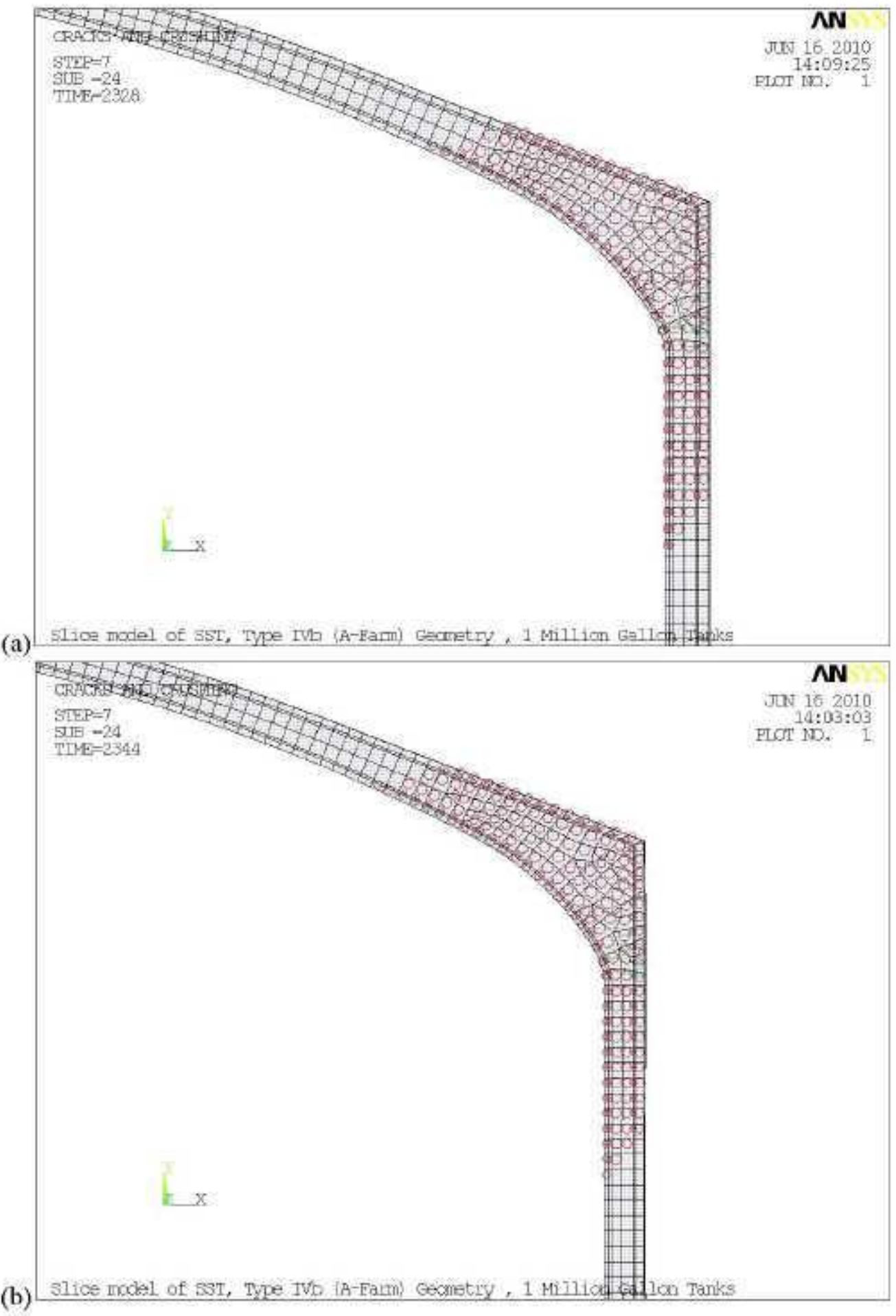




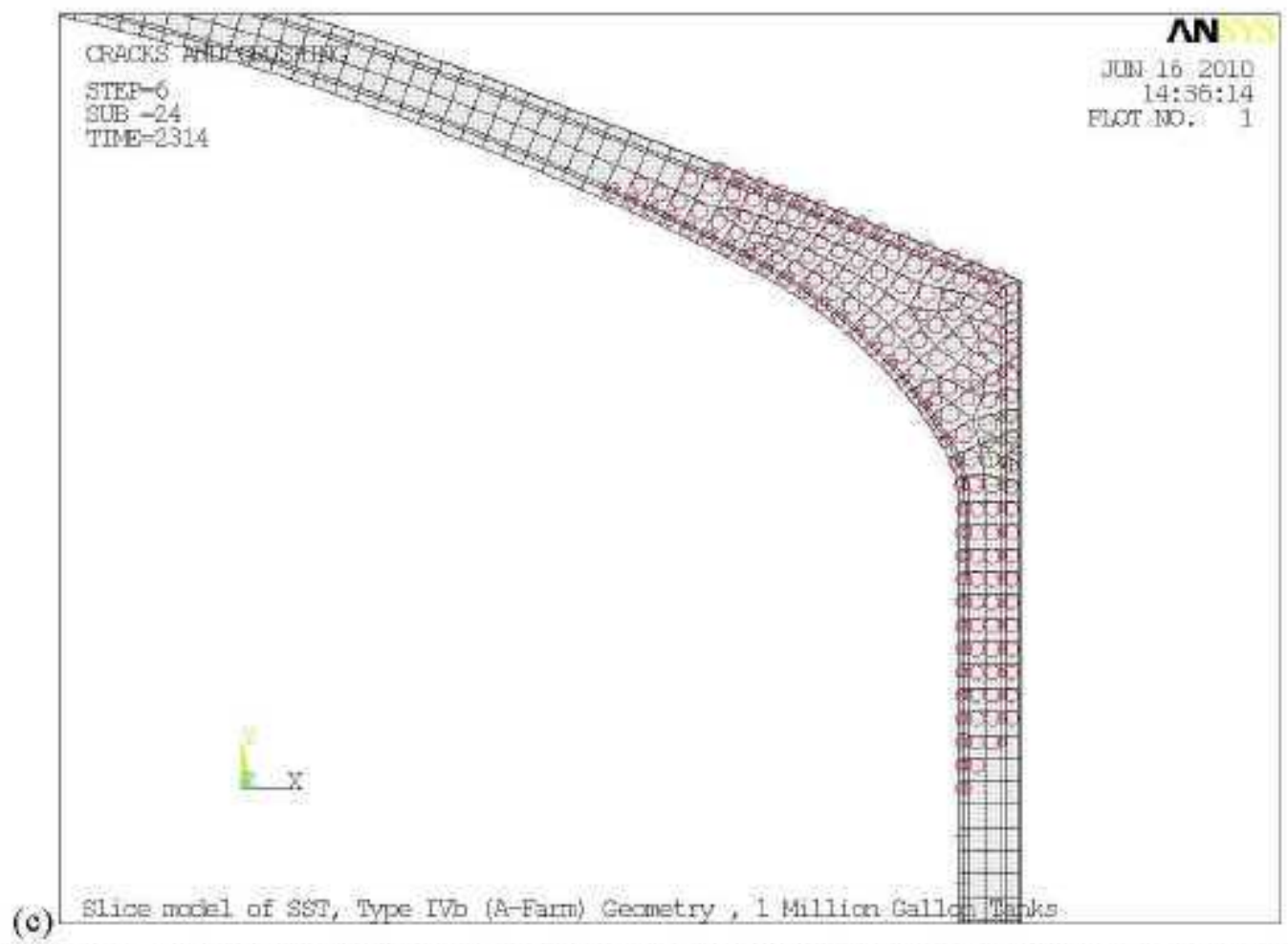

Figures 5.21(a) - (c) Concrete cracking in the haunch region of the tank at the peak temperature point for: (a) 36 Fahrenheit-degrees/day, (b) 6 Fahrenheit-degrees/day, and (c) steady state conditions.

\subsubsection{Temperature Variation within the Tank Waste}

The study to understand the effect of temperature variation within the tank waste was conducted by comparing two analyses results. One analysis was carried out by assuming that the entire waste was at a uniform temperature, while the other analys is was carried out by assuming that the waste temperature decreases linearly with waste height, with the maximum temperature location at the bottom of the tank and the minimum temperature at the waste surface. The waste surface temperature was assumed equal to 225 degrees Fahrenheit (assumed boiling point of the supernatant) when the maximum waste temperature was greater than the 225 degrees Fahrenheit and was assumed to be approximately 15 percent lower than the maximum waste temperature when maximum waste temperature value was below 225 degrees Fahrenheit. In the linearly-varying temperature case, no variation of temperature was used in the radial direction of the tank (that is, the nodes on the bottom of the tank were all assigned a uniform temperature equal to the maximum waste temperature).

The comparison of section fores and moments for the two temperature variation cases is shown in Figures 22 to 26 . The major noticeable variation is in the tank wall and the haunch region. No definitive conclusion can be drawn about which case can be characterized as conservative compared to the other. The concrete cracking in the haunch and footing for the two cases is shown in Figures 27 (a) to (d). Significantly higher amounts of cracking can be witnessed in the haunch region for the uniform waste temperature case, Figure 27 (d). While the cracking in the footing is almost similar for both cases, the linear temperature variation case shows a few additional cracks in the bottom section of the wall (just above the footing), Figure 27(a), that cannot be observed in the uniform waste temperature case. 
The linearly-varying waste temperature is an assumed temperature distribution state. The reason this distribution was chosen was because of the ease of implementation in the finite element analysis. The models have sufficient capability built into them to simulate other complex temperature distribution conditions. However, the temperature distribution data on hand for the time period prior to 1975 is limited, and it is difficult to obtain a reasonable estimate of the distribution. Further analysis into the waste properties may need to be carried out if an accurate temperature distribution is deemed necessary.

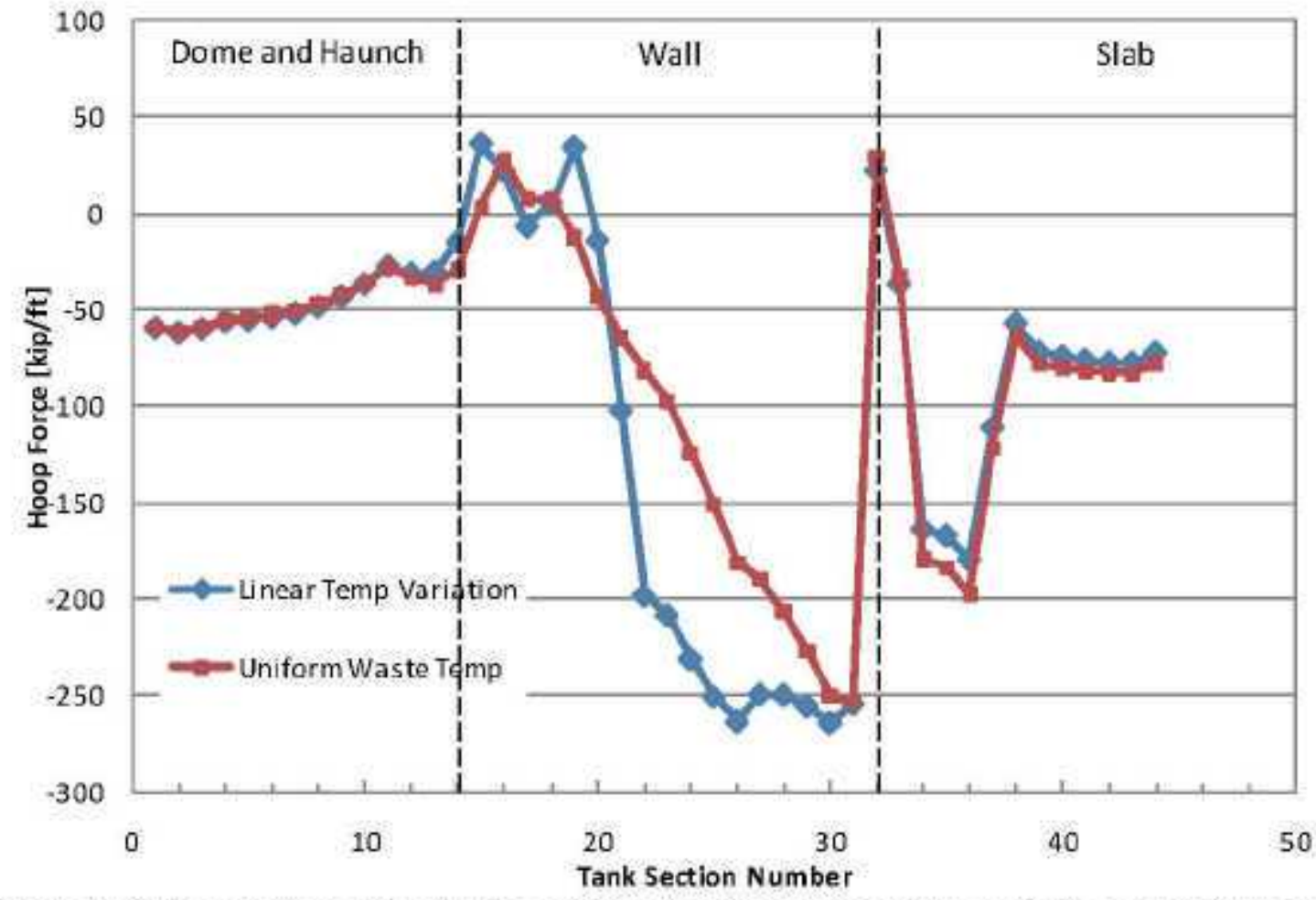

Figure 5.22 Comparison of section hoop forces for linear temperature variation and uniform waste temperature at the peak temperature point $\left(380^{\circ} \mathrm{F}\right)$. 
RPP-46644, Rev.0

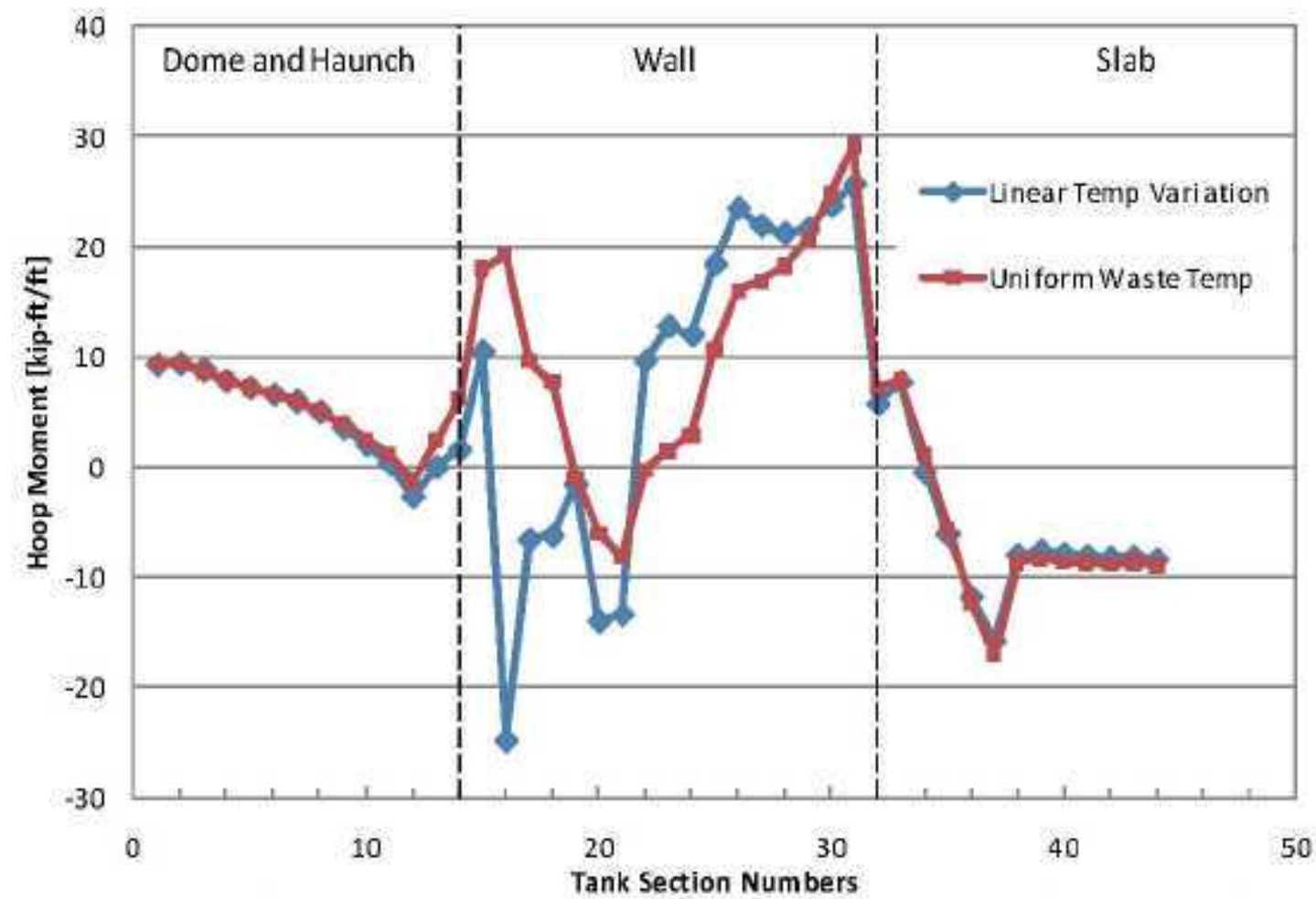

Figure 5.23 Comparison of section hoop moments for linear temperature variation and uniform waste temperature at the peak temperature point $\left(380^{\circ} \mathrm{F}\right)$.

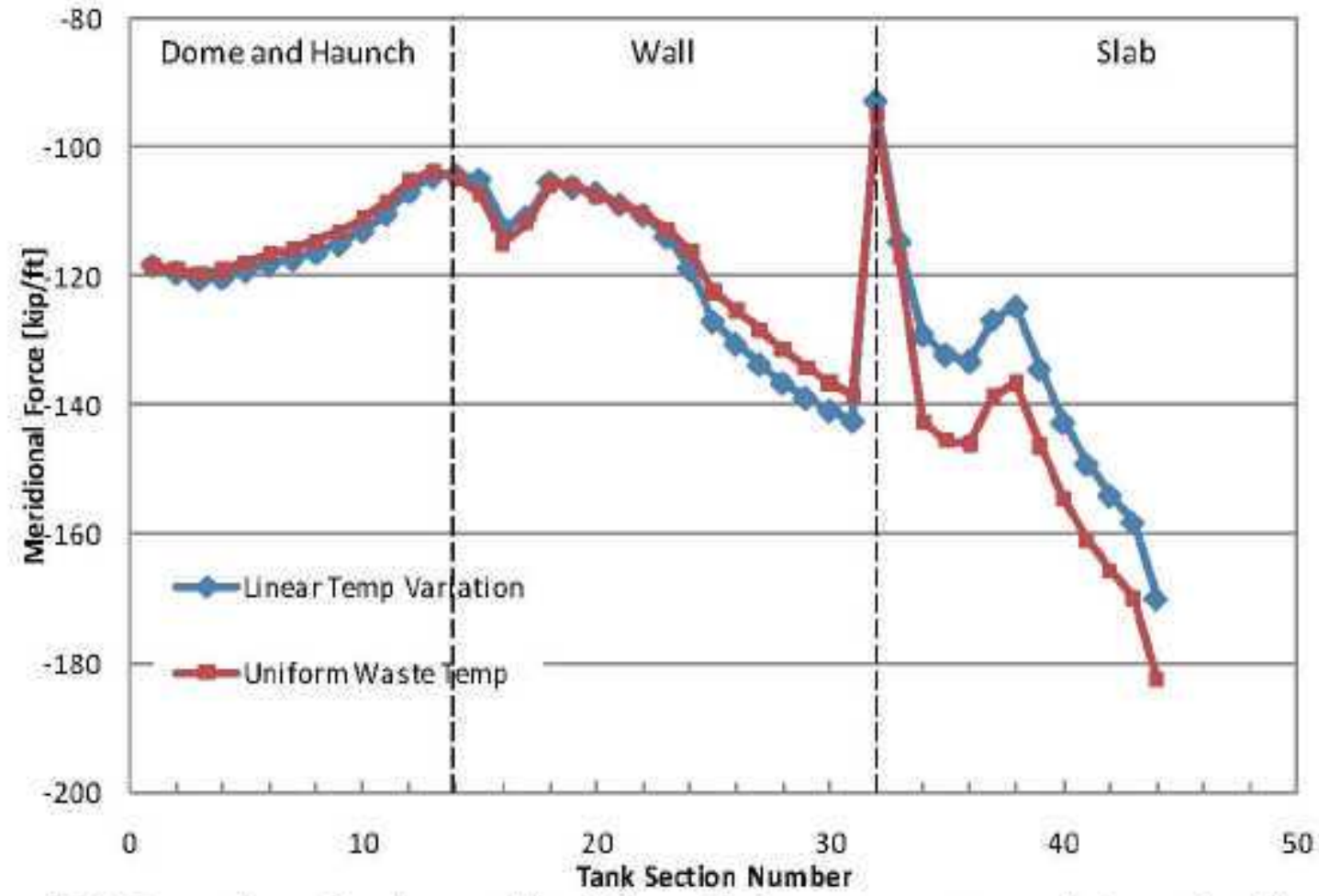

Figure 5.24 Comparison of section meridional forecs for linear temperature variation and uniform waste temperature at the peak temperature point $\left(380^{\circ} \mathrm{F}\right)$. 
RPP-46644, Rev.0

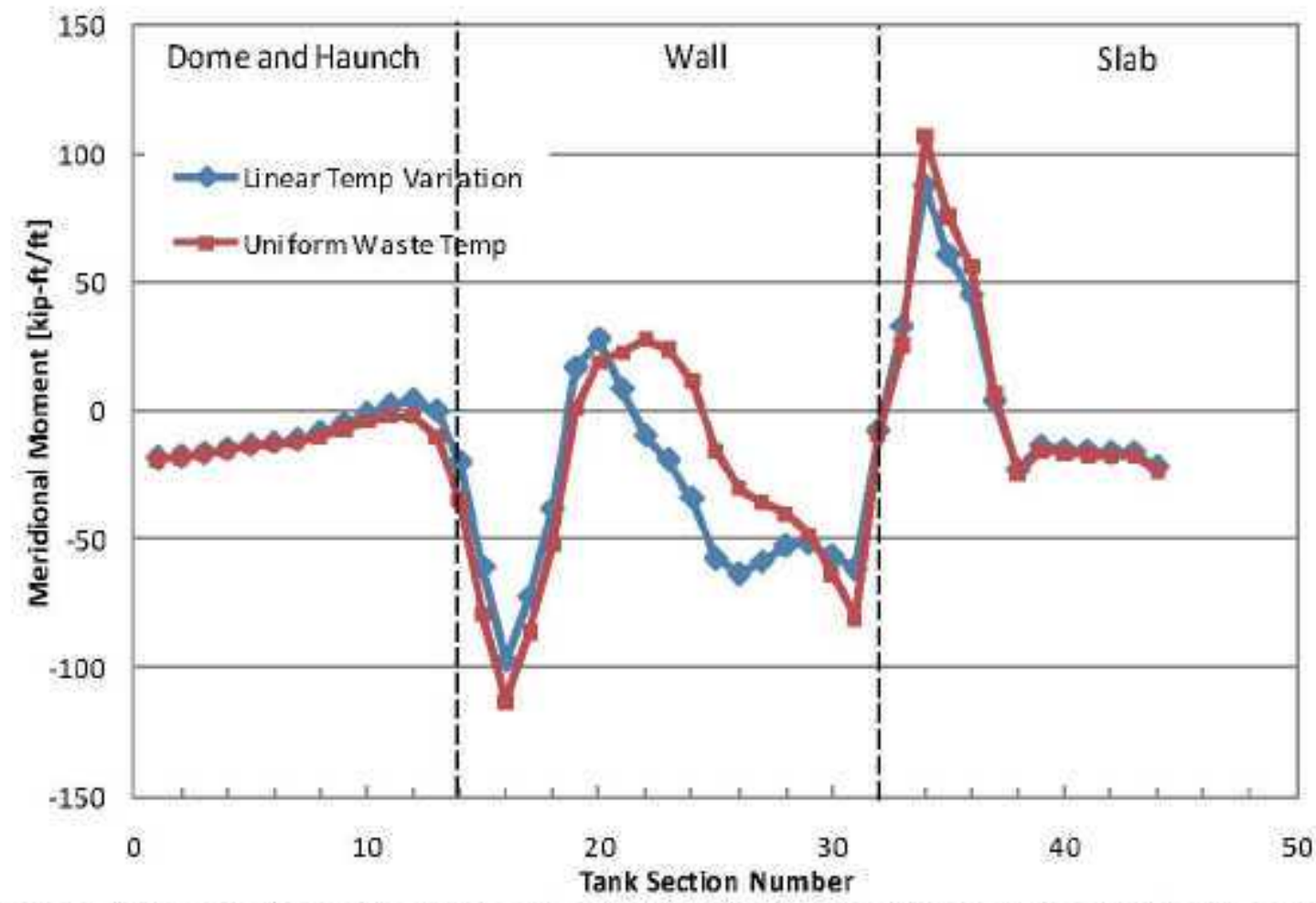

Figure 5.25 Comparison of section meridional moments for linear temperature variation and uniform waste temperature at the peak temperature point $\left(380^{\circ} \mathrm{F}\right)$.

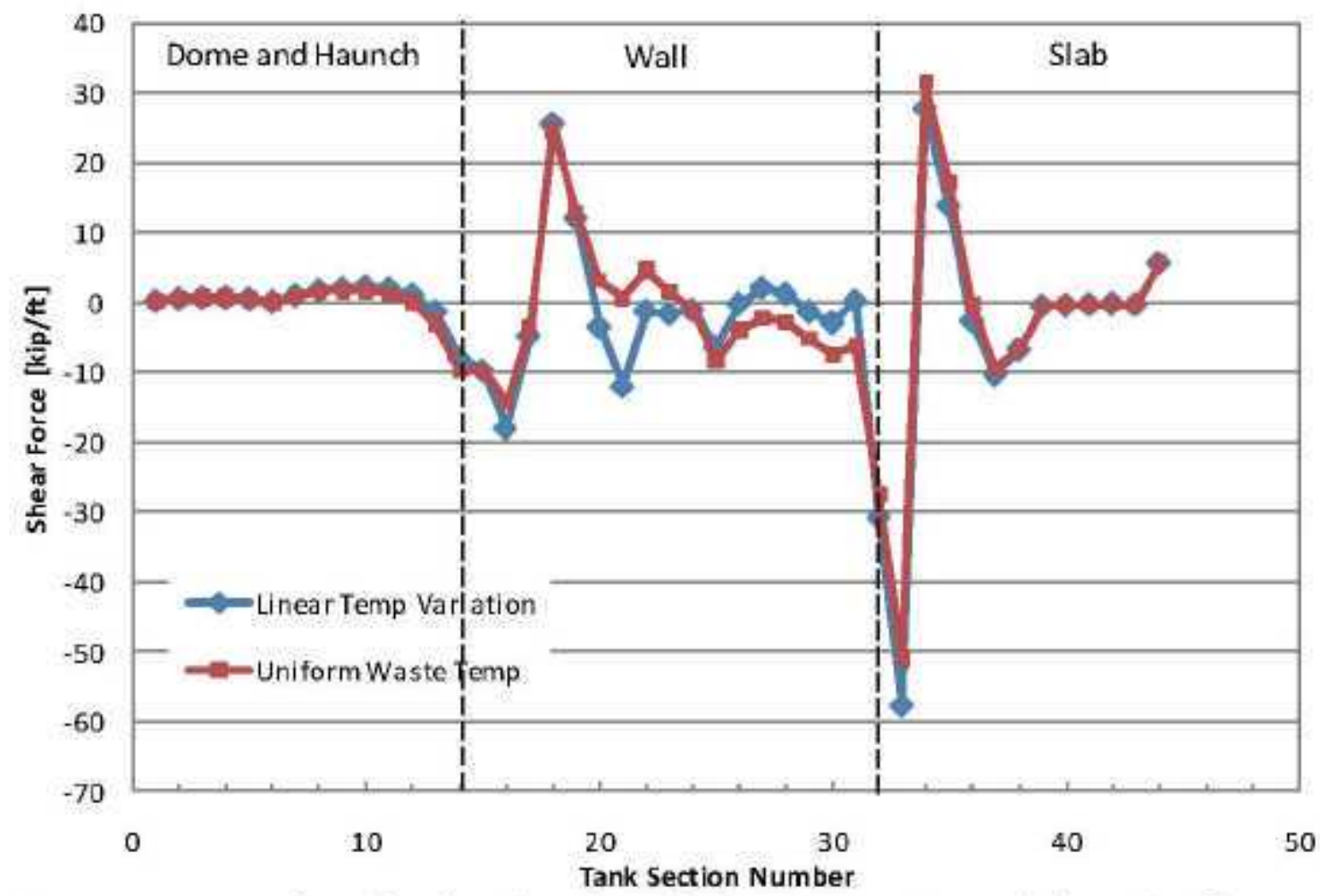

Figure 5.26 Comparison of section shear forces for linear temperature variation and uniform waste temperature at the peak temperature point $\left(380^{\circ} \mathrm{F}\right)$. 
(a)
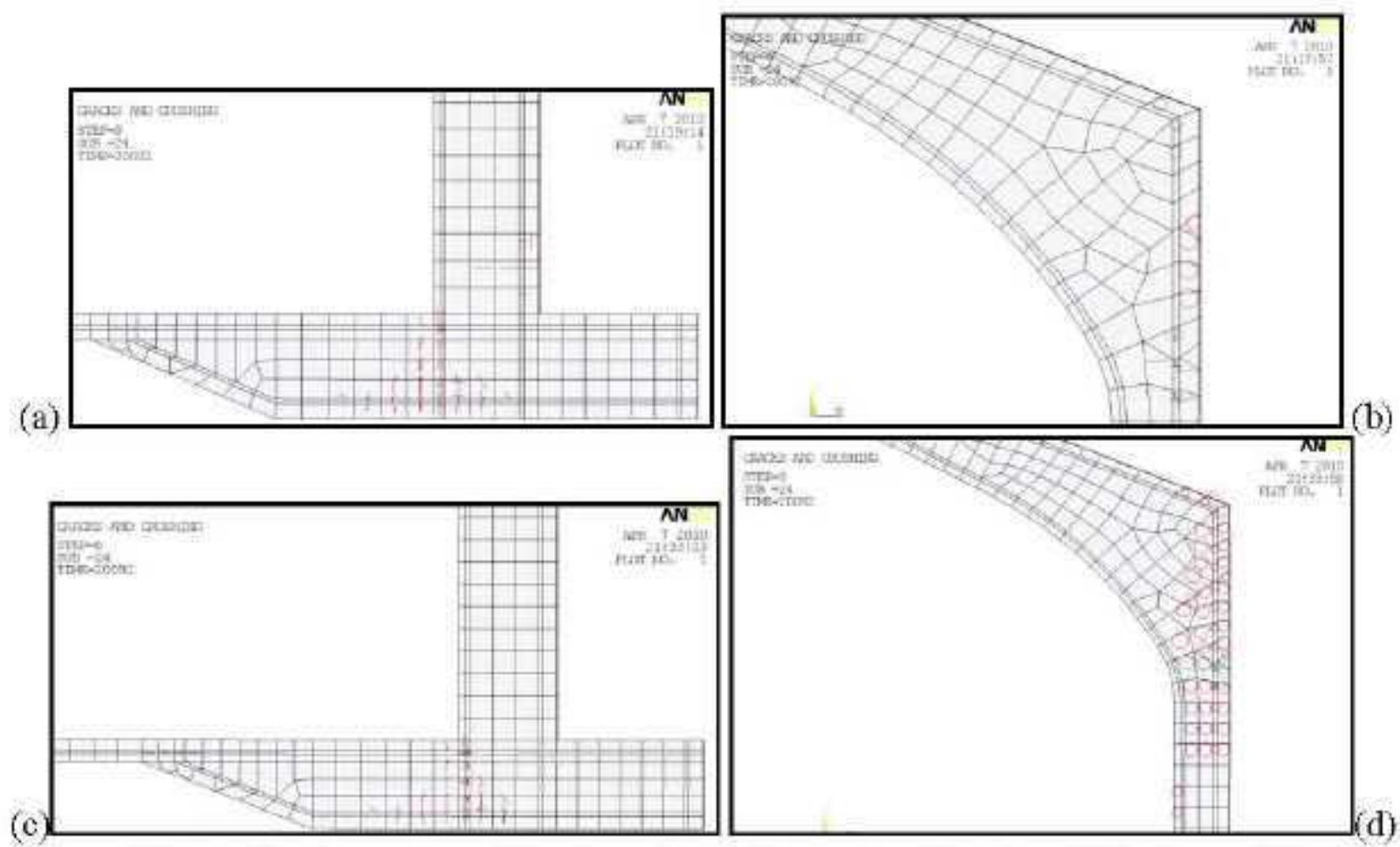

Figures 5.27(a)-(d) Comparison of Cracking: Linear Temperature Variation (a) footing and (b) hannch; uniform temperature variation (c) footing and (d) haunch

\subsubsection{Type III Thermal Modeling}

The Type III model was based on dimensions taken from drawings $\mathrm{H}-2-1783, \mathrm{H}-2-1785$, and H-2-1786. The steel liner was not included in the model. The three-inch grout layer in the floor of the tank and the asphaltic membrane and welded fabric located between the steel liner and the concrete tank were also neglected. The two degree ANSYS ${ }^{\text {s }}$ slice model of the tank is shown in Figure 5.28. The colors reflect the different materials used throughout the model. The model uses SOLID65 elements for the concrete and SOLID 185 elements for the soil. 


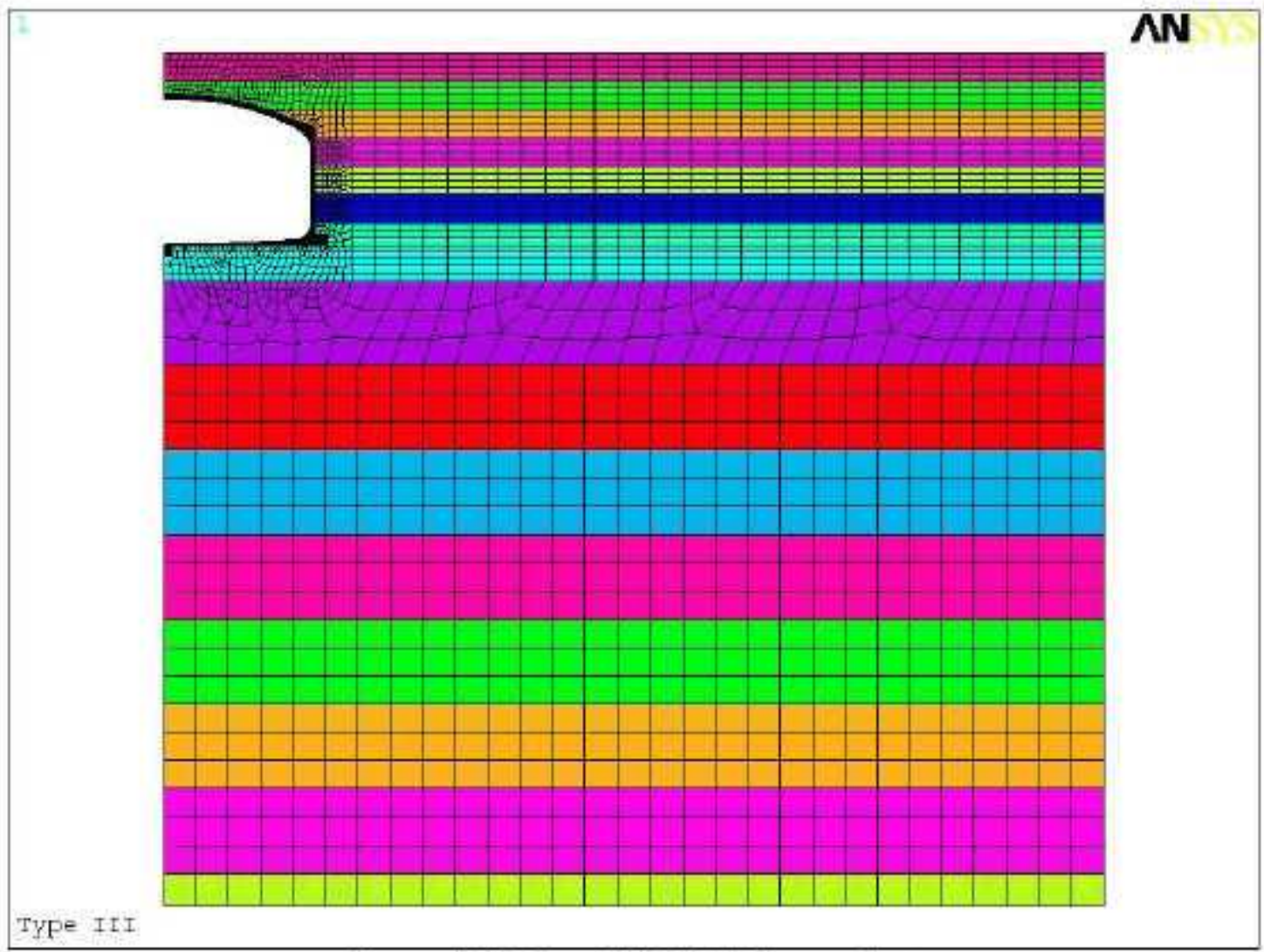

Figure 5.28 Type III Model Element Plot

The soil extends to a radius of 240 feet, approximately six times the tank radius. The soil depth is 168 feet below the foundation. The soil cover is 10.38 feet at the center of the dome, as reported in Table A.14, RPP.10435.

The material properties for the concrete and soil are summarized in the SST Evaluation Criteria report. Temperature-dependent elastic moduli and nominal tensile strengths were used for the concrete. Concrete ereep was not considered in this analysis.

Mechanical loads were applied in three load steps; gravity, waste load, and surface live loads. The waste depth was specified as 300 inches, as described above in the Temperature and Waste Profiles, Section 4.3.2. The surface live loads include a uniform $40 \mathrm{lb} / \mathrm{ft}^{2}$ and a $200 \mathrm{kip}$ concentrated load at the center of the dome. The thermal load was applied in load step 4 . The temperature peak waste temperature of 300 degrees Fahrenheit was prescribed over the full depth of the waste. The termperature distribution in the tank is shown in Figure 5.29. 


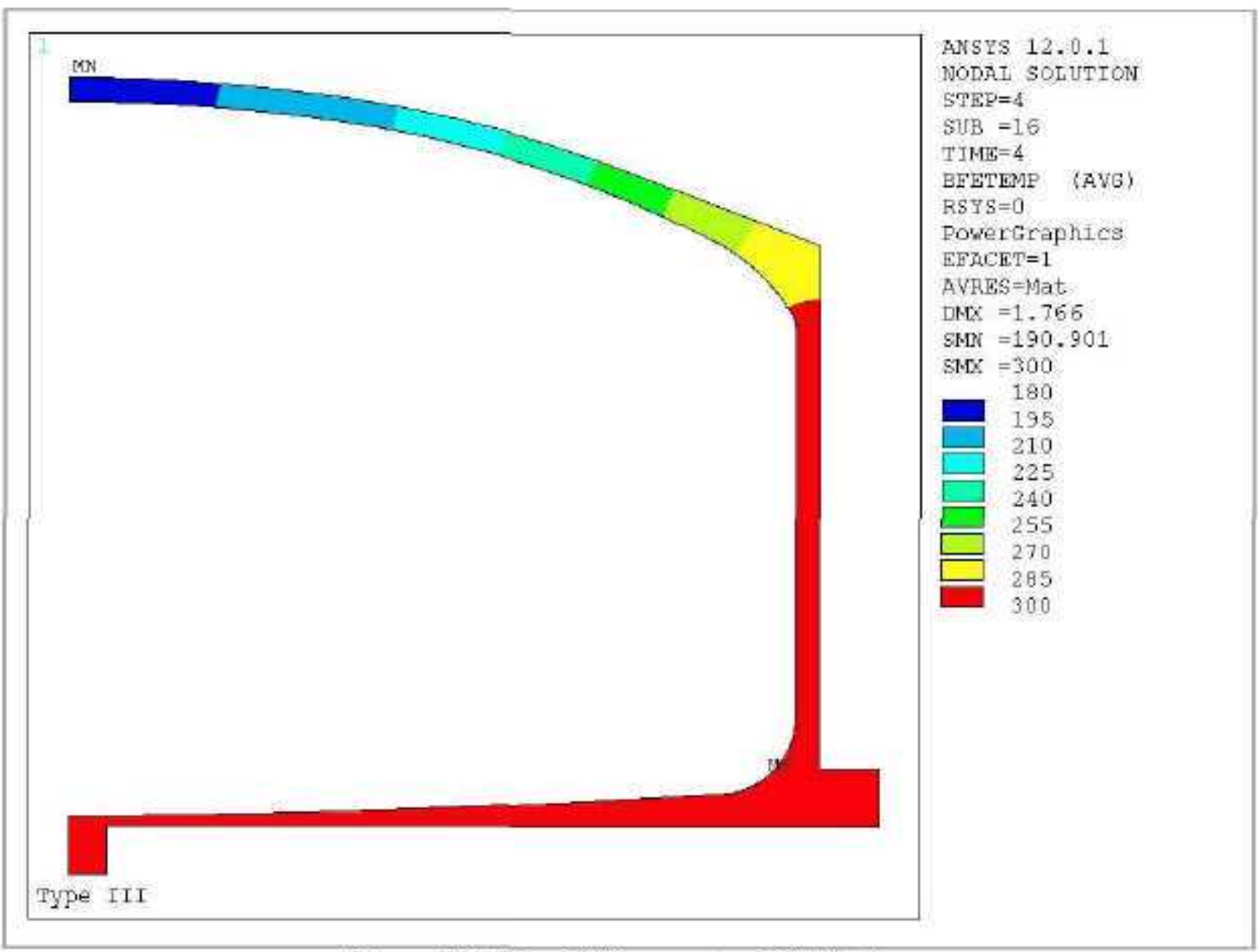

Figure 5.29 Type III Temperature Distribution

Structural integnity evaluation of the SST will follow the provisions of ACI-349-06. The code specifies load combinations with appropriate load factors to calculate section demands, which are evaluated against section capacities based on geometry and material properties. The detailed analyses will document the complete ACI evaluation. However, for the current preliminary analyses, only the concrete section demands under nominal loading will be presented for the more general purpose of determining the effect of thermal loads on section demands Figure 5.30 shows the location of the ACI sections. 


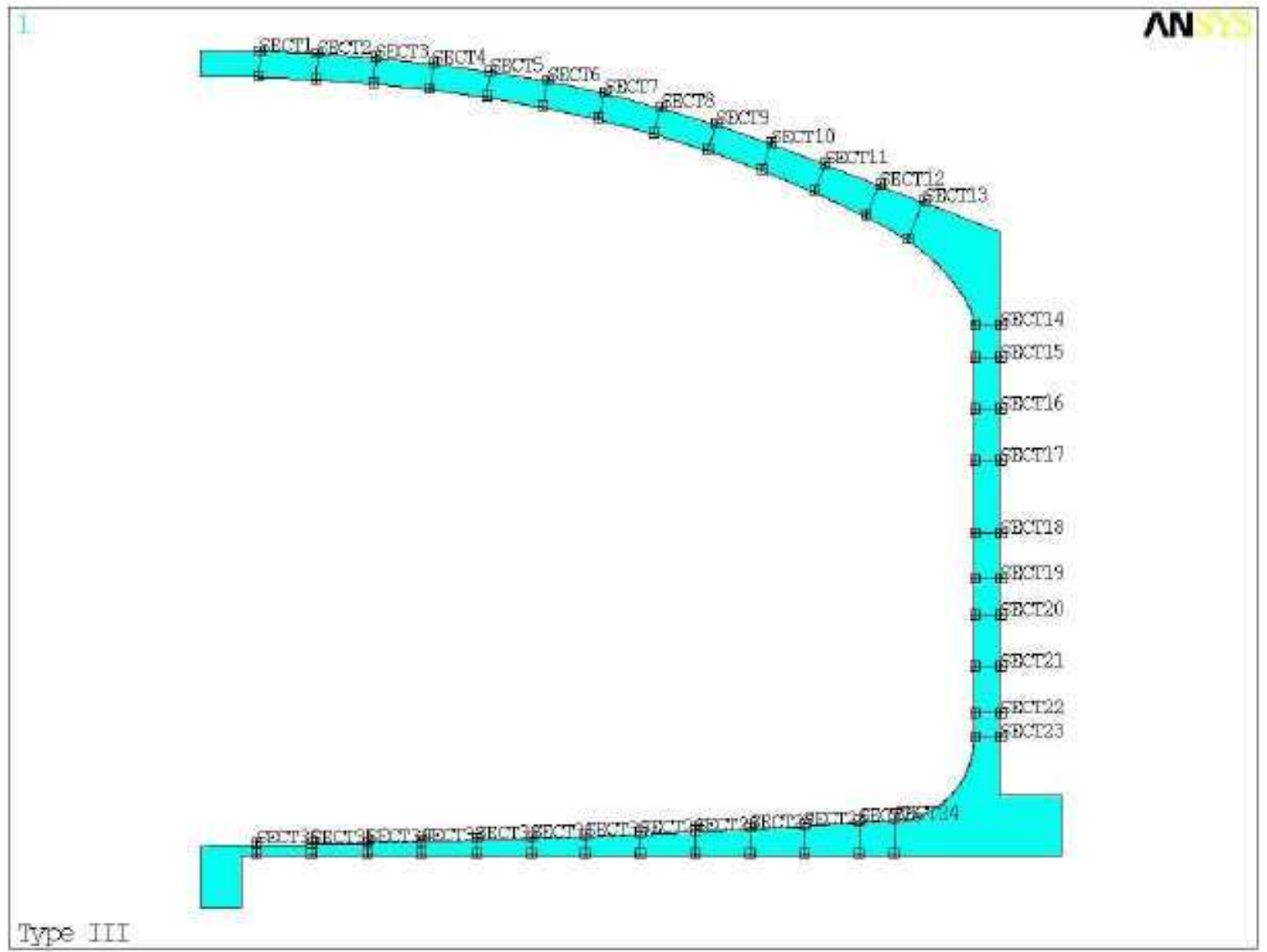

Figure 5.30 Type III ACI Section Location

Figures 31 through 35 show the effect of thermal loads on the meridional force, meridional moment, hoop force, hoop moment and shear force, respectively.

In general, the thermal expansion of the concrete is resisted by the soil, resulting in an increase in compressive forces. The dome response is complicated by the curvature and slip between the dome and soil. The complete $\mathrm{ACI}$ evaluation will be conducted in the detailed analysis. 
RPP-46644, Rev.0

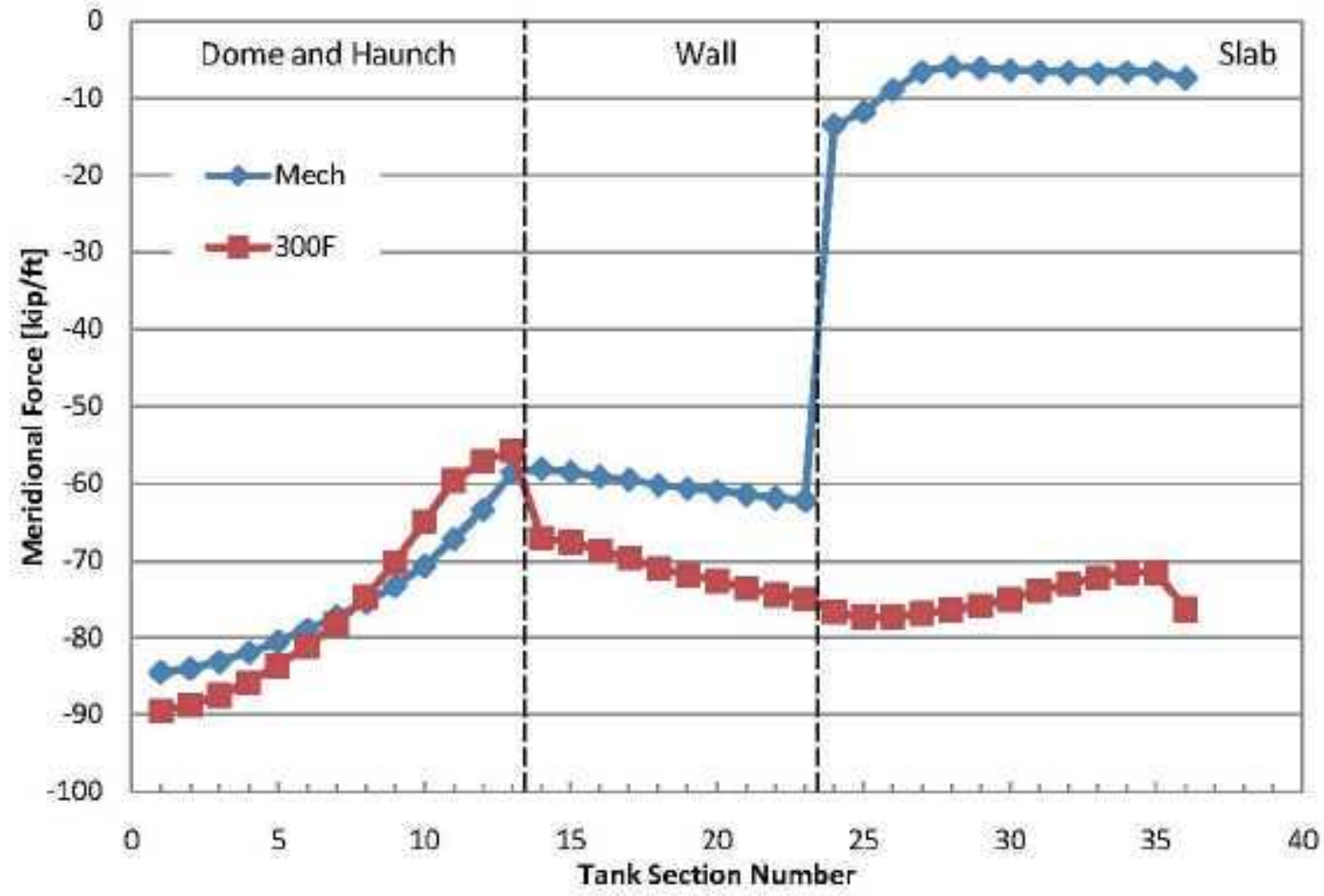

Figure 5.31 Type III Meridional Force

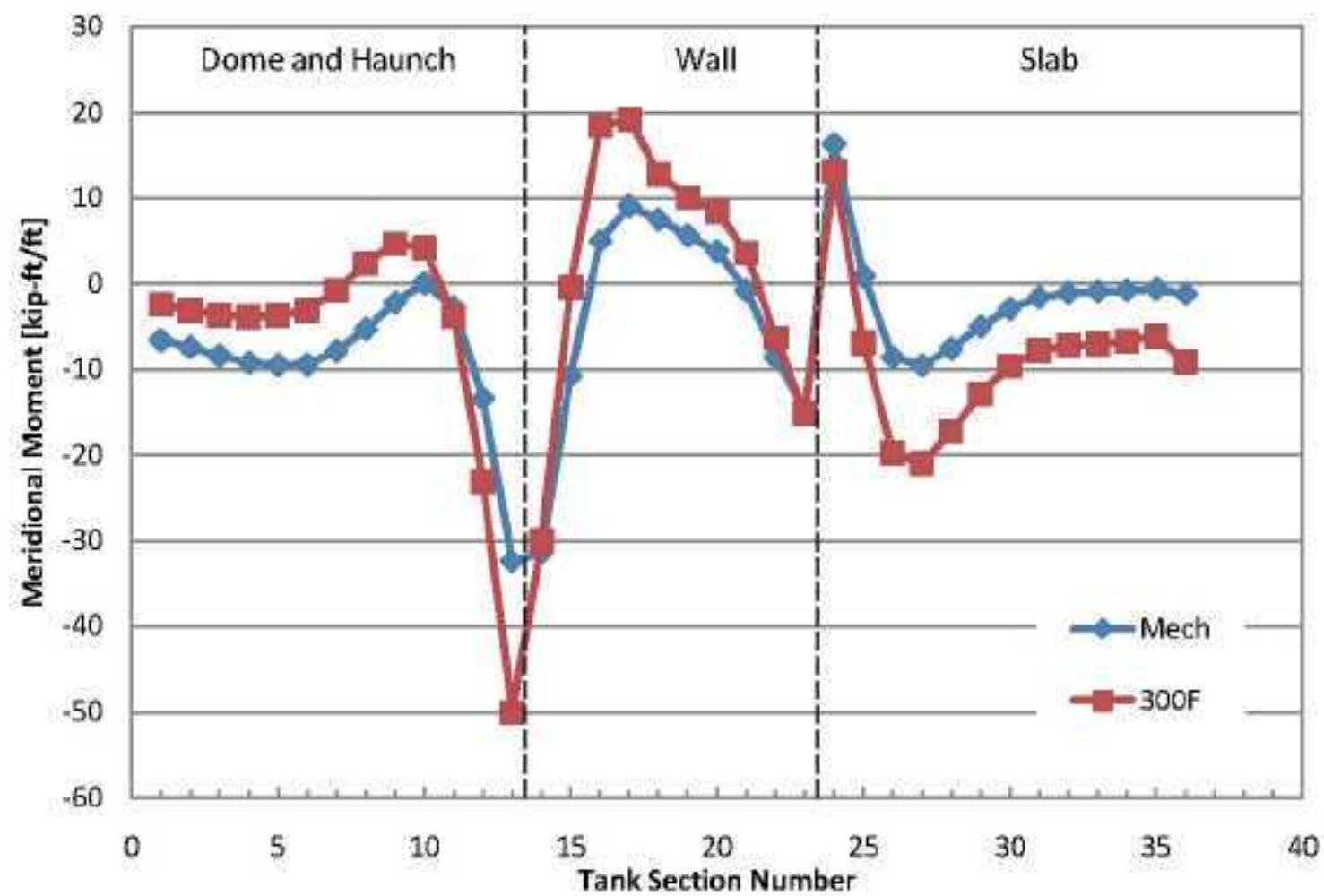

Figure 5.32 Type III Meridional Moment 
RPP-46644, Rev.0

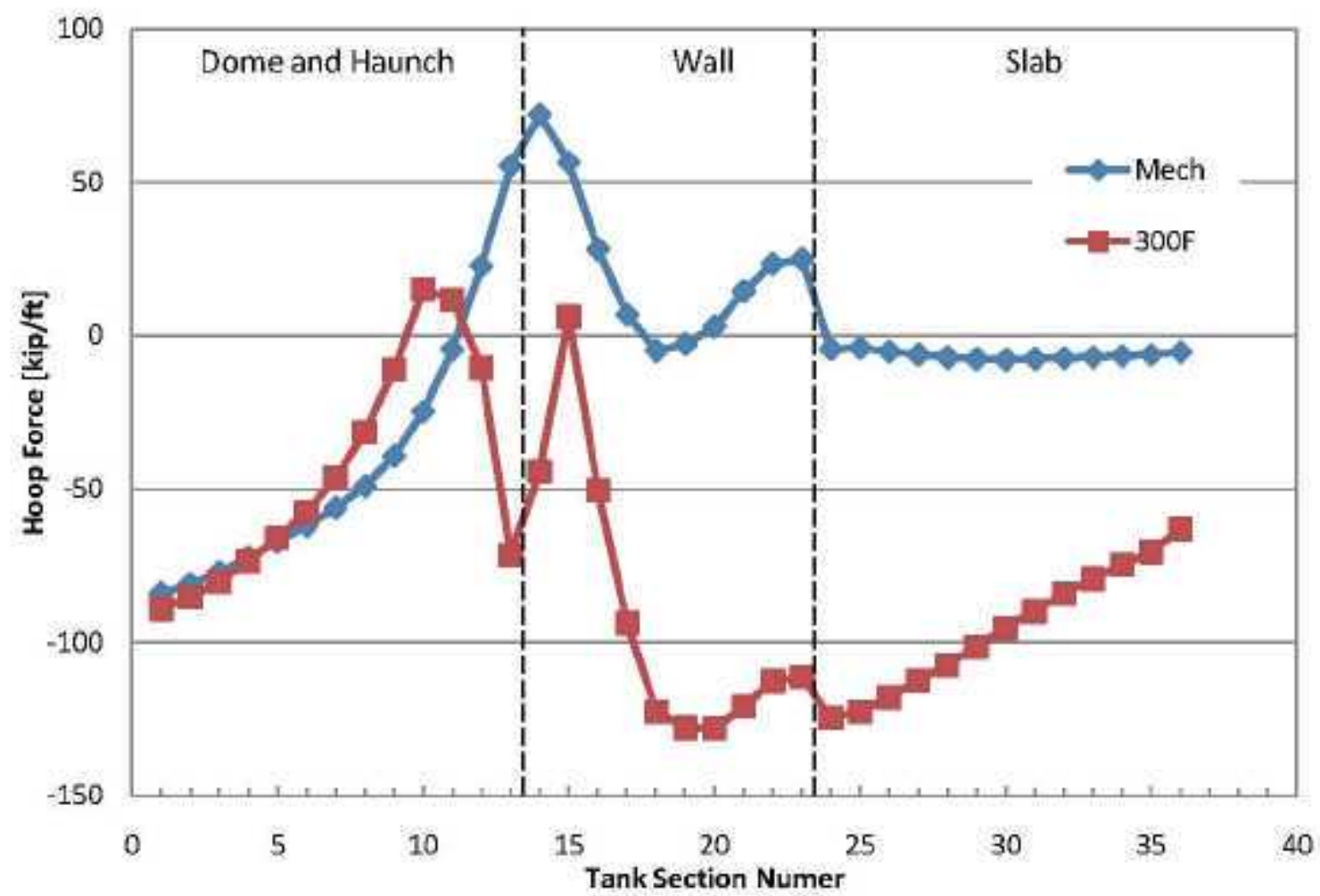

Figure 5.33 Type III Hoop Force

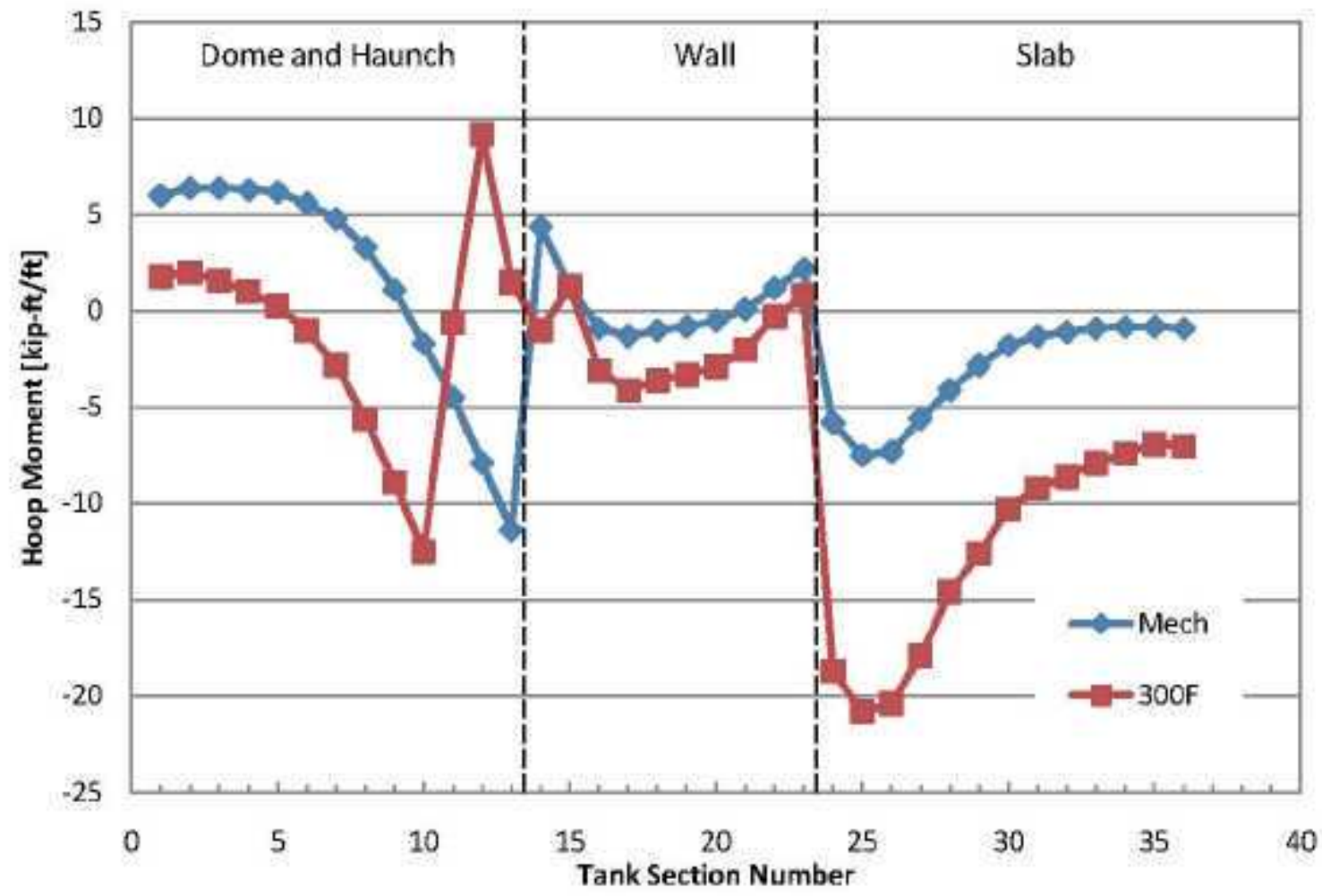

Figure 5.34 Type III Hoop Moment 


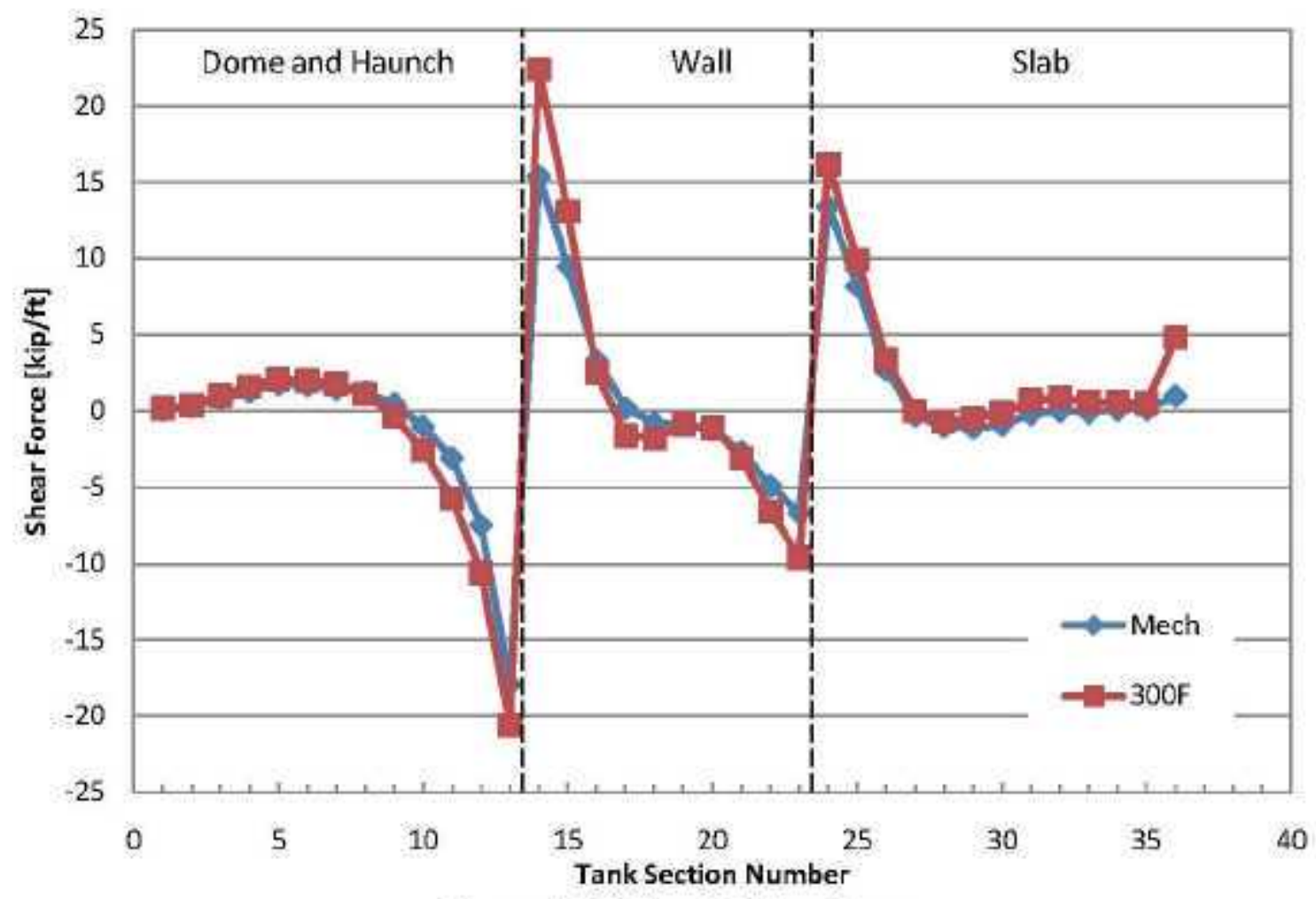

Figure 5.35 Type III Shear Force

\subsubsection{Type II Thermal Modeling}

Structural analyses were performed for two specific times in the estimated thermal history of C-106. First, the mechanical loads of gravity, waste, uniform surface load, and concentrated surface load were applied to the Type II tank model. The waste loads corresponded to a 1.7 specific gravity waste at a height from either January 1972 or October 1978. Next, a steady-state thermal analysis was performed on the tank geometry. In the steady-state thermal analysis, the temperature, corresponding to the January 1972 or October 1978 temperature profile, was prescribed to the inside of the concrete tank.

Additionally, far-field thermal boundary conditions similar to the previous thermal models described were applied. The steady-state thermal problem was solved to find the temperature field throughout the concrete and soil. Figure 5.36 shows the resulting temperature fields for both the January 1972 and October 1978 thermal analyses. These temperature fields were then applied as thermal nodal loads to the existing mechanical-only analysis for the January 1972 and October 1978 cases to get the mechanical plus thermal loads results. 


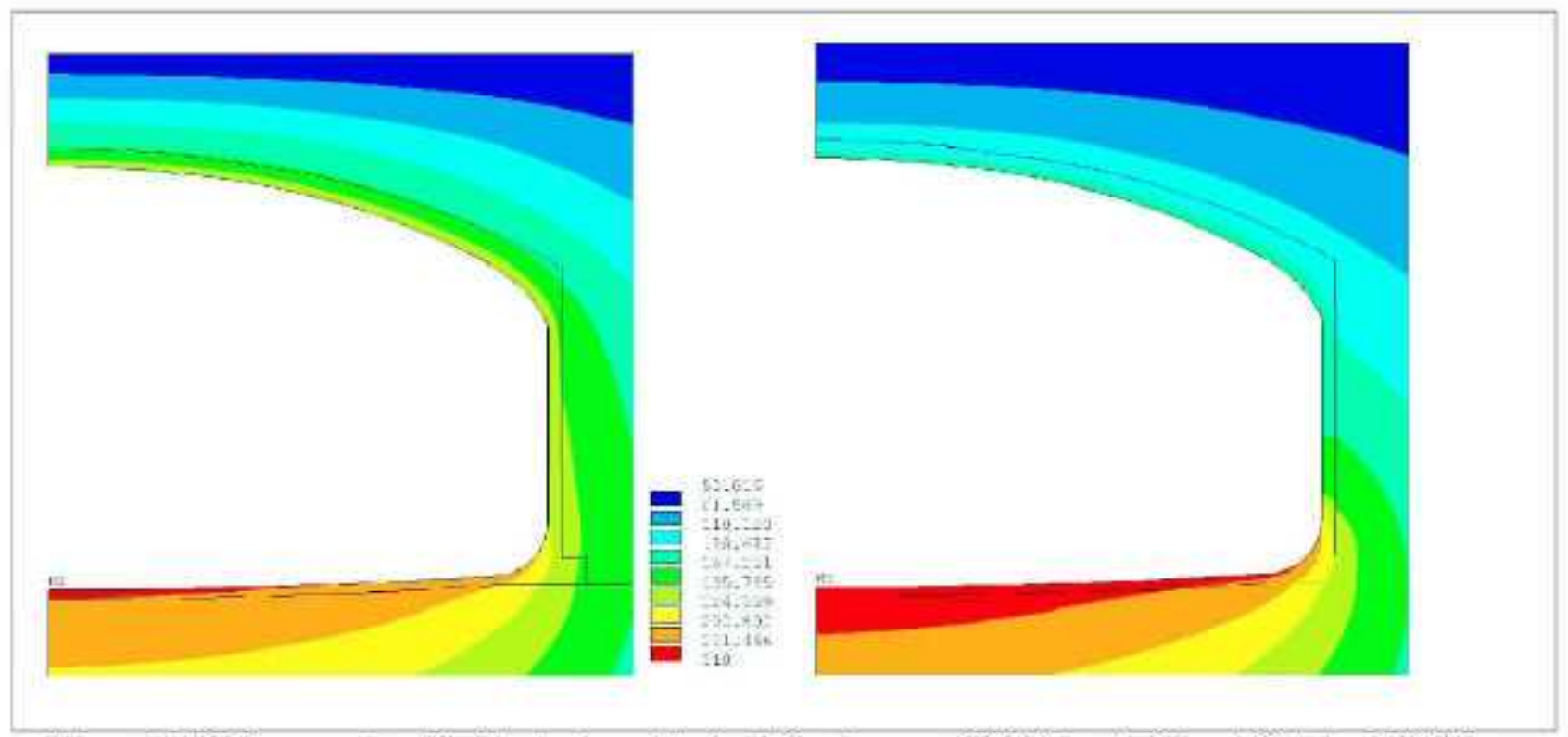

Figure 5.36 Temperature Profile Assigned to Tank for January 1972 Case (left) and October 1978 Case (right). Peak temperatures for January 1972 and October 1978 are $290^{\circ} \mathrm{F}$ and $310^{\circ} \mathrm{F}$, respectively.

Figure 5.37 shows the radial stress for the January 1972 and October 1978 mechanical loads only and for mechanical plus thermal loads cases. The peak tensile radial stress is smaller, while the peak compressive radial stress is larger under mechanical plus thermal loads. Hoop stress is shown in Figure 5.38 for January 1972 and October 1978 mechanical loads only and mechanical plus thermal loads cases. Again, the hoop stress is higher throughout the structure in both mechanical plus thermal loads when compared to structural only loads. The mechanical plus thermal load cases indicate a significant redistribution of hoop stresses in the haunch region. Figure 5.39 shows the vertical stress for the January 1972 and October 1978 mechanical loads only and mechanical plus thermal loads cases. The vertical stress contours indicate that there is an area of larger vertical stress on the outside of the lower wall that is only present under mechanical plus thermal loads. 
RPP-46644, Rev.0

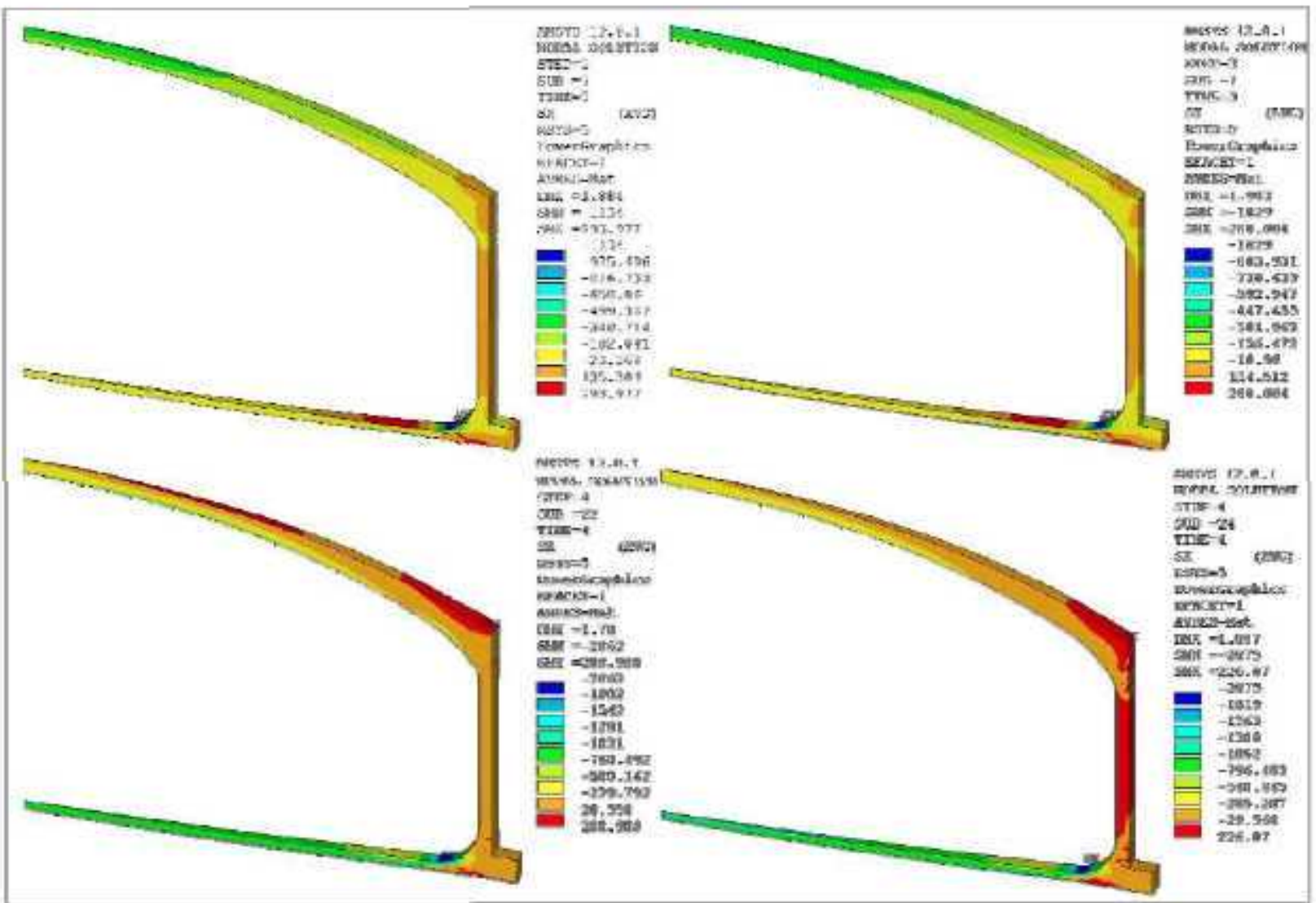

Figure 5.37 Radial Stresses for January 1972 Mechanical Loads Only (top left), October 1978 Mechanical Loads Only (top right), January 1972 All Loads (bottom left), and October 1978 All Loads (bottom right). 


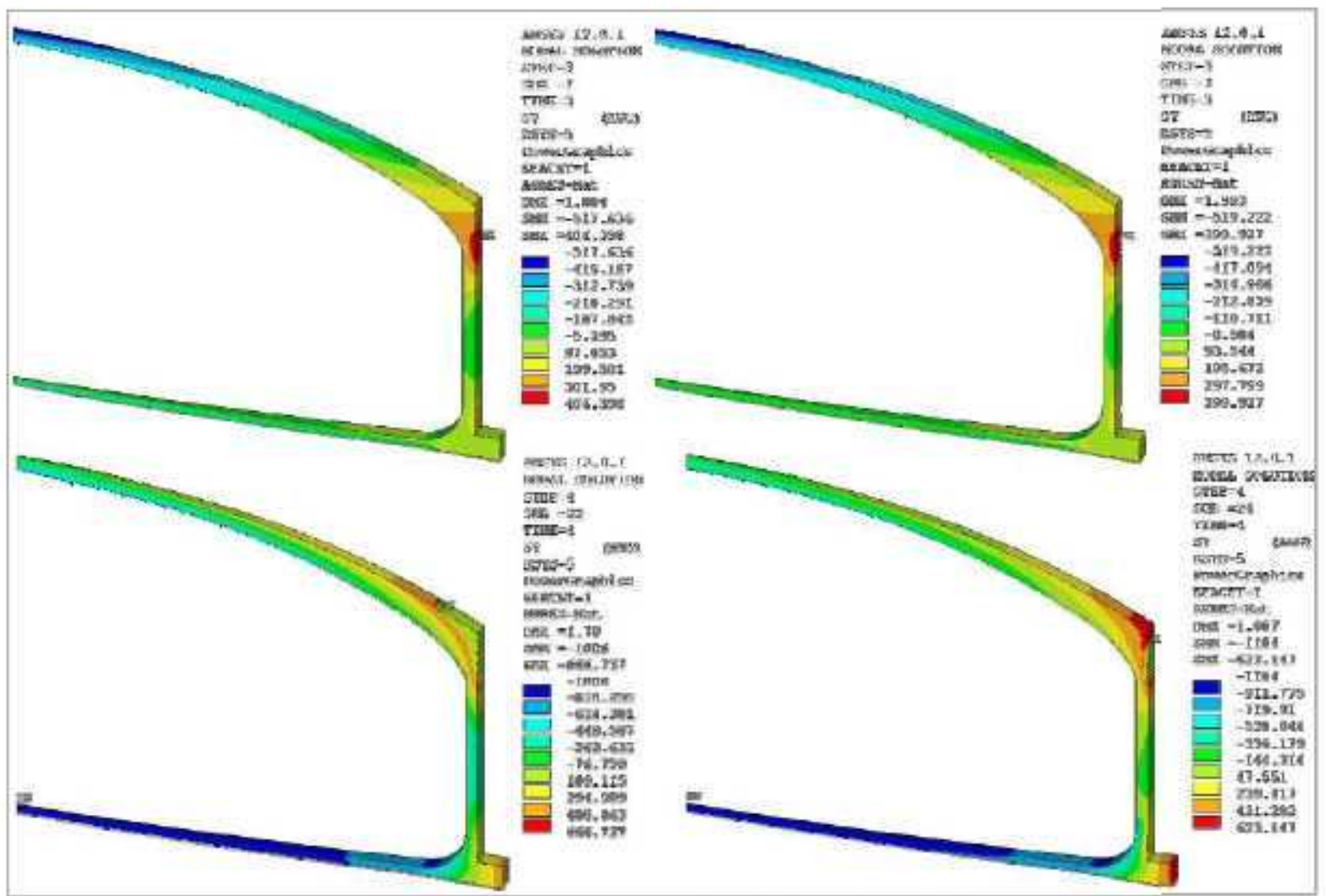

Figure 5.38 Hoop Stresses for Jamuary 1972 Mechatical Loads Only (top left), October 1978 Mechanical Loads only (top right), Jamuary 1972 All Loads (bottom left), and October 1978 All Loads (bottom right). 


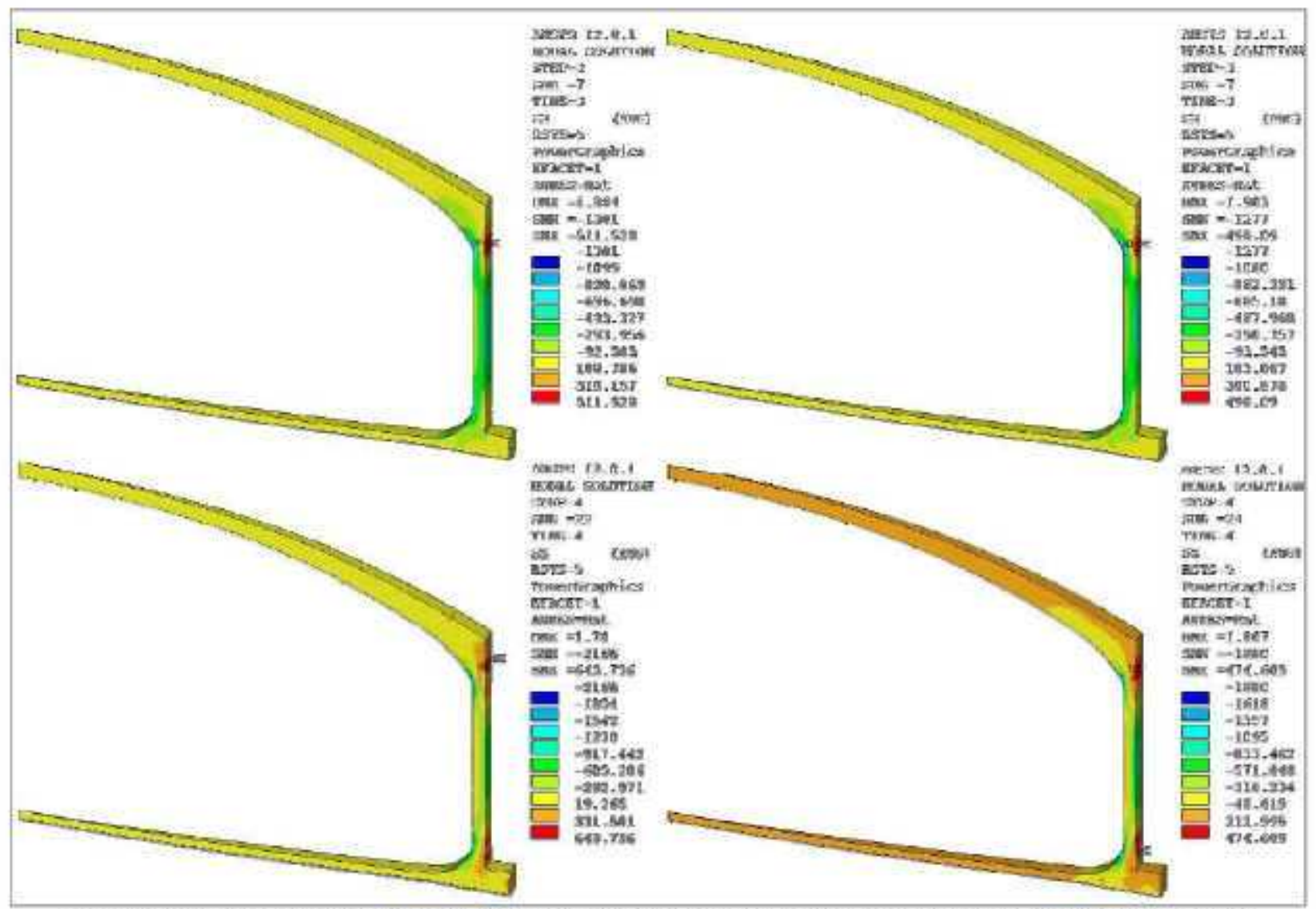

Figure 5.39 Vertical Stresses for January 1972 Mechanical Loads Only (top left), October 1978 Mechanical Loads Only (top right), January 1972 All Loads (bottom left), and October 1978 All Loads (bottom right).

Figure 5.40 shows the cracking at element integration points within the concrete for mechanical loads only and mechanical plus themal loads in Jamuary 1972 and October 1978 . It can be seen for both cases that the themal load introduces additional cracking in the haunch and in the outside of the lower wall. The October 1978 case has more cracking in the wall than the January 1972 case. Conversely, the January 1972 case has more cracking in the hannch than the October 1978 case. In both regions, the temperature profile with the higher thermal gradient, as seen by Figure 5.36, in the lower wall or the haunch leads to a higher number of cracks in the lower wall or haunch area. 


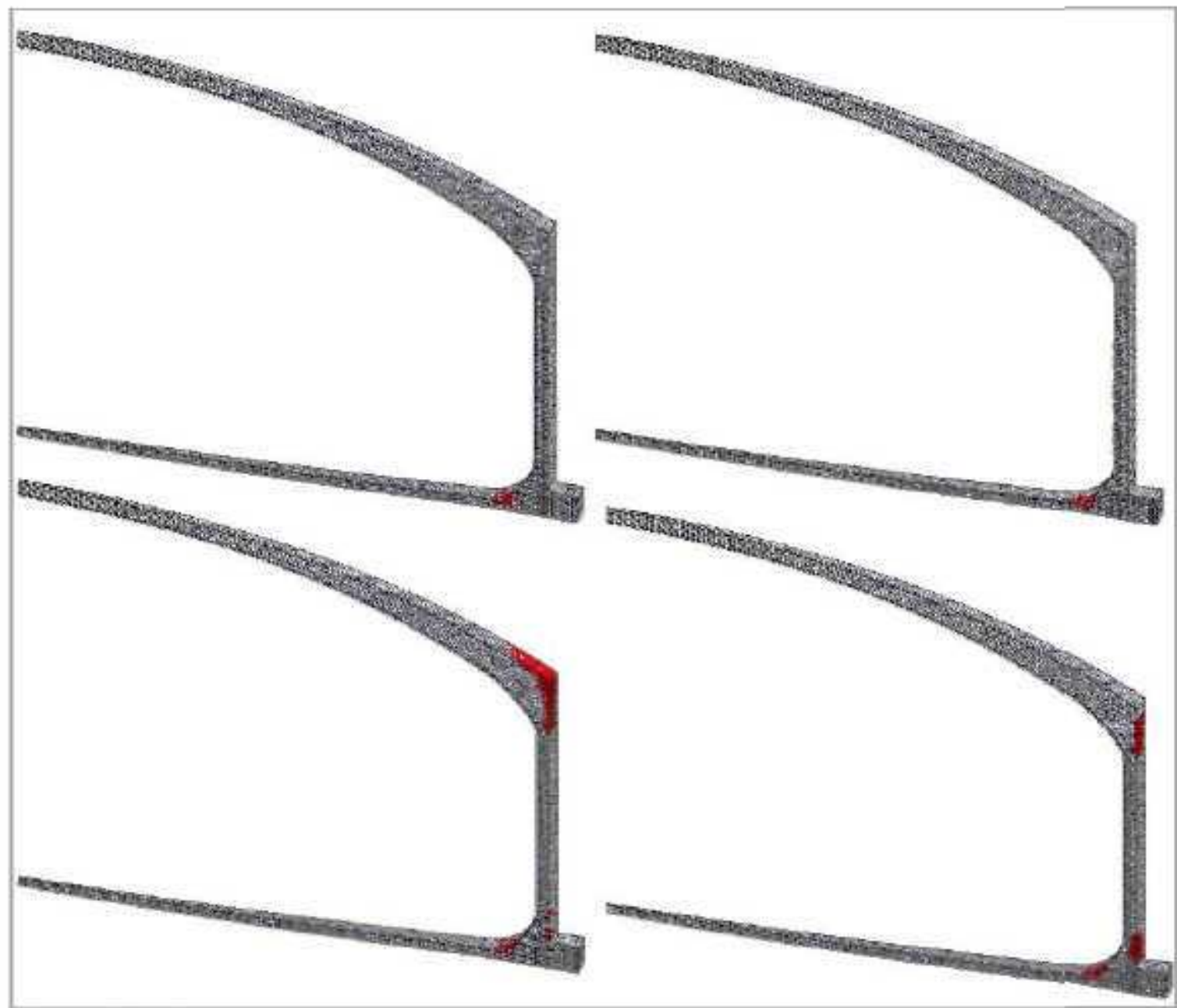

Figure 5.40 Concrete Cracking for Jamuary 1972 Mechanical Loads Only (top left), October 1978 Mechanical Loads Only (top right), January 1972 All Loads (bottom left), and October 1978 All Loads (bottom right)

The forces and moments were calculated for 53 sections throughout the concrete tank. These sections are shown in Figure 5.41. Section 1 is near the center of the dome, while Section 53 is near the center of the slab. Figures5.42 through 5.46 show the force and moment calculations through each of these sections for the Jamuary 1972 and October 1978 mechanical only and mechanical phus thermal load cases. The shear force is similar between all four load cases, with the exception that in the lower wall and start of the footing, the peak shear force increase for the themal load cases. The meridional force is slightly more compressive for the cases with themal loads through the dome, haunch, and wall and significantly more compressive in the footing and foundation. The meridional moment is similar for all four cases with the themnal cases changing the sign of the moment in the dome and having larger peaks in the haunch and wall. The hoop force is generally more compressive for the cases with thermal loads, with this compressive difference increasing as the section numbers increase. The hoop moment is of opposite sign in the dome and haunch for cases with themal loads, compared to those without themal loads. In the wall and footing the hoop moment is similar between all four cases, with the thermal load cases having higher peak values near the bottom of the wall. 


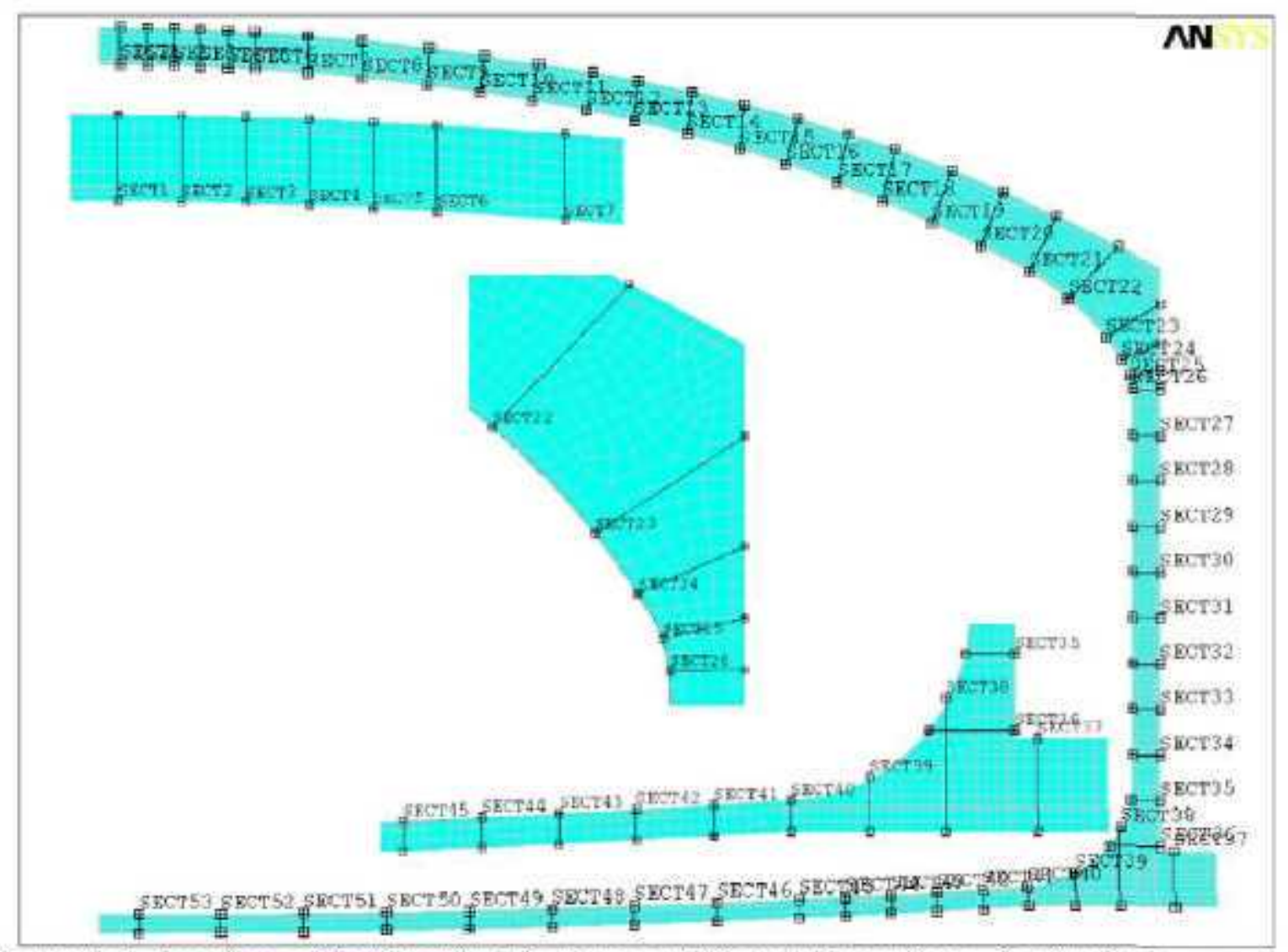

Figure 5.41 Locations of Sections Used for Force and Moment Evaluations, Sections in dome center, haunch, and outer footing are magnified for legibility.

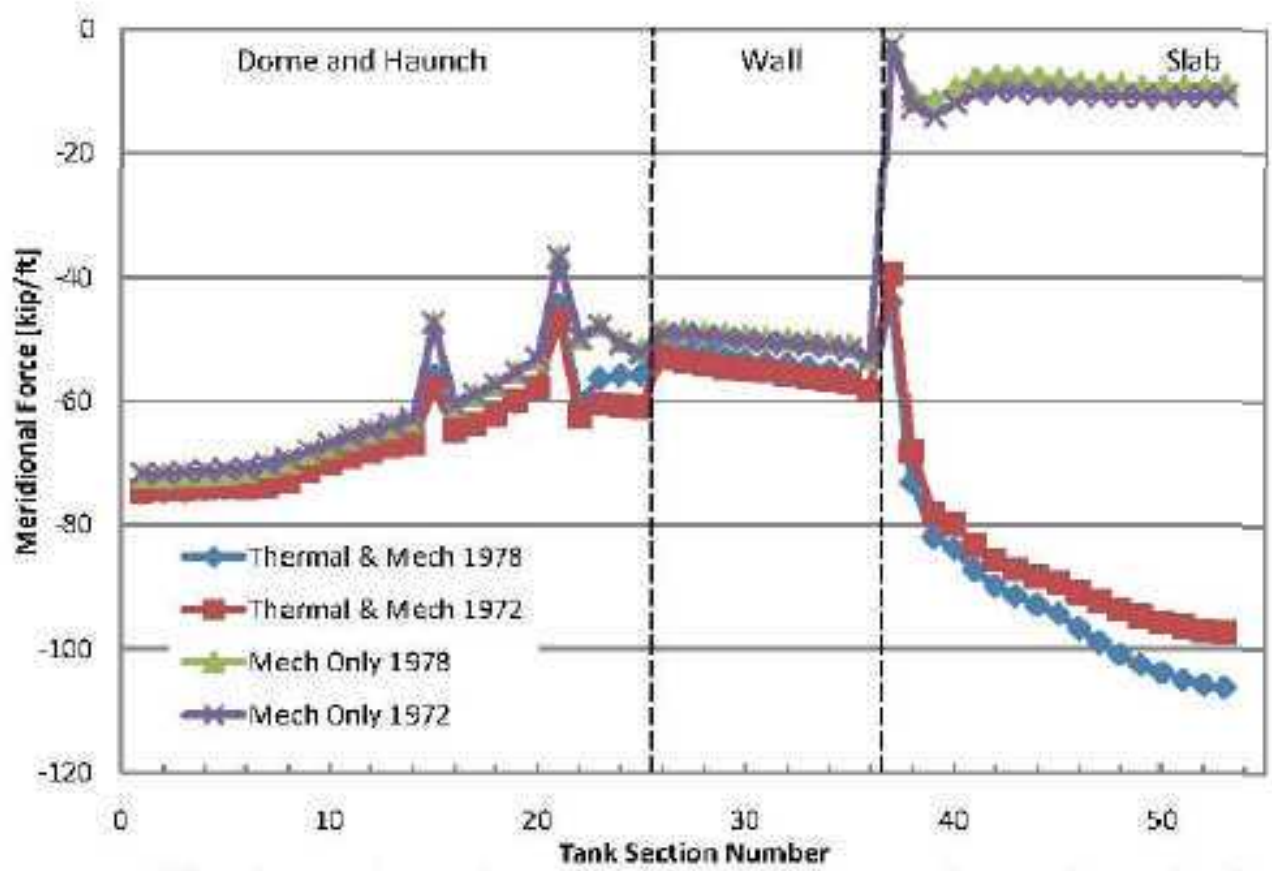

Figure 5.42 Meridional Force for Each Section Number for Cases of 1978 Thermal and Mechanical Loads, 1972 Thermal and Mechanical Loads, 1978 Mechanical Loads Only, and 1972 Mechanical Loads Only 
RPP-46644, Rev.0

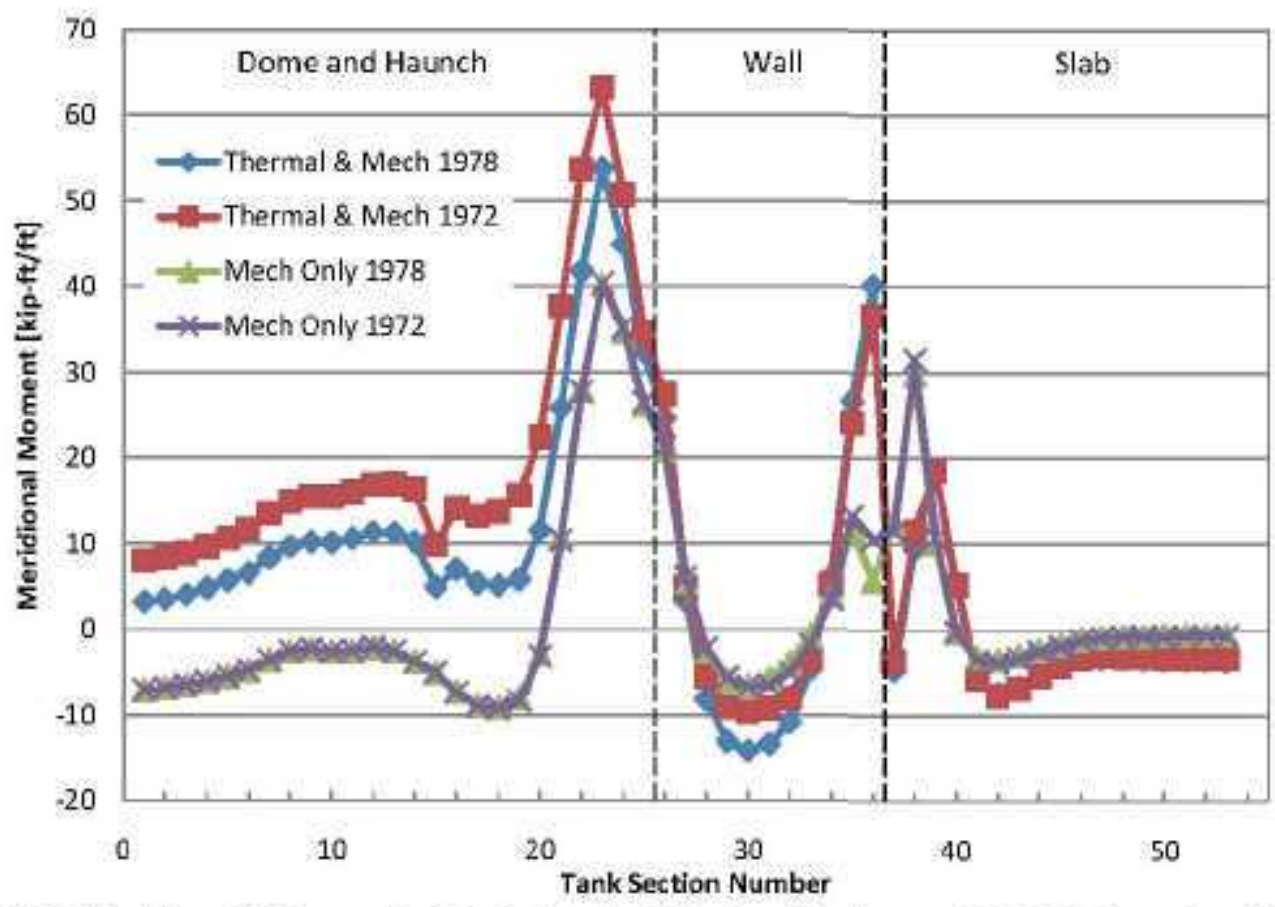

Figure 5.43 Meridional Moment for Each Section Number for Cases of 1978 Thermal and Mechanical Loads, 1972 Thermal and Mechanical Loads, 1978 Mechanical Loads Only, and 1972 Mechanical Loads Only

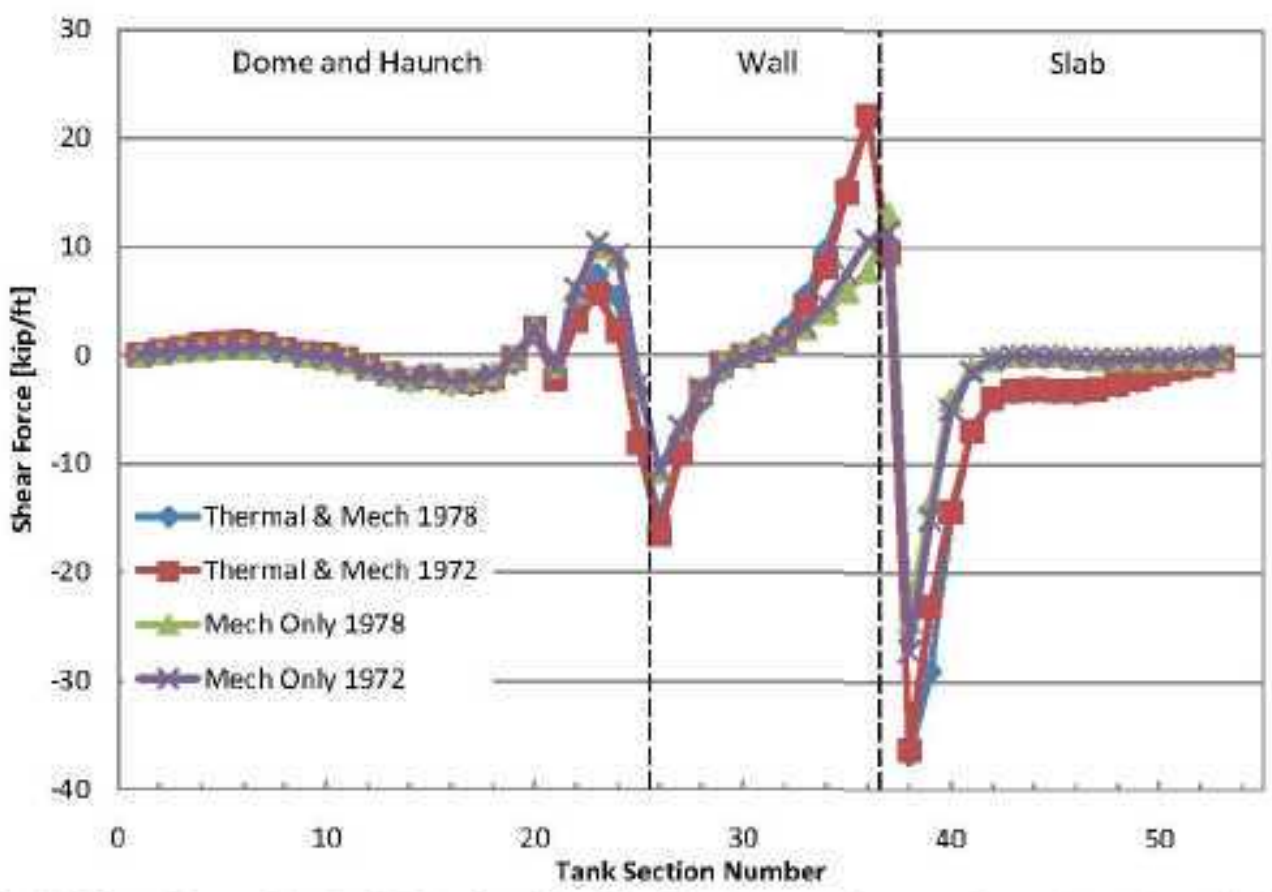

Figure 5.44 Shear Force for Each Section Number for Cases of 1978 Thermal and Mechanical Loads, 1972 Thermal and Mechanical Loads, 1978 Mechanical Loads Only, and 1972 Mechanical Loads Only 


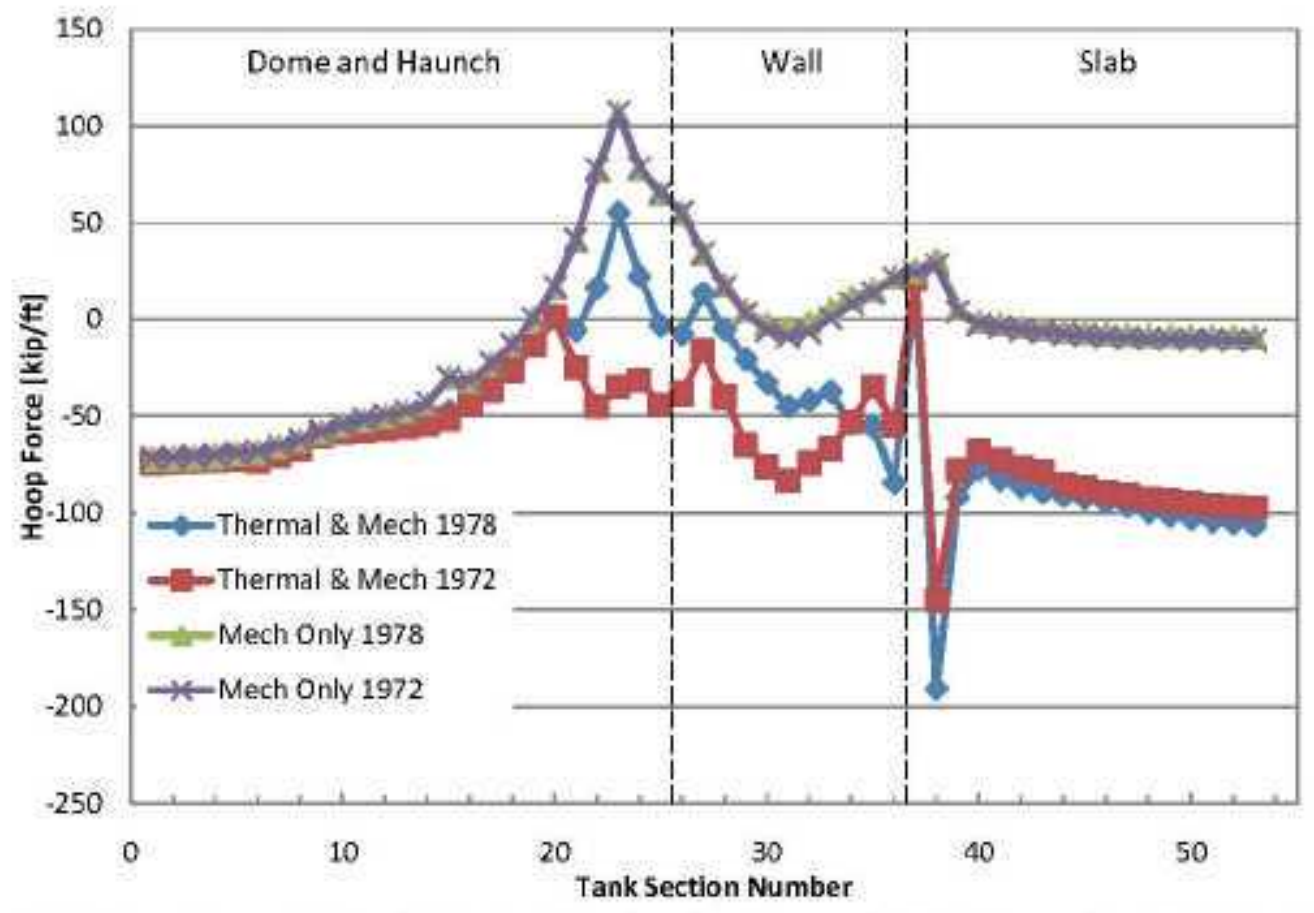

Figure 5.45 Hoop Force for Each Section Number for Cases of 1978 Thermal and Mechanical Loads, 1972 Thermal and Mechanical Loads, 1978 Mechanical Loads Only, and 1972 Mechanical Loads Only

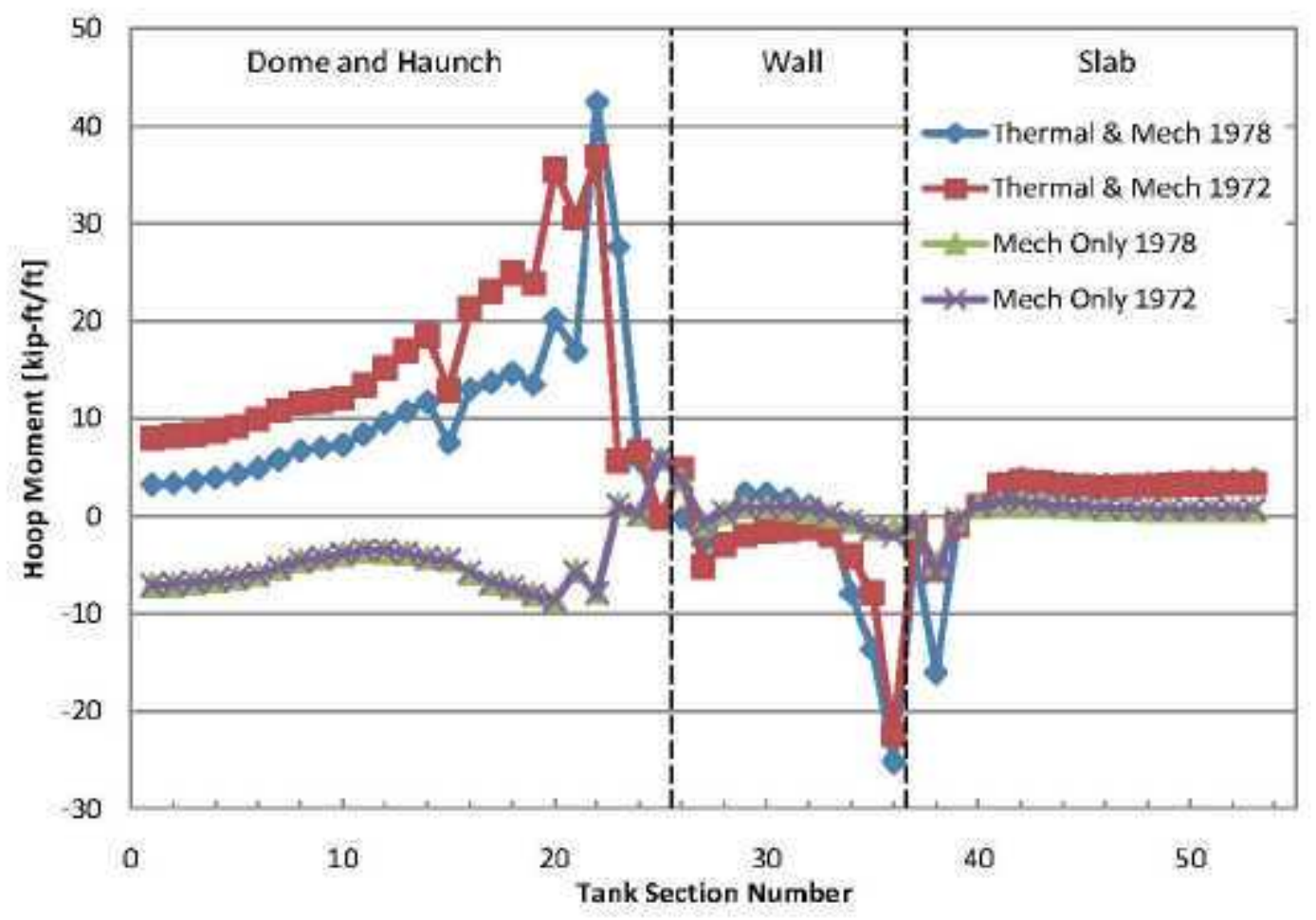

Figure 5.46 Hoop Moment for Each Section Number for Cases of 1978 Thermal and Mechanical Loads, 1972 Thermal and Mechanical Loads, 1978 Mechanical Loads Only, and 1972 Mechanical Loads Only 


\subsubsection{Type I Thermal Modeling}

The Type I model was based on dimensions taken from draxings D-20, D-21, and D-22. The steel liner was not included in the model. The two degree ANSYS slice model of the tank is shown in Figure 5.47. The model uses SOLID65 elements for the concrete and SOLID 185 elements for the soil.

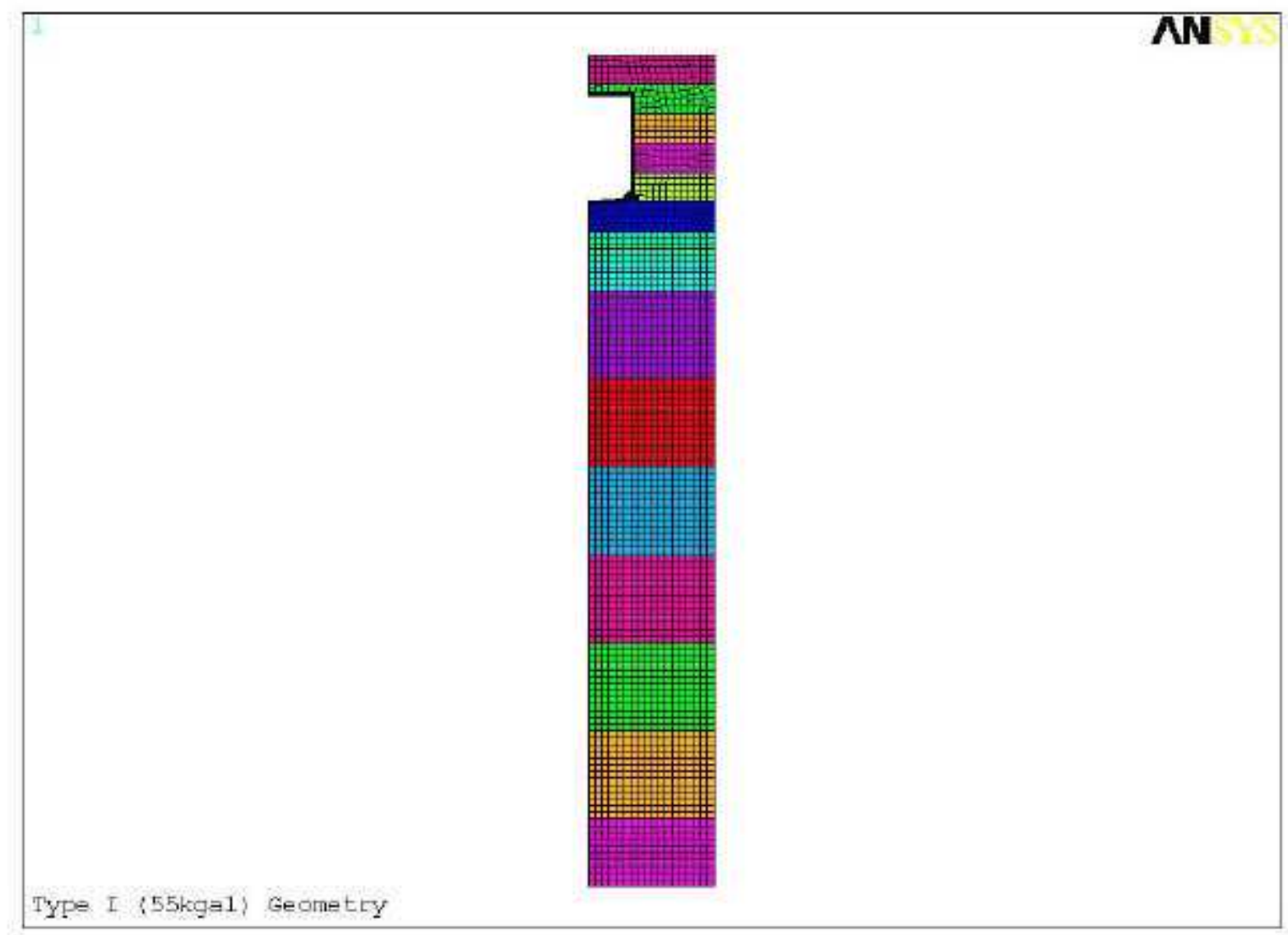

Figure 5.47 Type I Model Element Plot

The soil extends to a radius of 30 feet, approximately three times the tank radius. The soil depth is 168 feet below the foundation. The soll cover is nine feet at the center of the dome, as reported in Table A. 13 of RPP-10435.

The material properties for the concrete and soil are sumunarized in the SST Evaluation Criteria report. Temperature dependent elastic moduli and nominal tensile strengths were used for the concrete. Concrete creep was not considered in this analysis.

Mechanical loads were applied in three load steps: gravity, waste load, and surface live loads. The waste depth was specified as 284 inches, as described above in the Temperature and Waste Profiles, Section 4.3.2. The surface live loads include a uniform $40 \mathrm{lb}^{2} \mathrm{ft}^{2}$ and a $200 \mathrm{kip}$ concentrated load at the center of the dome. The thermal load was applied in step 4 . The temperature peak waste temperat ure of 250 degrees Fahrenheit was prescribed over the full depth of the waste. The temperature distribution in the tank is shown in Figure 5.48. 


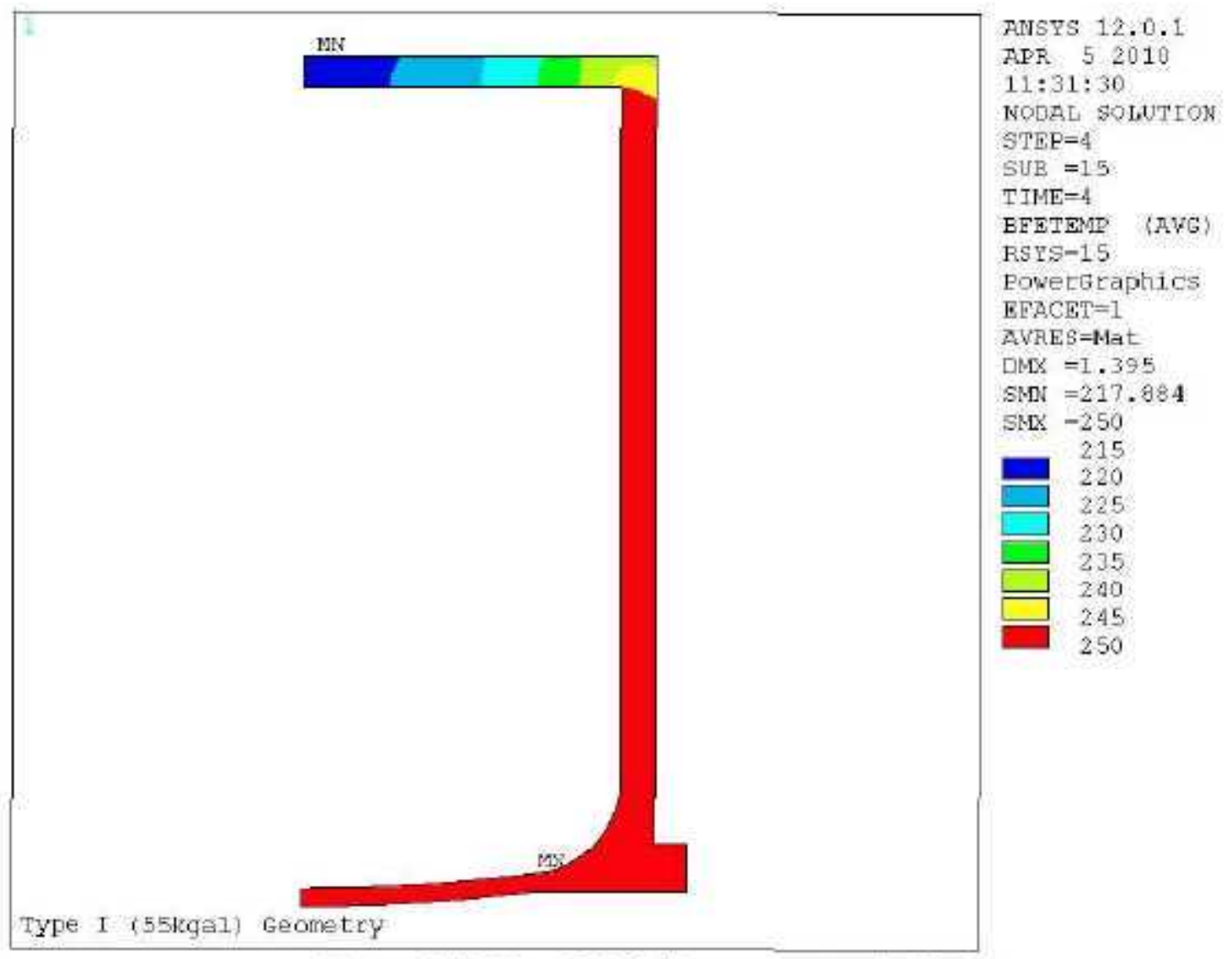

Figure 5.48 Type I Model Temperature Distribution

Figure 5.49 shows the location of the ACI sections. 


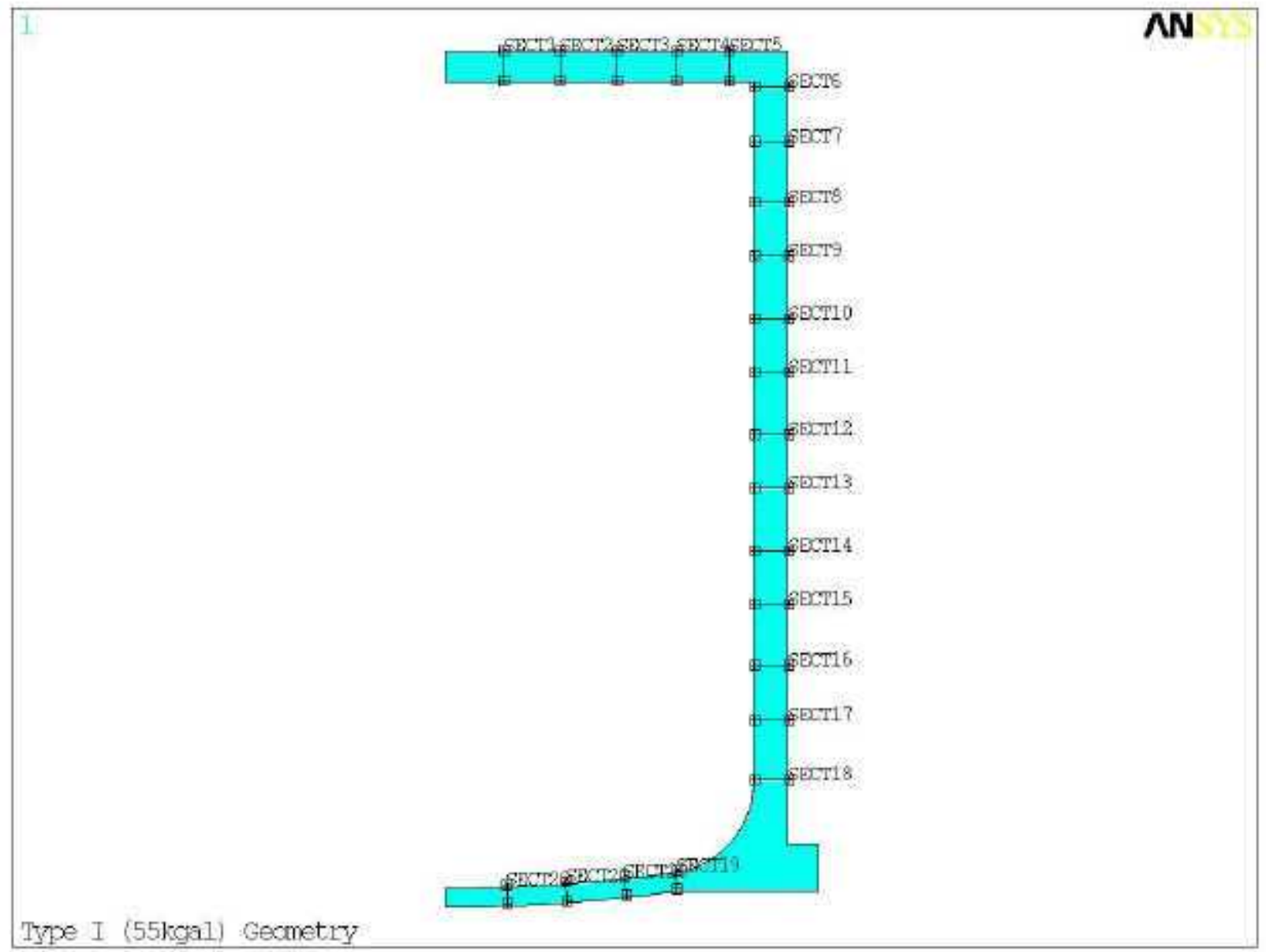

Figure 5.49. Type III ACI Section Location

Figures 5.50 through 5.54 show the effect of thermal loads on the meridional force, meridional moment, hoop force, hoop moment, and shear force, respectively.

In general, the thermal expansion of the concrete is resisted by the soil, resulting in an increase in compressive forces. The complete $\mathrm{ACl}$ evaluation will be conducted in the detailed analysis. 
RPP-46644, Rev.0

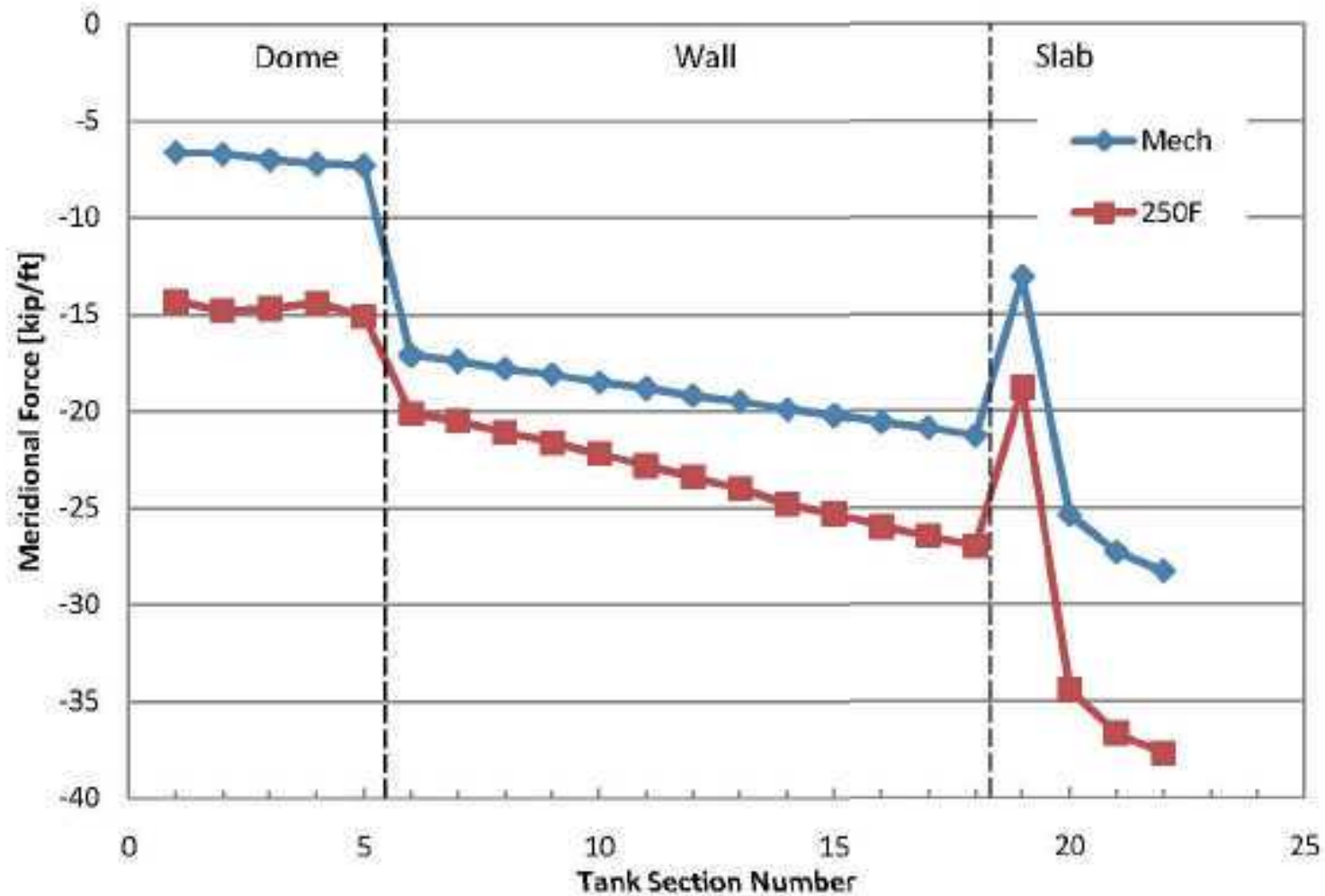

Figure 5.50 Type I Meridional Force

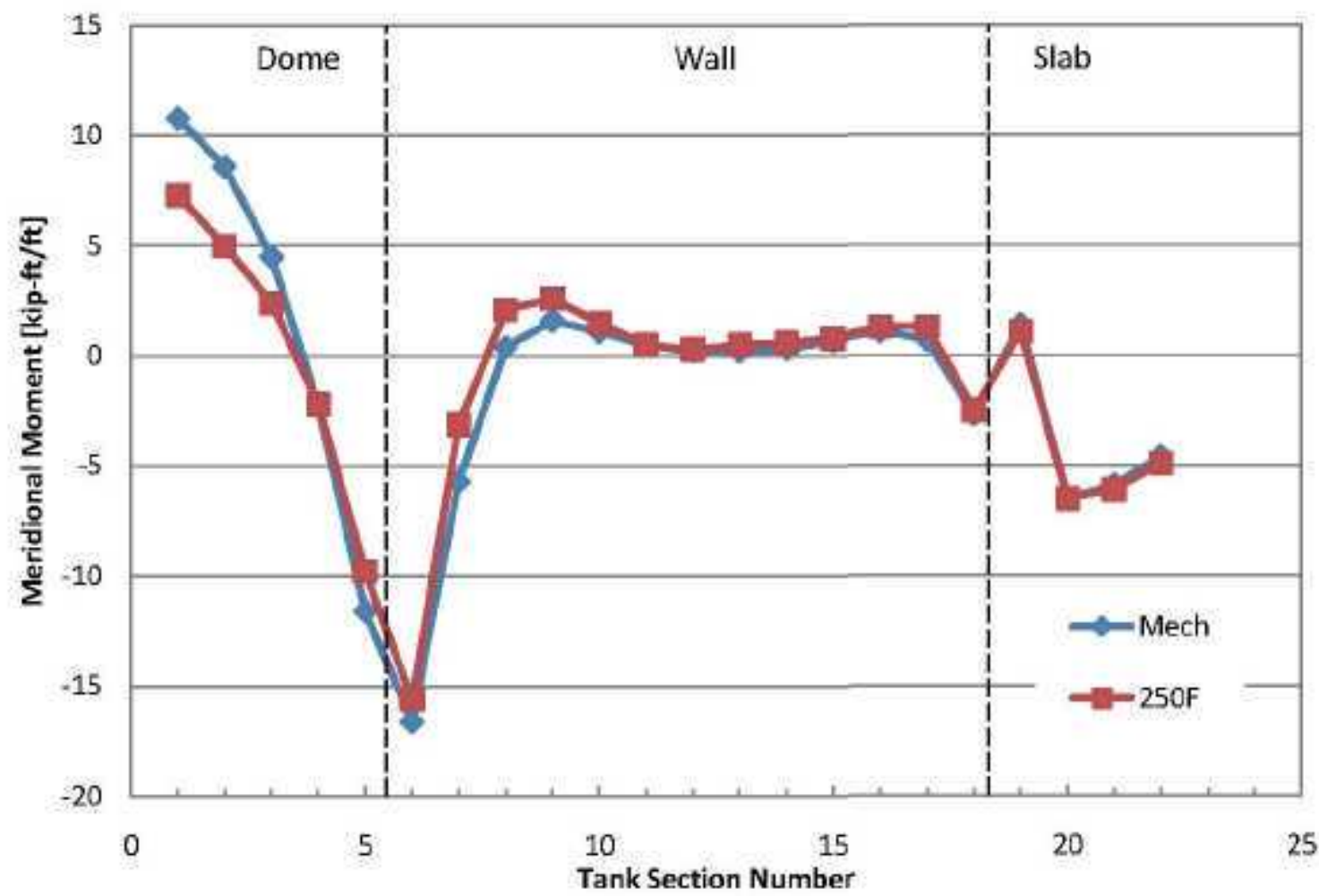

Figure 5.51 Type I Meridional Moment 
RPP-46644, Rev.0

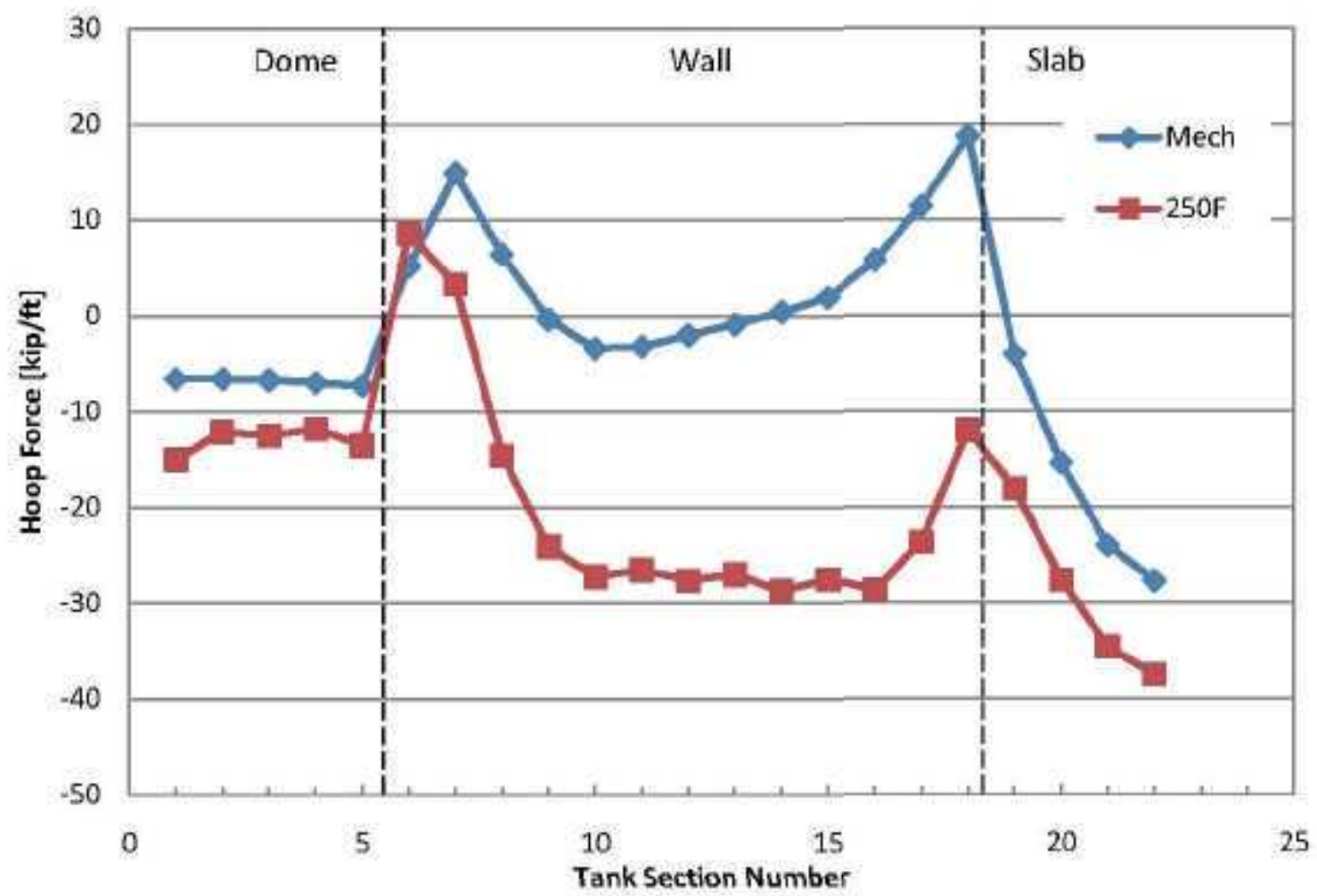

Figure 5.52 Type I Hoop Force

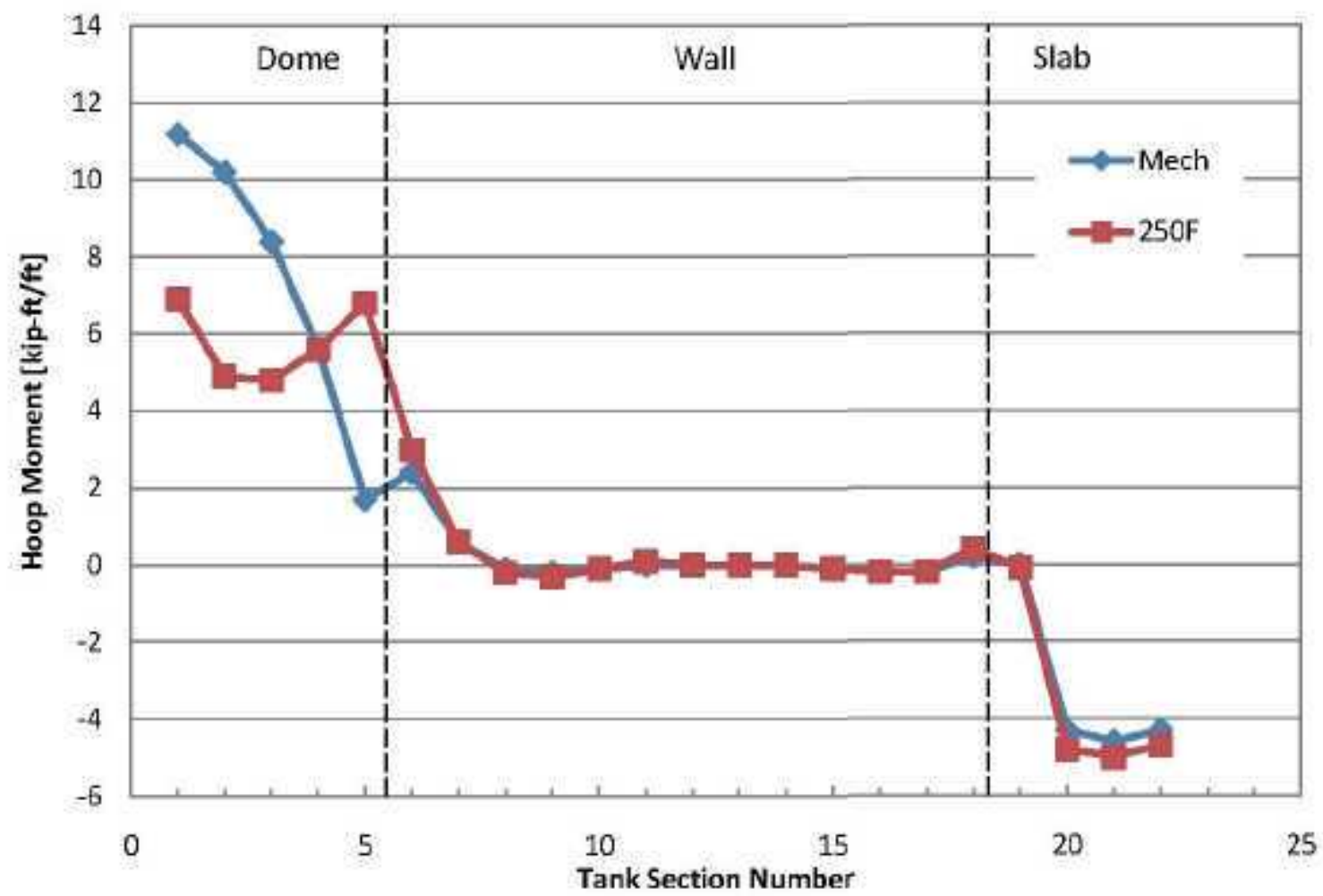

Figure 5.53 Type I Hoop Moment 


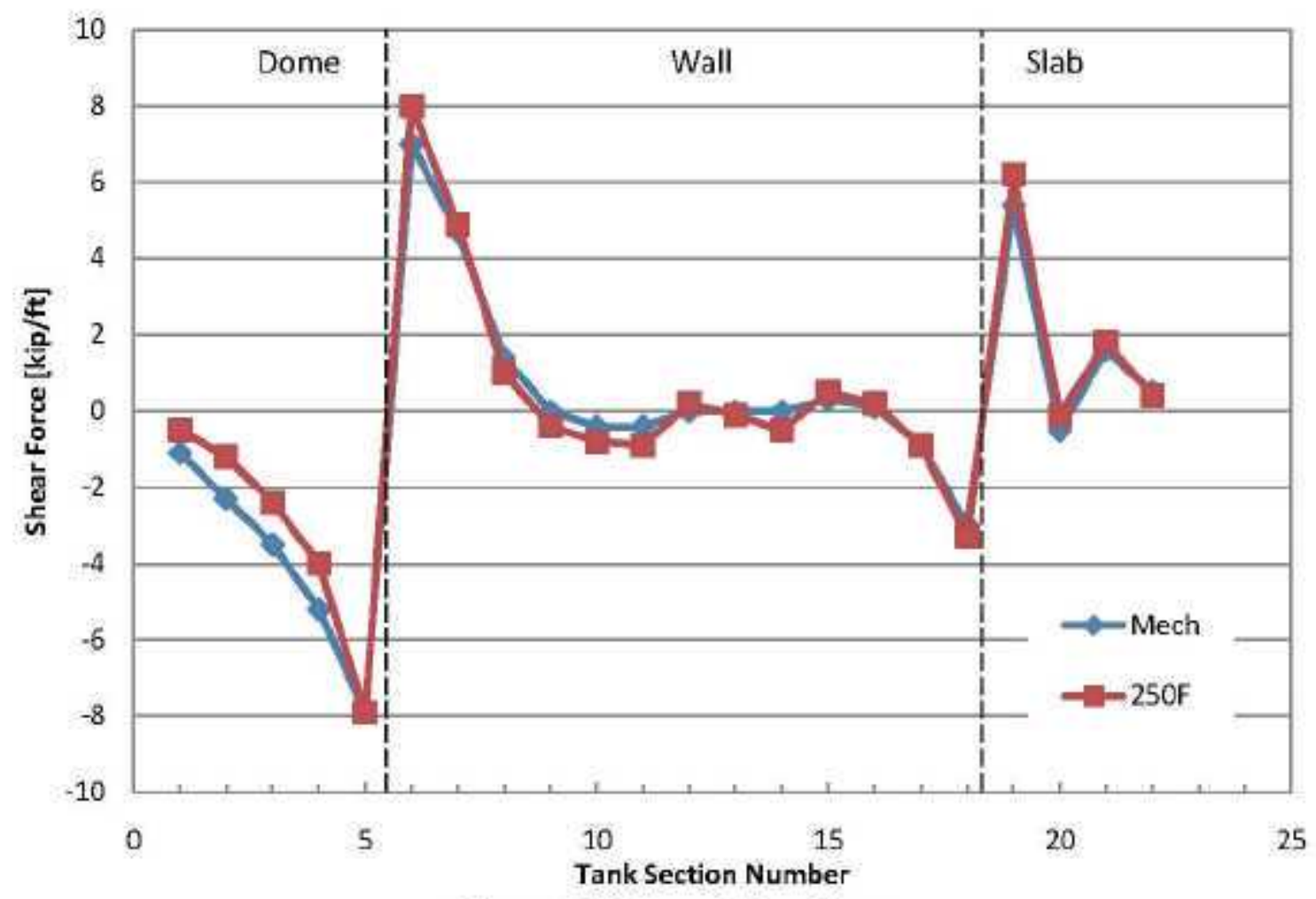

Figure 5.54 Type I Shear Force

\subsection{Waste Level Modeling Results}

As outlined in Section 4.3.4, two different waste level models were run using the existing C-107 Type II tank model. These runs each started with an empty tank configuration and then applied a load consistent with a tank either half full of waste or completely full of waste. Figures 5.55, 5.56, and 5.57 and show the radial stress, the hoop stress, and the vertical stress respectively for the empty tank, the half full tank, and the full tank, respectively. These figures show that the stress fields are extremely similar for all three cases. The empty tank always has the largest peak tensile and compressive values for these stresses, while the full tank always has the smallest peak tensile and compressive values for these stresses. 
RPP-46644, Rev.0

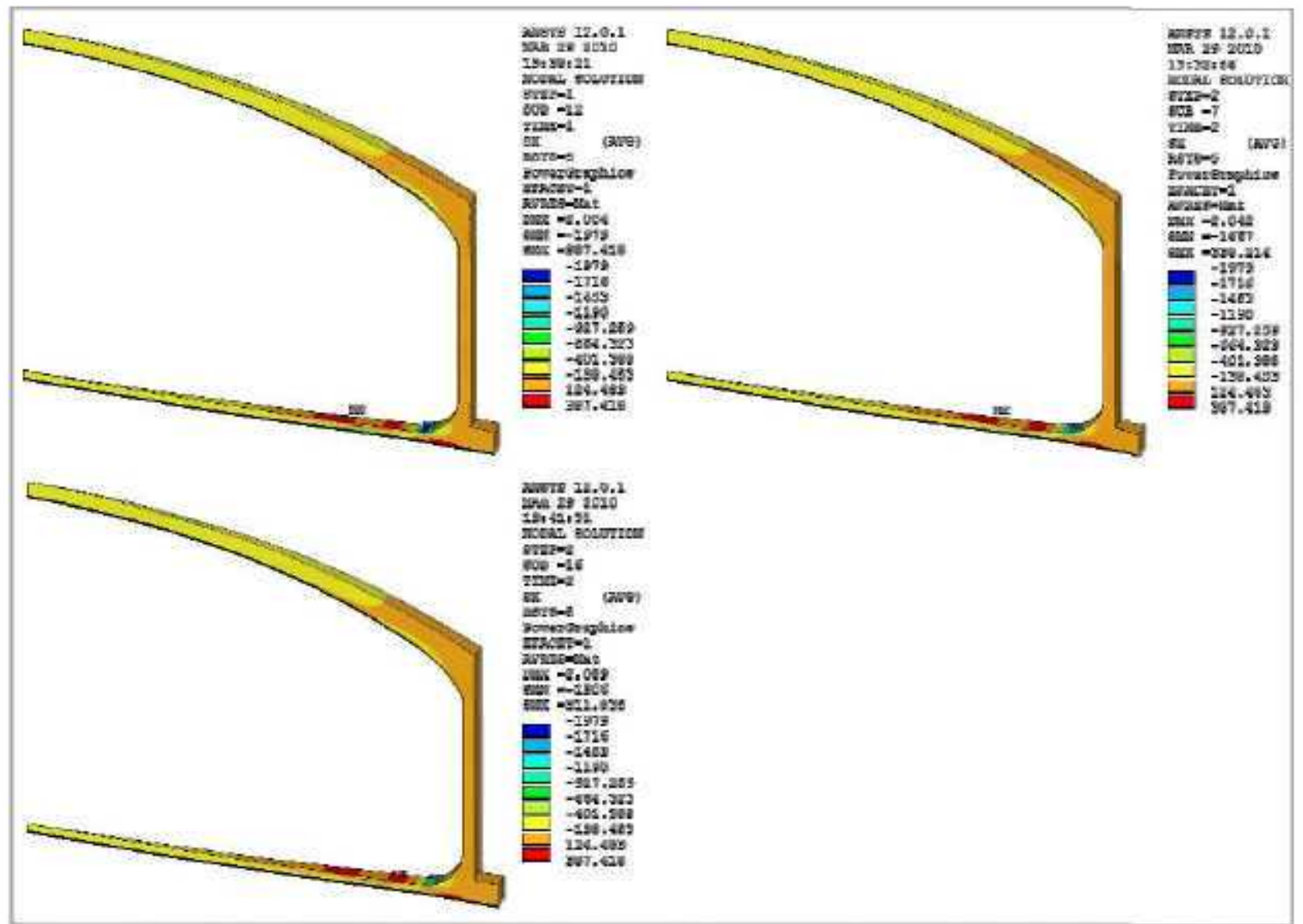

Figure 5.55 Radial Stress for Empty Tank (top left), Tank Half Full of Waste (top right), and Tank Full of Waste (bottomleft) 
RPP-46644, Rev. 0

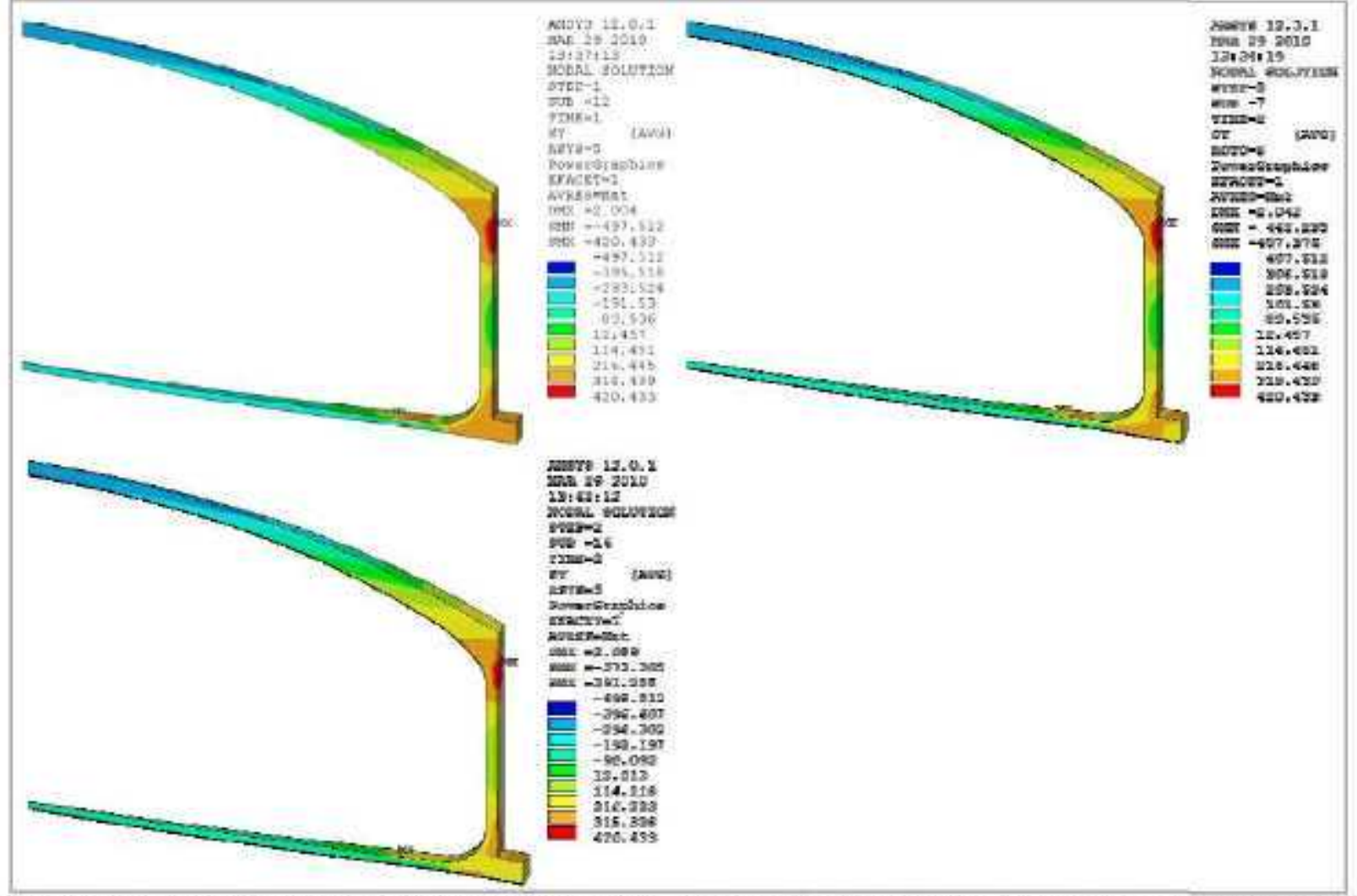

Figure 5.56 Hoop Stress for Empty Tank (top left), Tank Half Full of Waste (top right), and Tank Full of Waste (bottom left) 


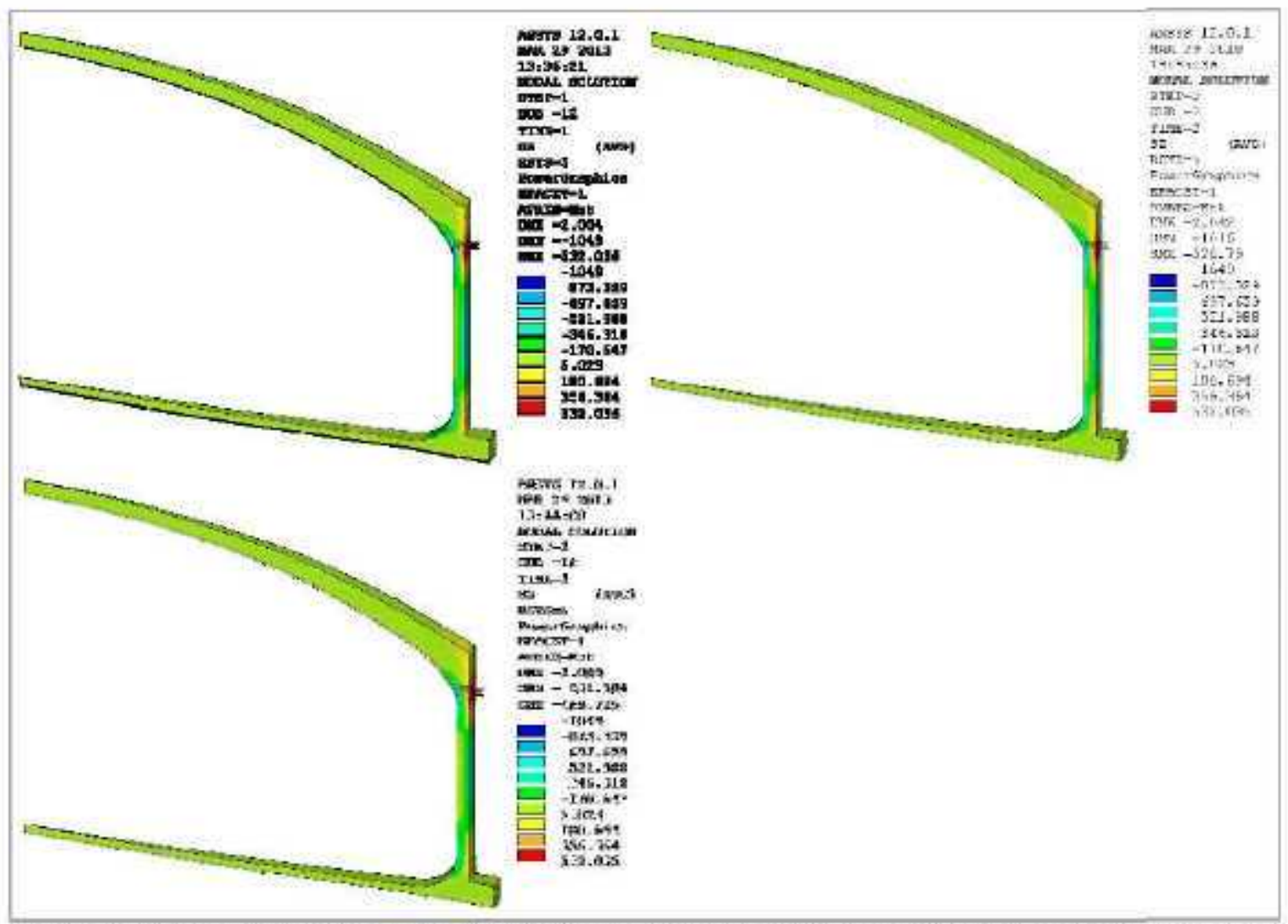

Figure 5.57 Vertical Stress for Empty Tarik (top left), Tark Half Full of Waste (top right), and Tank Full of Waste (bottom left)

Cracking at the concrete element integration points is shown in Figure 5.58 for the empty tank, the half full tank, and the full tank. Cracking only occurs in the concrete foundation inside the tank wall. The cracking patterns are very similar for all three cases - most of the cracking occurs during the application of the gravity loads. The waste load causes almost no additional cracking.
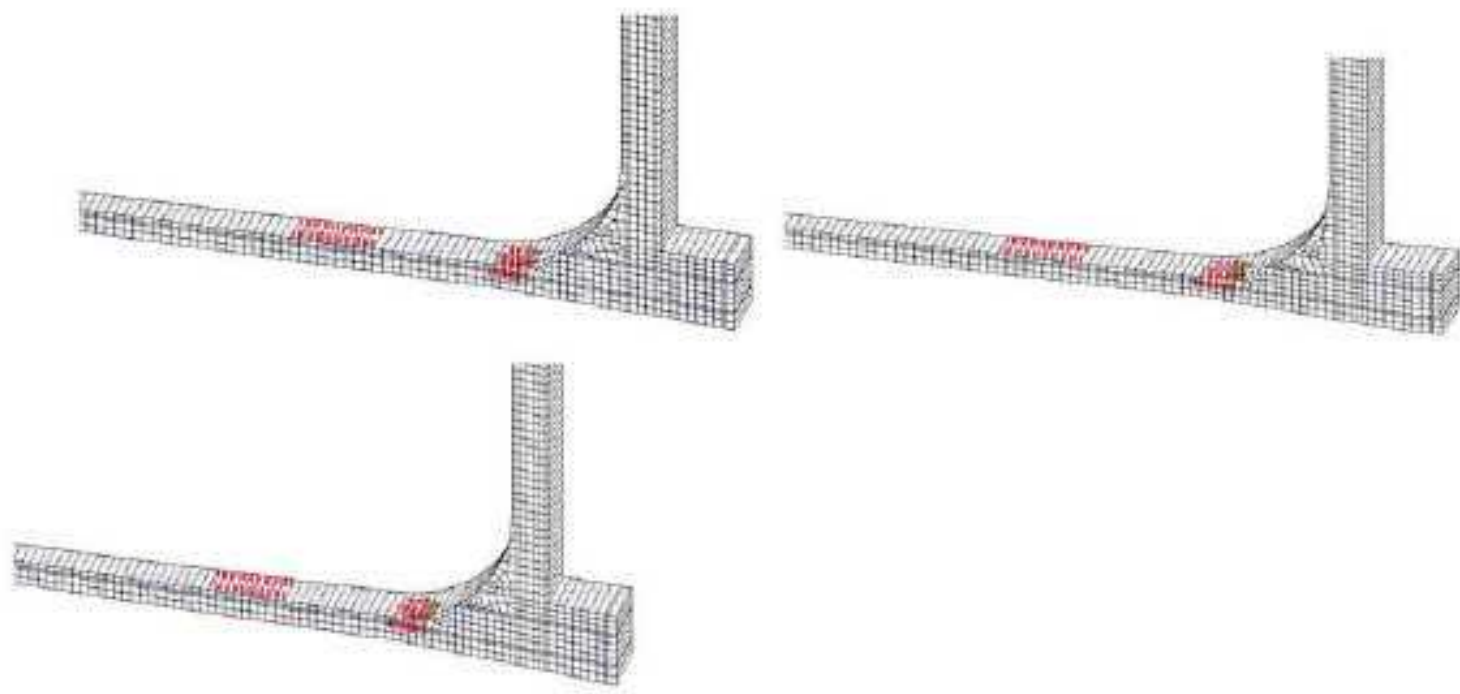

Figure 5.58 Cracking Observed in Concrete for Emipty Tark (top left), Tarik Half Full of Waste (top right), and Tank Full of Waste (bottom left) 
The forces and moments were calculated for 53 sections throughout the concrete in the tank. The same sections were used as those shown in Figure 5.41. The shear force, meridional force, meridional moment, hoop force, and hoop moment through each of these sections for all three cases is plotted in Figures 5.59 through 63 . All of these force and moments indicate that there is very little different between the empty tank, the half full tank, and the full tank. The empty tank generally has the highest force or moment values at the peaks, while the full tank generally has the lowest. The only significant relative sustained difference among the forces and moments is seen in the meridional force in the wall and footing. The empty tank through these sections is slightly more compressive than the half full tank or the full tank.

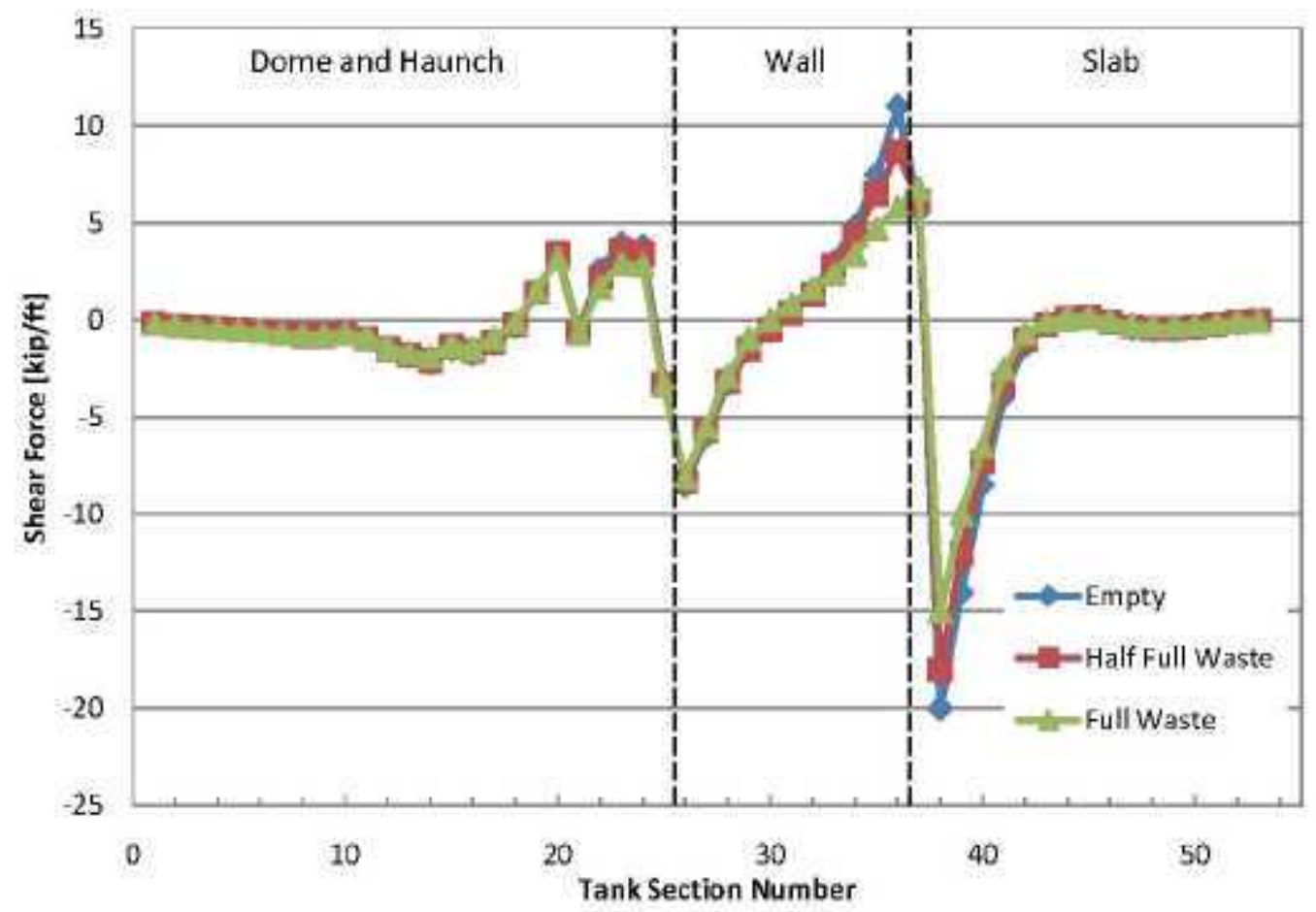

Figure 5.59 Shear Force for Each Section Number for Cases of Empty Tank, Tank Half Full of Waste, and Tank Full of Waste 


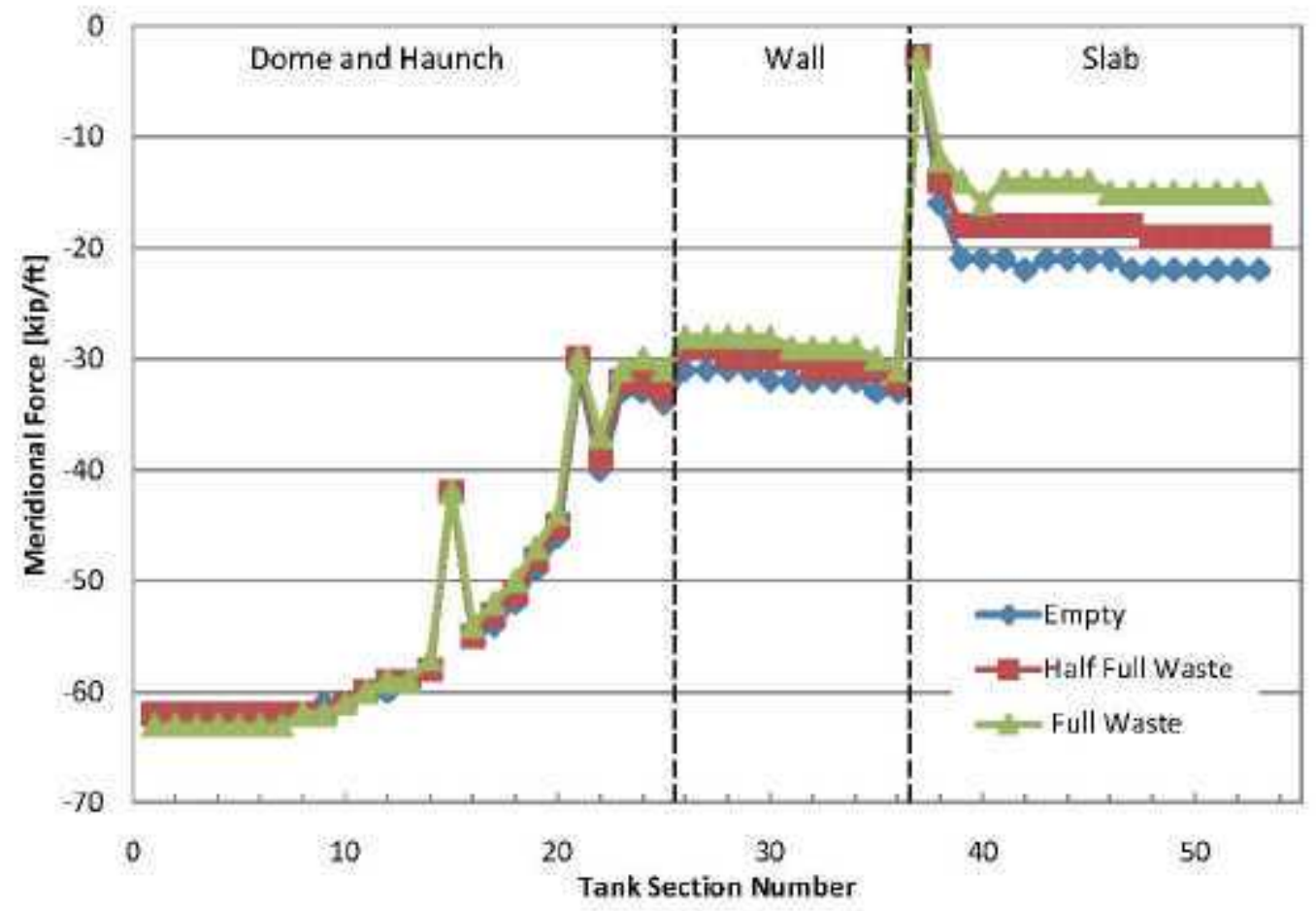

Figure 5.60 Meridional Force for Each Section Number for Cases of Empty Tank, Tank Half Full of Waste, and Tank Full of Waste

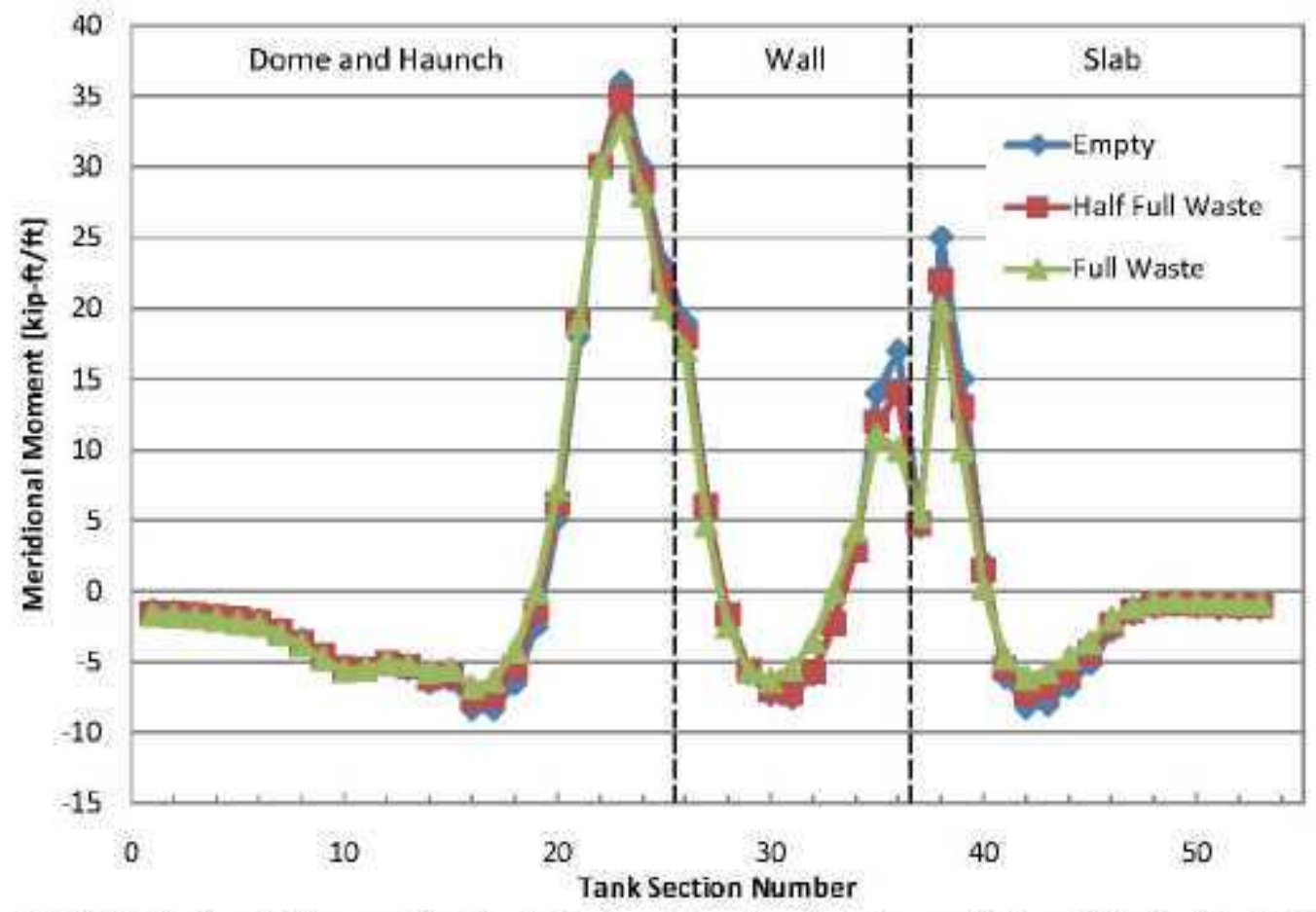

Figure 5.61 Meridional Moment for Each Section Number for Cases of Empty Tank, Tank Half Full of Waste, and Tank Full of Waste 
RPP-46644, Rev.0

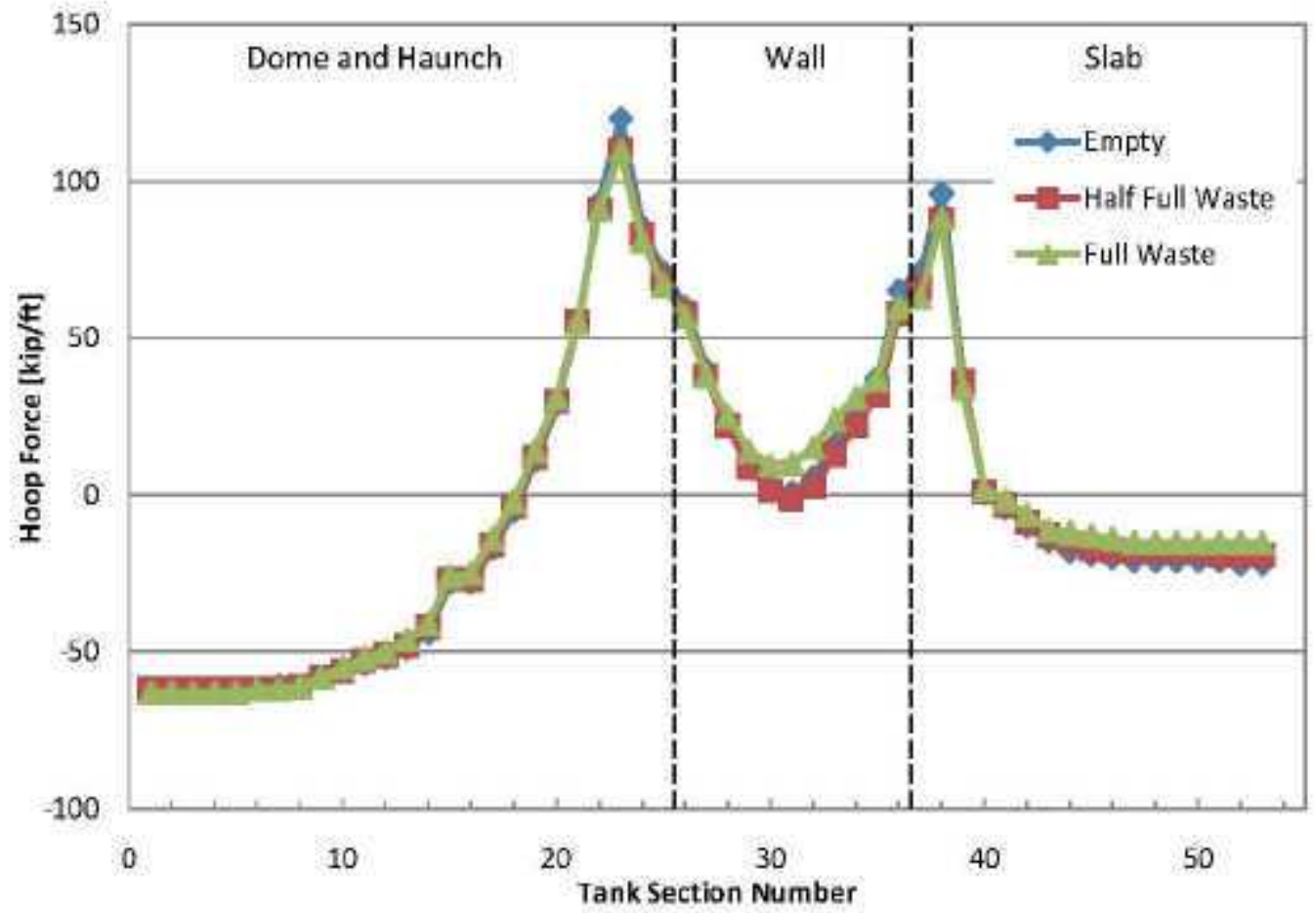

Figure 5.62 Hoop Force for Each Section Number for Cases of Empty Tank, Tank Half Full of Waste, and Tank Full of Waste

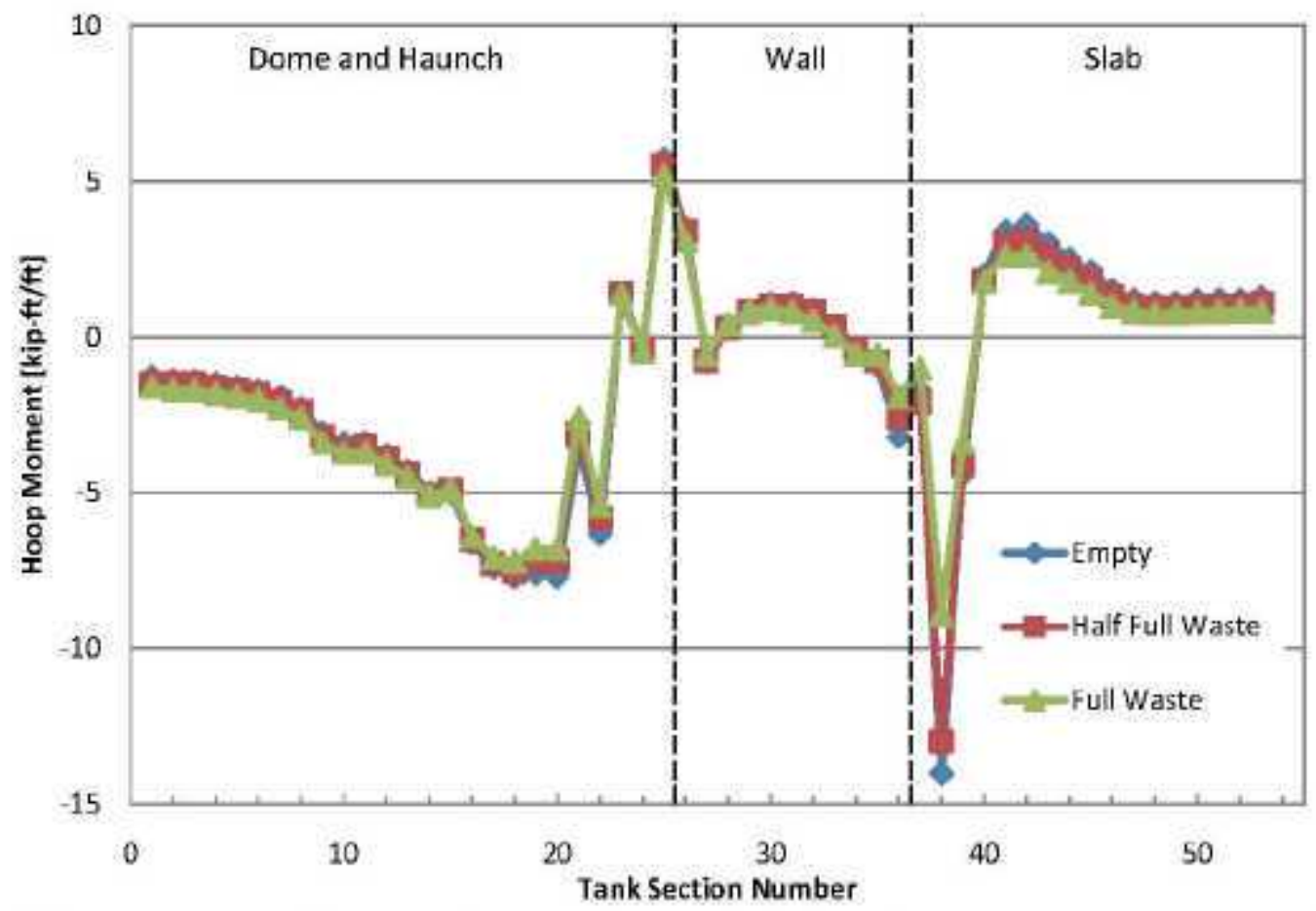

Figure 5.63 Hoop Moment for Each Section Number for Cases of Empty Tank, Tank Half Full of Waste, and Tank Full of Waste 


\subsection{Material Property Variation and Creep Results}

This section outlines the possible material combination strategy for the thermal and operating loads analysis of the single shell tanks. For concrete, uncertainties lie in the concrete strength and modulus, whereas for soil the uncertainty is in the soil modulus. A possible run matrix was developed using the material property variables. Sensitivity analyses were performed on some of the material property variables, and a reduced run matrix was developed.

\subsubsection{Material Property Combinations}

Table 5.1 shows the possible material property variables. Concrete modulus, concrete tensile strength, and soil modulus are presented as best estimate (nominal), lower-bound (low) and upper-bound (high). This range is considered to bound the uncertainty in the concrete and soil properties. In addition, the analysis can be run with and without concrete creep, shown in Table 5.1.

Table 5.1 Possible Material Property Variables

\begin{tabular}{|c|c|c|c|}
\hline Soil & \multicolumn{3}{|c|}{ Concrete } \\
\hline Modulus & Modulus & Tensile Strength & Creep \\
\hline Low Low & & Low & Yes \\
\hline Nominal Nom & inal & Nominal & No \\
\hline High H & igh & High & - \\
\hline
\end{tabular}

Recent analyses (Rinker et. al 2004) have provided insight into some of the variables listed in Table 5.1. For example, it was shown that a low concrete modulus may not conservatively bound the structural response. A high modulus tends to shift load to the concrete, which typically results more cracking than if a lower modulus is assumed. High concrete tensile strength is not conservative and need not be considered. For soil, a higher soil modulus increases soil stresses and tank support, while resulting in lower concrete stresses and is not conservative. This provides reduced material property variables as shown in Table 5.2.

Table 5.2 Reduced Material Property Variables

\begin{tabular}{|c|c|c|c|}
\hline Soil & \multicolumn{3}{|c|}{ Conerete } \\
\hline Modulus & Modulus & Tensile Strength & Creep \\
\hline Low (L) & Nominal $(\mathrm{N})$ & Low $(\mathrm{L})$ & Yes \\
\hline Nominal $(\mathrm{N})$ & High $(\mathrm{H})$ & Nominal $(\mathrm{N})$ & No \\
\hline
\end{tabular}

A possible run matrix is developed using the variables listed in Table 5,2 and is shown in Table 5.3. The total possible number of runs is 16 for each type of tank. Additional sensitivity analyses of concrete tensile strength and concrete creep were recommended in the Evaluation Criteria report. Also, such an analysis will provide justification to reduce the total run matrix to a size similar to double-shell tank (DST) analysis of record (AOR). Table 5.3 compares the possible run list with the DST Analysis of Record. 
Table 5.3 Possible Run Matrix Using Material Property Variables Listed in Table 5.2

\begin{tabular}{|c|c|c|c|c|c|}
\hline $\begin{array}{c}\text { Run } \\
\text { \# }\end{array}$ & $\begin{array}{c}\text { Soil } \\
\text { Modulus }\end{array}$ & $\begin{array}{c}\text { Concrete } \\
\text { Modulus }\end{array}$ & $\begin{array}{c}\text { Concrete } \\
\text { Tensile } \\
\text { Strength }\end{array}$ & $\begin{array}{c}\text { Concrete } \\
\text { Creep }\end{array}$ & $\begin{array}{c}\text { DST AOR } \\
\text { Comparison }\end{array}$ \\
\hline $1 \mathrm{~N}$ & & $\mathrm{~N}$ & $\mathrm{~N}$ & Yes & 1 \\
\hline $2 \mathrm{~N}$ & & $\mathrm{~N}$ & $\mathrm{~L}$ & Yes & \\
\hline $3 \mathrm{~N}$ & & $\mathrm{H}$ & $\mathrm{N}$ & Yes & 6 \\
\hline $4 \mathrm{~N}$ & & $\mathrm{H}$ & $\mathrm{L}$ & Yes & \\
\hline $5 \mathrm{~L}$ & & $\mathrm{H}$ & $\mathrm{N}$ & Yes & 5 \\
\hline $6 \mathrm{~L}$ & & $\mathrm{H}$ & $\mathrm{L}$ & Yes & \\
\hline $7 \mathrm{~L}$ & & $\mathrm{~N}$ & $\mathrm{~N}$ & Yes & 4 \\
\hline $8 \mathrm{~L}$ & & $\mathrm{~N}$ & $\mathrm{~L}$ & Yes & \\
\hline $9 \mathrm{~N}$ & & $\mathrm{~N}$ & $\mathrm{~N}$ & No & \\
\hline $10 \mathrm{~N}$ & & $\mathrm{~N}$ & $\mathrm{~L}$ & No & \\
\hline $11 \mathrm{~N}$ & & $\mathrm{H}$ & $\mathrm{N}$ & No & \\
\hline $12 \mathrm{~N}$ & & $\mathrm{H}$ & $\mathrm{L}$ & No & \\
\hline $13 \mathrm{~L}$ & & $\mathrm{H}$ & $\mathrm{N}$ & No & 2 \\
\hline $14 \mathrm{~L}$ & & $\mathrm{H}$ & $\mathrm{L}$ & No & 3 \\
\hline $15 \mathrm{~L}$ & & $\mathrm{~N}$ & $\mathrm{~N}$ & No & \\
\hline $16 \mathrm{~L}$ & & $\mathrm{~N}$ & $\mathrm{~L}$ & No & \\
\hline
\end{tabular}

\subsubsection{Concrete Tensile Strength-Sensitivity Analysis}

Sensitivity analysis of concrete tensile strength was performed using both nominal and a near zero (10 psi) tensile strength. The temperature dependent concrete tensile strength is shown in Figure 5.64. All sensitivity runs were made using Type IV(b) tanks, which are one million gallon tanks.

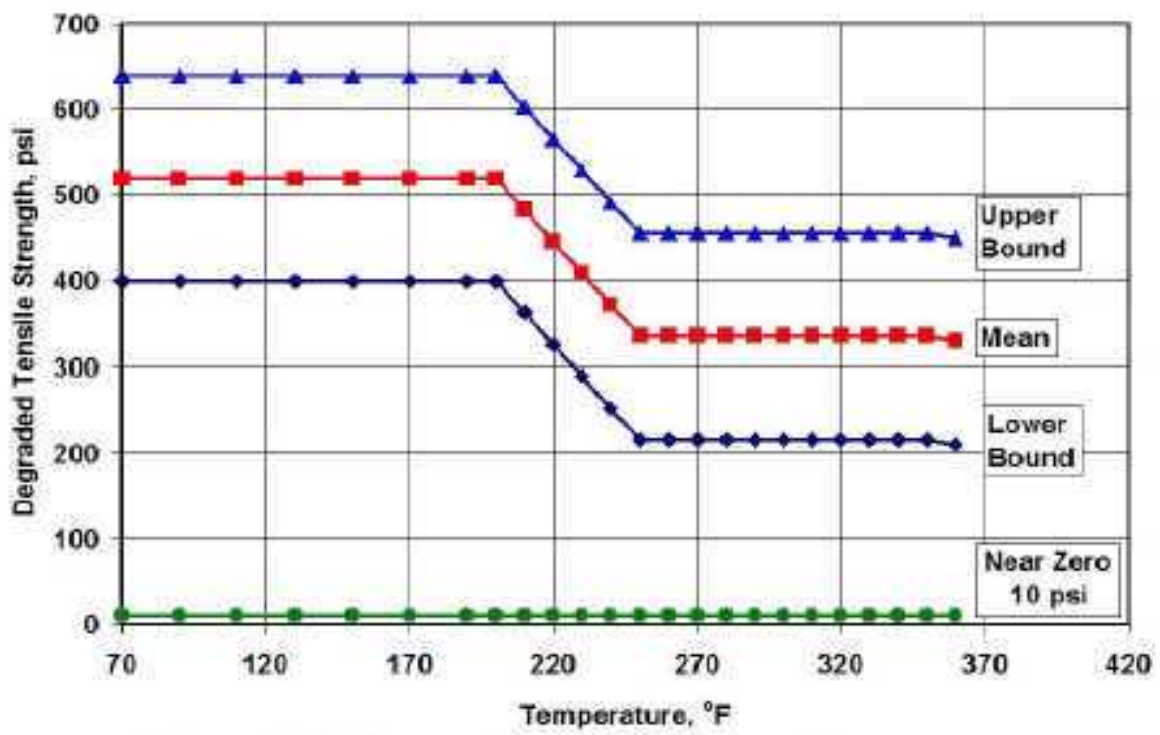

Figure 5.64 Concrete Tensile Strength vs. Temperature

Analysis was done in two steps. First gravity, dead loads, and live loads were applied in load steps 1 through 3 , followed by thermal loads, applied as body forces, in load steps 4 through 8 . Figure 5,65 shows the applied thermal loads. Figures 5.66 to 5.68 show the concrete crack plots at the end of load step 3,4 , and 8 . The mean concrete tensile strength model developed some cracks during the application of mechanical loads (load step 1 to 3 ), followed by major cracking of the haunch and wall/footing region at 
the end of load steps 4 and 8 . For zero concrete tensile strength, a large portion of the haunch and wall/footing region cracked during the application of mechanical loads (load step 1 to 3 ), followed by some additional cracking at the end of load steps 4 and 8 . In comparison, zero concrete tensile strength showed additional cracking when compared to mean concrete tensile strength as a consequence of nearzero value of tensile strength

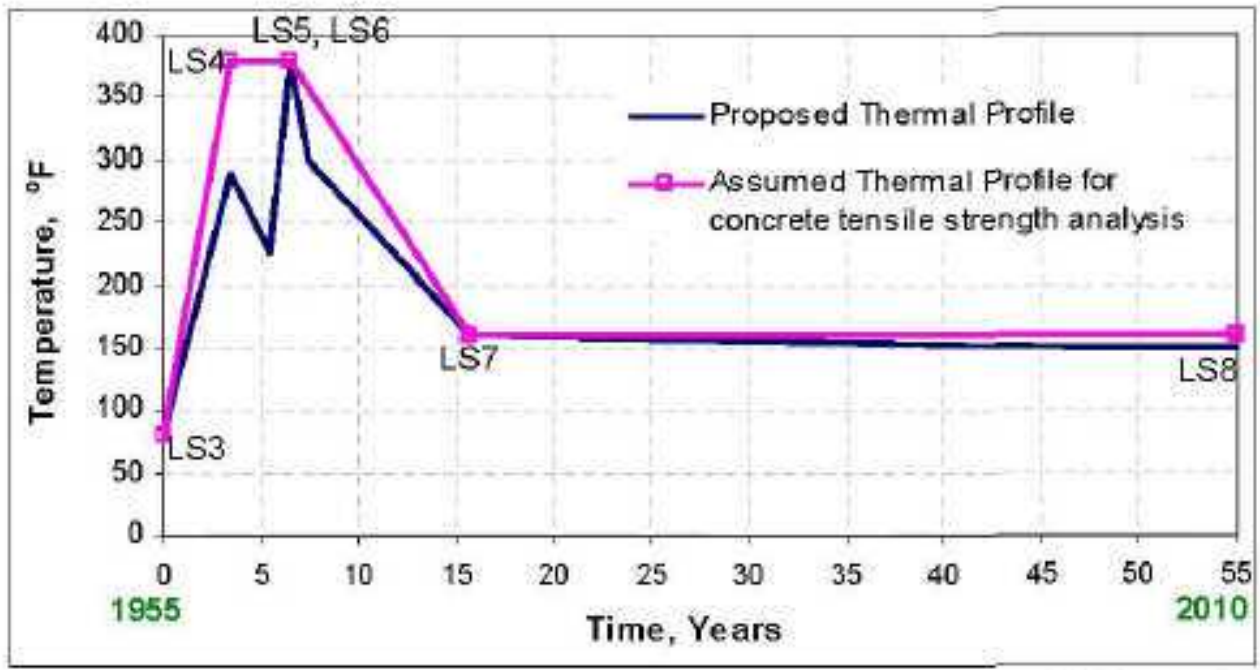

Figure 5.65 Thermal Profile Used for Concrete Tensile Strength Sensitivity Analysis
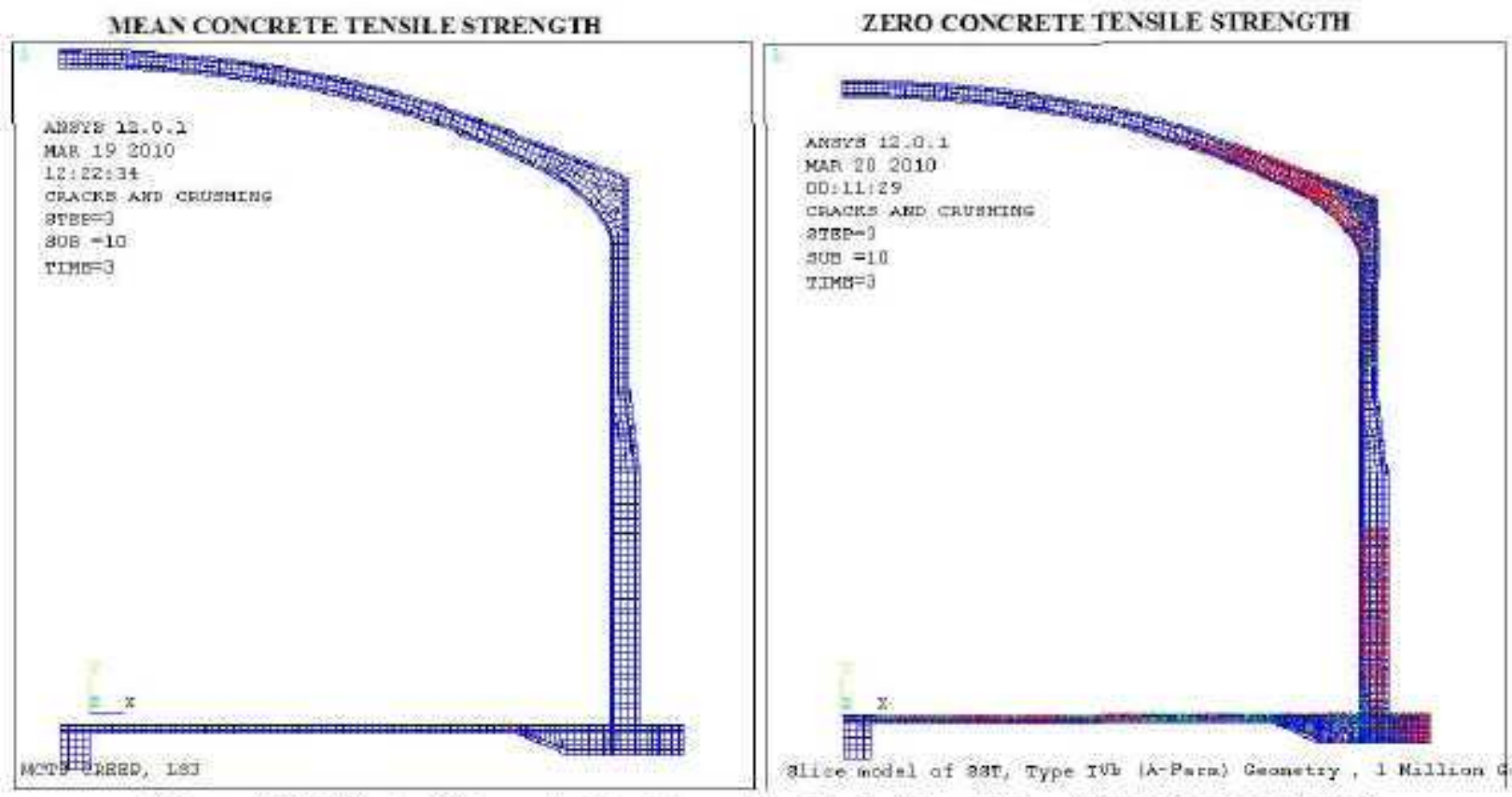

Figure 5.66 Plot of Concrete Cracking at the End of Load Step 3 (mechanical loads) 
MEAN CONCRETE TENSILE STREVGTH

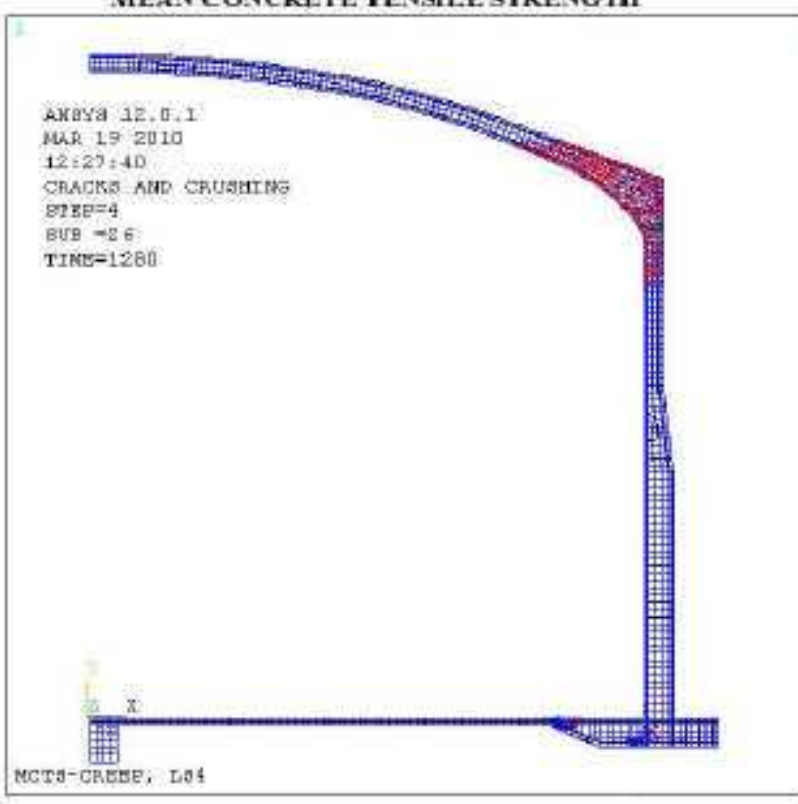

ZFRO CONCRETE TENSILE STRF VGTH

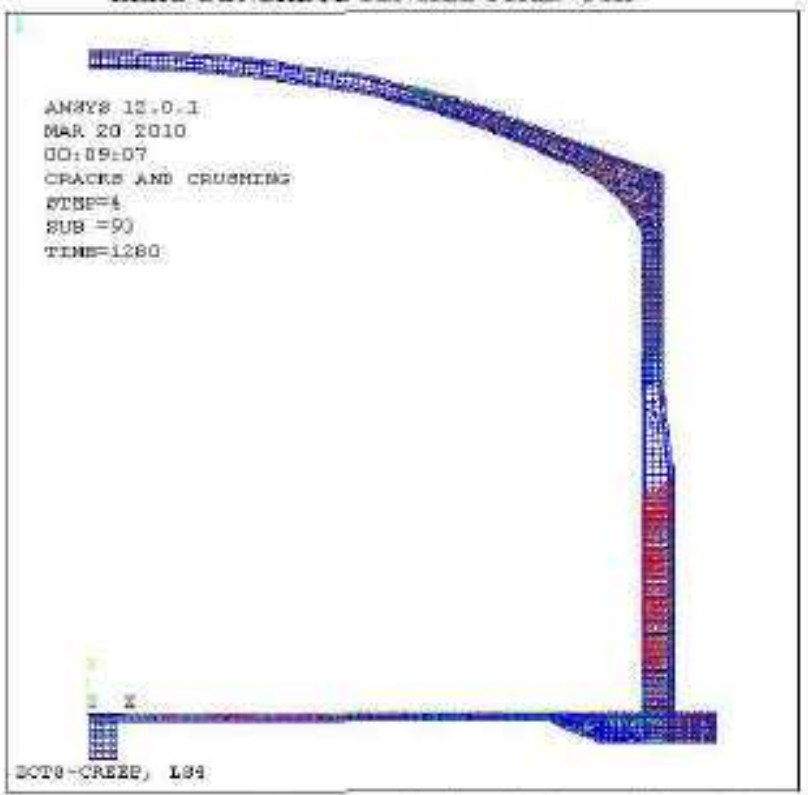

DOTa-CREEE, LSA

Figure 5.67 Plot of Concrete Cracking at the End of Load Step 4 (mechanical and thermal loads)

MEAN CONCRETE TENSILE STRENGTH

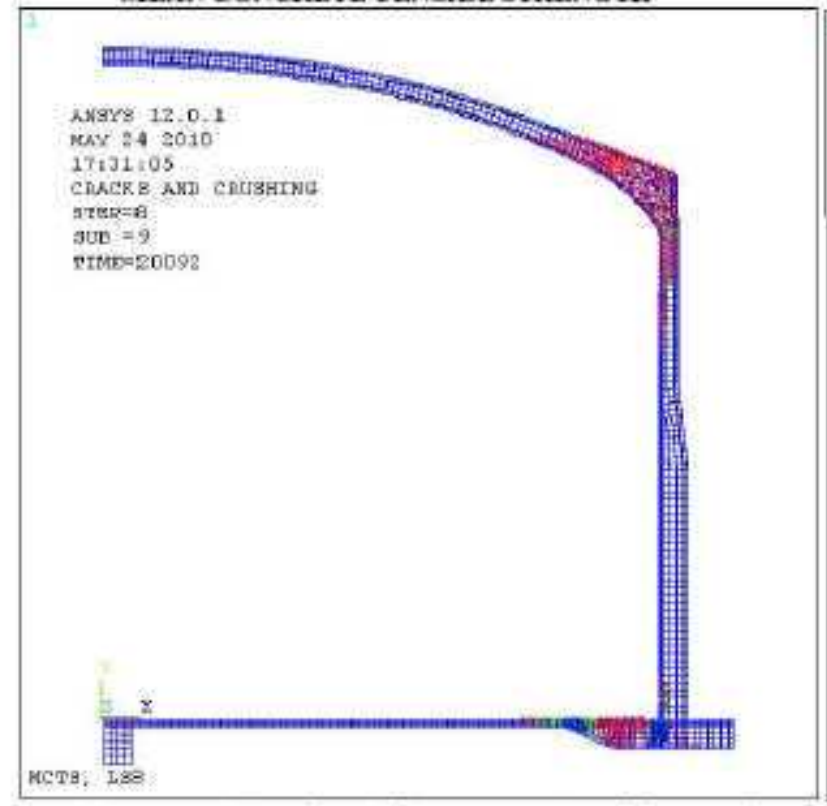

ZERO CONCRETE TENSILE STRENGTH

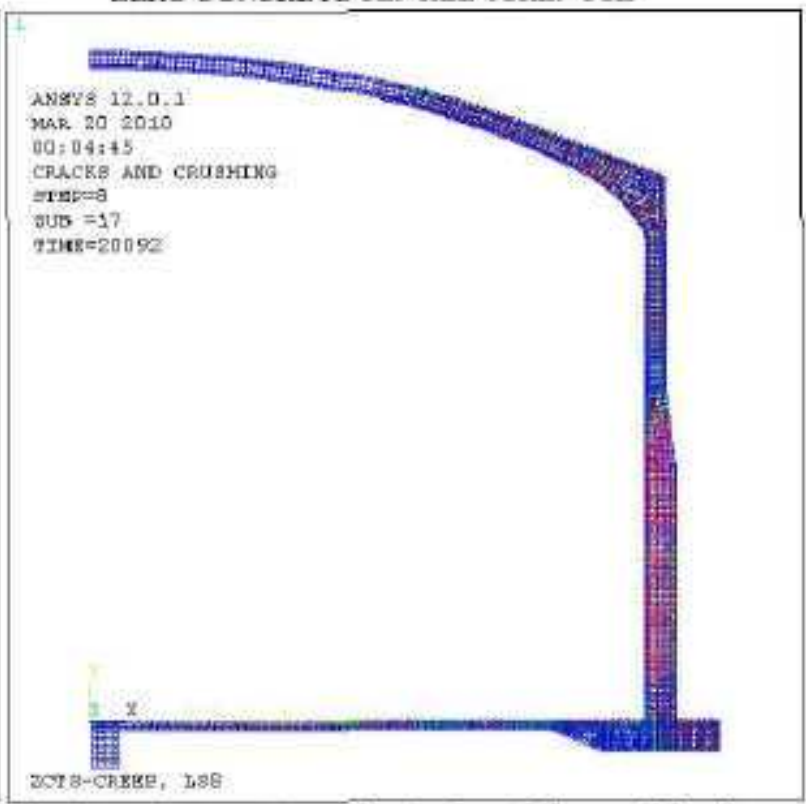

Figure 5.68 Plot of Concrete Cracking at the End of Load Step 8 (mechanical and thermal loads including creep)

Figure 5.69 shows the location of the sections where the concrete force and moments will be evaluated. Figures 5.70 through 5.74 show the force and moment comparisons at the end of load step 3 of the various sections through the concrete tank. Figures 5.75 through 5.79 show the force and moment. comparisons at the end of load step 8 . 
RPP-46644, Rev.0

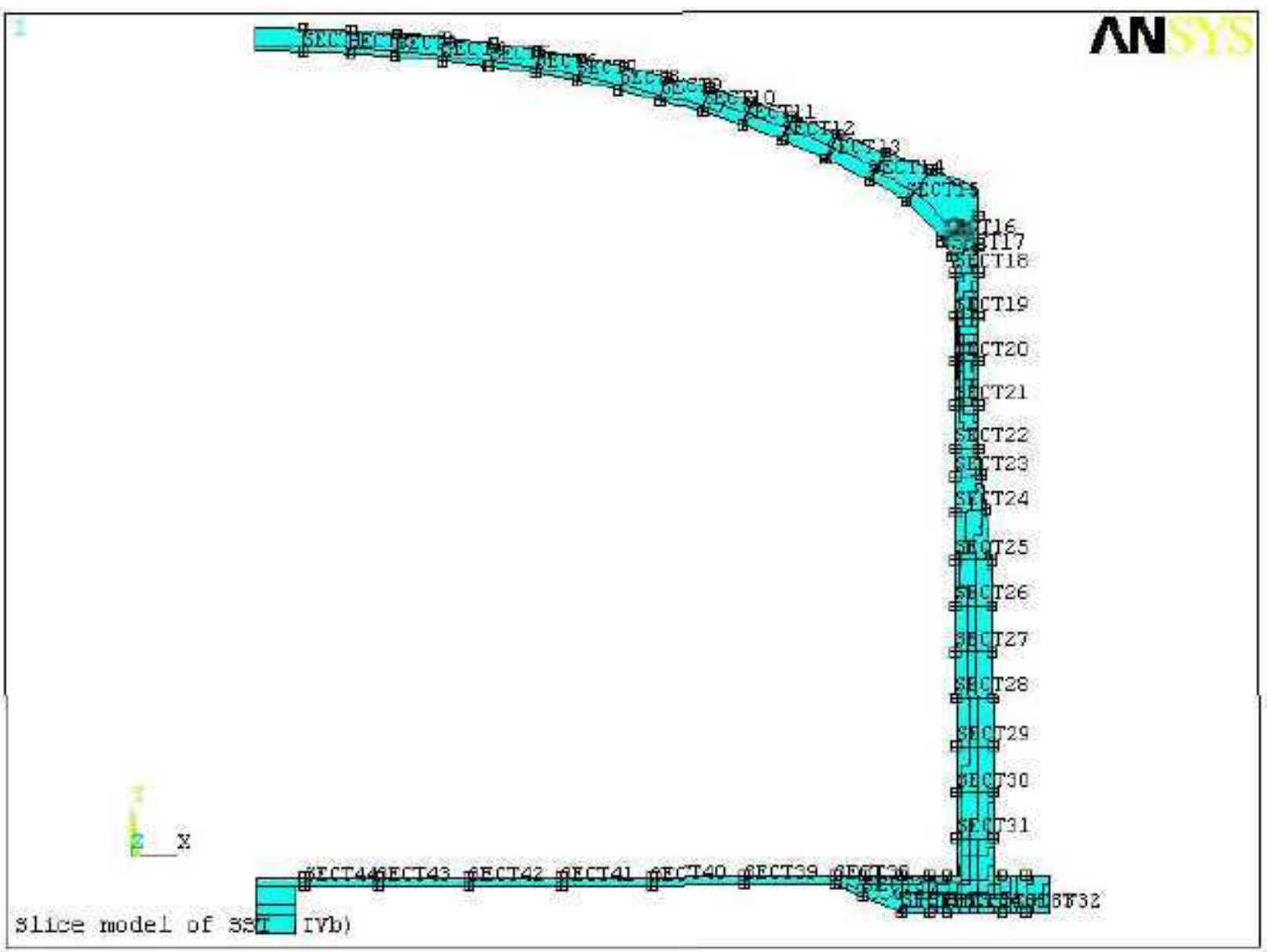

Figure 5.69 Force and Moment Section Locations 
RPP-46644, Rev.0

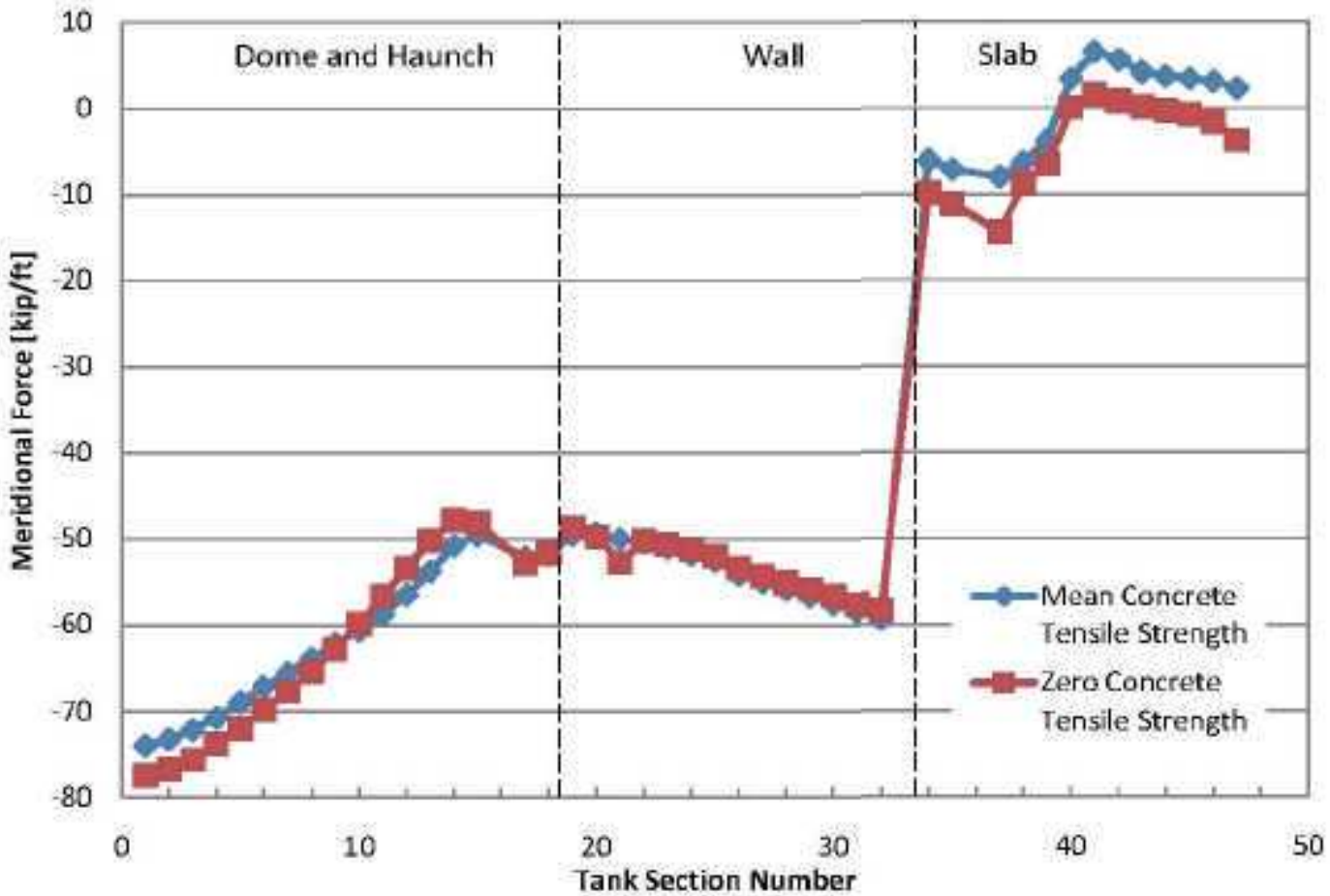

Figure 5.70 Meridional Force Comparison at the End of Load Step 3

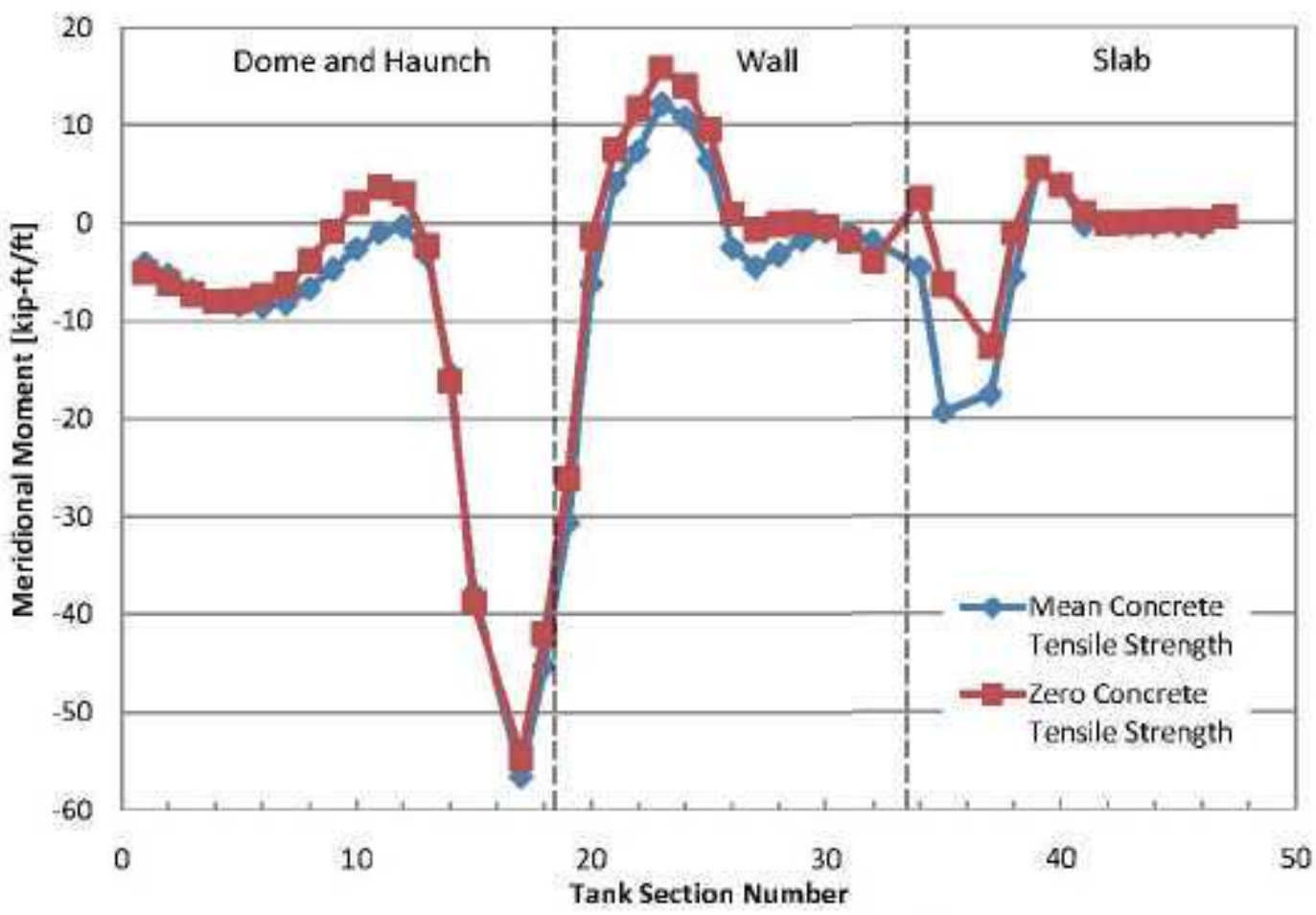

Figure 5.71 Meridional Moment Comparison at the End of Load Step 3 
RPP-46644, Rev.0

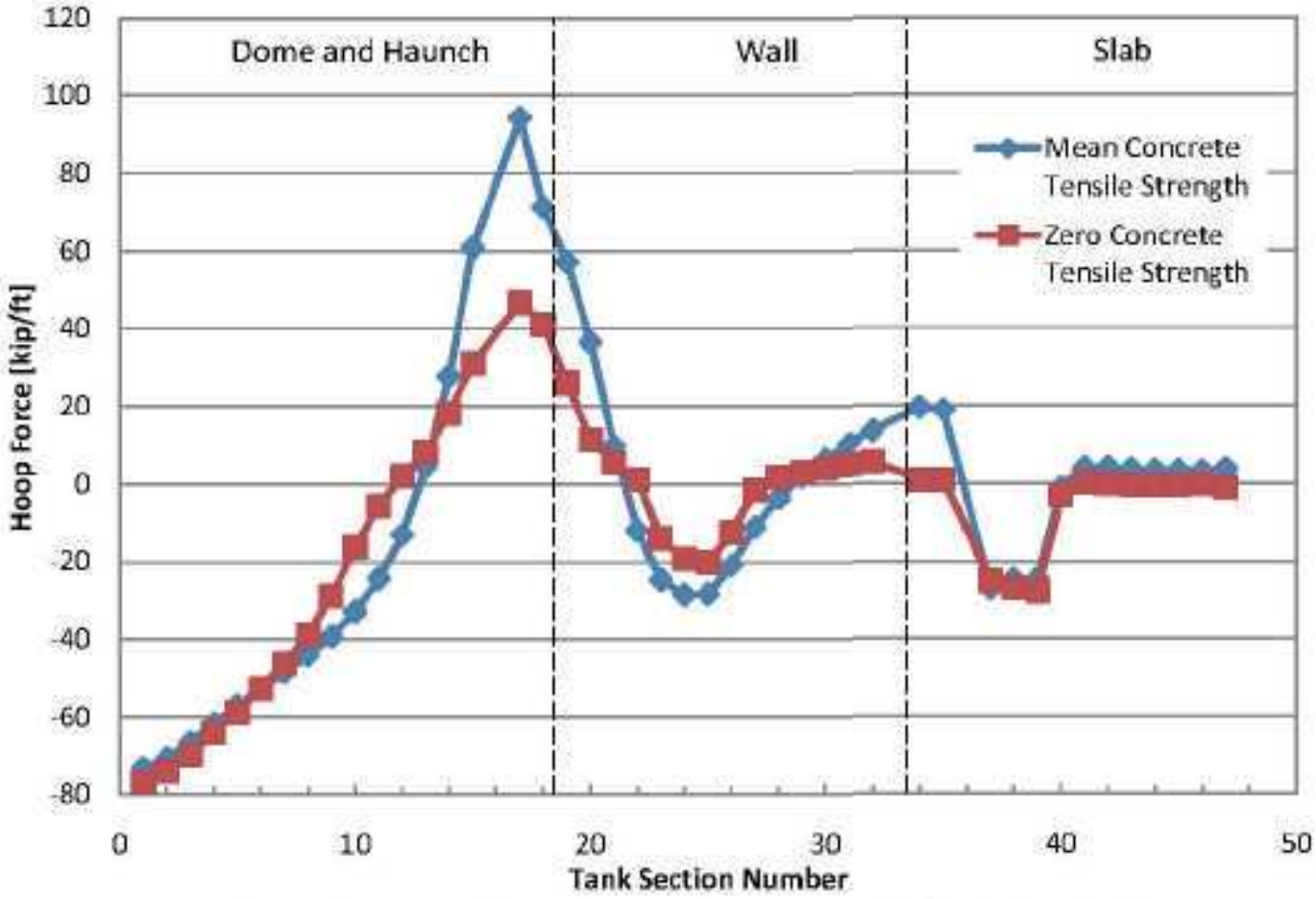

Figure 5.72 Hoop Force Comparison at the End of Load Step 3

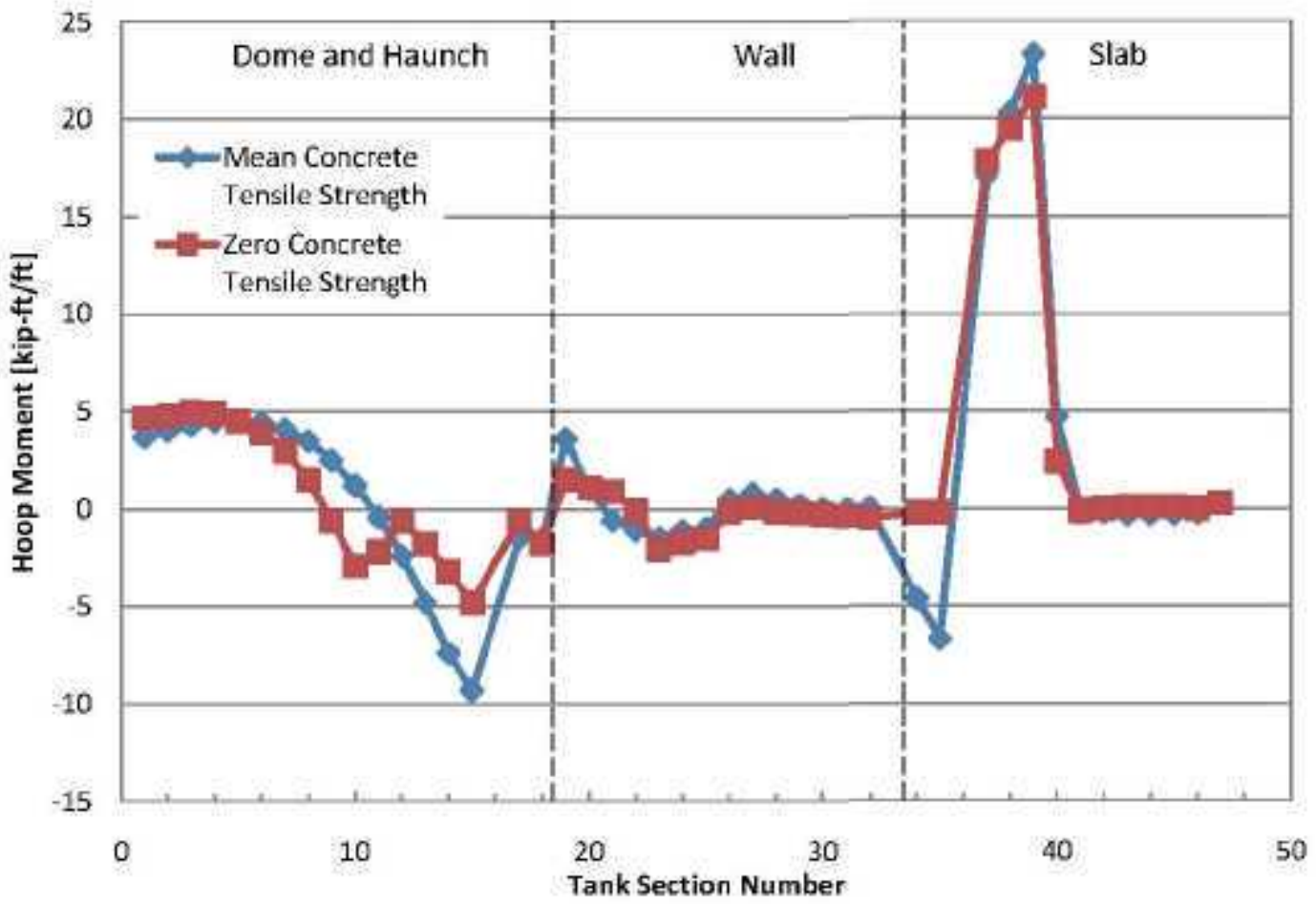

Figure 5.73 Hoop Moment Comparison at the End of Load Step 3 
RPP-46644, Rev.0

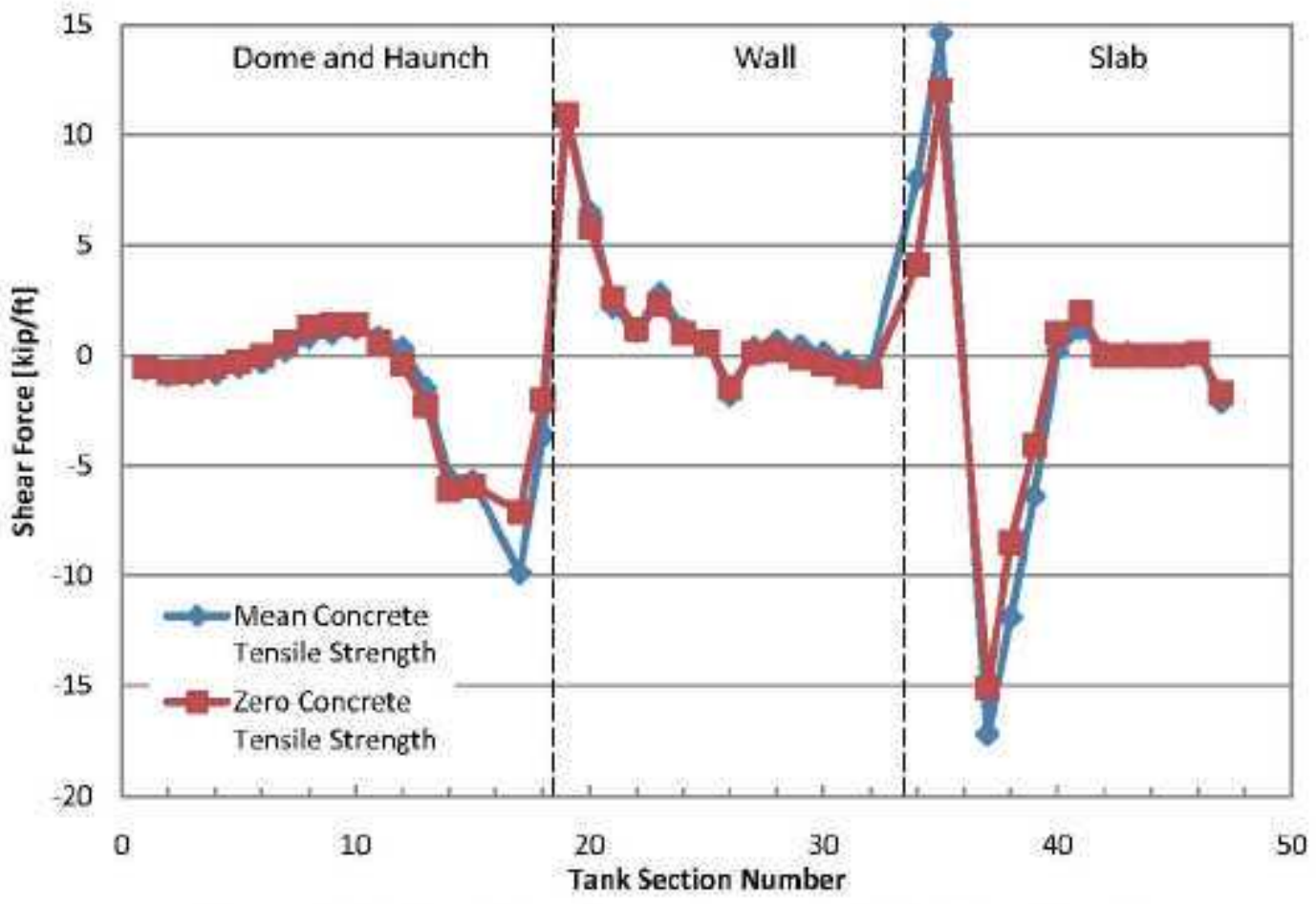

Figure 5.74 Shear Force Comparison at the End of Load Step 3

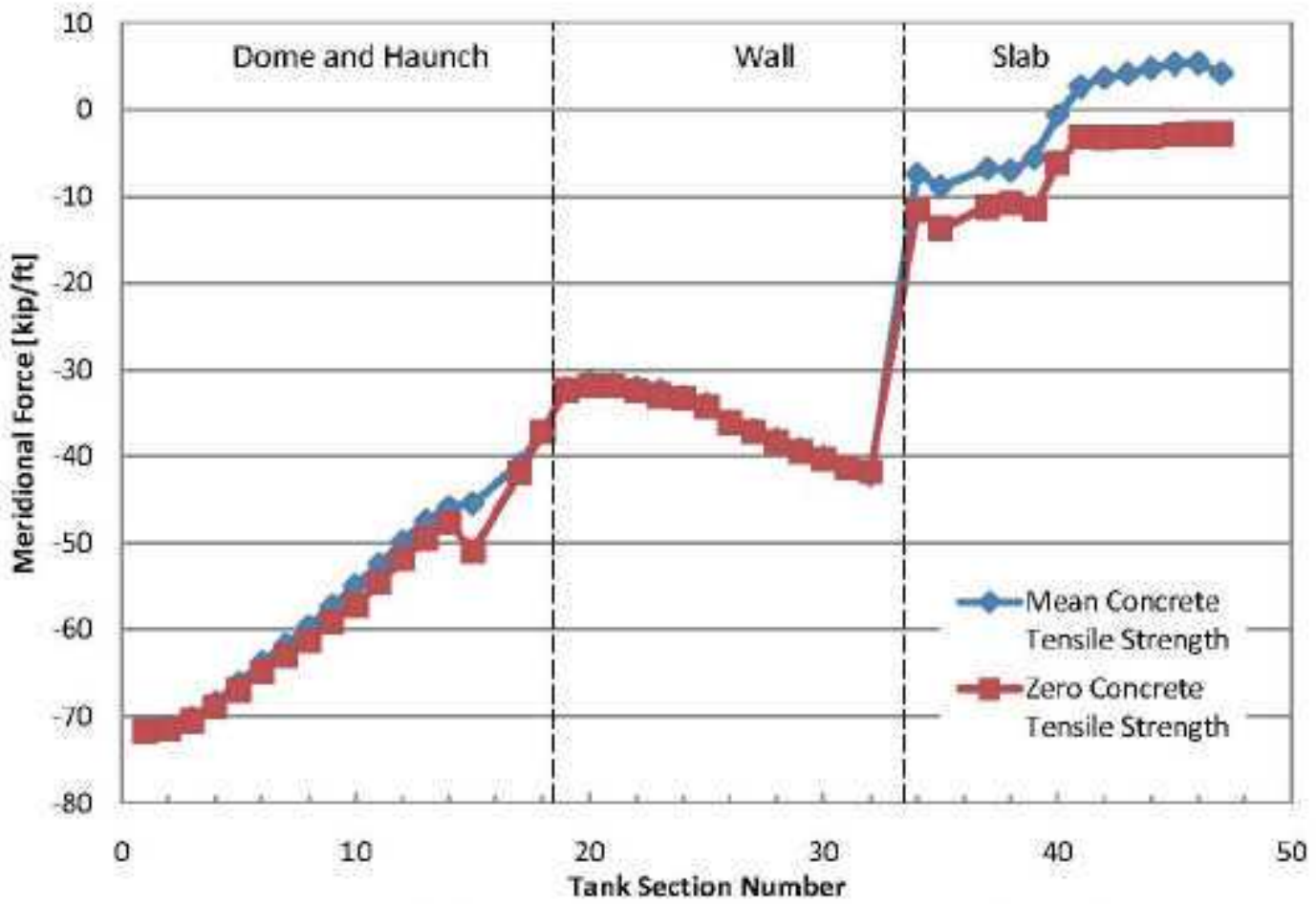

Figure 5.75 Meridional Force Comparison at the End of Load Step 8 
RPP-46644, Rev.0

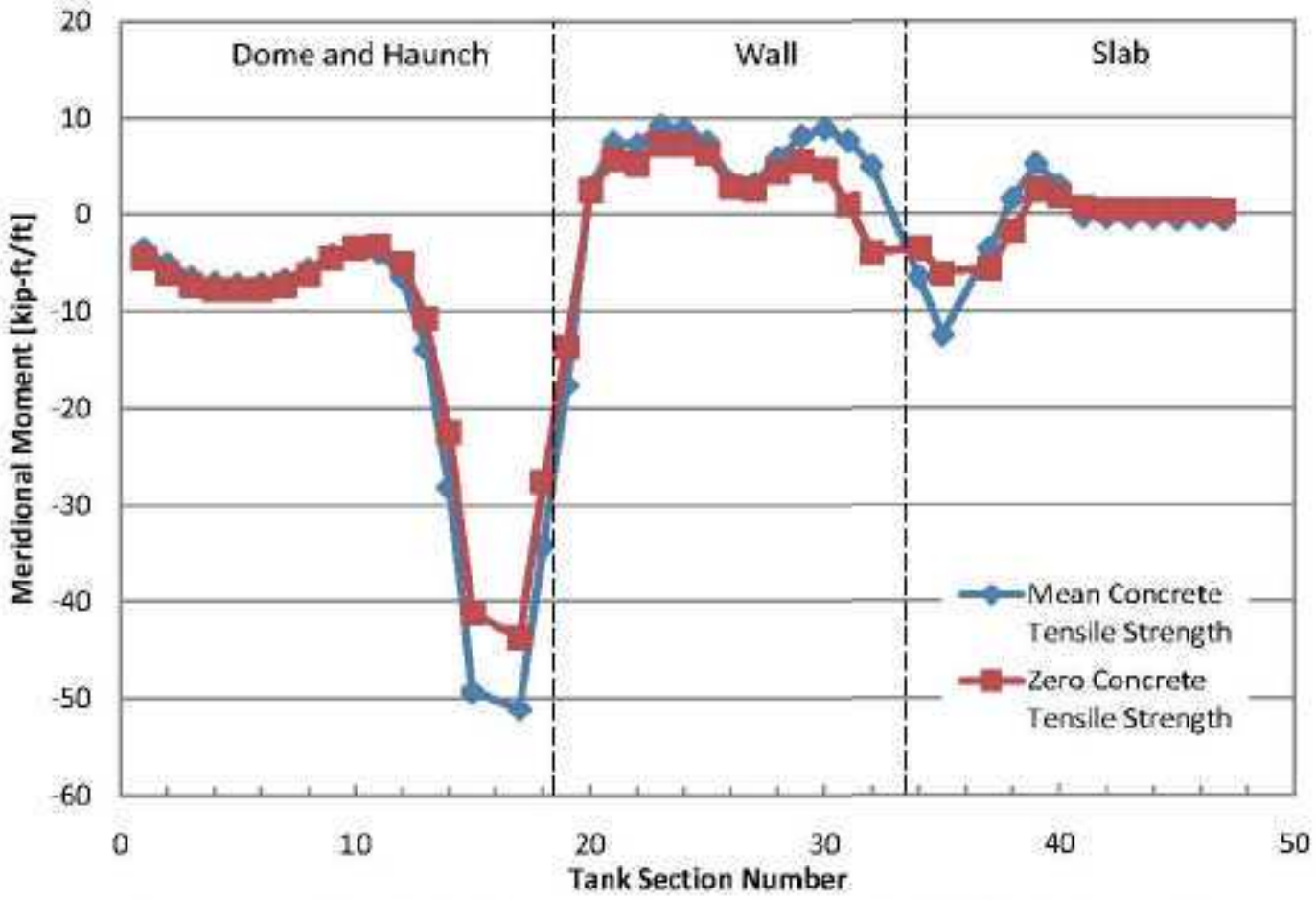

Figure 5.76 Meridional Moment Comparison at the End of Load Step 8

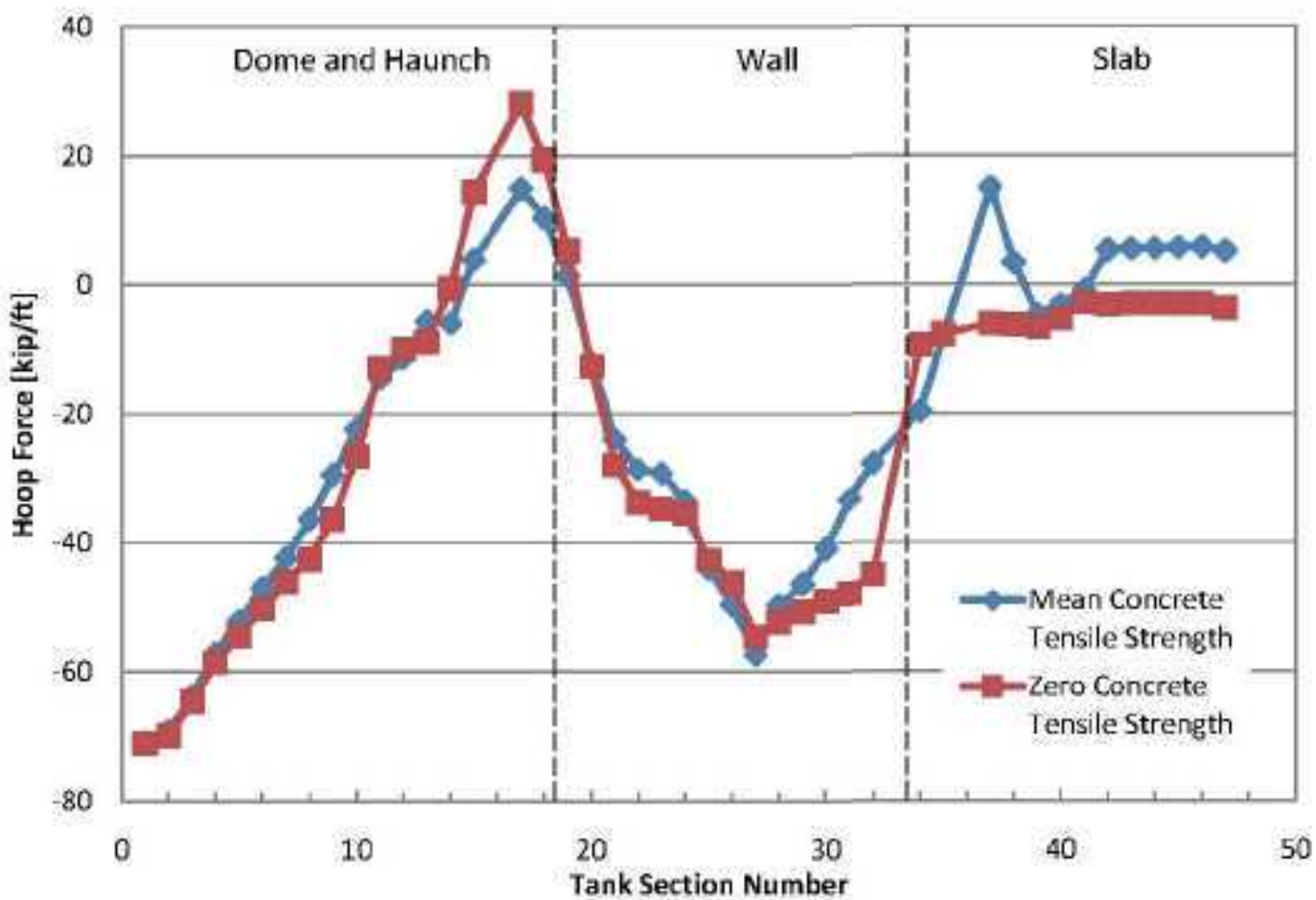

Figure 5.77 Hoop Force Comparison at the End of Load Step 8 


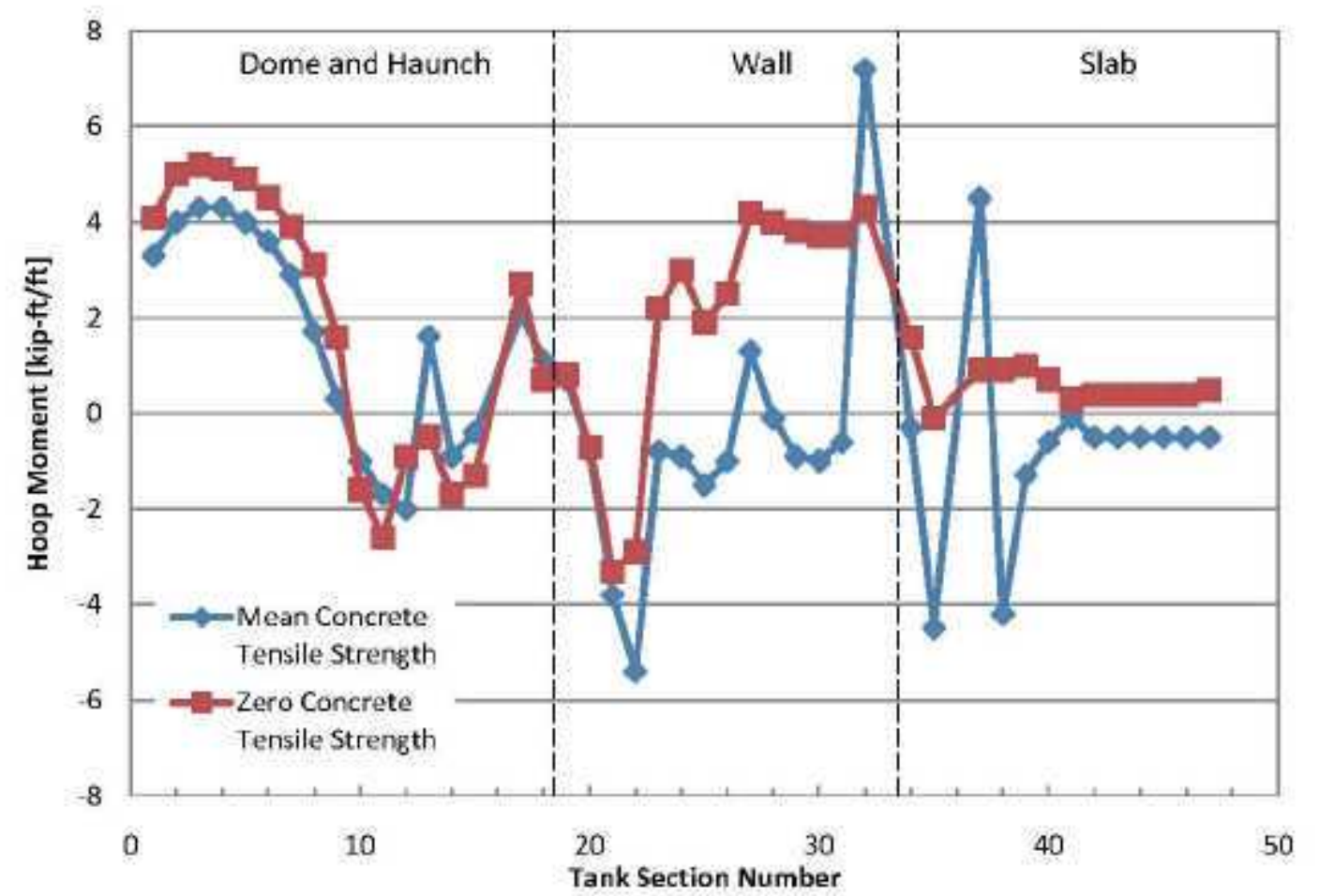

Figure 5.78 Hoop Moment Comparison at the End of Load Step 8

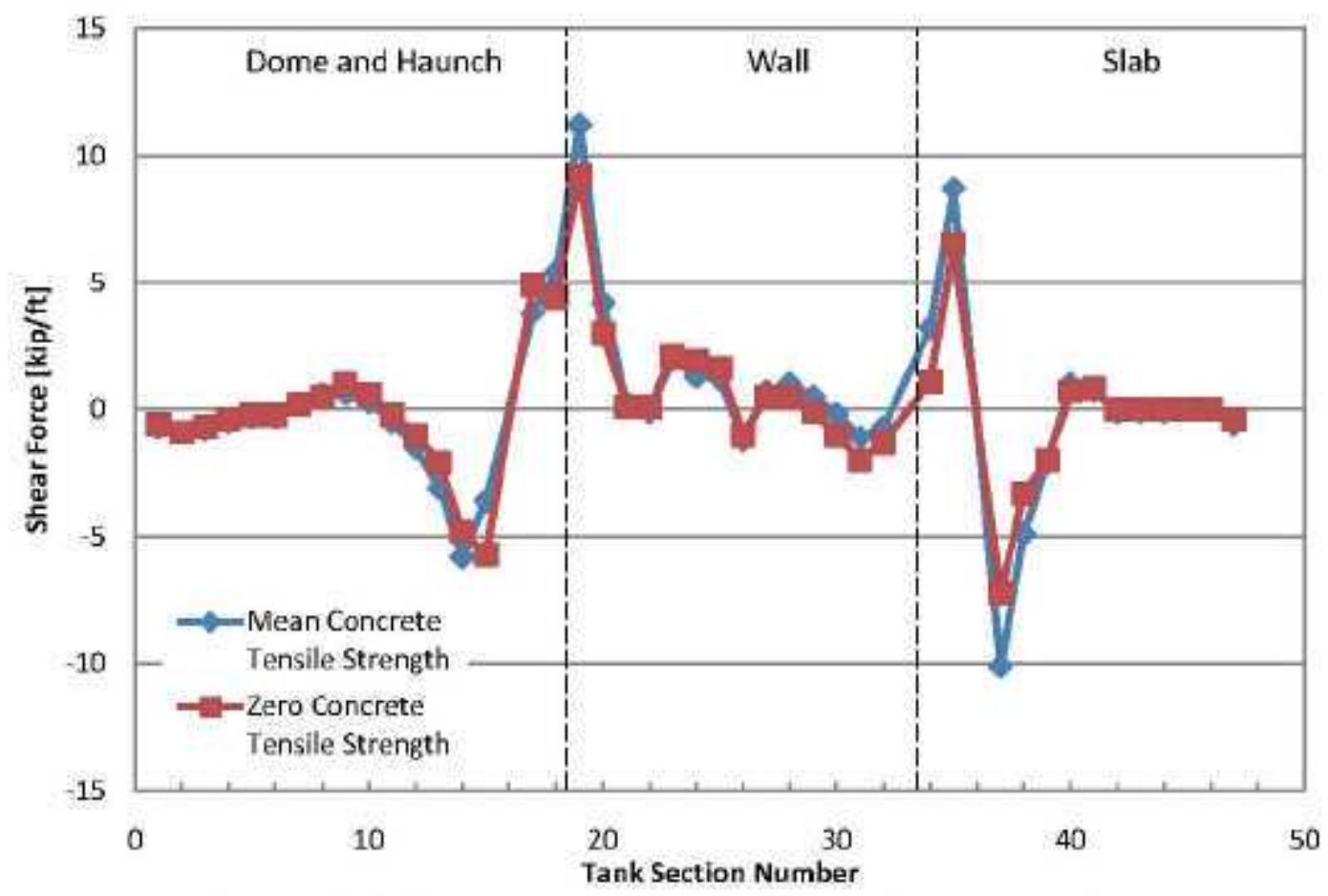

Figure 5.79 Shear Force Comparisons at the End of Load Step 8

From Figures 5.70 through 5.79 it can be observed that the hoop and the meridional demand show a similar trend for both the zero concrete tensile strength and the mean concrete tensile strength. It can also be observed that the hoop and the meridional demand show an increase/decrease in the haunch and 
footing region. This is because of the additional concrete cracking observed in zero concrete tensile strength, which was triggered in part because of the zero tensile strength. Although the decrease in hoop and meridional demand is not conservative, it is considered to be the best estimate of the actual conditions. Therefore it is recommended to use zero concrete tensile strength for detailed analysis. It is also recommended to run a mean concrete tensile strength case for comparison. A reduced run matrix is developed based on this observation and is shown in Table 5.4.

Table 5.4 Reduced Run Matrix Based on Concrete Tensile Strength and Creep Analysis

\begin{tabular}{|c|c|c|c|c|}
\hline Run \# & Soil Modulus & $\begin{array}{c}\text { Concrete } \\
\text { Modulus }\end{array}$ & $\begin{array}{c}\text { Concrete Tensile } \\
\text { Strength }\end{array}$ & Concrete Creep \\
\hline IN & & N & Near Zero & Yes \\
\hline $2 \mathrm{~N}$ & & N & Near Zero & No \\
\hline $3 \mathrm{~N}$ & & $\mathrm{H}$ & Near Zero & No \\
\hline $4 \mathrm{~L}$ & & $\mathrm{H}$ & Near Zero & No \\
\hline $5 \mathrm{~L}$ & & $\mathrm{~N}$ & Near Zero & No \\
\hline $6 \mathrm{~N}$ & & $\mathrm{~N}$ & $\mathrm{~N}$ & Yes \\
\hline $7 \mathrm{~N}$ & & $\mathrm{~N}$ & $\mathrm{~N}$ & No \\
\hline
\end{tabular}

\subsubsection{Concrete Creep-Sensitivity Analysis}

Sensitivity analysis of concrete creep was performed using both creep and no creep cases. Figure 5.80 shows the thermal profile for creep analysis, including the actual thermal profile used for thermal analysis. Analysis was done in two steps. First gravity, dead loads, and live loads were applied in load steps 1 to 3, followed by thermal loads, applied as body forces, in load step 4 through 8 . Table 5.5 lists the load steps and the associated temperature and time. Load step 6 redefines the concrete material properties to maintain the thermally degraded properties for the remainder of the analysis.

Figures 5.81 through 5.85 show the effect of concrete creep on the meridional force, meridional moment, hoop force, hoop moment, and shear force respectively.

In general, creep relieves the stress in the concrete, thereby decreasing the section force. Therefore, the recommendation is to conduct the ACI section evaluation in the detailed analyses without creep, as this will result in higher demands (i.e., more conservative). A reduced run matrix is developed based on this observation and is shown in Table 5.4. However, any collapse load or other ultimate load analyses should be conducted with creep to obtain the best estimate of the actual material condition. It may be noted that creep was important in the DST analyses because of the potential to increase the load on the primary steel liner during concrete creep. 


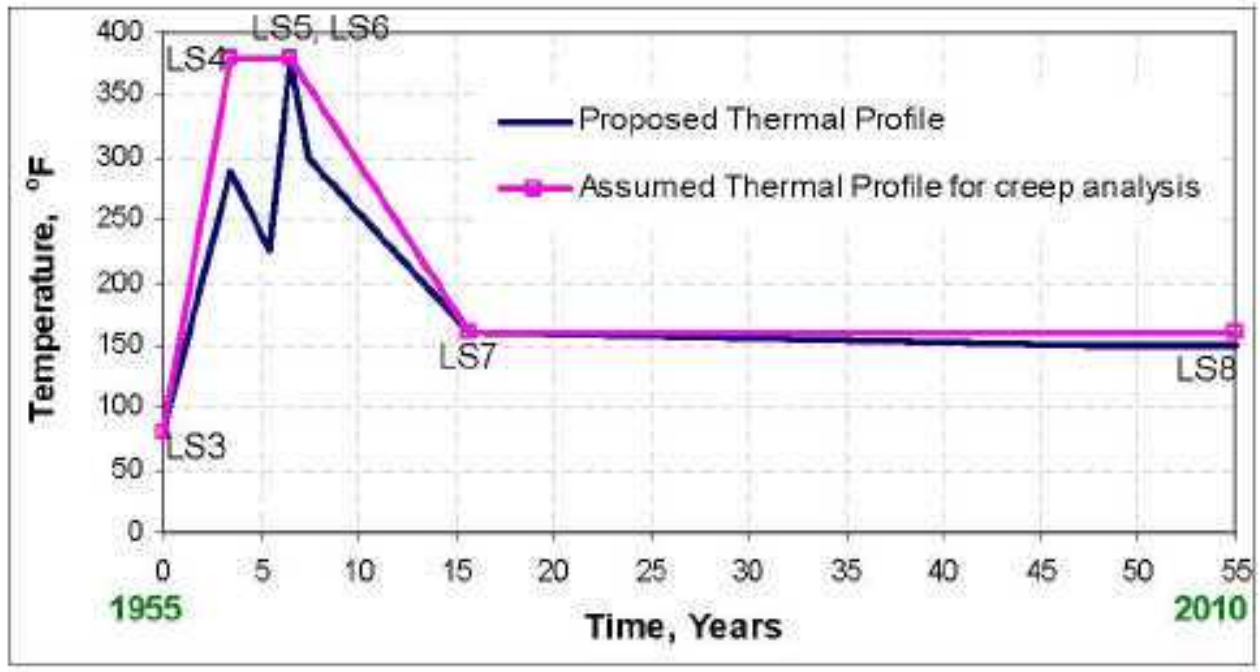

Figure 5.80 Thermal History for Creep Analysis

Table 5.5 Time and Temperature as a Function of Load Steps

\begin{tabular}{|c|c|c|}
\hline Time, Years & Temperature, ${ }^{~} \mathbf{F}$ & Load Step \# \\
\hline 0.00880 & & 3 \\
\hline 3.5138 & 0 & 4 \\
\hline 6.5138 & 0 & 5 \\
\hline 6.5138 & 0 & 6 \\
\hline 15.771 & 60 & 7 \\
\hline 55.051 & 60 & 8 \\
\hline
\end{tabular}

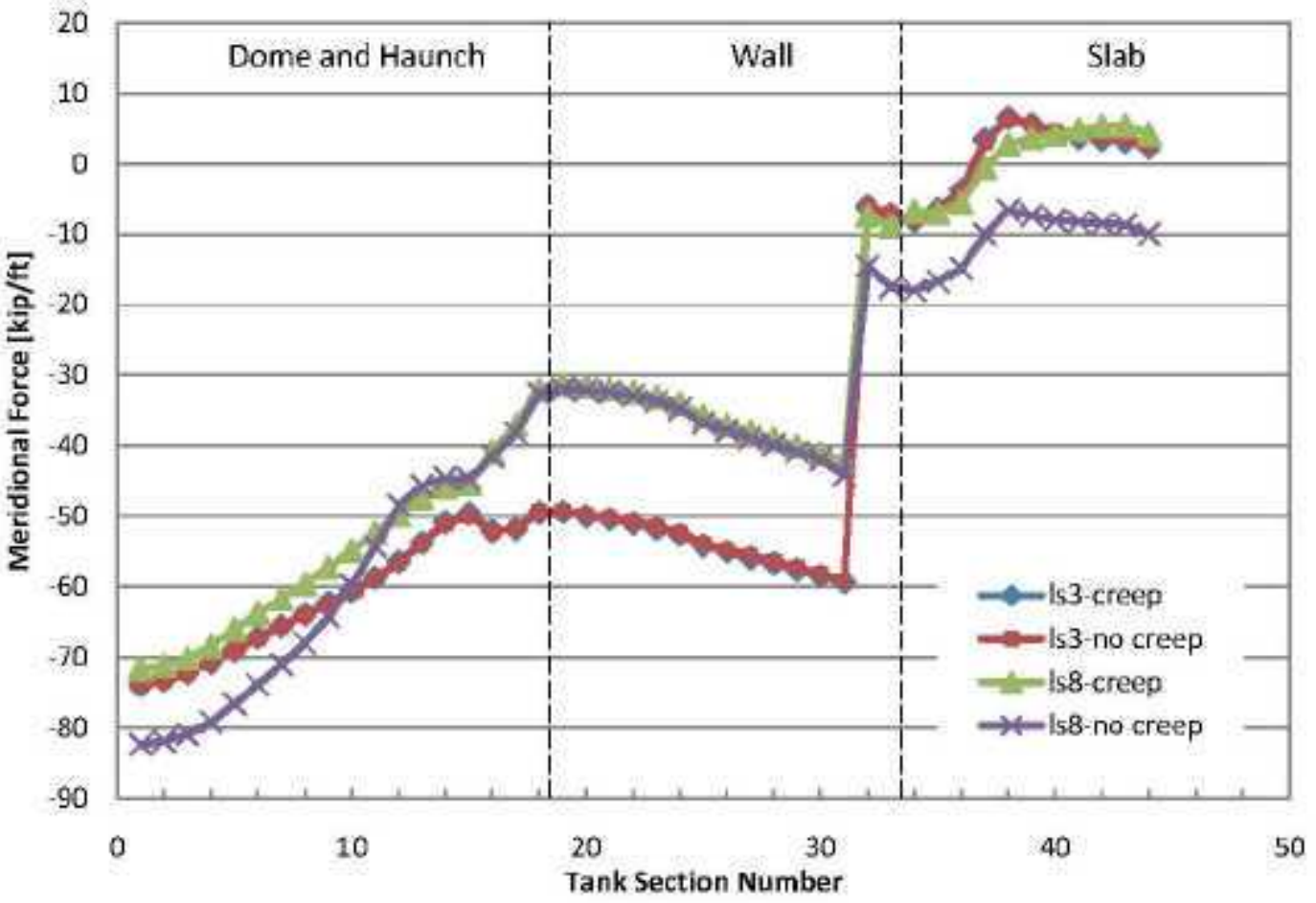

Figure 5.81 Effect of Creep on Meridional Force 
RPP-46644, Rev.0

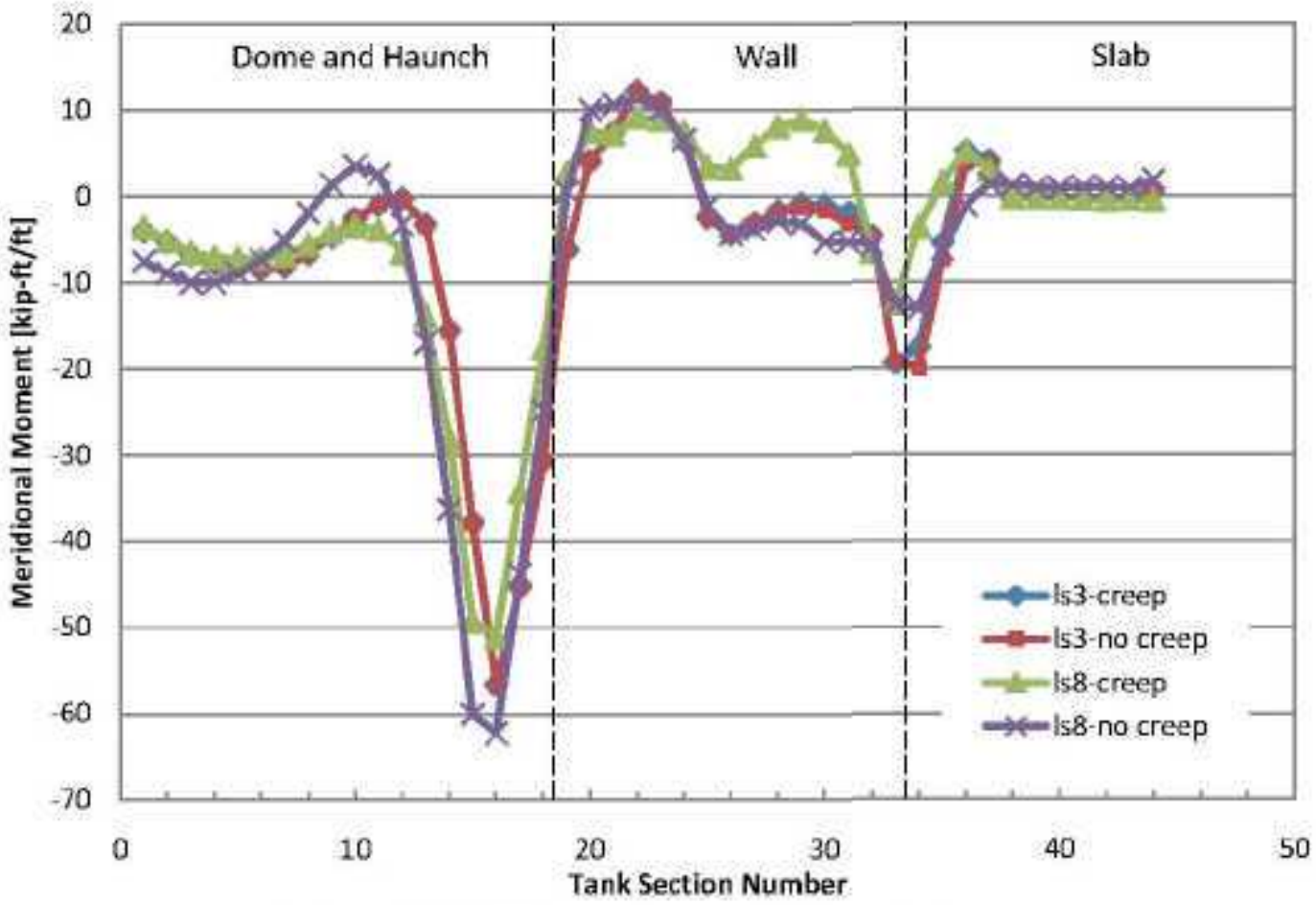

Figure 5.82 Effect of Creep on Meridional Moment

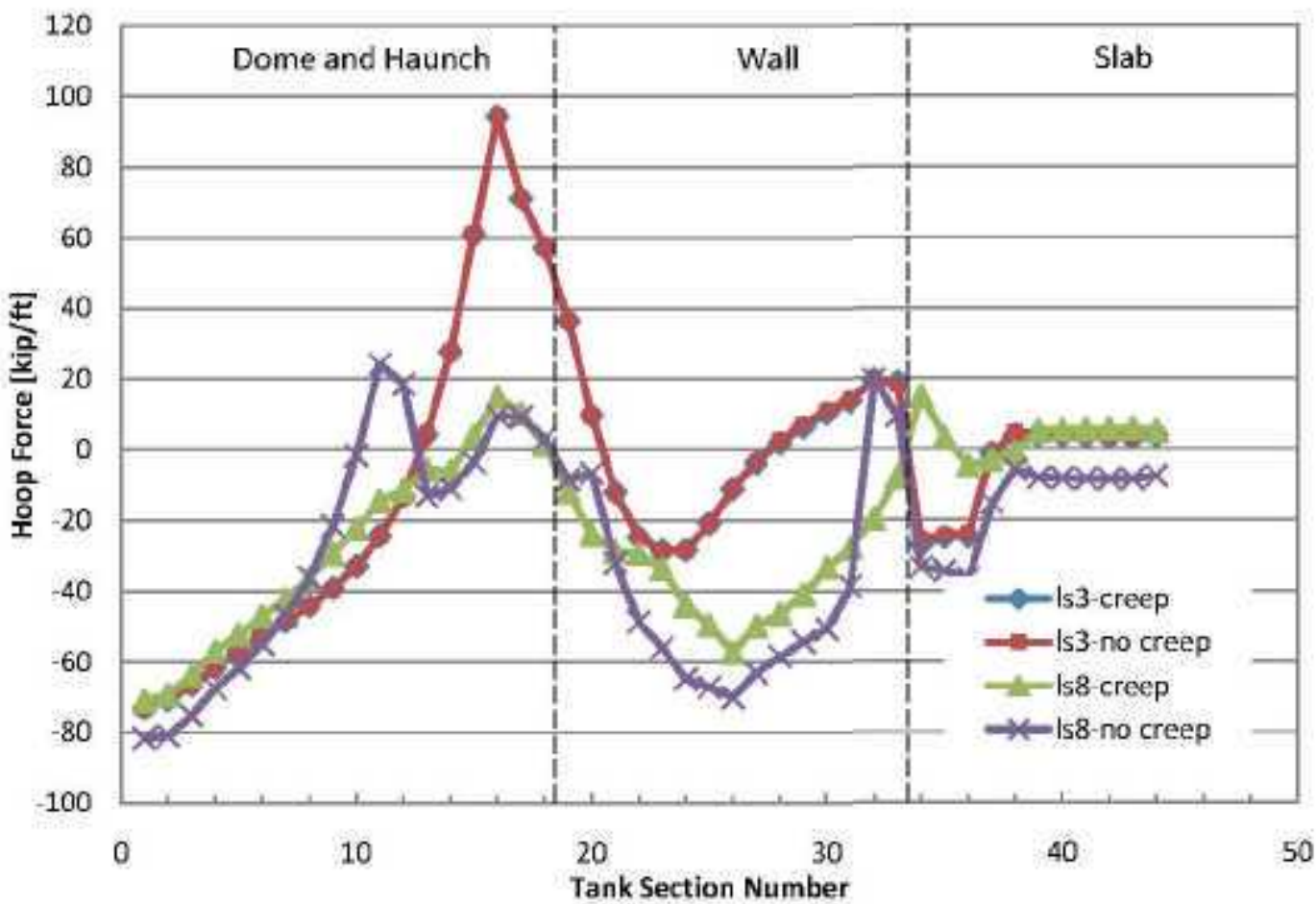

Figure 5.83 Effect of Creep on Hoop Force 
RPP-46644, Rev.0

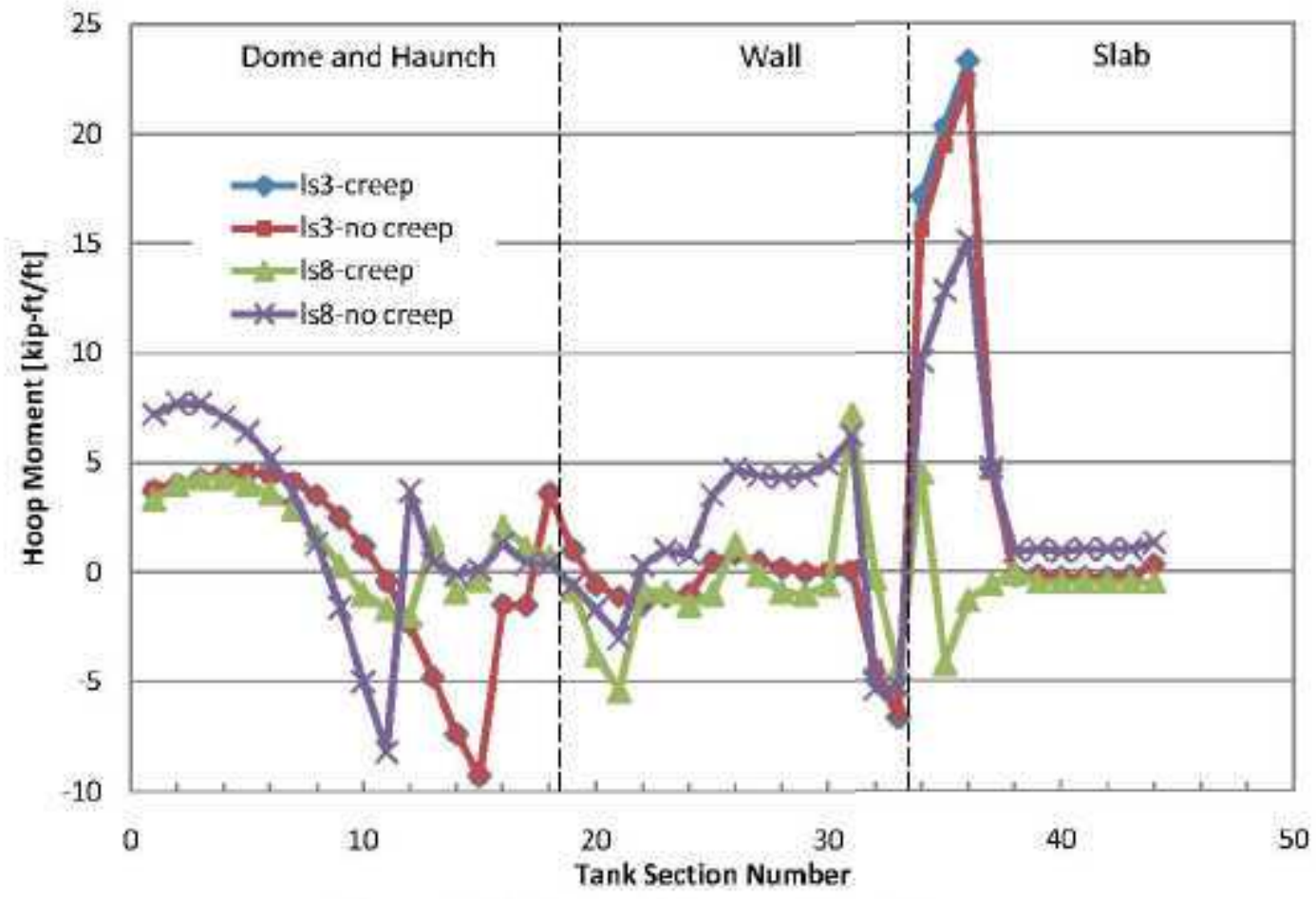

Figure 5.84 Effect of Creep on Hoop Moment

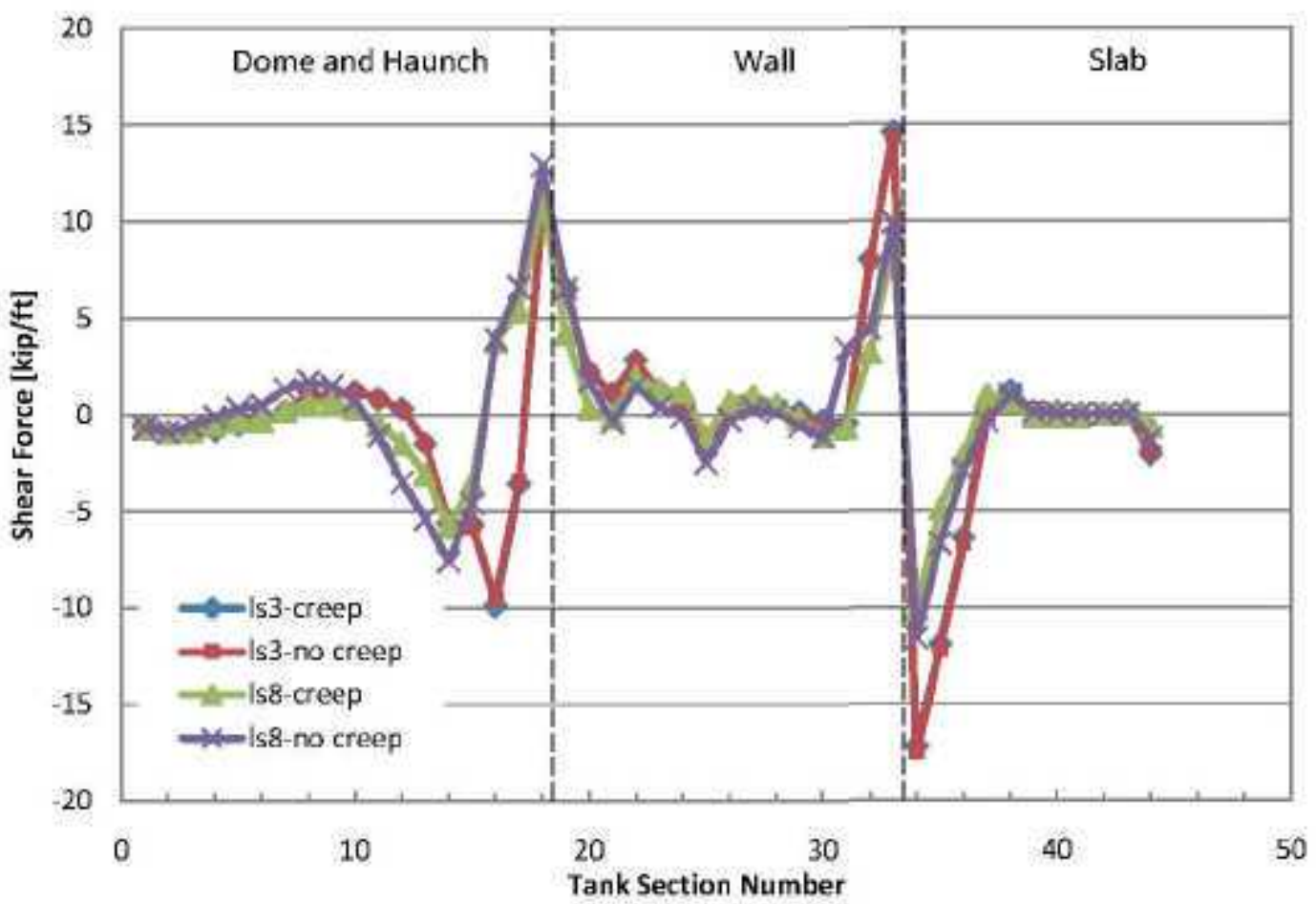

Figure 5.85 Effect of Creep on Shear Force 


\subsection{Type IV Tanks Case Studies and Results}

All the Type IV single-shell tanks (SSTs) are million gallon reinforced concrete tanks with a 75-foot internal diameter. There are three tank farms under Type IV, with significant differences are in their geometrics (slab, footing, dome radii, etc.). Table 5.6 compares drawings for selected tank features. Table 5.7 compares the major structural features of the Type IV SSTs as summarized by Fischer and Shank (1994).

The SX and A Tank Farms are older tanks constructed during the years 1953 through 1955. AX Tank Farm contains relatively newer tanks and was constructed during 1963-1964. Except for the dome inside radius at the apex, all other features indicate that $\mathrm{AX}$ tanks are relatively stronger and better designs. $\mathrm{AX}$ tanks have slabs of thickness close to 15 inches when the depth of drain slots is ignored. In contrast, A and SX tanks have slab thicknesses of 6 inches and 8 inches, respectively, at the concrete foundation centerline. The foundation thickness at the footing of AX tanks is 3 feet, whereas the thicknesses of footings for A and SX tanks are 2 feet and 1 foot 11 inches, respectively. The drawings for dome and wall reinforcement for all the Type IV tanks also indicate that AX walls have higher reinforcement, while all the domes ( $\mathrm{SX}, \mathrm{A}, \mathrm{AX}$ ) have similar reinforcement strengths.

The comparison of geometrical features, reinforcement strength, and the foundation concrete strengths of Type IV tanks indicate that the analyses of Type IV(a) and Type IV(b) would be conservative, as thinner slabs induce higher stresses; the lower material property strengths yield lower margins of safety and the least steel area for concrete reinforcement results in higher rebar stresses. Also, the AX tanks are relatively newer designs and are the only SSTs that were designed for "self-boiling" waste concentration in the tanks as normal operations. Hence, for the purpose of preliminary analysis, only Type IV(a) and Type IV (b) tanks are modeled and analyzed under various case studies. As mentioned before, the only exception where an AX tank might be weaker is in the design of the dome, as a relatively flatter dome radius would result in relatively higher local stresses at the haunch-to-cylindrical shell under similar loading conditions. However, the induced section force and moment demands due to these local stresses may not be significantly different from other Type IV tanks, as the domes curvatures are not significantly different. Some manual calculations or simple finite element models are required to quantify these demands.

Table 5.6 Type IV Tank Drawings for Comparison

\begin{tabular}{|l|c|c|c|c|c|}
\hline Tank & Tank & $\begin{array}{c}\text { Composite Tank } \\
\text { Details }\end{array}$ & $\begin{array}{c}\text { Wall \& Floor } \\
\text { Reinforcement }\end{array}$ & $\begin{array}{c}\text { Dome } \\
\text { Reinforcement }\end{array}$ & Steel Liner \\
\hline IV(a) SX & $\mathrm{H}-2-39511$ & $\mathrm{H}-2-39512$ & $\mathrm{H}-2-39513$ & $\mathrm{H}-2-39511$ \\
\hline IV(b) $\mathrm{A}$ & & $\mathrm{H}-2-55911$ & $\mathrm{H}-2-55912$ & $\mathrm{H}-2-55913$ & $\mathrm{H}-2-55911$ \\
\hline IV(c) A & $\mathrm{X}$ & $\mathrm{H}-2-44562$ & $\mathrm{H}-2-44562$ & $\mathrm{H}-2-44565$ & $\mathrm{H}-2-44562$ \\
\hline
\end{tabular}


Table 5.7 Type IV Tank Structural Features Comparison

\begin{tabular}{|c|c|c|c|}
\hline \multicolumn{4}{|c|}{$\begin{array}{l}\text { Single-Shell Tanks Having a Capacity of } 1,000,000 \text { - Gallons Located in Tank } \\
\text { Farms A, AX, And SX }\end{array}$} \\
\hline \multirow[b]{2}{*}{ Comparisons } & \multicolumn{3}{|c|}{ Tanks } \\
\hline & A & AX & SX \\
\hline \multicolumn{4}{|l|}{ Geometry } \\
\hline -cylindrical diameter, 75 feet & * & * & * \\
\hline - steel liner thickness, 0.375 inches & * & * & \% \\
\hline - concrete thickness, $15 / 24$ inches & * & * & 承 \\
\hline - inside radius, 1140 inches at apex & *. & & ${ }^{*}$ \\
\hline-1410 inches at apex & & \# & \\
\hline - concrete thickness, 15 inches & * & $*$ & $*$ \\
\hline Base Slab - steel liner (lower corner) - 4 in radius & & $\#$ & \\
\hline - right angle & * & & 8 \\
\hline- concrete -6 inches (flat) & & (1) & \\
\hline-8 inches ( $569.82 \mathrm{ft}$ radius) & & & 并 \\
\hline Reinforcement - shell, additional vertical bars & (2) & (2) & (2) \\
\hline- dome & * & \# & is \\
\hline - haunch & \% & \# & 8 \\
\hline - base slab & \% & * & * \\
\hline \multicolumn{4}{|l|}{ Materials } \\
\hline ASTM A283-52 & * & * & *is \\
\hline ASTM A201-61 & & \# & \\
\hline -reinforcement ASTM A15-50 & 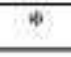 & & ${ }^{6}$ \\
\hline ASTM A $15-58$ & & $\#$ & \\
\hline Concrete $-3000 \mathrm{psi}$ & (⿻ & & $*$ \\
\hline$-4000 \mathrm{psi}$ & & $\#$ & \\
\hline
\end{tabular}

Notes:

1.18 inches

2. Reinforcement steel is somewhat different for each tank design.

3. The ${ }^{-k^{*}}$ indicates that the comparison is the same as another tank and the "\#" indicates that the comparison is applicable only to that tank

ANSYS $^{\star}$ Version 12.0 was used in all the analyses of Type IV(a) and Type IV(b) models. The dimensions for these tanks were taken from the "as built" drawings listed in Table 5.7. While building the 3-D finite element (FE) model, a 2-D geometry was initially built to represent the cross section, and is later swept (rotated) about the central axis through a two degrees to get the 3-D slice model. Unlike in DST TOLA (Deibler et al. 2004) analysis, where the angle of a slice was chosen to obtain a 24 -inch element length at circumference to represent anchor bolt spacing, here the rotation angle was chosen to obtain elements of good aspect ratios in the FE model, as there are no anchor bolts in SST and the stecl liners do not extend beyond walls into the dome in SSTs. Both IV(a) and IV(b) models were modeled with maximum soil overburden values reported for such types of tanks in those tank farms. The overburden values are 6.82 feet and 7.51 feet for IV(a) and IV(b), respectively (Table A.14, Rifaey et al. 2002). Similar to DST TOLA (Rinker et al. 2004) analysis, the sub-grade undisturbed soil depth is specified at 168 feet below the foundation. The radial extent of the soil, 240 feet, is nearly seven times the radius of the tank. The rationale for these dimensions is described in the Chapter 3 of the DST TOLA report. Since most of the case studies were performed using the A Farm tanks (Type IV-b), the soil properties and the depth and radial extent of soil in the models could be adapted from DST TOLA baseline (bounding) analyses. This is because both the DST baseline (AY Tank Farm) and the SST baseline (A Tank Farm, Type IV(b)) are closely located in the 200 East area and thus have the same soil 
stratigraphy. The compacted backfill excavation slope boundary that distinguishes backfill soil from undisturbed soil was not modeled in the analysis. A case study was performed to study the effect of excavation slope boundary on the forces and moments induced in the tank concrete sections. In the baseline (reference) model of Type IV(a) and Type IV(b) tanks, eight layers of backfill soil were modeled throughout the radial extent, and eight layers of undisturbed soil were included below the tank through a depth of 168 feet. The material properties for the concrete and soil are summarized in the SST Evaluation Criteria report.

SOLID65 elements with ability to simulate cracking, crushing, and creep are used to represent the reinforced concrete regions. As the condition of liner and stiffener rings is not exactly known, they were conservative excluded from the models. The soil surrounding the tank is modeled with SOLID185 elements, with Extended Drucker-Prager material model. The nonlinear contacts at the concrete and the soil interface use TARGE 170 and CONTA173 elements. The reinforced concrete is divided into regions that have different steel reinforcement ratios, where it is assumed that the thickness of each rebar is one inch. The volume fractions of steel and concrete (in one-inch thick slab) at the inner and the outer faces of the concrete tank at various sections was calculated and assigned as real constants to the rebar elements. For regions with non-zero reinforcement ratios, the element attributes include an element coordinate system and two rotation angles that identify the rebar orientation. In these regions the element coordinate system is defined such that the element $\mathrm{x}$-axis is parallel to the direction of vector connecting centroids of current and adjacent elements and $y$-axis is defined normal to this vector. These local coordinate systems are defined on the plane passing through z-centroids (plane passing through half the angle of slice) of the elements. The z-axis (for hoop reinforcement) for these elements will be automatically defined normal to the $x-y$ plane. Figures 5.86 (a) through (d) show various details of the finite element model of Type IV(b) tank. These details are similar for Type IV(a) tank models except for the values of volume fractions of steel and concrete at various locations in wall and slab regions. Figures 5.87 (a) through (d) show various details of the finite element model of Type IV(a) tank. 
RPP-46644, Rev.0

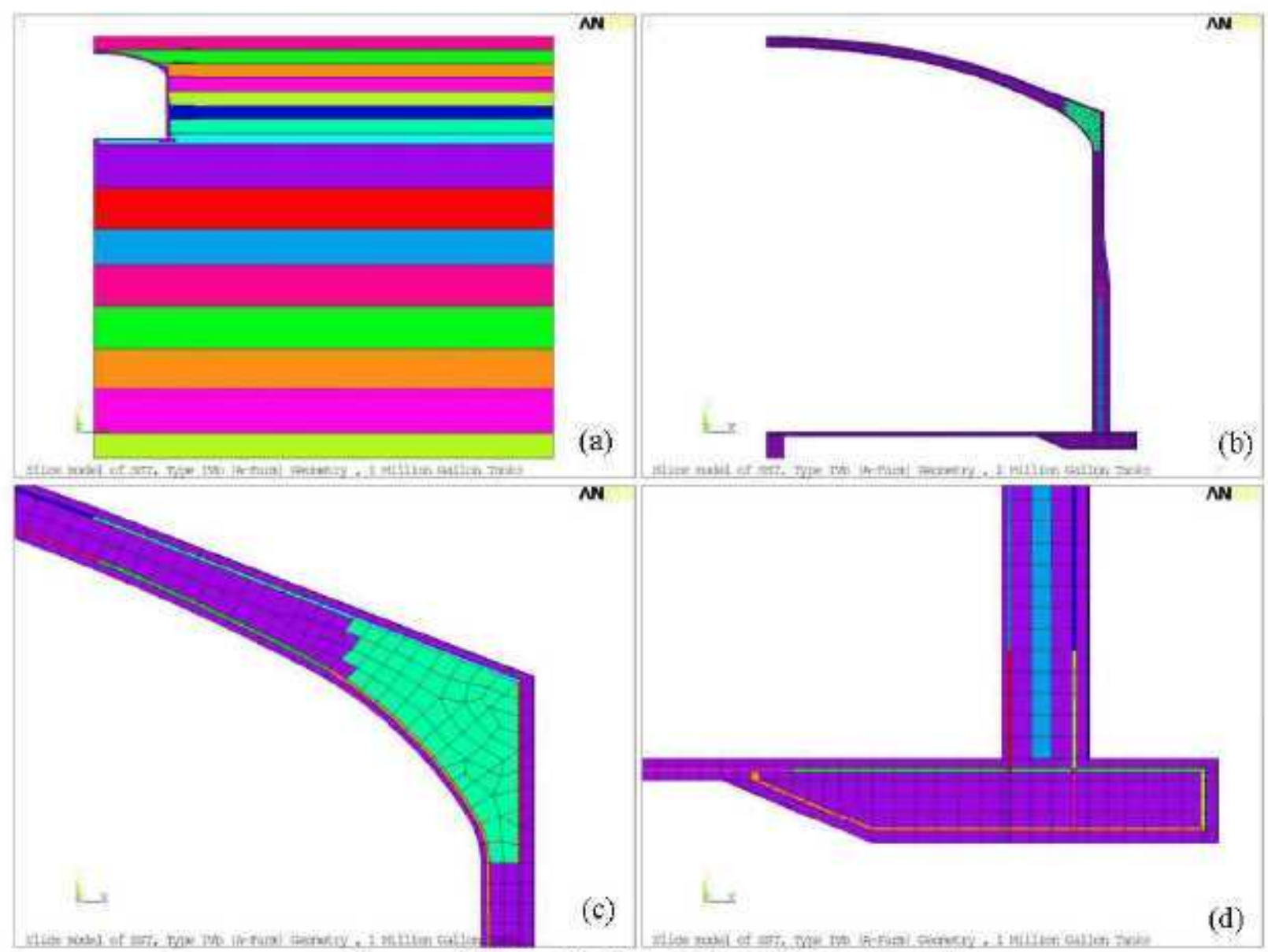

Figures 5.86(a) (d) Type IV(b) FE Model Detail 


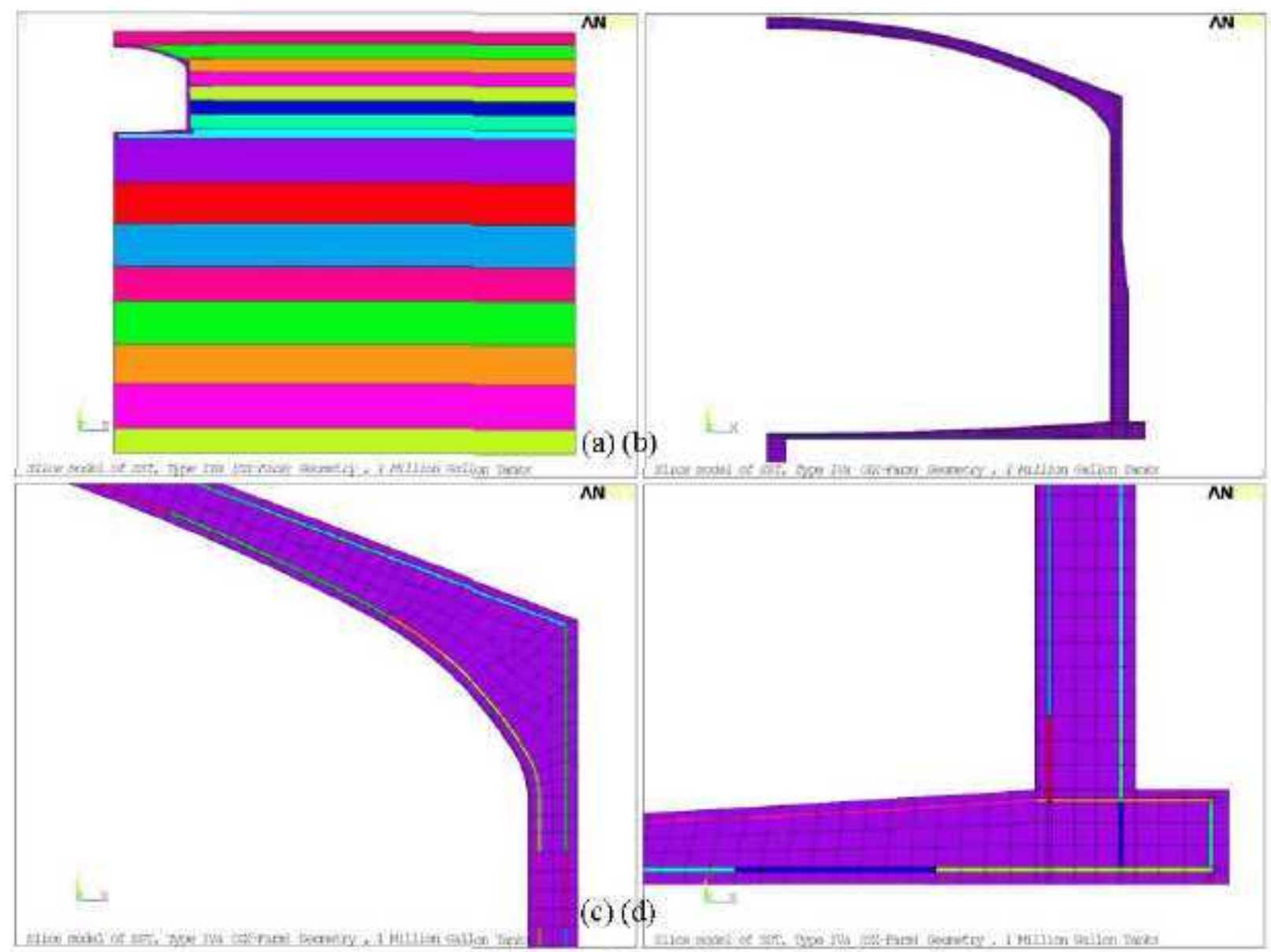

Figures 5.87(a) (d) Type IV(a) FE Model Details

In all the baseline models of Type IV tanks and the case studies using these tank models presented in the later sections, the following loads are applied as per the evaluation criteria document:

- Soil load (Soil overburden of $6.82 \mathrm{ft}$ for type IV-a and 7.51ft for IV-b @ 125lbft ${ }^{3}$ ) and self weight (gravity)

- Hydrostatic loads due to waste (350 in (a) 1.7 Specific Gravity)

- $40 \mathrm{lb}^{2} \mathrm{ft}^{2}$ uniform surface load to account for stiow, ashfall

- 200,0001 b concertirated load distributed over 15 -ft diameter circular area concentric with tank.

The mechanical loads were applied in three load steps, the first load step solves for gravity (self weight and soil overburden), the second solves for hydrostatic waste load, and the third load step solves surface live loads. The thermal loads are considered in the thermal analyses runs and are discussed in Section 4.3 .2 of this report.

\subsubsection{Case Studies}

Cases studies were perfomed to study the sensitivity of concrete section force and moment demands to excavation slope, radial extent of soil, and soil stratigraphy (properties and depth of soil layers). Only mechanical loads (live and dead loads) were applied in all these case studies. Thermal loads were not 
considered in these analyses. The following sections discuss the modeling aspects of each of these case studies and also the results from these analyses.

Case 1 - Soil Excavation Slope: The plot plan drawings H-2-39503 and H-2-55904 for SST Tank Farms SX and A respectively show an excavation slope nun to rise ratios of $1.25: 1$ and $1.5: 1$, respectively. beginning at a distance of 20 feet from the outermost tanks in the farm. This soil excavation slope forms a boundary between the compacted backfill and undisturbed soil that might induce some boundary effects in the models. However, neither is this bonndary realistic for all tanks in a tank farm nor is this boundary condition axisymmetric with respect to any tank's axis in a tank farm. Even the comer-most tanks in a farm have this boundary on only two of their sides, and hence, including such a boundary in an axisymmetric model may not represent an actual scenario. However, to study the significance of this boundary, an analysis was performed, using the A Farm model by including the excavation slope with run to rise ratio of $1.5: 1$ beginning at 20 feet from the tank foundation slab outer radius. The soil layers inside the excavated areas were modeled with compacted backfill, and the areas outside are undisturbed soil layers. Figure 5.88 shows the details of this model. Here, the idea is to study the effect of this boundary on force and moment demands in the concrete structure sections.

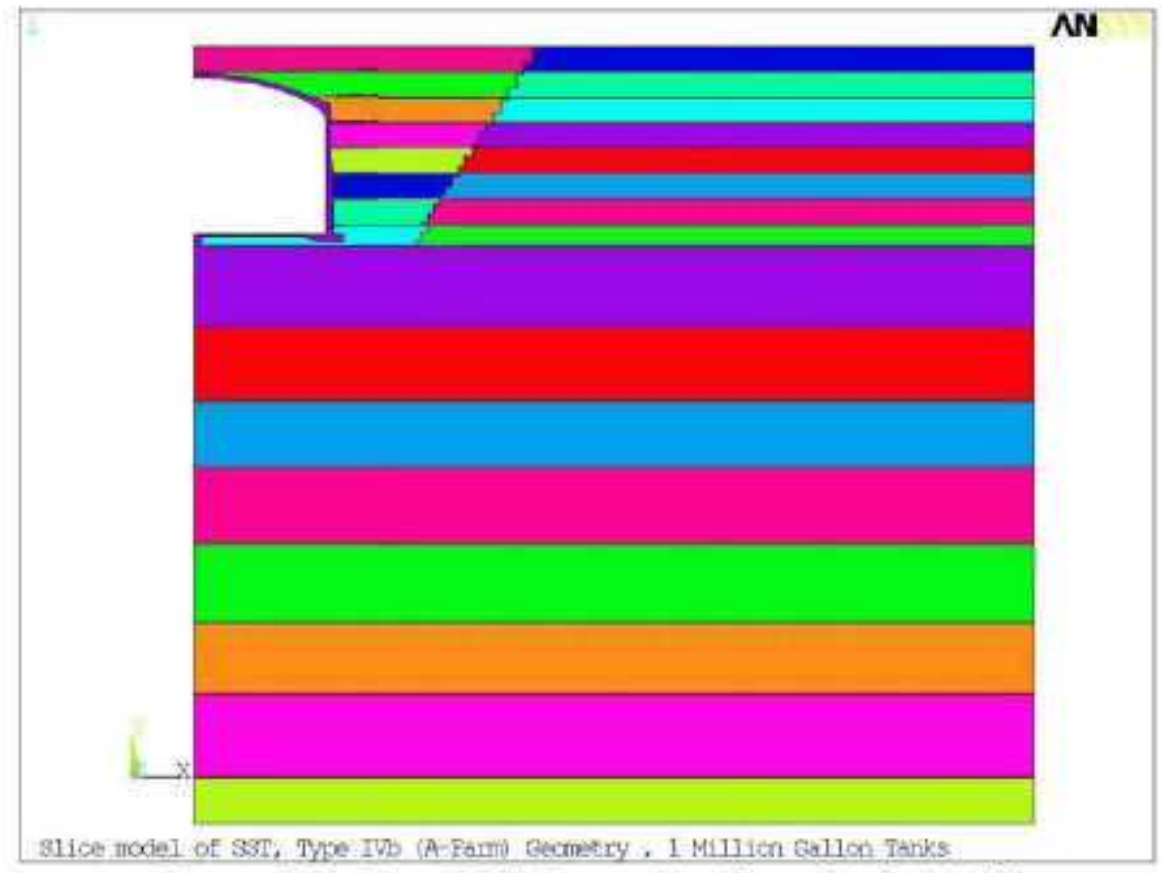

Figure 5.88 Type IV(b) Excavation Slope Study Model

Excavation Slope Resul ts: Figures 5.89 (a) and (b) show the location of ACI sections for Type IV(b) tanks, where the force and moment demands are calculated. 


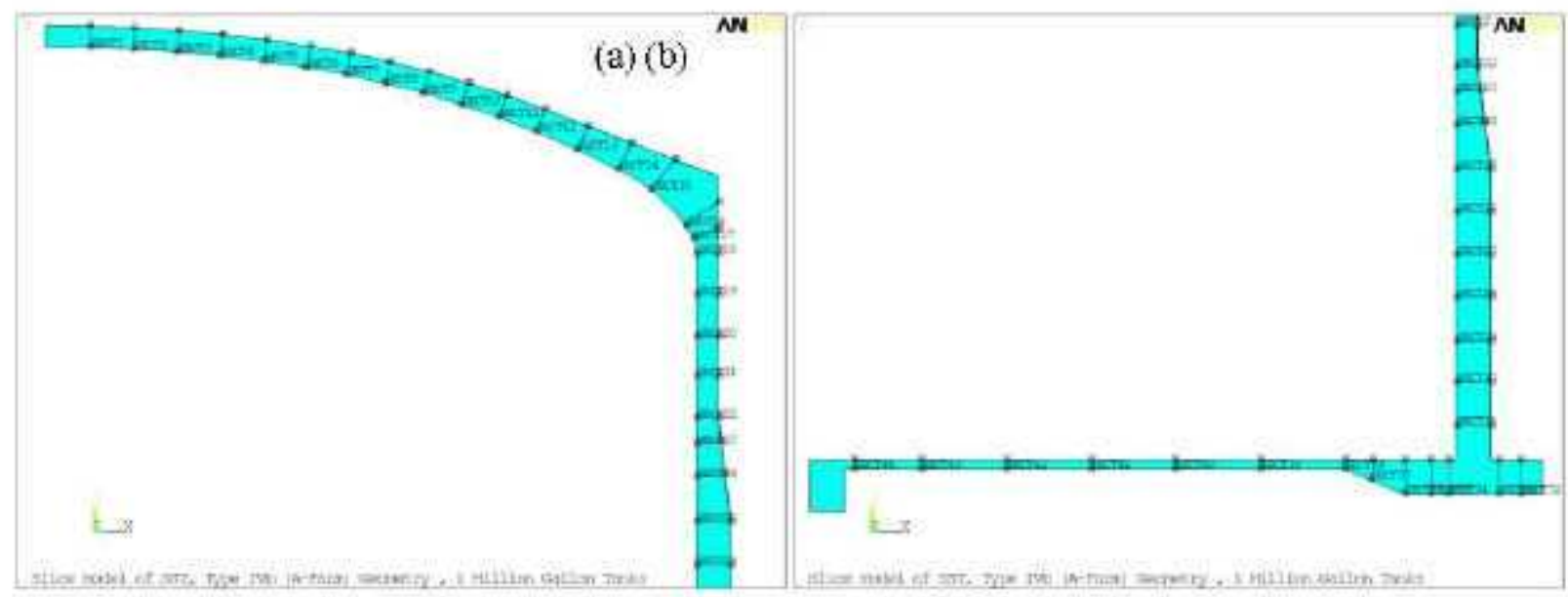

Figures 5.89(a) \& (b) Type IV(b) ACI Sections

Figures 5.90 through 5.94 show the effect of excavation slope on the sectional meridional force, meridional moment, hoop force, hoop moment, and shear forces, respectively. In these figures the sectional force and moment demands were compared against baseline demands ("no slope" lines). The results indicate that that except for the demands in hoop forces, shown in the wall in Figure 5.91, there is no significant change in the force and moment demands at various sections in the tank. Although no conclusive statement regarding inclusion of excavation boundary in the axisymmetricislice model can be derived without performing the full ACI evaluations, it can still be concluded that inclusion of such boundary will only result in conservative results in the wall.

Case 2- Radial Extent: In the baseline model of the Type IV(b) tank farm, the far-field horizontal dimension of the soil is taken as 240 feet, which is nearly seven times the tank radius as in DST TOLA analysis. The rationale for this dimension is presented in Section 3.5 of the TOL A report. However, this radial extent of soil may not be realistic for tanks in the middle of the farm where the nearest boundary is at the adjacent tank. Hence, to study the effect of this radial extent of soil in the FE models, two cases were simulated with half the baseline radial distance of 120 feet and with half the tank-to-tank distance of approximately 62.5 feet (Type IV(b), A Farm tank-to-tank center distance from drawing H-2-55901), and the resulting section forces and moment demands are compared against baseline demands. Figures 5.95 (a) and (b) show the details of 120-foot and 62.5-foot radial extent models, respectively. Except for the value of soil radial extent (parameter "ss" in input files), the model inputs for these cases are exactly same as the baseline model. 


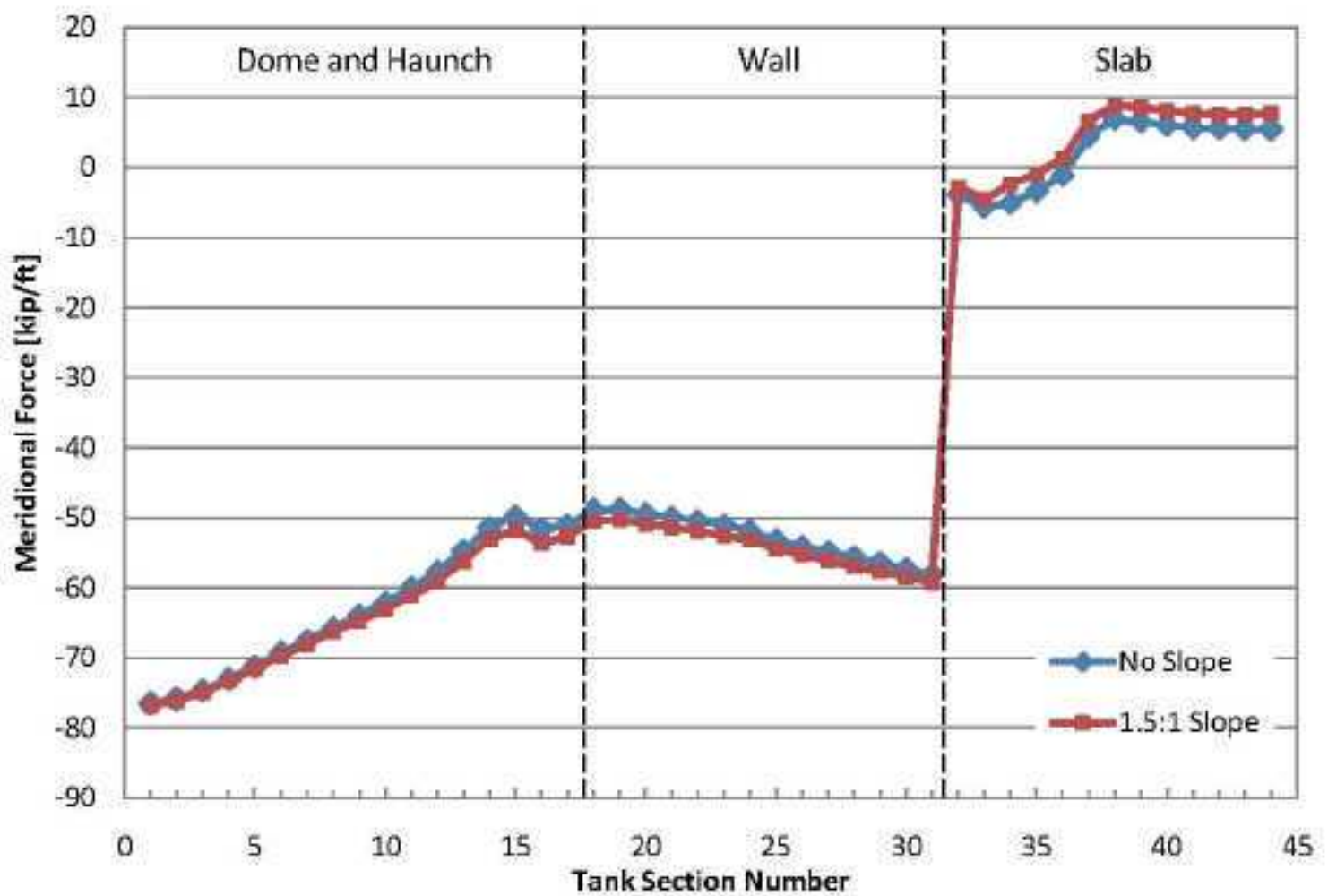

Figure 5.90 Type IV(b) Excavation Slope Study Meridional Forces

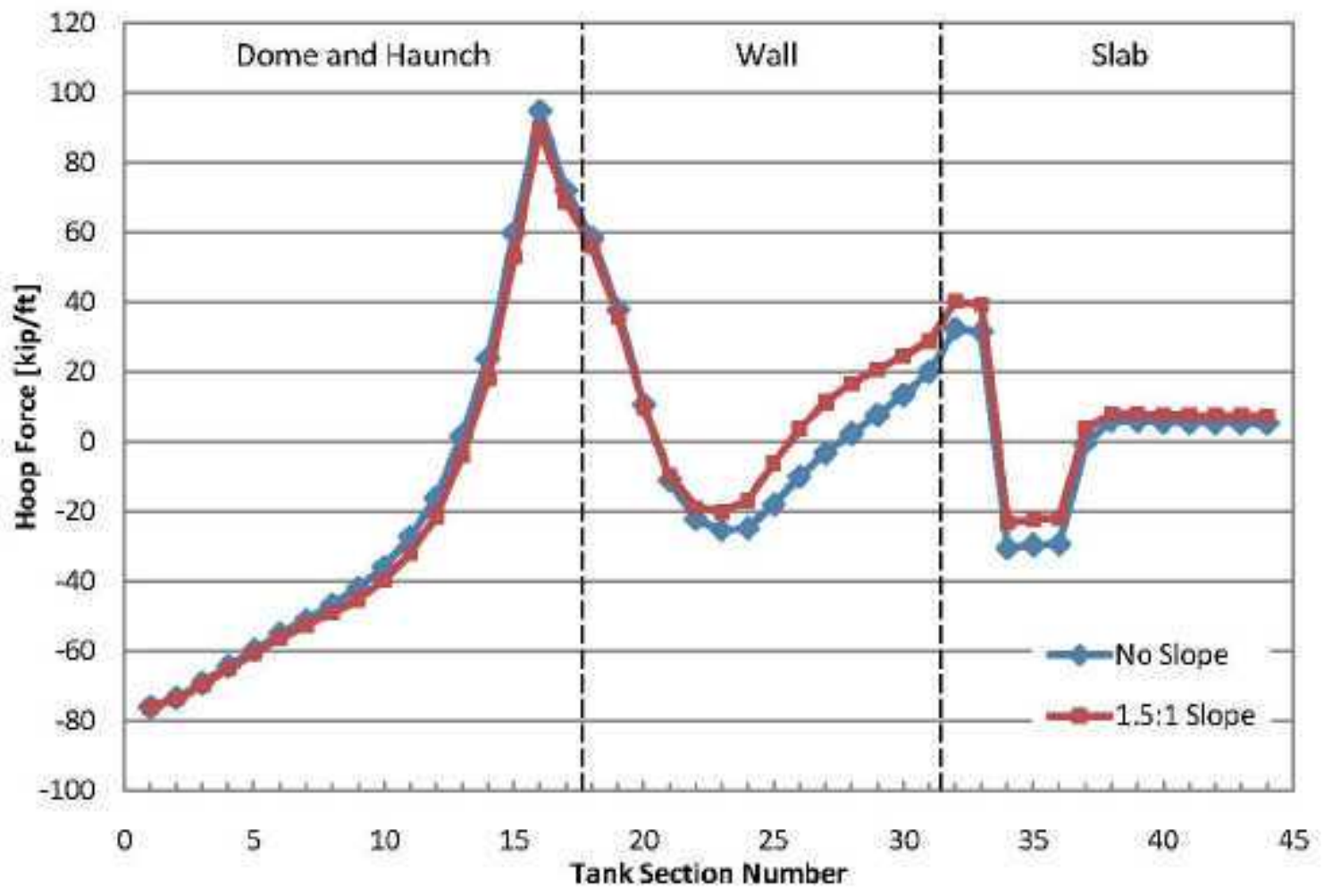

Figure 5.91 Type IV(b) Excavation Slope Study Hoop Forces 


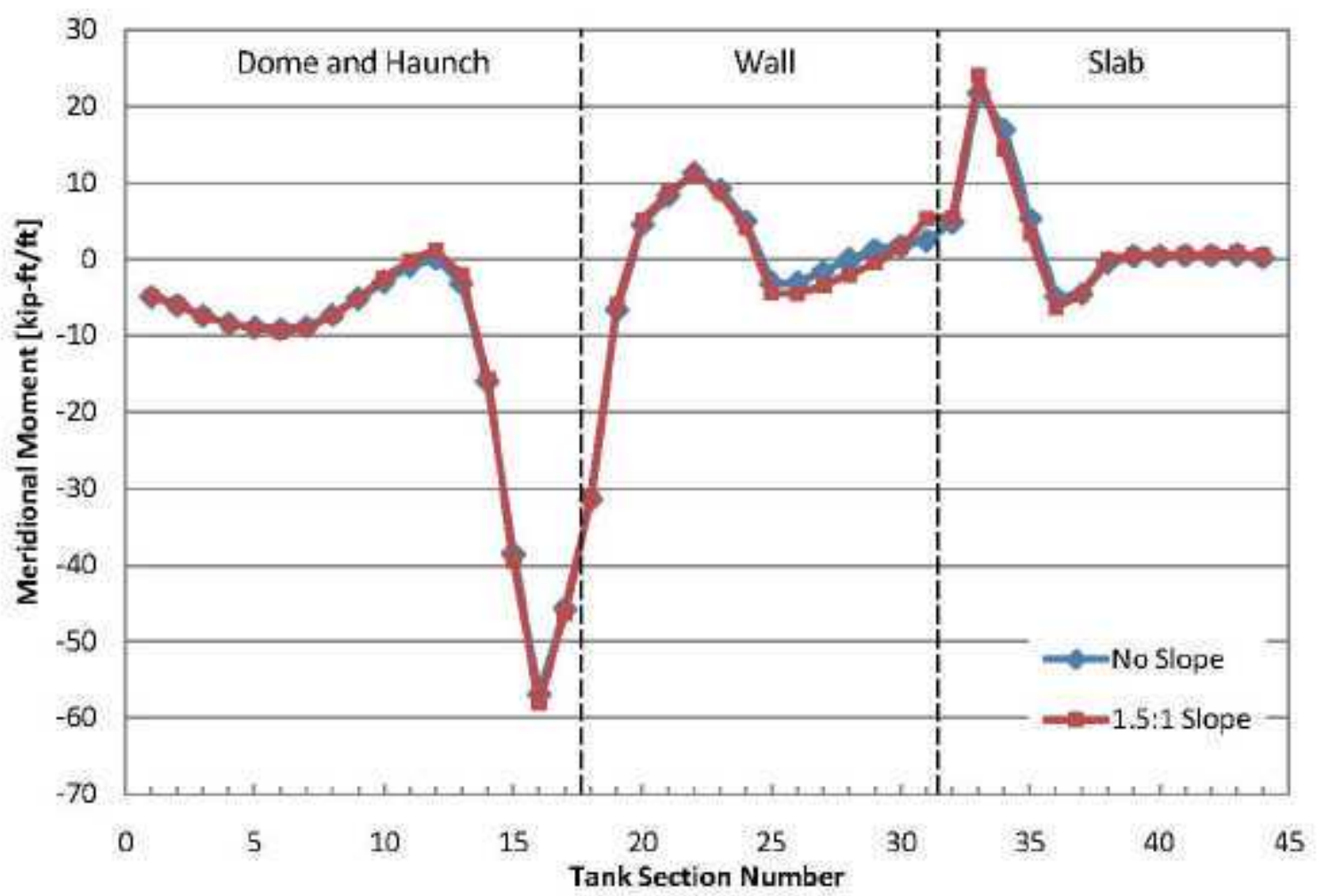

Figure 5,92 Type IV(b) Excavation Slope Study Meridional Moments

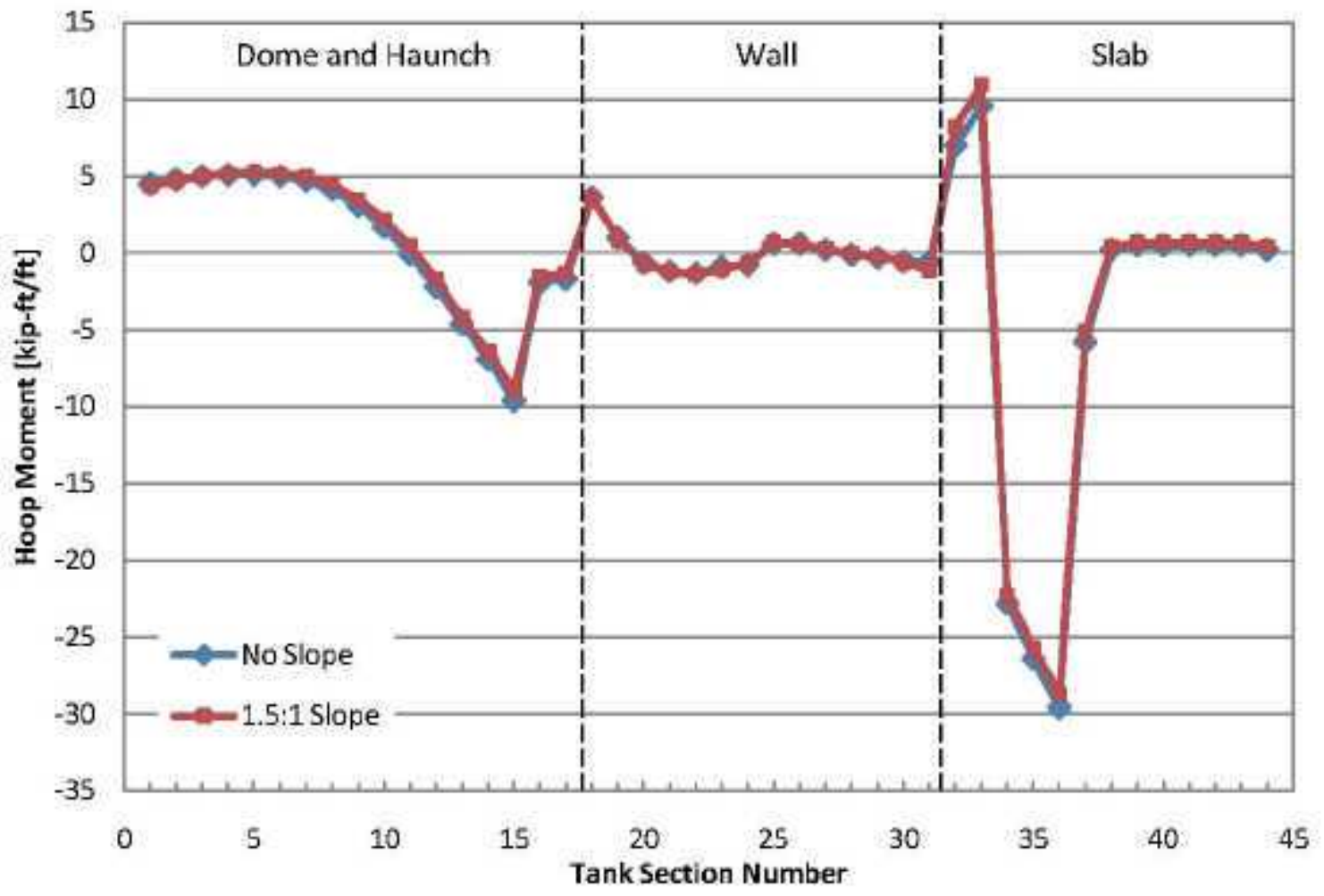

Figure 5.93 Type IV(b) Excavation Slope Study Hoop Moments 


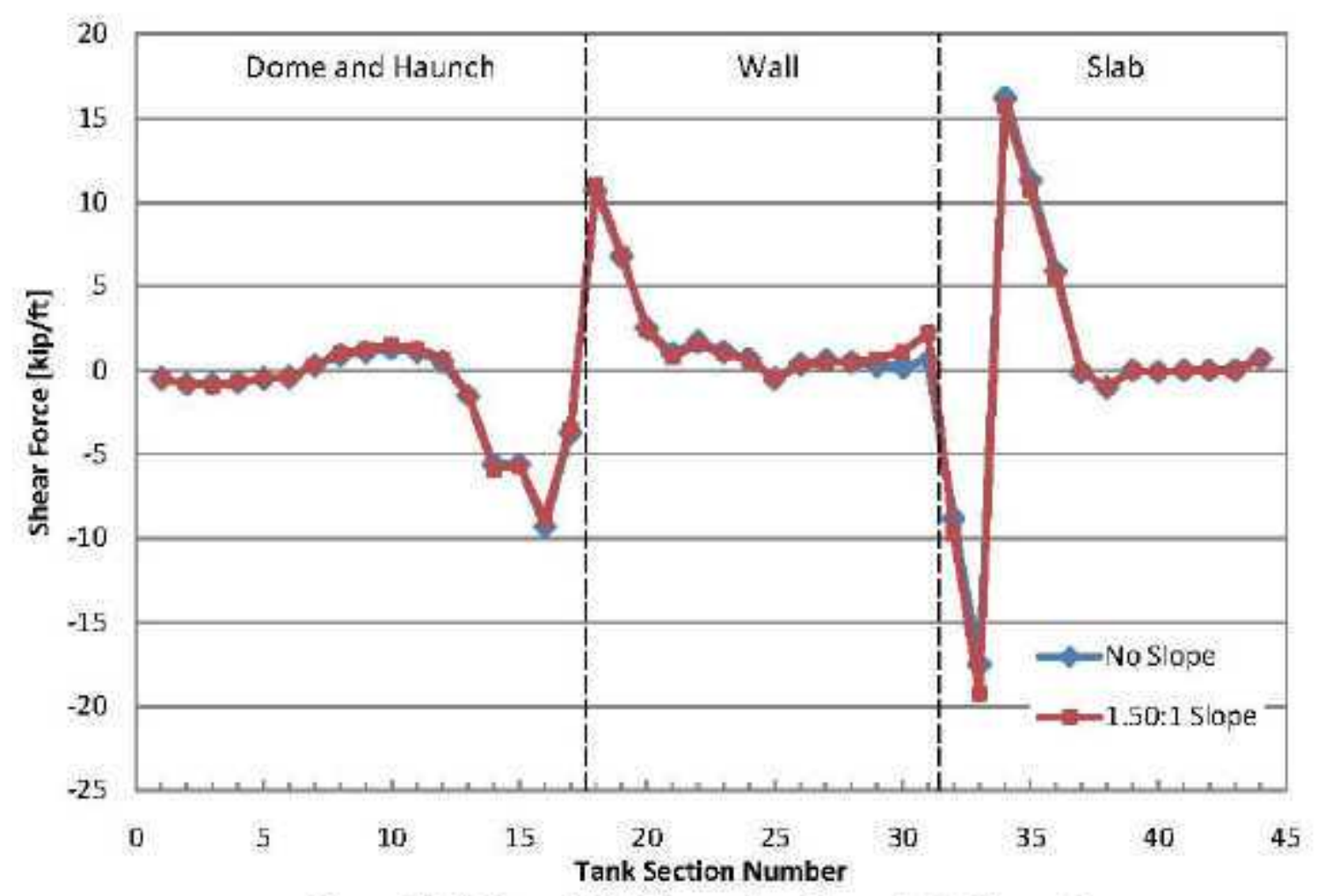

Figure 5.94 Type IV(b) Excavation Slope Study Shear Forces
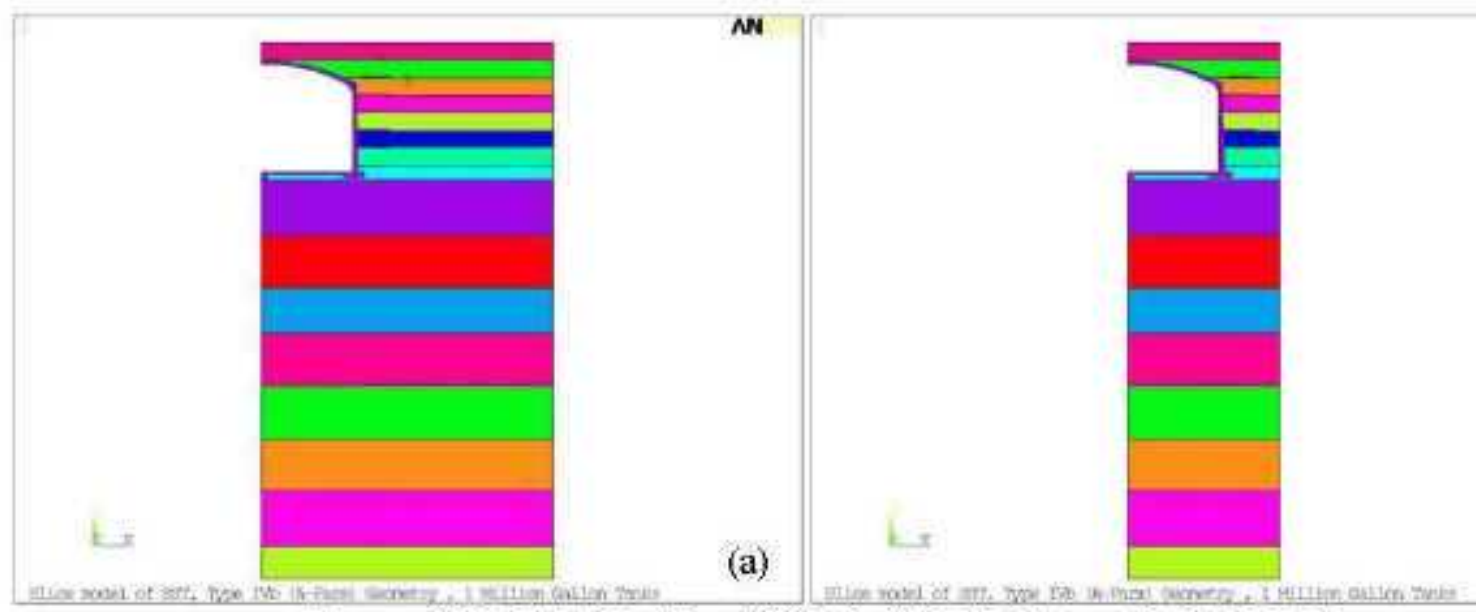

NN

Figures 5.95(a) \& (b) Type IV(b) Soil Radial Extent Study Models

\subsubsection{Radial Extent Results}

Figures 5.96 through 5.100 show the effect of soil radial extent consideration on the sectional meridional force, meridional moment, hoop force, hoop moment, and shear forces, respectively, In these figures the sectional force and moment demands were compared against baseline demands ( $R \times 240$ foot lines). Although these results are not enough to establish structural integrity until the capacities are calculated, they are sufficient to surmise that the radial extent of soil has no significant effect on the section forces and moments. It is clear from the results that there is little or insignificant change in the force and moment demands when the radial extent of soil is varied from 62.5 feet (half the tank-to-tank 
distance) through 240 feet (nearly seven times the radius) under mechanical loads. To further support this analysis, the radial stresses near the far-field soil boundary are observed each of these cases and compared against baseline case. Figures 5.101 (a) through (c) show the radial stresses at the far field boundary for 240 feet, 120 feet and 62.5 feet radial extent cases, respectively. It is clear that the radial stresses are very small and not significant enough to change the lateral soil loading on tanks to affect the force and moment demands.

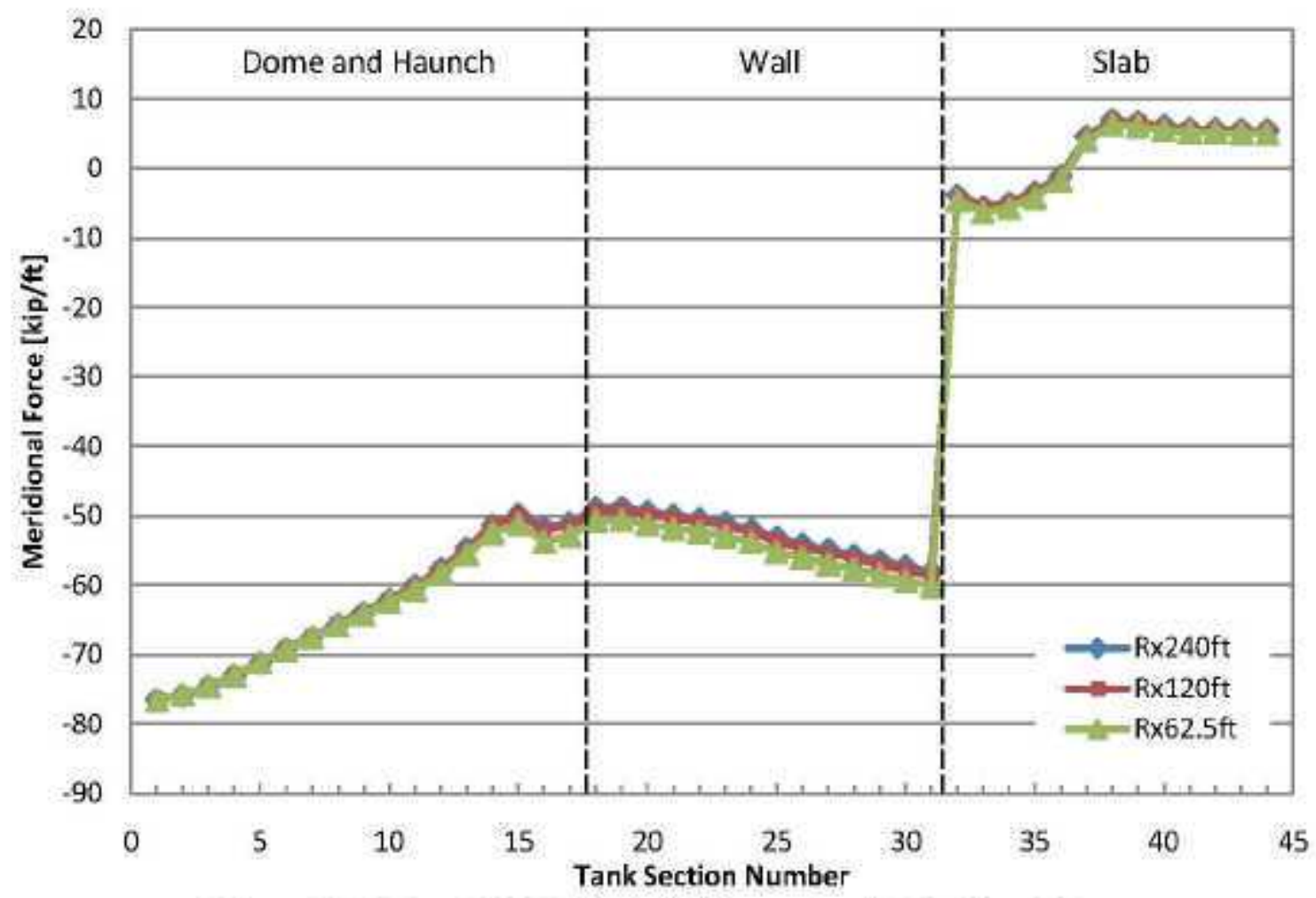

Figure 5.96 Type IV(b) Soil Radial Extent Study Meridional Forces 
RPP-46644, Rev.0

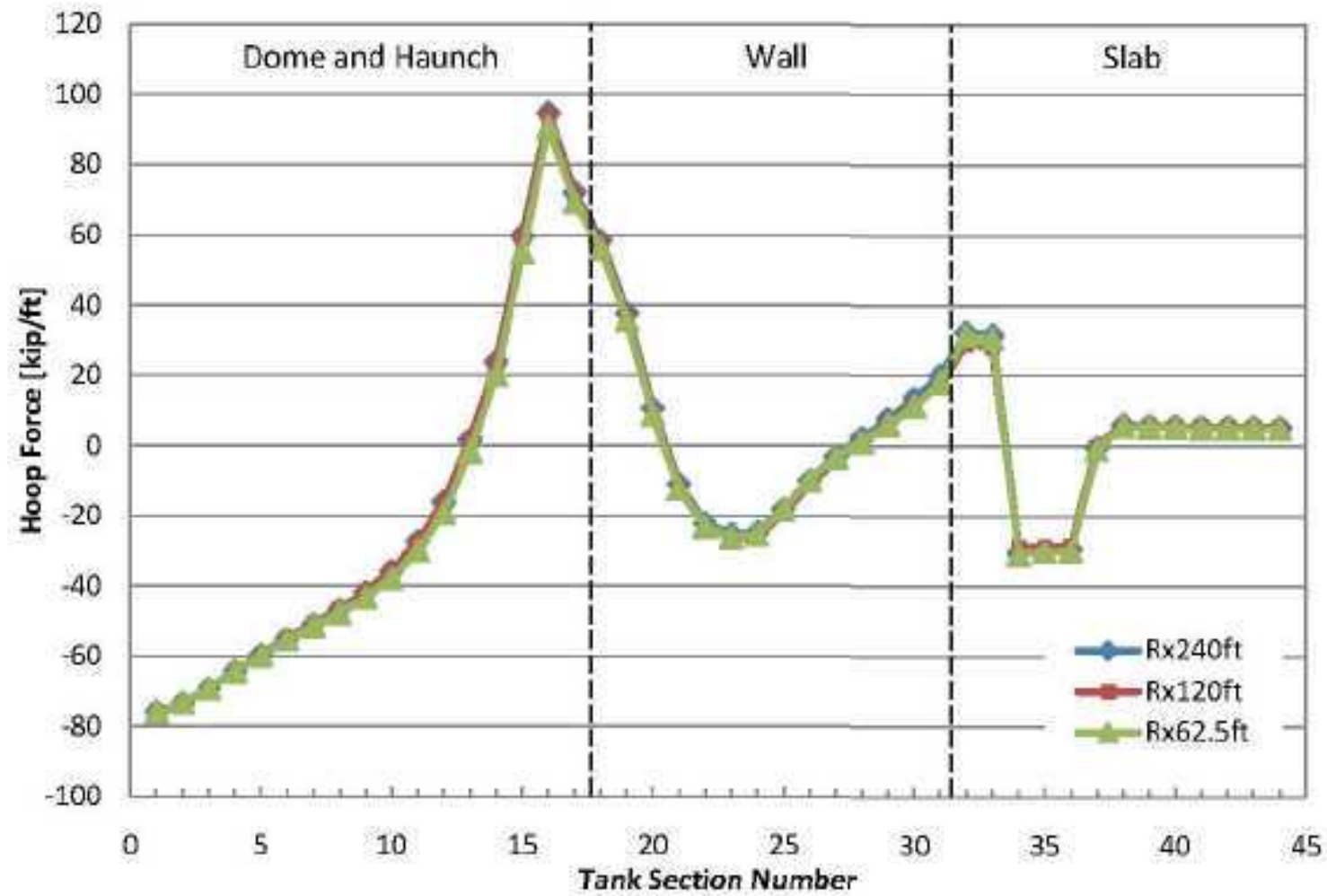

Figure 5.97 Type IV(b) Soil Radial Extent Study Hoop Forces

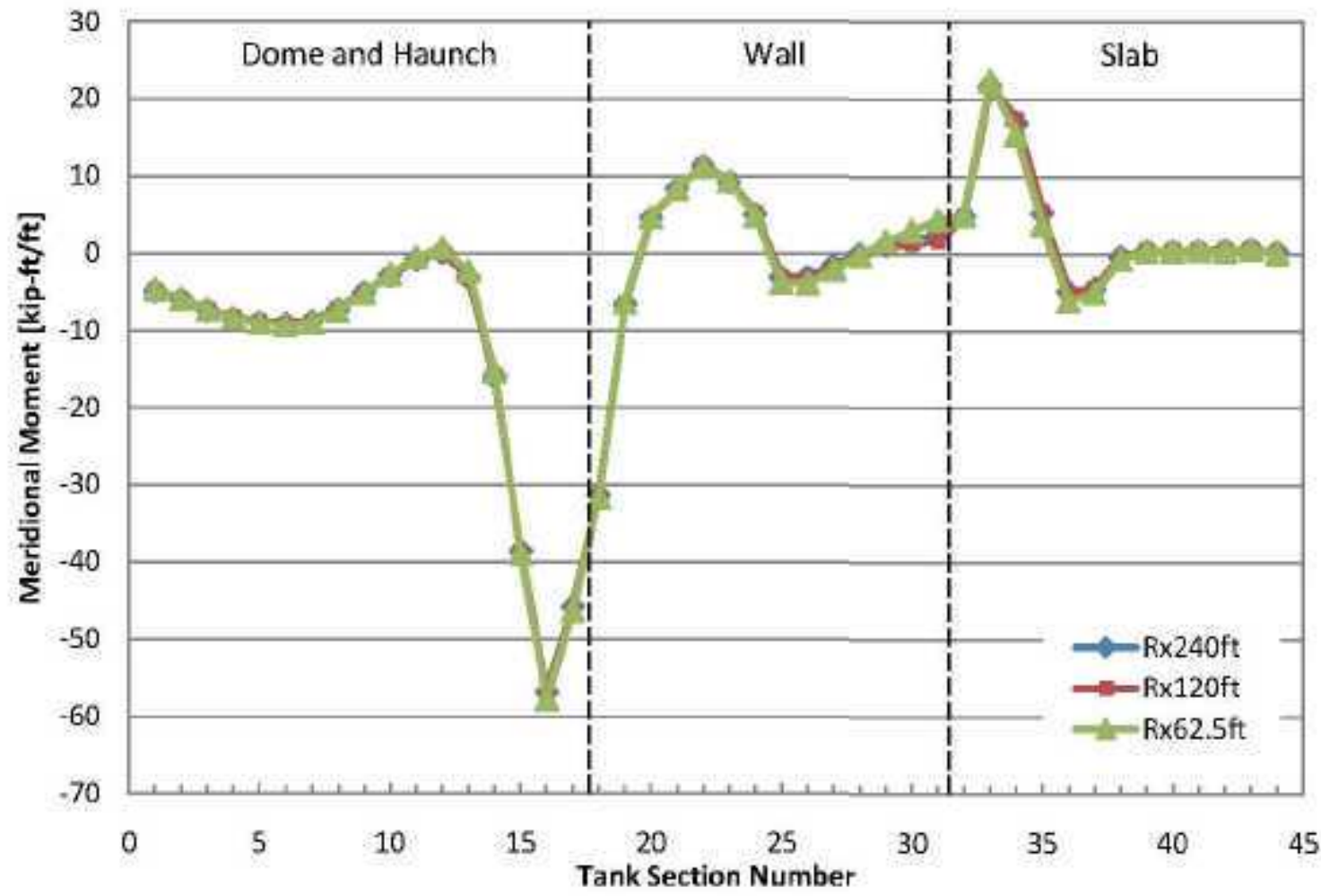

Figure 5.98 Type IV(b) Soil Radial Extent Study Meridional Moments 
RPP-46644, Rev.0

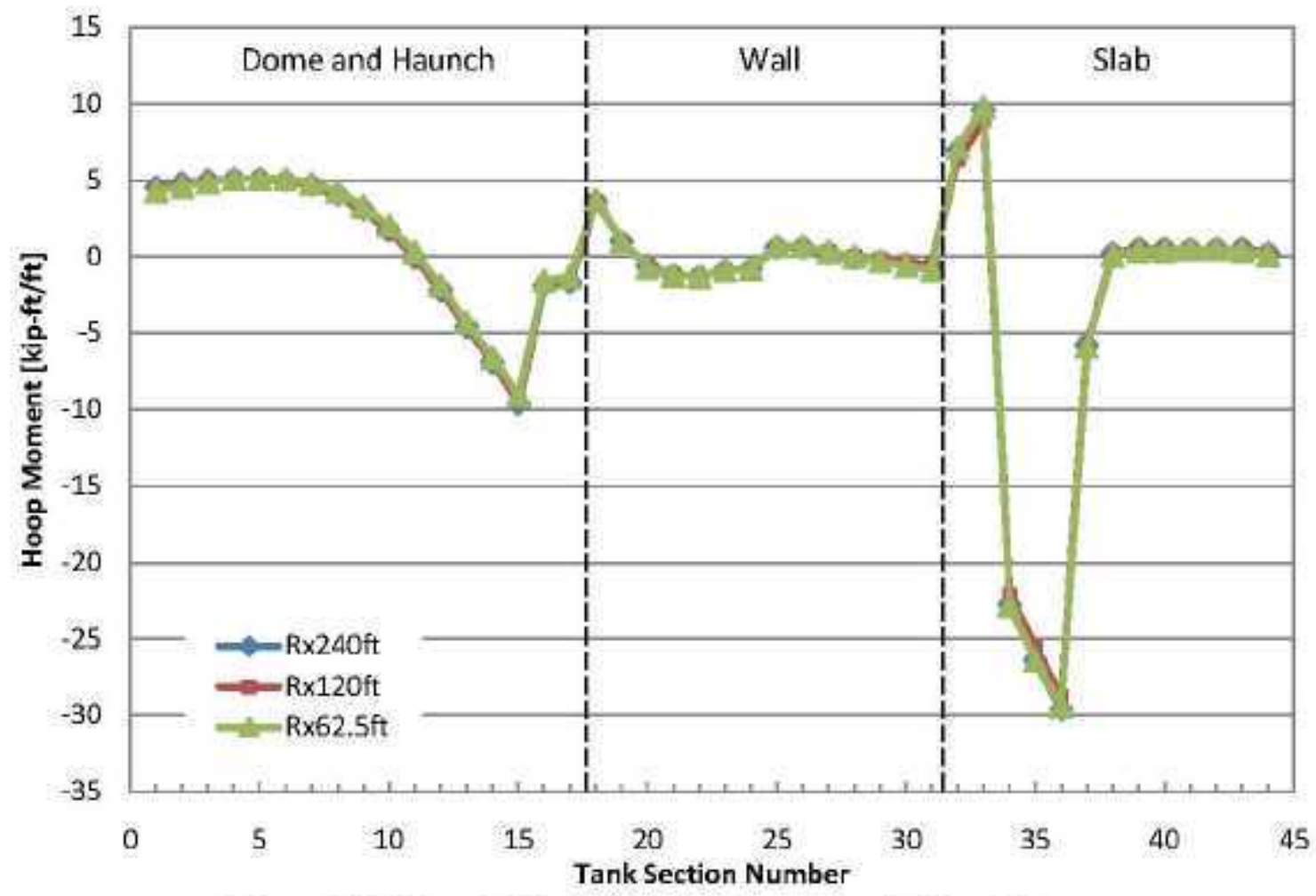

Figure 5.99 Type IV(b) Soil Radial Extent Study Hoop Moments

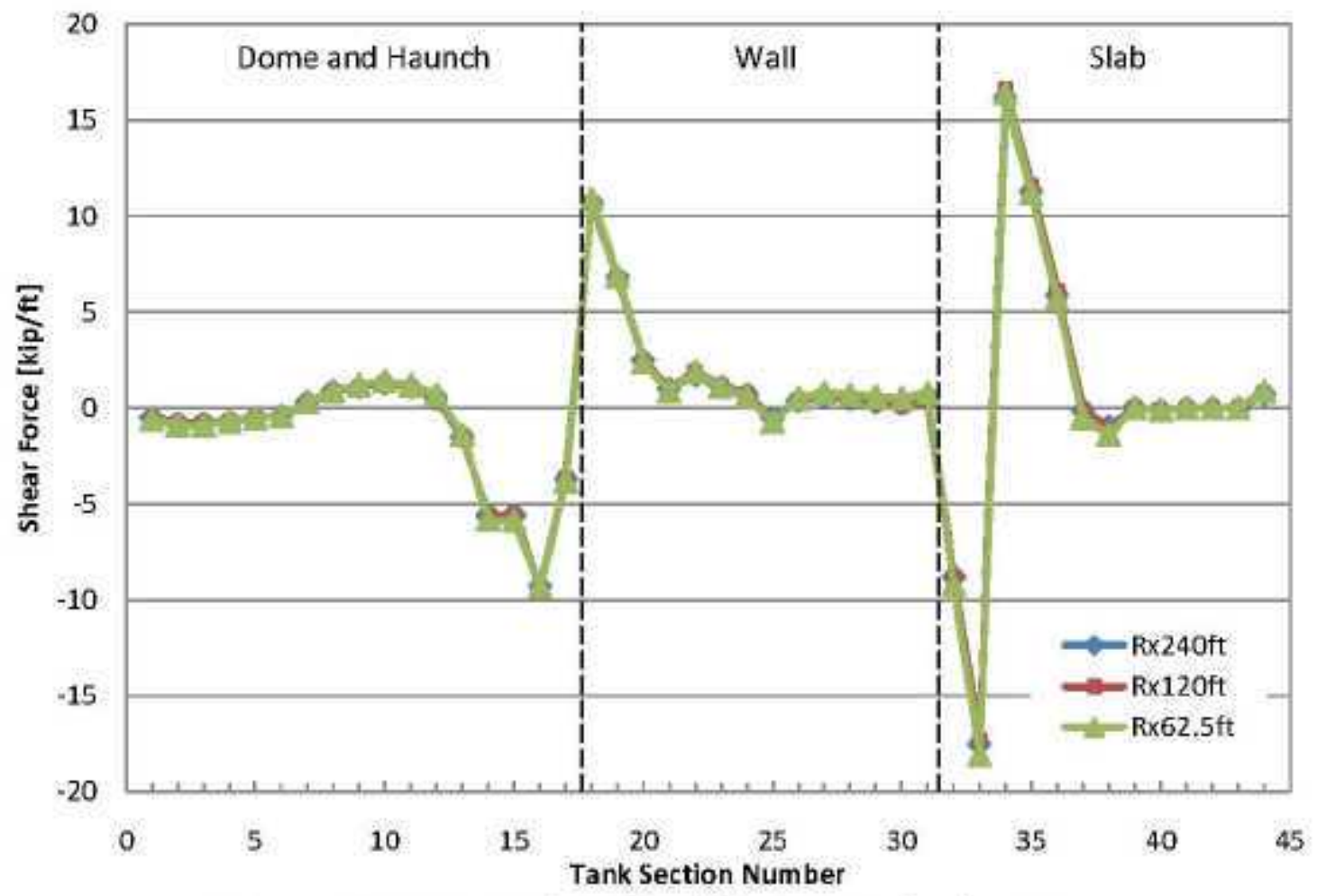

Figure 5.100 Type IV(b) Soil Radial Extent Study Shear Forces 


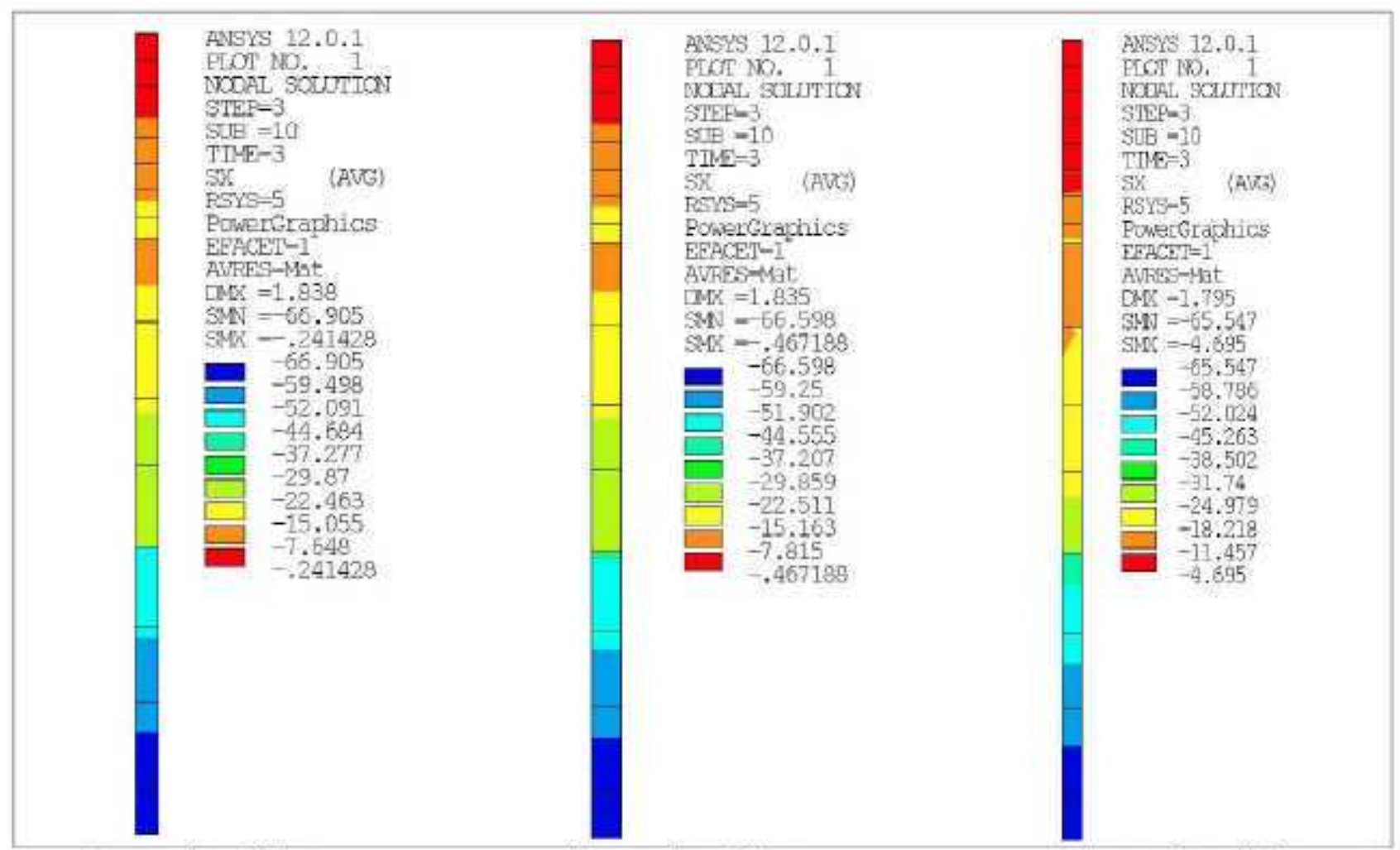
(a) $240 \mathrm{ft}$ Radial Extent
(b) $120 \mathrm{ft}$ Radial Extent
(c) $62.5 \mathrm{ft}$ Radial Extent

Figures 5.101(a)-(c) Far-Field Soil Radial Stresses

Case 3- Soil Layer Study: Since the soil stratigraphy varies at various SST farm locations in 200 East and 200 West areas, an analysis case was run to study the effect of this variation in soil stratigraphy (soil properties, layer thickness) on the section force and moment demands. The baseline Type IV(b) model uses soil layers similar to DST TOLA baseline analysis because both the DST baseline model AY-Tank farms and SST Type IV(b) baseline model of Tank Farm A are located closely in the 200 East area. The baseline SST Type IV(b) model uses eight layers of soil for compacted backfill modeled throughout the radial extent and eight layers of undisturbed soil below tank foundation. The analysis case contains four layers of backfill and four layers of undisturbed soil below tank foundation. The soil properties for this analysis case are obtained by taking the average values of the properties of two adjacent layers of soil in base line model, and the thickness of each layer is the sum of thicknesses of those adjacent layers considered for averaging the property values. Figure 5.102 shows the details of this four layer model. 
RPP-46644, Rev.0

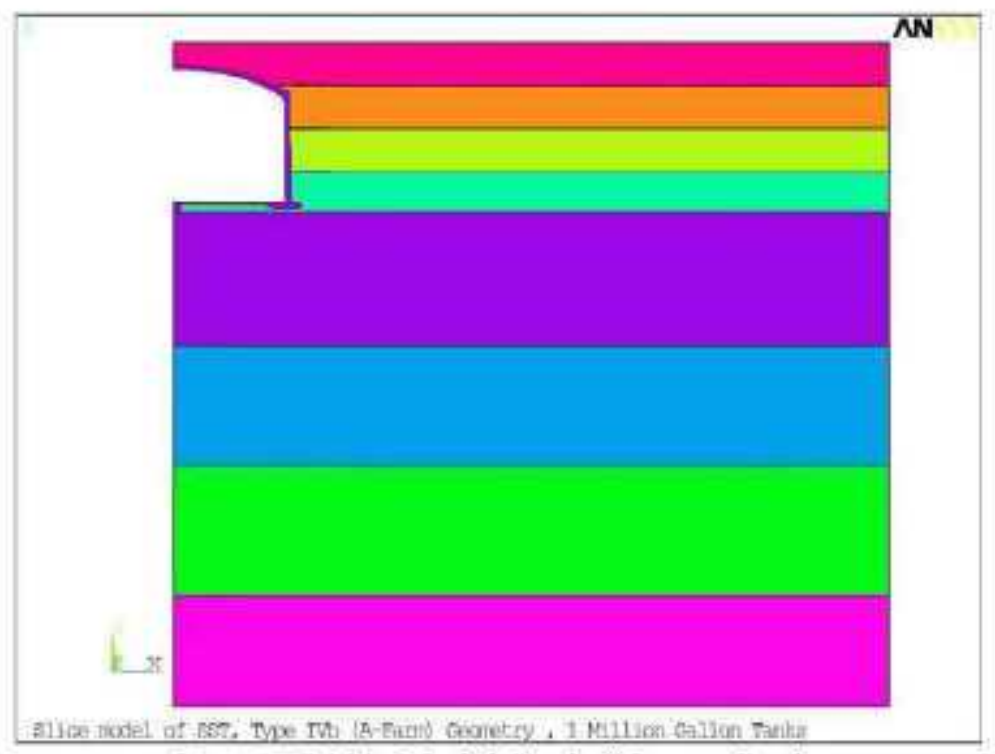

Figure 5.102 Model for Soil Layer Study

Soil Layer Study Results Figures 5.103 through 5.107 show the effect of soil stratigraphy on the sectional meridional force, meridional moment, hoop force, hoop moment, and shear forces respectively. In these figures the sectional force and moment demands were compared against baseline demands. Although these results are not complete to establish structural integrity until the capacities are calculated, these are sufficient enough to surmise that slight variation in thickness and material properties of soil layers has no significant effect on the section forces and moments. It is clear from the results that there is little or insignificant change in the force and moment demands when the averaged values of properties are used for adjacent layers of soil. 
RPP-46644, Rev.0

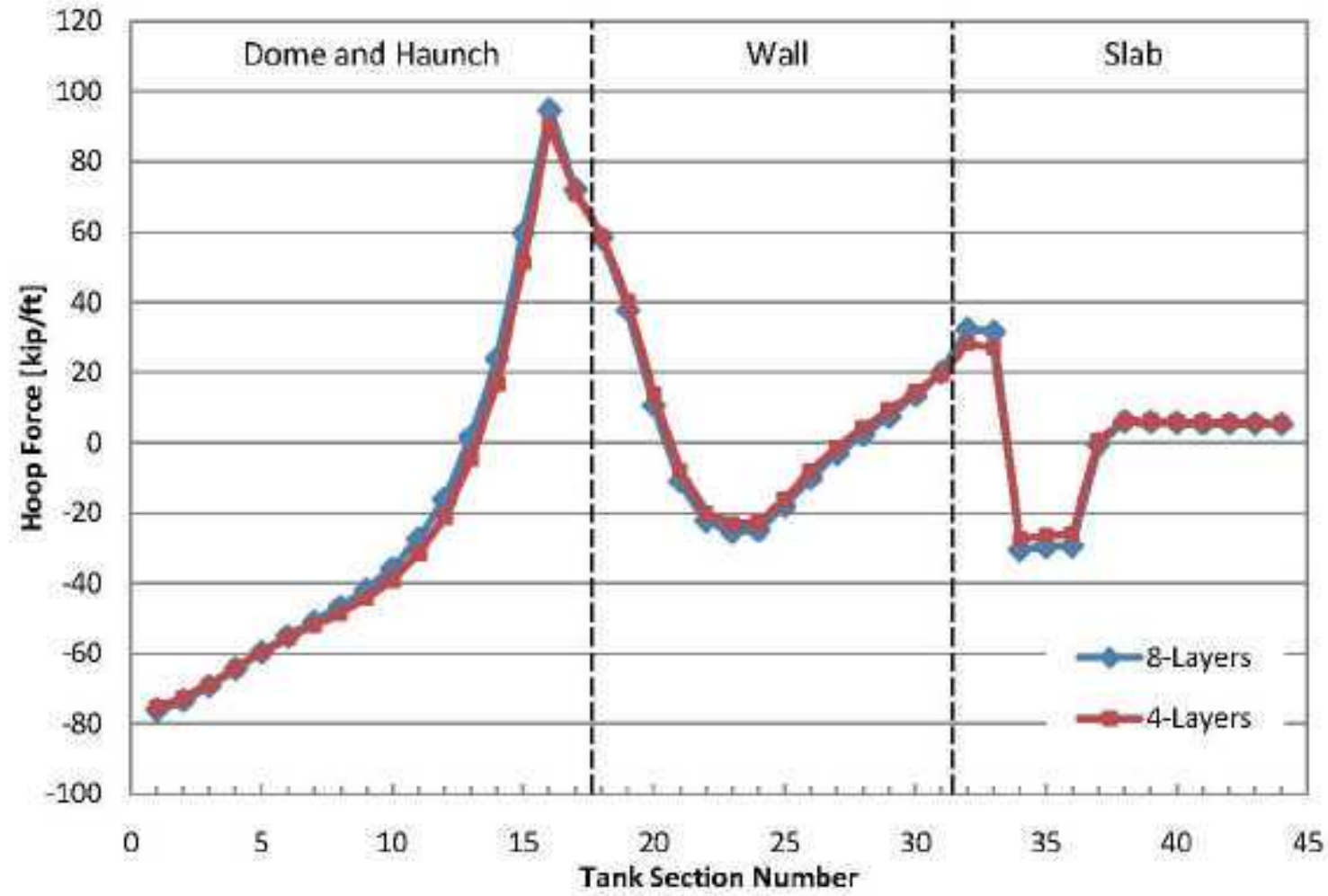

Figure 5.103 Type IV(b) Soil Layer Study Hoop Forces

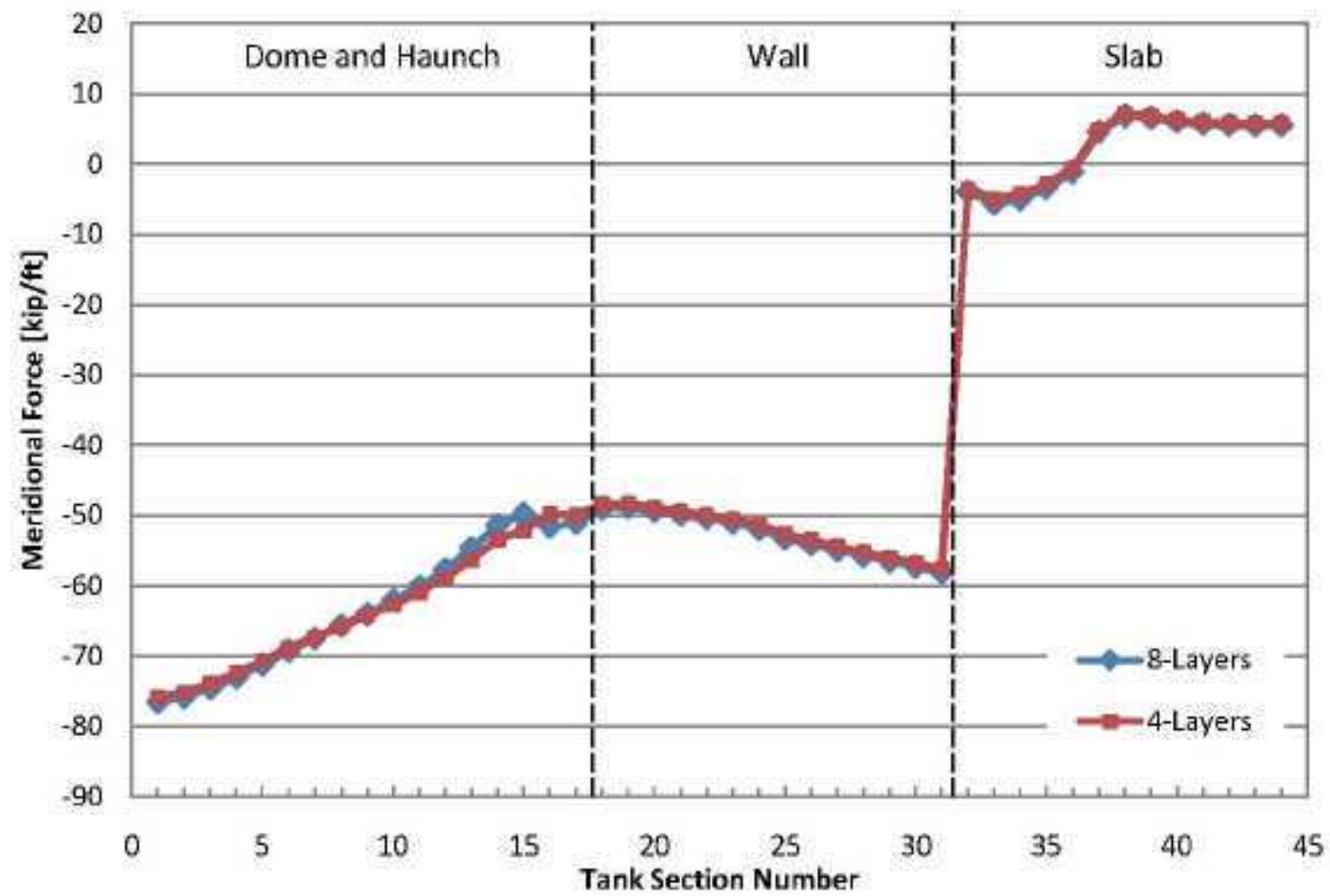

Figure 5.104 Type IV(b) Soil Layer Study Meridional Forces 
RPP-46644, Rev.0

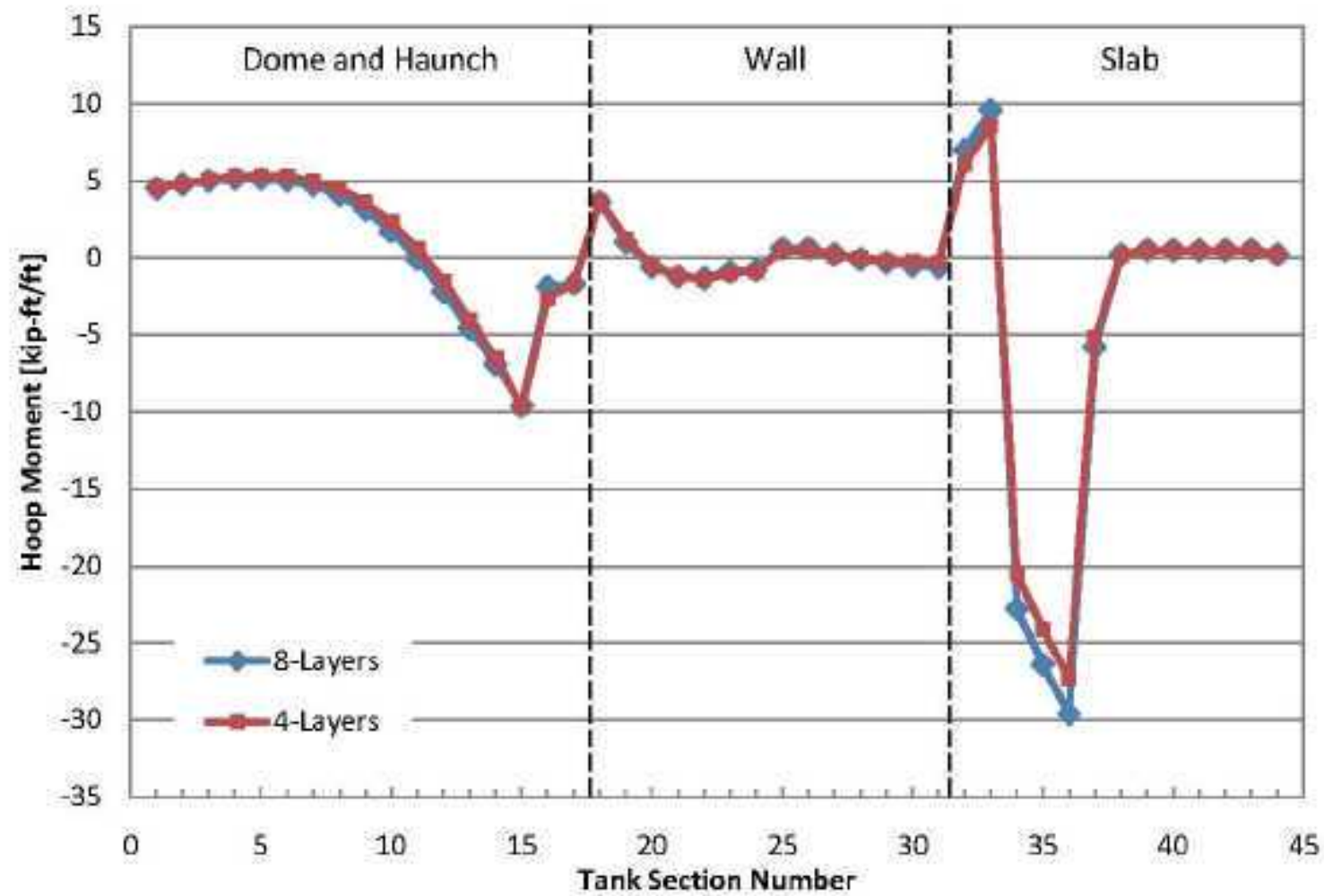

Figure 5.105 Type IV(b) Soil Layer Study Hoop Moments

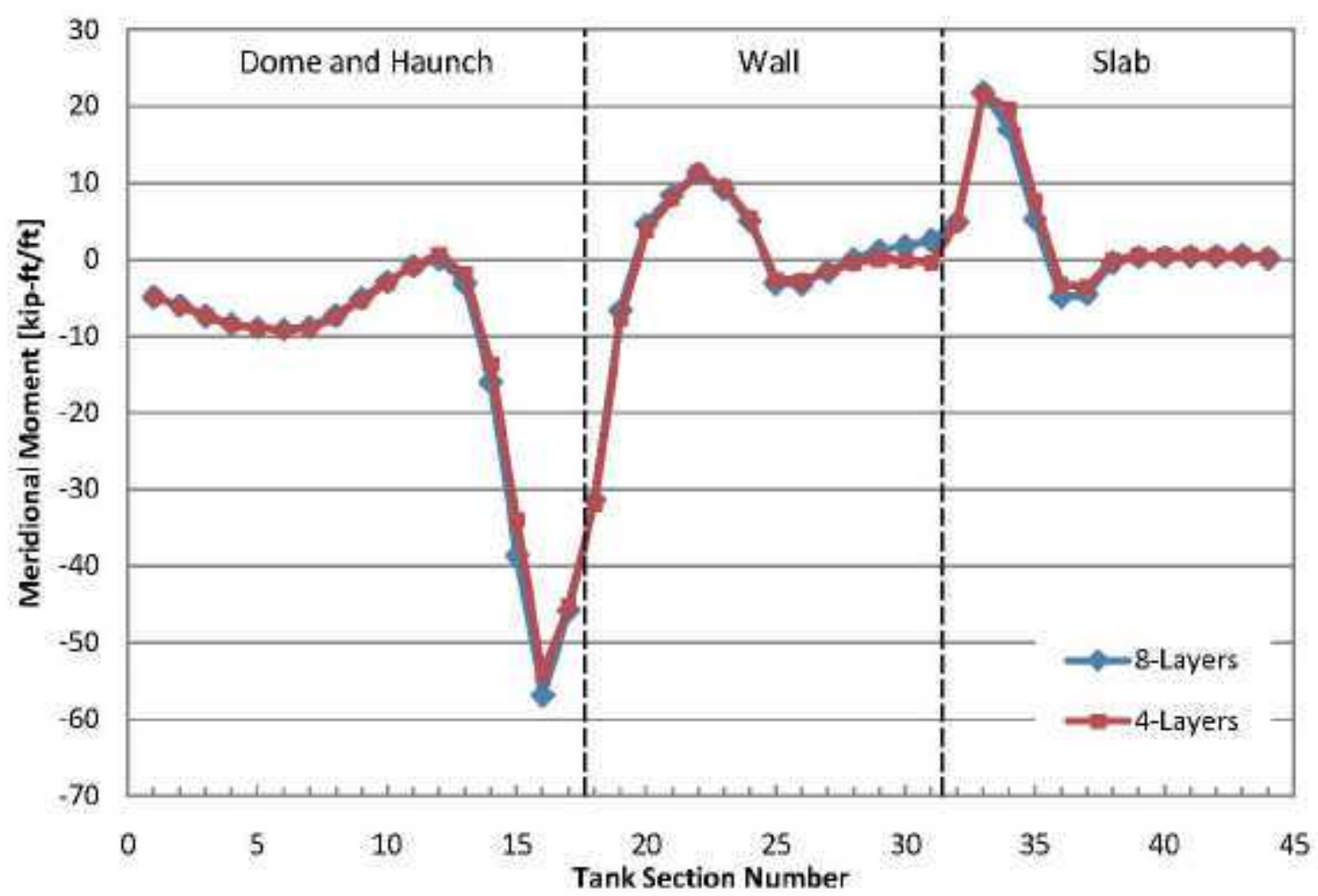

Figure 5.106 Type IV(b) Soil Layer Study Meridional Moments 
RPP-46644, Rev.0

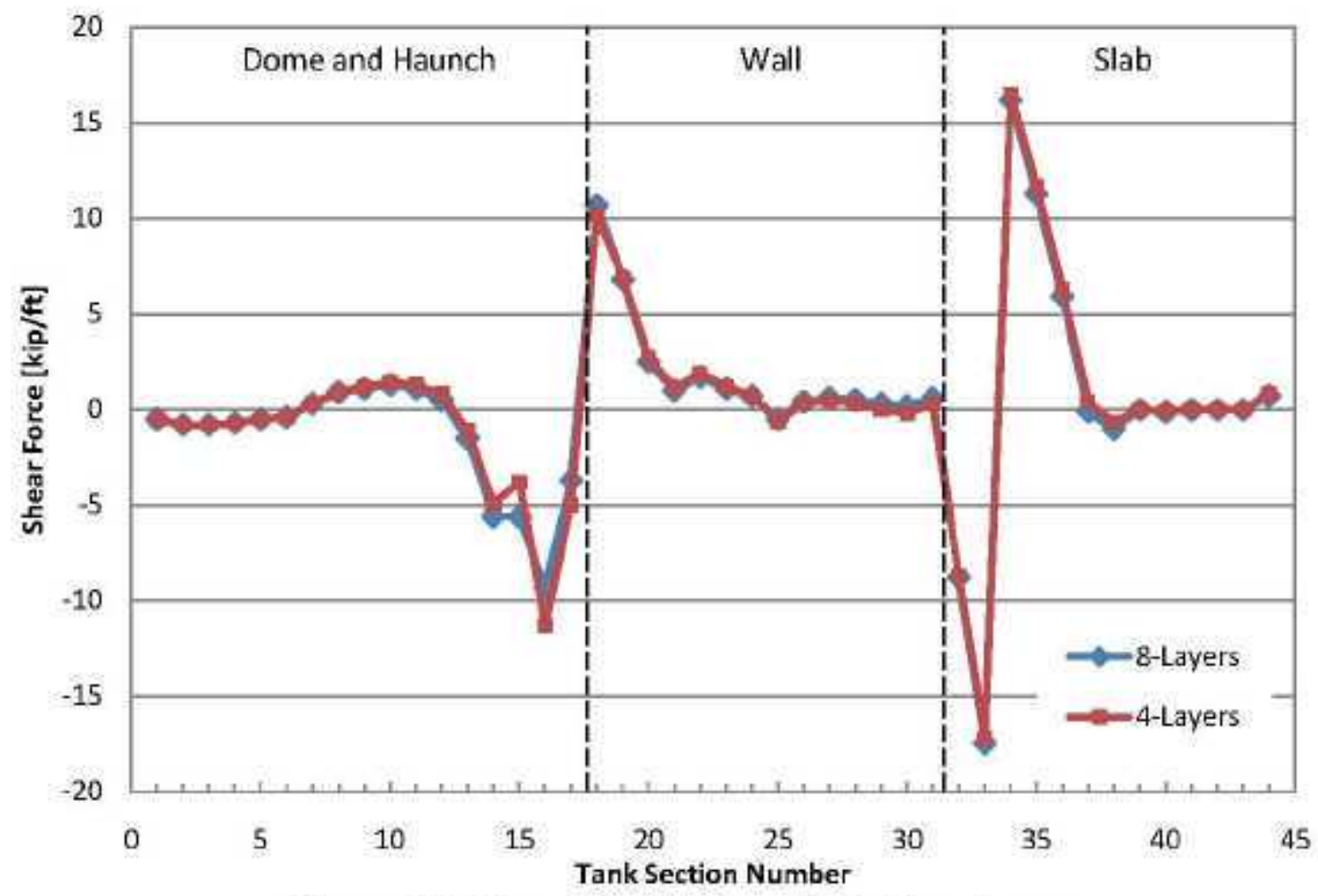

Figure 5.107 Type IV(b) Soil Layer Study Shear Forces 
RPP-46644, Rev.0

\subsection{Conclusion}

Single-shell tank (SST) reports and drawings were acquired and reviewed to compile detailed information needed for building SST finite element models. The reviews determined the level of detail necessary to perform the analyses of the SSTs. Preliminary modeling topics and their impact to tank structural integrity investigated were material properties, waste temperature and waste height histories, and tank geometry variations.

Document reviews for waste temperature history data of SSTs clearly indicate that the data is insufficient for detailed modeling phase, except for Type IV tanks. Reviews also point to the fact that there may be additional data in a raw form (handwritten) in the US Department of Energy's Richland Operations Office (DOE-RL) records in Seattle, Washington. It is necessary to conduct a deeper review of the raw data that may be available in these records and extract as much data as possible, so that at least a good basis could be established for some of the assumptions during the detailed modeling of Type I, II and III tanks. Type I, II, and III tank models were analyzed with representative thermal loads or best estimates, but final evaluation will occur in the Phase II detailed modeling. In most cases, for periods prior to 1975 , only one waste temperature value is available for cases where such temperature was at all available. The location of the thermocouples or thermometers has not been established beyond doubt due to conflicting descriptions from three different sources. In contrast, the temperature data available after 1975 contains up to 18 thermocouple measurements at different points through the waste height. It is necessary to obtain further temperature history data for all types of SSTs so that more accurate thermal stress analysis can be carried out during detailed analysis phase. In case no additional temperature data can be obtained, there are two proposed approaches. One approach is to apply the Type IV temperature profiles on Type I, II and III tanks. Type IV tanks have experienced the highest temperatures of all tank types and thus this can be viewed as a conservative approach. However, there is a possibility that the Type I, II and III tanks may not be able to pass the structural integrity test when subjected to such high temperatures. In such an event, the temperature profiles may be scaled down based on some criteria (to be established) such that the resulting profiles represent a more reasonable temperature profile for the Type I, II and III tanks.

The 2-D finite element models for thermal analysis include radiation, with lumped convection boundary conditions, to simulate radiation and convection from the waste surface to the tank dome and walls. The nodal temperature distributions are extracted from the 2-D thermal models and imposed on the 3-D slice models for thermal stress analysis. The thermal stress analysis models have sufficiently enhanced capabilities to simulate different spatial temperature distribution conditions and different temporal temperature variation conditions. The capabilities also include the ability to alter the material properties to degraded concrete properties. These capabilities provide great flexibility to simulate different stress analysis scenarios as well as sensitivity studies for all types of tanks during the detailed analysis phase. In light of availability of the transient thermal analysis models and their ease of implementation, these models should be utilized where necessary to carry out the thermo-structural analysis of the SSTs.

Studies comparing the rate of increase in waste temperature in Type IV(b) tanks indicate that a transient analysis produces significantly different forces and moments in the tank structure, compared to steady-state analysis when the rate of temperature rise is high. Analyses were conducted for four different rates of temperature rise and it was observed that significant differences in the forces and 
moments exist when compared to the steady state case especially in the wall and slab regions of the Type IV(b) tanks. Therefore, if there is reasonable evidence of large fluctuations of waste temperature over short periods of time, then this should be taken into account during the detailed analysis phase.

Unlike the double shell tanks (DSTs), the SSTs were not subjected to scheduled drain-fill-drain type of thermal cycling for an extended period of time, even though some SSTs may have been subjected to brief periods of rapid fill and drain cycles. A special case, Tank A-106, was analyzed to study the effect of thermal cycling. Brief periods of thermal cycling do not appear to alter the stress distribution or the cracking state of the concrete. Unless there is evidence to suggest that certain tanks may have been subjected to extended periods of thermal cycling, this effect may be neglected.

Studies with uniform waste temperature and linearly-varying (with waste height) waste temperature did not yield a clear argument for one analysis as a conservative case over the other. Even though uniform waste temperature analysis produced a higher amount of cracking in the haunch region, the lincarly-varying analysis produced additional section moments in the tank walls that were not captured by the uniform waste temperature case. The recommendation is to carry out similar analyses for each tank type, during the detailed analysis phase, based on availability of temperature history data.

Studies with two different sizes of hot spot showed a relatively small difference in tank forces and moments, except for the sections in the slab region (hot spot region) which were directly exposed to the high temperature conditions. The cracking in the tank footing increased with increase in the diameter of the hot spot. But this cracking did not significantly alter the load distribution in the rest of the tank structure. Since the extent of damage in the slab region is dependent on the size of the hot spot, it may be necessary to obtain a reasonable estimate of the size of the hot spot. However, it is evident from the document reviews that such data may not be available and, therefore, a conservative value (to be established) may be assumed, wherever applicable, for the hot spot diameter.

Steady state thermal analysis on the Type II tanks using best estimate thermal profiles revealed significant cracking in the tank. This cracking, along with exposure to high temperatures, may affect the present day structural response. These results suggest it is important to try to retrieve as much thermal history data as possible.

Waste height studies performed on a Type II tank indicate that there is little difference in forces and moments through tank sections for different waste heights. The forces and moments through the sections are generally insignificantly larger in magnitude for an empty tank compared to a half full tank and a full tank. It is not important to accurately capture the waste height level histories from a mechanical-only loading perspective.

The backfill transition slope boundary, though not axisymmetric in reality, results from the case study indicate that inclusion of such boundary in an axisymmetric model will result in conservative demands in the wall. Since the comer tanks have such a boundary in at least two of their sides, it is recommended that this boundary be included in detailed analysis of SSTs.

The radial extent studies indicate that there is no significant effect of this far-field dimension when changed from 62.5 feet (half the tank to tank distance) to 240 feet (nearly seven times the tank radius) under mechanical loads. Hence, for the cases where a quarter or half the tank models are necessary 
instead of just a slice, this radial extent can be reduced to minimize the computational time in structural runs.

The soil layer thickness and material properties variation studies indicate that slight changes in soil stratigraphy and its properties may not significantly affect the structural demands, as long as the properties are captured at a higher level by averaging them over different layers.

Material property variation load cases addressed concrete tensile strength and creep effects with a Type IV(b) model. The hoop and meridional demand showed a similar trend for both the zero concrete tensile strength and the mean concrete tensile strength. It is therefore recommended that a value of near zero is used for concrete tensile strength in detailed analysis. The creep load case was performed ran for 55 years (from year 1955 to 2010). and included temperatures of 80,380 , and 160 degrees Fahrenheit. In general, creep relieves the stress in the concrete, thereby decreasing the section force. Therefore the recommendation is to conduct the ACI section evaluation in the detailed analyses without creep as this will result in higher demands (i.e., more conservative). However, any collapse load or other ultimate load analyses should be conducted with creep to obtain the best estimate of the actual material condition.

\subsection{Recommendations}

- The effects of the vapor headers (20" in A and AX and $24^{\prime \prime}$ in SX) in the Type IV tanks should be investigated in the detailed analyses. Other tank to tank piping need not be considered.More detailed temperature history data needs to be obtained for all SST tank types. Even limited raw data could prove to be of significant value to establish reasonable thermal stress analysis cases for each tank type. In case no additional data can be obtained, the Type IV temperature histories could be scaled down and applied to other tank types. This procedure will be carried out with the client's consent and after careful consideration of all available data such as waste characteristics and waste height.

- Rate of increase in temperature has a significant effect on the tank stresses and the extent of concrete cracking. During the detailed analysis phase, if there is some evidence pointing to a history of sudden temperature increase or decrease in a tank, then such incidents should be taken into account. Temperature rise rates above 10 Fahrenheit-degrees/day may be assumed to be significant. .

- For thermal stress analysis during detailed modeling, both uniform waste temperature versus linearlyvarying waste temperature distributions need to be studied for each type of SST.

- A conservative value may be assumed for the size of the hot spot, wherever applicable, in order to capture the damage in the slab and footing region due to the high temperatures in the hot spot.

- If it can be established with reasonable certainty that the SSTs have not been subjected to extended periods of thermal cycling (drain-fill-drain-fill cycles), then the thermal cycling effect on the tank structure can be ignored.

- The waste height study results shown in Section 5.2 indicate that the waste level has little effect on the static demand on the tank, with the empty tank providing slightly more force and moment demands on the tank. The mechanical load, due to a change in the waste height level, is of little importance from a structural perspective.

- From the case study of backfill transition slope effect on section force and moment demands, it is recommended to include this transition boundary in axisymmetric or 3-D slice models, as it results in conservative demands in wall, while demands at other locations remain unaffected. 
- The radial extent case study recommends that a 62.5 -foot (half the tank-to-tank distance or nearly two times the tank radius) radial extent of soil is sufficient to capture force and moment demands under mechanical loads.

- The hoop and meridional demand showed a similar trend for both the zero concrete tensile strength and the mean concrete tensile strength. It is therefore recommended that a value of near zero is used for concrete tensile strength in detailed analysis.

- It is recommended to conduct the ACI section evaluation in the Detailed Analyses without creep, as this will result in higher demands. However, any collapse load or other ultimate load analyses should be conducted with creep to obtain the best estimate of the actual material condition.

- Type II detailed model must be revised to: 1) remesh concrete to align with sections for ACI force and moment calculation as done in other tank type models, 2) include a total of 16 soil layers, and 3) remove any the grout/mortar/waterproofing layers (which are a remnant of the existing C-107 model and should not be considered structurally integrated with the tank concrete) layer from the concrete on the exterior of the dome, interior of the wall, and interior of tank bottom.

- Apply $200,000 \mathrm{lb}$. concentrated load over $20 \mathrm{ft}$. diameter area on all tanks. 
RPP-46644, Rev.0

\subsection{References}

Abrams MS, M Gillen, and DH Campbell. 1979. Elastic and Strength Properties of Hanford Concrete Mixes at Room and Elevated Temperatures. RHO-C-28, Construction Technology Laboratories, Portland Cement Association, Skokie, Illinois.

Alger CG. 1963. Specification for Purex 241-AX Tank Farm. HWS-8237, General Electric Company, Hanford Atomic Products Operation, Richland, Washington.

Bandyopadhyay, K, A Cornell, C Costantino, R Kennedy, C Miller and A Veletsos. 1995. Seismic Design and Evaluation Guidelines for the Department of Energy High Level Waste Tanks and Appurtenances. BNL 52361. Brookhaven National Laboratory. Associated Universities, Inc. Upton, New York.

Boomer, KD. 2009. "Presentations to the Single-Shell Tank Integrity Panel-Single-Shell Tank History"; Single-Shell Tank Integrity Project-Workshop, January 26-28, 2009. WRPS-40224-VA, Richland, Washington.

Brevick, CH. 1994. Supporting Document for the Historical Tank Content Estimate for SX-Tank Farm. WHC-SD-WM-ER-324, Rev.0, ICF Kaiser Hanford Company, Richland, Washington.

Construction Technology Laboratories, Portland Cement Association. 1981. Effects of Long-Term Exposure to Elevated Temperature on the Mechanical Properties of Hanford Concrete. RHO-C-54, Rockwell Hanford Operations, Richland, Washington.

Daniel IL, and AO Buck. 1980. A Comparison of the Microstructure of Hanford Type II Concrete Structures and Test Specimens. RHO-C-39, Rockwell Hanford Operations, Richland, Washington.

Daniel Л, DC Stark, and PH Kaar. 1982. Long-Term Effects of Waste Solutions on Concrete and Reinforcing Steel. RHO-RE-CR-8 P, Rockwell Hanford Operations, Richland, Washington.

DeFigh-Price, C. 1984. Strength and Elastic Properties of Concrete Exposed to Long-Term Moderate Temperature and High Radiation Fields. RHO-RE-SA-55. Rockwell Hanford Operations, Richland, Washington.

DP. 1945. Construction HEW US Contract Number W7412 ENG 1 Du Pont Project 9536 History of the Project Volume 3. INDC-356-VOL3, Du Pont, Wilmington, Delaware.

Doud E, HW Stivers, GH Bauer, FA MacLean, GW Morrow, and SP Robertson. 1962. Process Destgn Engineering Purex Essential Waste Routing System and 241-AX Tank Farm. HW-72780, General Electric Company, Hanford Atomic Products Operation, Richland, Washington.

Engler AE. 1953. Specifications for Waste Disposal Factlity $241-S X$. HW-4957, General Electric Company, on Hanford Works, Richland, Washington.

Engler AE. 1953. Specifications for Purex Waste Disposal Facility. HWS- 5614, General Electric Company, Hanford Atomic Products Operation, Richland, Washington. 
Fisher TW and DJ Shank. 1994. Single- and Double-Shell Waste Tank Design Comparisons at Hanford, Washington, WHC-SD-WM-TI-598, Rev, 0, Westinghouse Hanford Company, Richland, Washington.

GE. 1943. Specification for Composite Storage Tanks Butlding - 241. HW-1946, Hanford Engineer Works, Richland, Washington.

GE. 1943. Specification for 20 Foot Diameter Composite Storage Tanks - Building. 241. HW-1961, General Electric Company, Richland, Washington.

GE. 1947. Specifications for Construction of Composite Storage Tanks. HW-3061, General Electric Company, Richland, Washington.

GE. 1948. Design Requirement Specification for Waste Disposal Tank Farm-24l R \& S. HW-4038, General Electric Company, Richland, Washington.

GE. 1953a. Design and Construction History 241-BY Tank Farm 200 East Area. HW-24800-30, General Electric Hanford Works, Richland, Washington.

GE. 1953b. Design and Construction History 24l-7X Tank Farm 200 West. HW-24800-35, General Electric Hanford Works, Richland, Washington.

GE. 1956. A Cell Type Temperature Monitor System. HWS-5814, General Electric Company, Hanford Atomic Products Operation, Richland, Washington

GE. 1962. Standard Specification for Batching and Delvery of Concrete. HW-4799-S, General Electric Company, Hanford Atomic Products Operation, Richland, Washington.

Gillen M. 1978. Expansion of Hanford Concrete. RHO-C-21, Rockwell Hanford Operations, Richland, Washington.

Gillen M. 1978. Strength and Elastic Properties of Concretes from Wasfe Tank Farms. RHO-C-22, Rockwell Hanford Operations, Richland, Washington.

Gillen M. 1978. Effects of Temperature Cycling on Strength and Elastic Properties of Hanford Concretes. RHO-C-23, Construction Technology Laboratories, Portland Ccment Association, Skokic, Illinois.

Gillen M. 1979. Creep and Cycling Tests - Thermal Properties of Hanford Concretes. RHO-C-27, Construction Technology Laboratories, Portland Cement Association, Skokie, Illinois.

Gillen M. 1979. Cyclic Thermal Expansion Testing of Hanford Concrete. RHO-C-35, Construction Technology Laboratories, Portland Cement Association, Skokie, Illinois.

Gillen M. 1979. Strength and Elastic Properties of 1580-Day Hanford Concrete Cylinders at Room Temperature and 350F. RHO-C-40, Construction Technology Laboratories, Portland Cement Association, Skokie, Illinois. 
Gillen M. 1980. Final Report on Long-Term Creep of Hanford Concrete at $250^{\circ} \mathrm{F}$ and $350^{\circ} \mathrm{F}$. RHO-C50, Rockwell Hanford Operations, Richland, Washington.

Gillen MP. 1981. Effects of Moisture Loss Due to Radiolysis on Concrete Strength. RHO-RE-CR-4, Rockwell Hanford Operations, Richland, Washington.

Gillen MP. 1982. Strength and Elastic Properties Tests of Hanford Concrete Cores - 241-SX-115 Tank and 202-4 Purex Canyon Building. RHO-RE-CR-2, Rockwell Hanford Operations, Richland, Washington.

Gillen MP. 1982. Durability \& Estimated Lifetime of Hanford Concrete. RHO-RE-CR-6, Rockwell Hanford Operations, Richland, Washington.

Giller RA. 1992. Bibliography and Summary of Geotechnical Studies at the Hanford Site. WHC-SDGN-ER-30009, Rev. 0, Westinghouse Hanford Company, Richland, Washington.

Harvey RW. 1970. Management of Radioactive Wastes Stored in Underground Tanks at Hanford. ARH-R-43, Rev. 2, Atlantic Richficld Hanford Company, Richland, Washington.

Henager CH, GF Piepel, WE Anderson, PL Koehmstedt, and FA Simonen. 1988. Modeling of TimeVariant Concrete Properties at Elevated Temperatures. PNL-7779, Pacific Northwest Laboratory, Richland, Washington.

HEW. 1944. Specifications for Construotion of Composite Storage Tanks Building No. 24I. Blue Print File 73550, Hanford Engineer Works, Richland, Washington.

Johnson KI, JE Deibler, FG Abatt, and MW Rinker. 2010. Single Shell Tank Structural Evaluation Criteria. PNNL-18837, Limited Distribution, Pacific Northwest National Laboratory, Richland, Washington.

Julyk, LJ. 1994. Tank 24l-C-106 Structural Integrity Evaluation for InSitu Conditions. SD-W320-Anal001, Rev. 0, Westinghouse Hanford Company, Richland, Washington.

Kaar PH, and DC Stark. 1981. Interim Report on the Effects of Waste Solutions on Reinforced Hanford Concrete. RHO-C-52, Rockwell Hanford Operations, Richland, Washington.

Kassir MK, KK Bandyopadhyay, and M Reich. 1996. Thermal Degradation of Concrete in the Temperature Range from Ambient to 315 C (600 F). BNL 52384 (Rev. 10/96), Brookhaven National Laboratory, Upton, New York.

Mackey TC, and LJ Julyk. 2004. Soil Load Above Hanford Waste Storage Tanks. WHC-SD-WM-TI665, Rev. 0D, CH2M Hill Hanford Group, Inc., Richland, Washington.

Mercier PF, MD Wonacott, and C DeFigh-Price. 1981. Survey of the Single-Shell Tank Thermal Histories. RHO-CD-1172, Rockwell Hanford Operations, Richland, Washington. 
Moore CJ, RD Holtz, and GR Wagenblast. 1995. Soil Structure Analysts Tools and Properties for Hanford Site Waste Tank Evaluation. WHC-SD-WM-DA-208, Westinghouse Hanford Company, Richland, Washington.

Moore CJ and WS Peterson. 1995. Concrete Structural Analysis Tools and Properties for Hanford Site Waste Tank. WHC-SD-WM-DA-207, Westinghouse Hanford Company, Richland, Washington.

Nelson RD and E Vey. 1967. Investigation of Earth Pressures and Settlement of Waste Tank Structures at Hanford, Washington. ISO-R-83, Department of Civil Engineering, Illinois Institute of Technology, Chicago, Illinois.

Oland CB, DJ Naus, and GC Robinson. 1980. Final report of Comprehensive Testing Program for Concrete at Elevated Temperatures. ORNL/BRP-80/5, Oak Ridge National Laboratory, Oak Ridge, Tennessee.

Overbeck WP. 1946. Project Proposal Additional Underground Waste Tank Facilities 241-B-Tank Farm. H-7-5264, Hanford Engineer Works, Richland, Washington.

Peterson WS. 1994. Evaluation of Strength and Modulus Degradation due to Temperate Effects on Hanford Concrete. WHC-SD-WM-DA-153, Westinghouse Hanford Company, Richland, Washington.

Pianka EW, 1994. Soil Weight at Hanford Waste Storage Tank Locations. WHC-SD-WM-SOIL-001, Rev, 0, Westinghouse Hanford Company, Richland, Washington.

Pianka EW. 1995. Soil Load Above Hanford Waste Storage Tanks. WHC-SD-WM-TI-665, Rev. 0, Westinghouse Hanford Company, Richland, Washington.

Price WH, and KR Fecht. 1976. Goneralized Geology of the 241-SY Tank Farm. ARH-LD-139, Atlantic Richfield Hanford Company, Richland, Washington.

Rifaey SH. 2002. Single Shell Tank System Integrity Assessment Report. RPP-10435, Rev. 0, CH2M Hill Hanford Group, Inc., Richland, Washington.

Rinker MW, JE Deibler, KI Johnson, SP Pilli, CE Guzman-Leong, and OD Mullen. 2004. Hanford Double-Shell Tank Thermal and Setsmic Project - Thermal and Operating Load Analysis. RPP-RPT23308, Rev. 0, Pacific Northwest National Laboratory, Richland, Washington.

Rinker MW, NK Karri, CE Guzman-Leong, SP Pilli, JE Deibler, FG Abatt, and KI Johnson. 2009. An Evaluation of Single-Shell Tank 241-C-107 for the Addition of a Large Penetration in the Tank Dome. PNNL-18734, Pacific Northwest National Laboratory, Richland, Washington.

Rutherford MJ. 1948. Additional Waste Storage Facilities 200 East Area. HW 3783, General Electric Company, Hanford Works, Richland, Washington.

Rutherford MJ. 1949. Specifications for Construction of Waste Disposal Facilities 241-S, 216-S, and 207-S 200 West Area. HW-3937, General Electric Company, Hanford Works, Richland, Washington. 
Rutherford MJ. 1951. Waste Disposal Facilities 241-BZ and TY Tank Farms 200 East and West Areas. HW 4696, General Electric Company, Hanford Works, Richland, Washington.

Shefcik JJ. 1964. Purex 24l-AX Tank Farm and Waste Routing System Injormation Mantal. RL-SEP-9, General Electric Company, Hanford Atomic Products Operation, Richland, Washington.

Smith EF. 1955. Struotural Evaluation Underground Waste Storage Tanks. HW-37519, General Electric Company, Hanford Atomic Products Operation, Richland, Washington.

Stark D. 1976. Final Report Concrete Testing Program. ARH-R 217, Atlantic Richfield Hanford Company, Richland, Washington.

Stivers HW. 1955. A Study to Determine the Economical Tank Size for Radioactive Waste Disposal. HW-34860, General Electric Company, Hanford Atomic Products Opcration, Richland, Washington.

Stivers HW. 195 7. Hazards Study Self-Boiling Radioactive Wastes Storage Facilities - Process Technology - Recommendation Report. HW-53 641, General Electric Com pany, Hanford Atom ic Products Operation, Richland, Washington.

Stivers HW. 1961. Basis for Process Design Engineering Purex Tank Farm-241-AX. HW-70529, General Electric Company, Hanford Atomic Products Operation, Richland, Washington .

Winkel, BV. 1994. Concrete Material Characterization Reinforced Conorete Tank Structure MultiFunction Waste Tank Facility. WHC-SD-W236A-ER-013, Rev. 0, Westinghouse Hanford Company, Richland, Washington.

\section{SST AOR Drawings}

Hanford Drawing H-2-44562, Rev. 4, checked for as built, 241-AX Structural Waste Composite Sections and Details, U.S. Department of Energy, Office of River Protection.

Hanford Drawing H-2-55911, Rev. 1, as built, 241-A Composite Section, U.S. Department of Energy, Office of River Protection.

Hanford Drawing H-2-39511, Rev. 3, as built, 241-SX 75-Foot Tank Composite Section, U.S. Department of Energy, Office of River Protection.

Hanford Drawing H-2-1312, Rev. 2, checked for as built, 241-BY 75-Foot Tank Sections, U.S, Department of Energy, Office of River Protection.

Hanford Drawing H-2-1783, Rev. 3, checked for as built, 241-S 75-Foot Composite Storage Tank Sections, U.S. Department of Energy, Office of River Protection.

Hanford Drawing, H-2-808, Rev. 7, checked for as built, 241-TX 75-Foot Tank Sections, U.S. Department of Energy, Office of River Protection. 
Hanford Drawing H-2-2244, Rev. 2, checked for as built, 241 TY 75-Foot Tank Composite Storage Sections, U.S. Department of Energy, Office of River Protection.

Hanford Drawing H-2-1313, Rev. 4, checked for as built, 241-BY 75-Foot Tank Steel Plate Details, U.S. Department of Energy, Office of River Protection.

Hanford Drawing H-2-1784, Rev. 2, checked for as built, 241-S 75-Foot Tank Steel Tank Liner Details, U.S. Department of Energy, Office of River Protection.

Hanford Drawing H-2-809, Rev. 0, 241-TX 75-Foot Tank steel Plate Details, U.S. Department of Energy, Office of River Protection.

Hanford Drawing H-2-2245, Rev, 3, checked for as built, 241-TY 75-Foot Tank Steel tank Liner Details, U.S. Department of Encrgy, Office of River Protection.

Hanford Drawing W-71387, Rev. 19, Hanford Engineering Works 75-Foot Diameter Tanks Building 241 T-U-B \& C Concrete Details of Tank, U.S. Department of Energy, Office of River Protection.

Hanford Drawing H-2-602, Rev. 8, Composite Tank Typical Details Concrete 241-BX, U,S. Department of Energy, Office of River Protection.

Hanford Drawing HW-72742, Rev, 14, Hanford Engineer Works 20-Foot Diameter Storage Tanks Arrangement Building 241-T, 241-U, 241-B, 241-C, U.S. Department of Energy, Office of River Protection.

Hanford Drawing D-21, Rev. 8, Floor \& Wall Reinforcing Steel for 20-Foot Tanks, U.S. Department of Energy, Office of River Protection.

Hanford Drawing HW-72417, Rev. 11, Hanford Engineer Works - Building 241 20-Foot Diameter Composite Storage Tanks Concrete Plan \& Details, U.S. Department of Energy, Office of River Protection.

Hanford Drawing D-2, Rev. 6, Typical Section 75-Foot Tanks, U.S. Department of Energy, Office of River Protection.

Hanford Drawing D-20, Rev. 6, Typical Sections for 20-Foot Tanks, U.S. Department of Energy, Office of River Protection.

Hanford Drawing, H-2-601, Rev 11, Excavation and Layout 241-BX, U.S. Department of Energy, Office of River Protection.

Hanford Drawing D-22, Rev. 1, Roof Reinforcing Steel for 20-Foot Tanks, U,S, Department of Energy, Office of River Protection.

Hanford Drawing D-23, Rev. 0, Structural Steel Lining for 20-Foot Tanks, U.S. Department of Energy, Office of River Protection. 
Hanford Drawing H-W-72743, Rev. 19, Hanford engineering works 75-Foot Diameter Storage Tanks Building 241 T, U, B \& C Arrangement, U.S. Department of Energy, Office of River Protection.

Hanford Drawing D-1, Rev. 4, Tanks T, U, B \& C General Layout, U.S. Department of Energy, Office of River Protection.

Hanford Drawing D-5, Rev. 4, Floor \& Wall Reinforcing Steel for 75-Foot Tanks, U.S. Department of Energy, Oflice of River Protection.

Hanford Drawing D-6, Rev. 2, Dome Reinforcing Steel for 75-Foot Tanks, U.S. Department of Energy, Office of River Protection.

Hanford Drawing D-3, Rev. 2, Structural Steel Lining for 75-Foot Tanks, U.S. Department of Energy, Office of River Protection.

Hanford Drawing D-4, Rev. 1, Structural Steel Lining for 75-Foot Tanks, U.S. Department of Energy, Office of River Protection.

Hanford Drawing H-2-605, Rev. 8, Reinforcing - Concrete Wall \& Floor 241-BX, U.S. Department of Energy, Office of River Protection.

Hanford Drawing H-2-606, Rev, 3, Reinforcing - Concrete Roof Details 241-BX, U.S. Department of Energy, Office of River Protection.

Hanford Drawing H-2-696, Rev. 0, 241-BX Steel Plate Details, U.S. Department of Energy, Office of River Protection.

Hanford Drawing H-2-1314, Rev. 2, 241-BY 75-Foot Tank Base Footing and Wall Reinforcing, U.S. Department of Energy, Office of River Protection.

Hanford Drawing H-2-1315, Rev. 2, 241-BY 75-Foot Tank Dome Reinforcing, U.S. Department of Energy, Office of River Protection.

Hanford Drawing H-2-1785, Rev, 1, 241-S 75-Foot Tank Base Footing and Wall Reinforcing, U.S. Department of Energy, Office of River Protection.

Hanford Drawing H-2-1786, Rev. 1, 241-S 75-Foot Tank Dome Reinforcing, U.S. Department of Energy, Office of River Protection.

Hanford Drawing H-2-812, Rev, 3, 241-TX 75-Foot Tank Base Footing \& Wall Reinforcing, U.S. Department of Energy, Office of River Protection.

Hanford Drawing H-2-813, Rev. 2, 241-TX 75-Foot Tank Dome Reinforcing, U.S. Department of Energy, Office of River Protection.

Hanford Drawing H-2-2246, Rev. 2, 241-TY 75-Foot Tank Base Footing and Wall Reinforcement, U.S. Department of Energy, Office of River Protection. 
Hanford Drawing H-2-2247, Rev, 2, 241-TY 75-Foot Tank Dome Reinforcing, U.S. Department of Energy, Office of River Protection.

Hanford Drawing H-2-39512, Rev. 2, 241-SX 75-Foot Tank Base Footing and Wall Reinforcing, U.S. Department of Energy, Office of River Protection.

Hanford Drawing H-2-39513, Rev. 1, 241-SX 75-Foot Tank Dome Reinforcing, U.S. Department of Energy, Office of River Protection.

Hanford Drawing H-2-55912, Rev. 1, 241-A Base Footing and Wall Reinforcing, U.S. Department of Energy, Office of River Protection.

Hanford Drawing H-2-55913, Rev. 2, 241-A Dome Reinforcing, U.S. Department of Energy, Office of River Protection.

Hanford Drawing, H-2-56350, Rev 0, 241-A AirLift Circulators Arrangement, U.S. Department of Energy, Office of River Protection.

Hanford Drawing H-2-44563, Rev. 2, 241-AX Structural Waste Storage Tanks Drain Arrangement \& Details, U.S. Department of Energy, Office of River Protection.

Hanford Drawing H-2-44565, Rev, 2, 241-AX Structural Waste Storage Tanks Dome Reinforcement \& Plan Details, U.S. Department of Energy, Office of River Protection.

Hanford Drawing H-2-44676, Rev 6, , 241-AX AirLift Piping Arrangement \& Circulator Details, U.S. Department of Energy, Office of River Protection. 
RPP-46644, Rev.0

\section{Appendix A}

\section{Preliminary Modeling Document Reviews}


RPP-46644, Rev.0

This page intentionally left blank. 
RPP-46644, Rev.0

\section{Appendix A}

\section{Preliminary Modeling Document Reviews}

Preliminary analysis document reviews were performed; these reviews showed original technical information on which to construct accurate and detailed, analyses of record and SST finite element models. The resulting documentation reviews under the preliminary analysis task intended to provide detailed information necessary to support the detailed single-shell tank (SST) modeling analyses. Document reviews focused on the following topics: SST construction and design specifications, soil, concrete, steel liner and rebar reinforcement material properties and standards, waste and temperature histories, soil backfill, tank waterproofing, and tank ancillary equipment such as pump pits, hanging long length equipment, risers, and tank-to-tank piping. Concrete material properties also addressed creep and thermal degradation.

The following sections present the strategy used to review, document, and summarize information obtained during the preliminary analysis document review effort.

\section{A.1 Review Strategy}

For the SST documentation reviews, search categories were identified and titled: SST design and specifications, waste and thermal histories, drawings and tank appurtenances, and material properties for soil, concrete, steel liner, and rebar reinforcement steel. A PNNL team member was assigned to a search category and was responsible for acquiring and reviewing all documentation providing information on the search category. To prevent the dismissal of a document with helpful search category information, documents were selected for review if there was any chance pertinent information was provided within.

SST drawings were obtained from various sources. Some drawings were found during the course of document reviews, as some of the construction and/or design specifications, and reports provided tank drawing lists. In other instances, some drawings included drawings lists. A spreadsheet was oreated to organize drawings retrieved, as well as keeping track of drawings yet to be retrieved, if deemed helpful to the tank modeling effort. As stated before, drawings were retrieved if there was any chance they contained useful information for the tank finite element modeling.

To summarize some of the SST document reviews, and conveniently find SST information, an Excel file was created to capture information that may assist finite element modeling efforts. The Excel file uses at least one worksheet for each search category. The worksheets associated with the SST design and specifications search category apply to the full template. The template has baseline columns taken from a WRPS presentation (January 2009) and a row for each SST. Baseline columns provide tank type, year of construction, farm, series, location, diameter, waste volume, capacity, and leak integrity status for each tank, as well as a calculated waste column. Additional columns pertaining to the assigned search category were created at the discretion of the PNNL team member. In general, columns were created for information that could assist the finite element modeling effort. "Reference" columns are next to each data column for recording the source documents of data entered for traceability. In addition to the "reference" column, there is also a comment column to add supplemental notes, and applicable standards. Relevant data to the search category was entered into a cell, for each SST. However, some search categories present the reviewed SST data in a different format to accommodate the type of information. 
This Preliminary Analysis Document Review Summary file is for information use only as values therein have not gone through technical reviews in accordance with the NQA-1 Project Quality Assurance Plan 57926. This file will only be used by PNNL as a tool for quick value access. However, quality assurance reviews should revert to the original source of the value (as documented therein).

Since leak integrity of SSTs is not in the scope of the SST AOR project, SSTs that leaked were not treated differently than those that did not leak. Explicitly, SSTs that were identified as leaking tanks were not excluded from information inquiries and considerations, in particular when looking at waste and temperature histories. It should also be noted that information pertaining to the waterproof painting materials and applicable standards were not documented as the paint layer is not considered to affect the SST structural modeling results. Consequently, the paint layer was not included in the preliminary finite element tank models.

\section{A.2 Guidance}

Per WRPS email on November 17, 2009, the original document reference should be obtained and reviewed when content is referenced in a more recent document.

While there are limited, and/or incomplete records for the early service life of SSTs, there is still a vast wealth of information on Hanford's SSTs ranging from specifications, drawings, as-built drawings, and a multitude of technical reports. Unfortunately, they don't always list values that agree as the original design basis for the SSTs. Consequently, final values selected for reference in the SST AOR project efforts, as documented in the information only file discussed in Section 3.1, were identified per the document source hierarchy approved by WRPS on via email on December 12, 2009:

- Drawings marked as "checked for as-built" and/or "as-built" (receive highest priority-credibility)

- Specification

- Drawing (not marked as "as-built")

- Reports (receive lowest priority)

- When multiple reports are under consideration, obtain WRPS concurrence for deciding which report value is most credible/applicable.

The drawing list was verified to be adequate, and sufficient, for the SST AOR project's modeling efforts by WRPS via email on December 29, 2009.

Search category parameter values were applied to every tank in the respective tank farm. There were reports, specifications, and/or drawings that provided conflicting search category parameter values. Other times, values for search category parameters were not found. Fortunately, values that were not found were not assessed as critical to the modeling effort. Final values for associated search category parameters were identified for conflicting values and when values for a search category parameter were not found, a clause "Not Found" is entered in each cell. Final values for conflicting search category parameters were determined by selecting the most credible and representative value, considering tank historical design limits and operations.

Complete temperature and waste level histories for every single-shell-tank were not obtained from the documents reviewed. Consequently, best effort temperature and waste level profiles were produced and 
used for preliminary modeling efforts with WRPS approval. However, an effort to retrieve additional temperature and surface level data for SST is underway. Preliminary temperature and waste level profiles may be revised for application in the detailed modeling phase as additional data is retrieved.

\section{A.3 Assumptions}

Specifications HW-70529, and HW-72780 were found for the AX Tank Farm, but they were not listed as final specifications. Even though they were not final, if design values were provided in HW70529, and HW-72780, but not found or superseded by values in HW-4798-S and HWS-8237, or drawings these values were assumed to be applicable to the AX Tank Fam.

Document reviews found that SST temperatures recorded were of two types, bulb temperature and waste temperature. Per the 2002 Rifaey report, these were both treated as waste temperatures taken from the bottom of the tank. In contrast, Brevick 1994 and Mercier 1981 reports correlate the bulb temperature to the dome head space. However, for creating the temperature profiles to use in the preliminary modeling efforts, no distinction was made amongst the available temperature data - temperature profiles were created from the available temperature data.

The maximum SST temperatures reported in the 2002 Rifaey report were not regarded as the historical peak temperatures of the SSTs. Maximum temperatures reported by the Rifaey report were based on the available data reviewed at the time of the report. It is noted that there may be more unreviewed temperature data at DOE-RL records from the storage warehouse in Seattle, Washington. Therefore, maximum SST waste temperatures were treated as historical, or absolute, when complete temperature history, as for the type IV tanks, is available and data has been reviewed.

Tank waterproofing included a layer of waterproof paint. However, document reviews did not focus on the paint applications, and layer thickness to tank waterproofing as the paint layer would not be considered in the structural modeling.

The loads on tanks in all the models were considered to be axisymmetric and applied on a two degree slice model.

Since the steel liners are not structural member of the SSTs, they were excluded from the models. Any material between the concrete tank and the steel liner like grout, water proofing asphaltic membrane, mortar etc. were neglected in the analyses.

\section{A.4 Material Properties}

Material property data for concrete and reinforcing steel are listed in Evaluation Criteria report, Johnson et al. (2010). The required material properties were compiled from an extensive review of past studies as discussed in Appendix A. Most of these reports provide test results specific to Hanford concrete and soil. Some reports are not site-specific but provide a good discussion of the properties based on broader databases. Recommendations of the required properties for finite element models (FEM) were made based on this review. 
RPP-46644, Rev.0

This page intentionally left blank. 


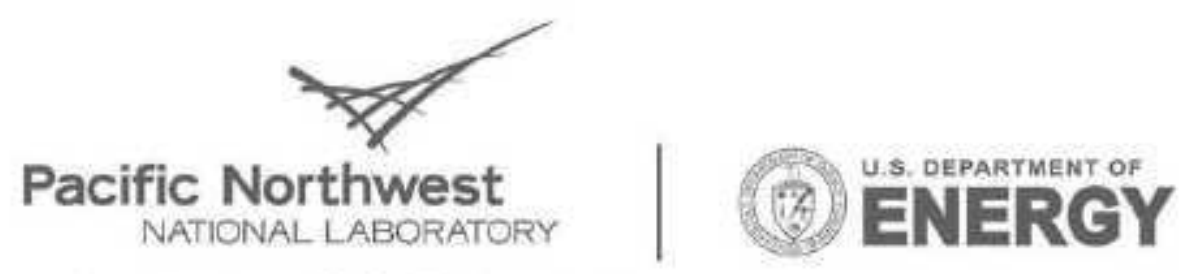

Proudly Operated by Battelle Since 1965

902 Battelle Boulevard

P.O. Box 999

Richland, WA 99352

1-888-375-PNNL (7665)

www.pnl.gov 